\author{
UNIVERSIDADE DE SÃO PAULO \\ ESCOLA DE ARTES, CIÊNCIAS E HUMANIDADES \\ PROGRAMA DE PÓS-GRADUAÇÃO EM SUSTENTABILIDADE
}

\author{
LAERTE JOSE DURAN JUNIOR
}

Modelo para análise sistêmica das relações entre as características das cidades, o consumo direto de energia e emissão de $\mathrm{CO}_{2}$

São Paulo 


\title{
Modelo para análise sistêmica das relações entre as características das cidades, o consumo direto de energia e a emissão de $\mathrm{CO} 2$
}

\author{
Tese apresentada à Escola de Artes, Ciências e \\ Humanidades da Universidade de São Paulo para \\ obtenção do título de Doutor em Ciências pelo \\ Programa de Pós-Graduação em \\ Sustentabilidade. \\ Versão Corrigida contendo as alterações \\ solicitadas pela comissão julgadora em 07 de \\ Julho de 2017. A versão original encontra-se em \\ acervo reservado na Biblioteca Digital de Teses e \\ Dissertações da USP (BDTD) de acordo com a \\ Resolução CoPGr 6018, de 13 de Outubro de \\ 2011. \\ Área de Concentração: \\ Ciências Ambientais \\ Orientador: \\ Prof. Dr. Sérgio Almeida Pacca
}

São Paulo 
Autorizo a reprodução e divulgação total ou parcial deste trabalho, por qualquer meio convencional ou eletrônico, para fins de estudo e pesquisa, desde que citada a fonte.

CATALOGAÇÃO-NA-PUBLICAÇÃO

(Universidade de São Paulo. Escola de Artes, Ciências e Humanidades. Biblioteca)

Duran Junior, Laerte Jose

Modelo para análise sistêmica das relações entre as características das cidades, o consumo direto da energia e emissão de $\mathrm{CO}_{2} /$ Laerte Jose Duran Junior ; orientador, Sérgio Almeida Pacca. - São Paulo, 2017 162 p. : il

Tese (Doutorado em Ciências) - Programa de Pós-Graduação em Sustentabilidade, Escola de Artes, Ciências e Humanidades, Universidade de São Paulo Versão corrigida

1. Sustentabilidade. 2. Energia - Uso racional. 3. Energia Consumo - Redução. 4. Dióxido de carbono - Emissão. 5. Cidades - Aspectos ambientais - Simulação computacional. I. Pacca, Sérgio Almeida, orient. II. Título

CDD 22.ed. -577 
Nome: DURAN JUNIOR, Laerte Jose

Título: Modelo para análise sistêmica das relações entre as características das cidades, o consumo direto de energia e a emissão de $\mathrm{CO}_{2}$.

Tese apresentada à Escola de Artes,

Ciências e Humanidades da

Universidade de São Paulo para

obtenção do título de Doutor em

Ciências pelo Programa de Pós-

Graduação em Sustentabilidade.

Aprovado em: 07 / 07 / 2017

\section{Banca Examinadora}

Prof. Dr. Sergio Almeida Pacca

Instituição: EACH - USP

Julgamento: APROVADO

Assinatura:

Prof. Dr. Célio Bermann

Instituição: IEE - USP

Julgamento: APROVADO

Assinatura:

Prof. Dr. Camilo Rodrigues Neto

Instituição: EACH - USP

Julgamento: APROVADO

Assinatura:

Prof. Dr. André Felipe Simões

Julgamento: APROVADO

Instituição: EACH - USP

Assinatura:

Dra. Viviane Roberto da Silva Romeiro Conturbia Julgamento: APROVADO

Instituição: EXTERNO

Assinatura: 
Ao meu filho Pedro e minha família, pelo amor, compreensão, carinho e apoio. À memória de meus pais. 


\section{Agradecimentos}

Ao Professor Doutor Sergio Almeida Pacca pelo apoio incondicional e por todas as horas disponibilizadas para orientação, incentivo e apoio a este trabalho.

À todos os professores do programa de pós-graduação em Sustentabilidade por terem compartilhado conhecimento e pelo incentivo em todos os momentos.

À minha família, sempre me apoiando e incentivando.

Àquela que, mesmo a distância, está sempre presente.

Ao meu amigo Fábio Seco, amigo para todas as horas.

Ao meu amigo Ivens Alves, por colaborar na realização deste sonho.

A todos aqueles que somaram comigo na crença de que chegar até aqui seria possível. 


\section{RESUMO}

DURAN JUNIOR, Laerte Jose. Modelo para análise sistêmica das relações entre as características das cidades, o consumo direto de energia e a emissão de $\mathbf{C O}_{2}$. 2017. 162p. Tese (Programa de Pós Graduação em Sustentabilidade) - Escola de Artes, Ciências e Humanidades, Universidade de São Paulo, São Paulo, 2017. Versão corrigida.

As cidades consomem cerca de $75 \%$ da energia primária global, que por sua vez é responsável por $68 \%$ das emissões de $\mathrm{CO} 2$. Análises que integrem as variáveis responsáveis pelo consumo de energia das cidades são fundamentais para a avaliação de ações de planejamento visando a redução do consumo de energia e das emissões. Através da modelagem baseada em agentes (ABM), este trabalho procura explorar as relações entre as características das cidades, o consumo direto de energia e as emissões de $\mathrm{CO}_{2}$, provenientes do consumo direto de energia. Inicialmente, apresenta-se uma discussão da base teórica a partir da revisão da literatura publicada nos últimos cinco anos. Em seguida apresenta-se o modelo proposto, desde os pressupostos para a sua construção até as fórmulas para cálculo da estimativa de consumo energético e emissões. Os resultados das simulações mostram que as características das cidades afetam o consumo direto de energia, contudo o efeito bumerangue pode cancelar os benefícios das ações de planejamento urbano voltados para a conservação de energia. Verificou-se que a integração das variáveis em um modelo sistêmico apresenta resultados distintos de modelos isolados. Por fim, é concluído que o aumento da densidade urbana e a inserção de áreas verdes podem anular os benefícios das ações estratégicas ou ainda culminar em aumento da demanda energética, se considerados os impactos diretos e indiretos em todos os usos finais energéticos. Apesar disso, devido às características da oferta elétrica local, o aumento da densidade populacional contribui para a redução das emissões. Os resultados apresentados podem servir de base para discussões no âmbito do planejamento urbano de cidades de baixo consumo de energia e emissões de GEE.

Palavras-chaves: Sustentabilidade. Energia. Cidades. Planejamento. Modelagem. 


\section{ABSTRACT}

DURAN JUNIOR, Laerte Jose. Model for systematic analysis of the relationships between the characteristics of cities, direct energy consumption and $\mathrm{CO} 2$ emissions. 2017. 162p. PhD Thesis (Pos-Graduate Program in Sustainability) School of Arts, Sciences and Humanities, University of São Paulo, São Paulo, 2017. Corrected version.

Worldwide cities consume $75 \%$ of the primary energy, which is related to $68 \%$ of the $\mathrm{CO} 2$ emissions. Analyses that integrate the variables responsible for energy consumption in cities are fundamental in planning procedures aiming energy efficiency and emission reductions. This work explores, through agent-based modeling $(A B M)$, relationships between city characteristics, direct energy consumption, and $\mathrm{CO} 2$ emissions from direct energy consumption. Initially, we discuss the theoretical basis and present the literature review predominantly based on five years. In the methods section the proposed model and the formulas for calculating the consumption and emission estimates are presented. The numerical results of the simulations show that city characteristics affect direct energy consumption and $\mathrm{CO} 2$ emissions, but the rebound effect may cancel out the benefits of urban planning actions targeting energy conservation. The integration of multiple variables in a systhemic model yields distinct results when compared to results from models based on specific variables. Finally, it is concluded that increasing urban density and expanding green areas may cancel out the benefits of strategic actions or even lead to greater energy demand and greater emissions, considering the direct and indirect impacts on all energy services. However, due to the local electricity supply, increasing population density yields emission reductions. Results provide a basis for discussions in urban planning towards low energy cities.

Keywords: Sustainability. Energy. Cities. Planning. Modelling. 


\section{LISTA DE FIGURAS}

Figura 1 - Evolução da população mundial .............................................................. 16

Figura 2 - Evolução do consumo de energia .............................................................. 17

Figura 3 - Distribuição da oferta mundial de energia por fonte ............................................ 21

Figura 4 - Evolução temporal da população mundial urbana e rural (1950 - 2050) .............. 23

Figura 5 - Panorama e projeção do consumo de energia no mundo .................................. 24

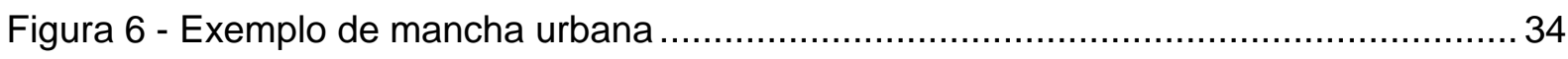

Figura 7 - Elevação ou perfil da cidade - ocupação vertical ............................................. 34

Figura 8 - Barreira para incidência solar em edificação................................................ 35

Figura 9 - Exemplo de interferência da ocupação vertical na dinâmica de ventos................ 36

Figura 10 - Alteração na dinâmica de circulação de ar....................................................... 37

Figura 11 - Gráfico de evolução das fontes de energia utilizadas no Brasil......................... 40

Figura 12 - Relação entre consumo de gasolina por habitante $\mathrm{x}$ densidade urbana ............ 44

Figura 13 - Representação da curva de Kuznets ..................................................... 46

Figura 14 - Distribuição da oferta mundial de energia por fonte. .................................... 48

Figura 15 - Fluxograma de atividades do desenvolvimento do trabalho .............................51

Figura 16 - Organização dos indicadores em temas e grupos, proposta pelo autor............54

Figura 17 - Gráfico de frequência de uso dos grupos de indicadores................................. 55

Figura 18 - Demanda mundial por energia - com e sem economia. ....................................65

Figura 19 - Projeção do consumo de energia até o ano de 2060 para os cenários simulados.

Figura 20 - Comparativo entre a condição empírica e a condição simulada........................70

Figura 21 - Captura da tela do software NetLogo. Interface com o usuário. Modelos de

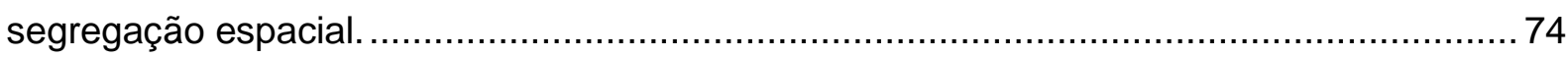

Figura 22 - Variação do fator de emissão para produção de energia elétrica no Brasil ......... 85

Figura 23 - Variação da população com referência ao ano de 2006 .................................... 89

Figura 24 - Variação do PIB municipal com referência ao ano de 2006 ............................ 90

Figura 25 - Variação do Consumo direto de energia com referência ao ano de 2006 ..........91

Figura 26 - Variação do Consumo total de energia com referência ao ano de 2006 ............92

Figura 27 - Variação das emissões totais de CO2 com referência ao ano de 2006 .............93

Figura 28 - Distribuição percentual do consumo de energia por fonte para as 10 cidades estudadas. 
Figura 29 - Distribuição percentual das emissões oriundas do consumo direto de energia, separados por fonte energética, para as 10 cidades estudadas. 95

Figura 30 - Variação anual dos indicadores do IPAT com base no ano de 2006 96

Figura 31 - Relação das variáveis polos atratores, população e área urbana em função da quantidade de famílias que habitam nas 10 cidades estudadas pelo modelo STIRPAT .... 100 Figura 32 - exemplo de evolução do processo de auto-organização da cidade 104 Figura 33 - exemplo da formação das ilhas de calor no decorrer da auto-organização da cidade 105

Figura 34 - Exemplo de posicionamento das áreas verdes nas cidades simuladas para o cenário 1 (pontos verdes no mapa) e as respectivas áreas. 105

Figura 35 - Consumo diário de energia per capita em função da densidade da cidade...... 106

Figura 36 - Consumo energético diário per capita (MJ) por serviço energético. 107

Figura 37 - Média do consumo diário per capita de energia (MJ) para o cenário 1. 108

Figura 38 - Média do consumo diário per capita de energia (MJ) para o cenário 2. 108

Figura 39 - Média do consumo diário per capita de energia (MJ) para o cenário 3. 109

Figura 40 - Média do consumo diário per capita de energia (MJ) para o cenário 4. 109

Figura 41 - Média do consumo diário per capita de energia (MJ) em função das áreas verdes para o cenário 1. 110

Figura 42 - Média do consumo diário per capita de energia (MJ) em função das áreas verdes para o cenário 2

Figura 43 - Média do consumo diário per capita de energia (MJ) em função das áreas verdes para o cenário 3 . 112

Figura 44 - Média do consumo diário per capita de energia (MJ) em função das áreas verdes para o cenário 4 . 112

Figura 45 - Média do consumo diário per capita de energia para os cenários 2 e 4, em função da taxa de ocupação do solo 113

Figura 46 - Emissão diária per capita de $\mathrm{CO}_{2}$ em função da densidade da cidade 114 Figura 47 - Emissões diárias per capita de CO2 (g) por serviço energético. 115 Figura 48 - Média das emissões diárias per capita de CO2 (g) em função da taxa de ocupação do solo para o cenário 1 . 116

Figura 49 - Média das emissões diárias per capita de CO2 (g) em função da taxa de ocupação do solo para o cenário 2 . 116 
Figura 50 - Média das emissões diárias per capita de CO2 (g) em função da taxa de ocupação do solo para o cenário 3 .

Figura 51 - Média das emissões diárias per capita de CO2 (g) em função da taxa de ocupação do solo para o cenário 4.

Figura 52 - Média das emissões diárias per capita de CO2 (g) em função das áreas verdes para o cenário 1 118

Figura 53 - Média das emissões diárias per capita de CO2 (g) em função das áreas verdes para o cenário 2 . 118 Figura 54 - Média das emissões diárias per capita de CO2 (g) em função das áreas verdes para o cenário 3. 119

Figura 55 - Média das emissões diárias per capita de CO2 (g) em função das áreas verdes para o cenário 4 .

Figura 56 - Média da emissão diária per capita de energia para os cenários 2 e 4, em função da taxa de ocupação do solo. 120 


\section{LISTA DE TABELAS}

Tabela 1 - Classificação do tipo de consumo de energia ................................................ 26

Tabela 2 - Consumo per capita de energia em vários países............................................. 27

Tabela 3 - Desmembramento do consumo de energia em residências ................................ 31

Tabela 4 - Série histórica de dados de consumo de energia no Brasil (BRASIL, 2014) ....... 41

Tabela 5 - Resultado quantitativo das buscas realizadas para pesquisa bibliográfica com

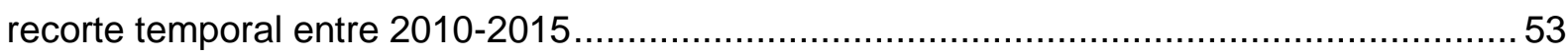

Tabela 6 - Lista de temas e frequência verificada na revisão da literatura ..........................55

Tabela 7 - Classificação hierárquica dos indicadores mais utilizados em estudos relacionados as características das cidades e o consumo de energia ...............................56

Tabela 8 - Sequencia de etapas do funcionamento do modelo proposto por (DE CASAS

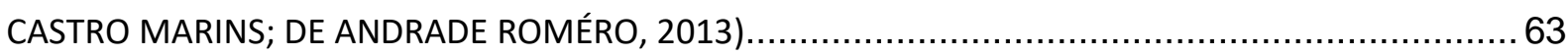

Tabela 9 - Indicadores e respectivas unidades de medida que são utilizada no modelo ...... 64

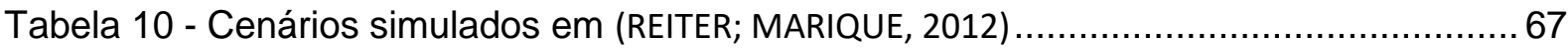

Tabela 11 - Análise Comparativa dos modelos descritos ................................................. 71

Tabela 12 - Usos finais energéticos e possíveis fontes de alimentação de energia ............. 83

Tabela 13 -Fatores de emissão por tipo de fonte energética............................................ 83

Tabela 14 - Identificação das variáveis utilizadas no modelo de regressão ......................... 86

Tabela 15 - Coeficientes resultados da regressão realizados para o modelo 1 e 2 .............97

Tabela 16 - resultado da análise de regressão das 216 cidades simuladas pelo MBA....... 100

Tabela 17 - Comparação da influência das variáveis nos modelos MBA e STIRPAT......... 102

Tabela 18 - Características dos arranjos das cidades simuladas .................................... 103

Tabela 19 - Resumo do foco e características das cidades estudadas na revisão bibliográfica 138

Tabela 20 - Valores médios encontrados para 10 repetições de cada cenário simulado ... 141 Tabela 21 - Participação percentual de cada serviço energético no consumo total de energia para os 64 ajustes 143

Tabela 22 - Participação percentual de cada serviço energético nas emissões de $\mathrm{CO}_{2}$ para os 64 ajustes. 


\section{LISTA DE ABREVIATURAS E SIGLAS}

ABM - Agent-Based Model (Modelo Baseado em Agentes)

CO2 - Dióxido de Carbono

EIA - Energy Information Agency (Agência de Informações Energéticas)

GEE - Gases do Efeito Estufa

GHE - Greenhouses Gases (Gases do Efeito Estufa)

GJ - Giga-Joules

GLP - Gás Liquefeito de Petróleo

GN - Gás Natural

GNV - Gás Natural Veicular

GWh - Giga-Watts horas

IPCC - Intergovernamental Panel Climate Changes (Painel Intergovernamental de Mudanças Climáticas)

LTS - London Transportation Studies (Estudos sobre Transportes em Londres)

MBA - Modelo Baseado em Agentes

OECD - Organisation for Economic Cooperation and Development (Organização para Cooperação e Desenvolvimento Econômico)

ONU - Organização das Nações Unidas

PIB - Produto Interno Bruto

SIG - Sistema de Informações Georeferenciadas

TUS - Time-Use Survey (Avaliação pelo tempo de uso)

UN - United Nations (ONU - Organização das Nações Unidas) 


\section{SUMÁRIO}

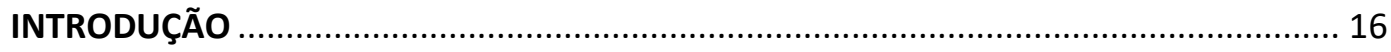

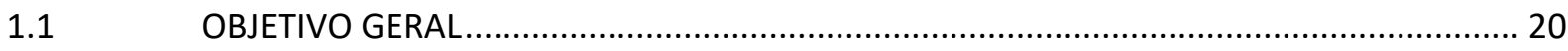

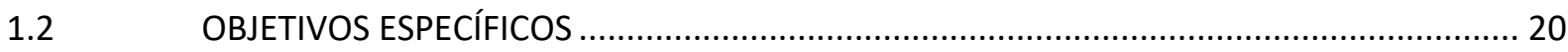

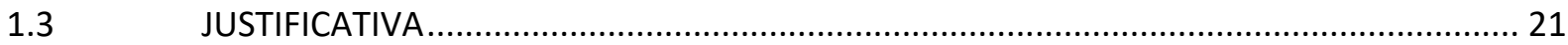

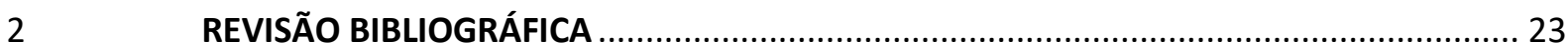

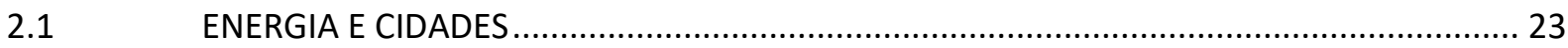

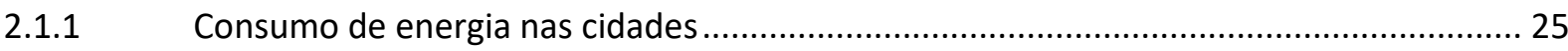

2.1.2 Estudo do consumo direto de energia nos centros urbanos ........................................... 30

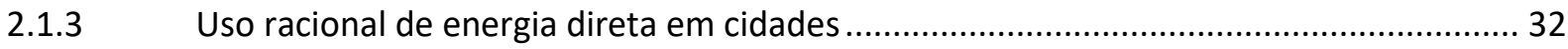

2.1.4 Características das cidades e a influência no consumo energético .................................. 32

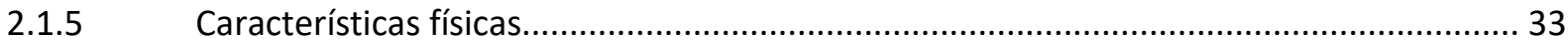

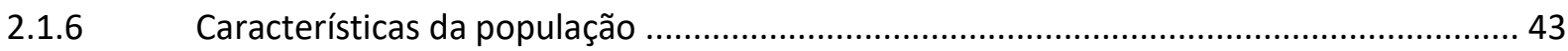

2.1.7 Atividades cotidianas e o consumo de energia .................................................................... 46

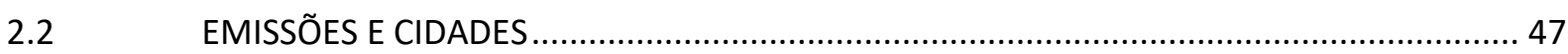

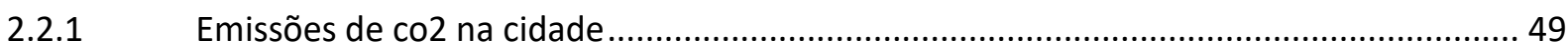

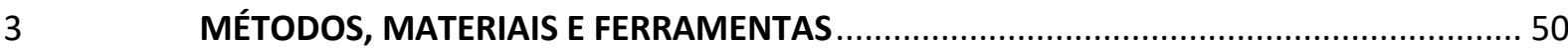

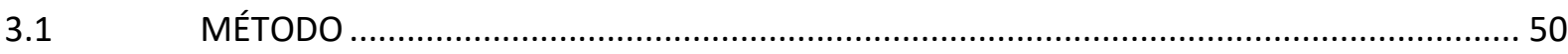

3.1.1 Construção do modelo baseado em agentes ................................................................... 51

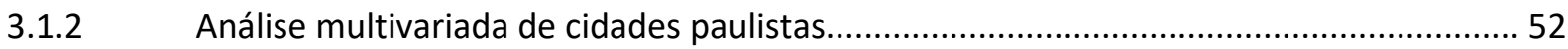

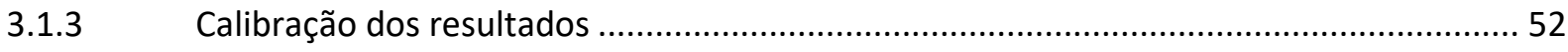

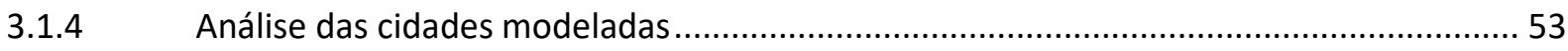

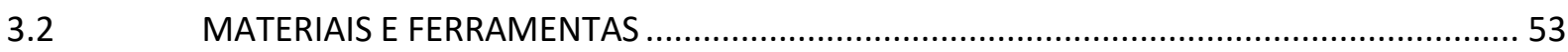

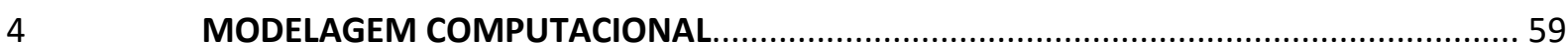

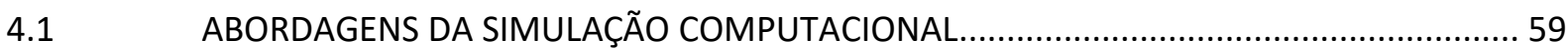

4.2 ALGUMAS PREMISSAS DE MODELAGEM EM USO DIRETO DE ENERGIA EM CIDADES

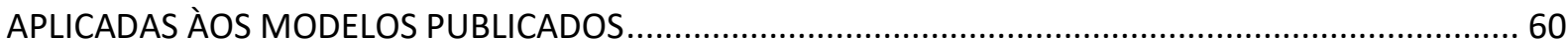

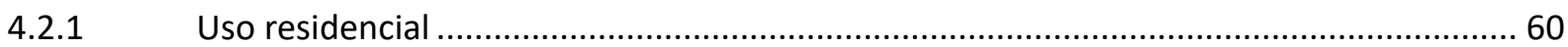

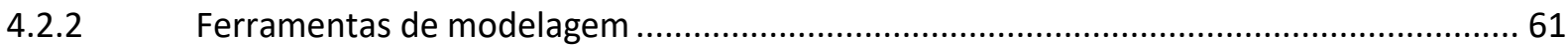

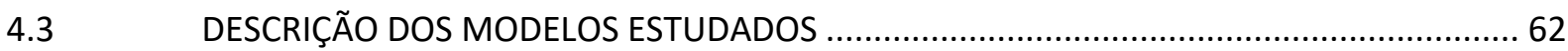

4.3.1 Modelo 1 - estudo integrado do uso de energia, considerando a morfologia e mobilidade

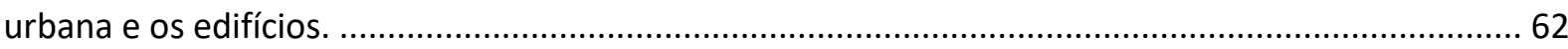

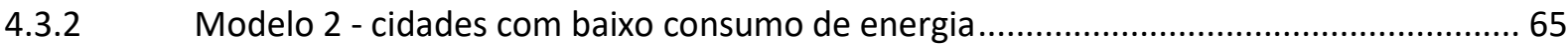

4.3.3 Modelo 3 - consumo de energia e atividades cotidianas .................................................. 69 


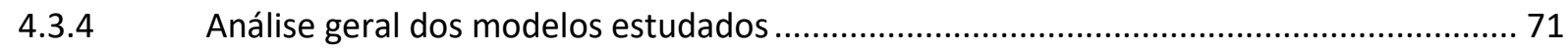

$4.4 \quad$ NetLogo COMO FERRAMENTA DE MODELAGEM ....................................................... 73

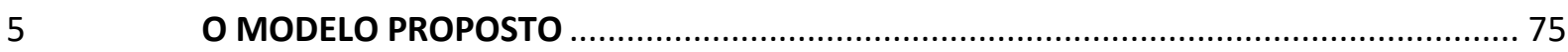

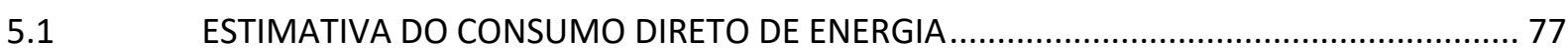

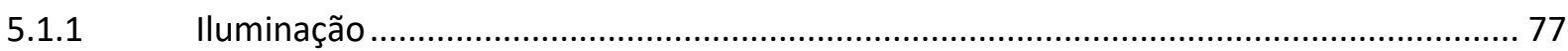

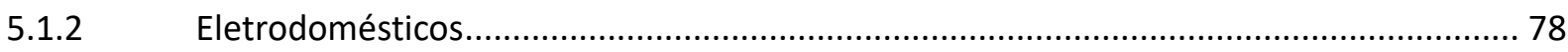

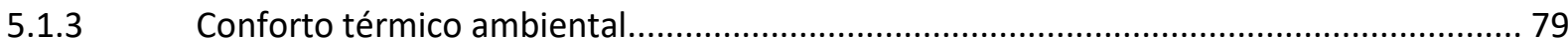

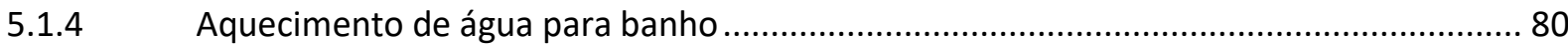

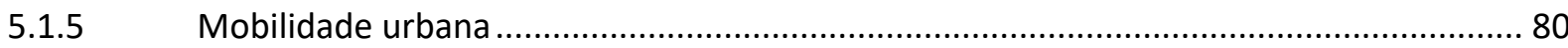

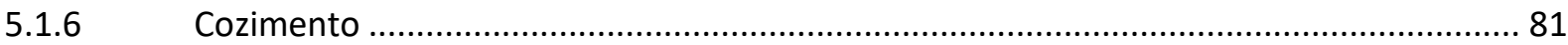

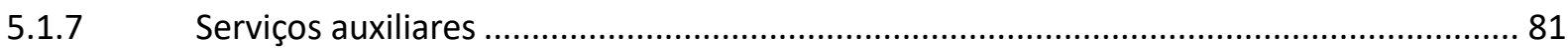

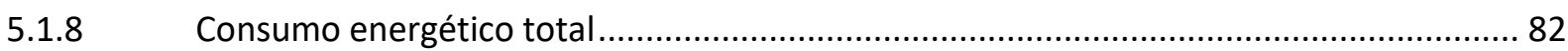

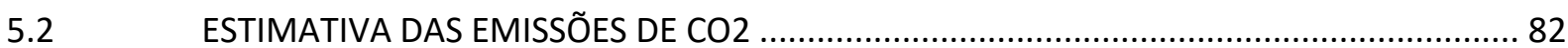

$6 \quad$ ANÁLISE DE REGRESSÃO E CALIBRAÇÃO DO MBA PROPOSTO …................................ 84

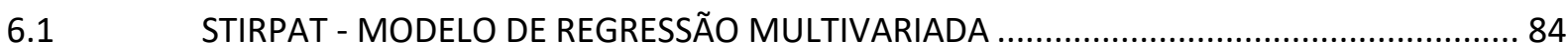

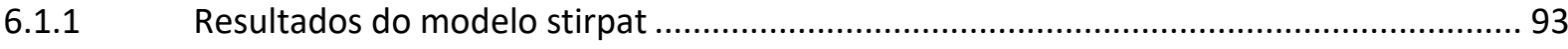

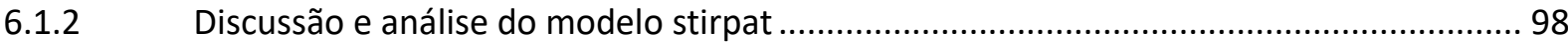

6.2 ANÁLISE COMPARATIVA DOS RESULTADOS INICIAIS DOS MODELOS STIRPAT E MBA .... 99

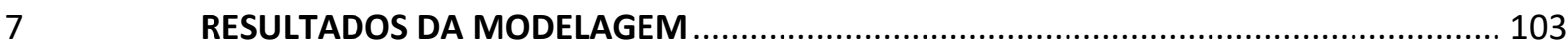

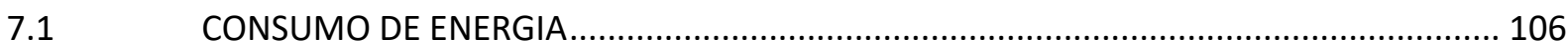

7.1.1 Efeito da taxa de ocupação do solo no consumo energético ......................................... 107

7.1.2 Efeito das áreas verdes na demanda energética .......................................................... 109

7.1.3 Efeito dos polos atratores na demanda energética ..................................................... 112

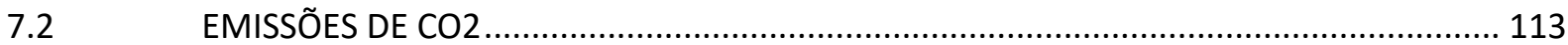

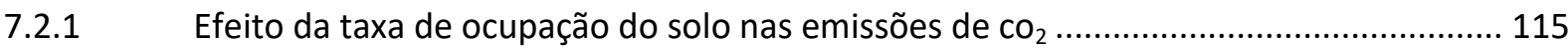

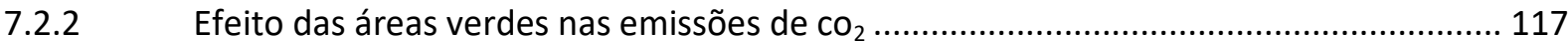

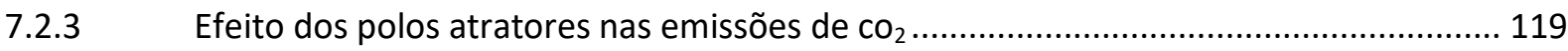

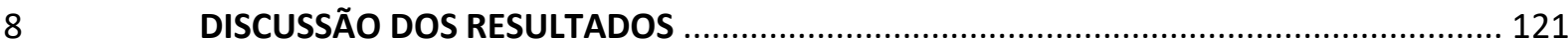

9 CONCLUSÃO

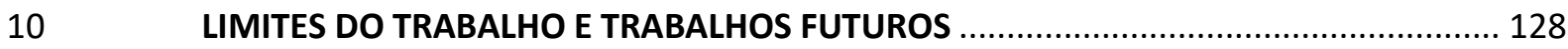

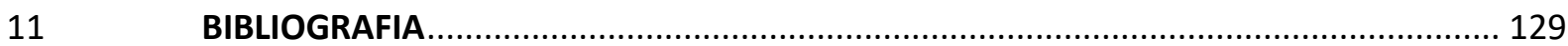

APÊNDICE A - SÍNTESE DOS ESTUDOS CONSIDERADOS NA REVISÃO BIBLIOGRÁFICA ......................... 138

APÊNDICE B - MÉDIAS DOS RESULTADOS PARA OS 64 AJUSTES INICIAIS UTILIZADOS NA CALIBRAÇÃO DO MBA 141 
APÊNDICE C - CONSUMO PERCENTUAL POR SERVIÇO ENERGÉTICO ............................................. 143

APÊNDICE D - EMISSÕES PERCENTUAIS POR SERVIÇO ENERGÉTICO ….......................................... 145

APÊNDICE E - DEFINIÇÕES DE TERMOS UTILIZADOS NESTE TRABALHO …....................................... 147

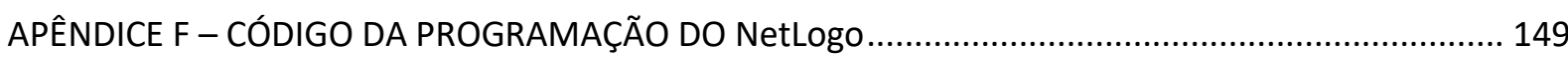




\section{INTRODUÇÃO}

Os centros urbanos ocupam $2 \%$ da extensão territorial do planeta e abrigam mais do que 50\% da população mundial (GAUBE; REMESCH, 2013; PAGLIARA, 2010; YIN; MIZOKAMI; MARUYAMA, 2013a), Neste local ocorre o consumo de aproximadamente $75 \%$ do total da energia primária (direta e indiretamente) (DHAKAL, 2009; GRUBLER et al., 2012; LAZAROIU; ROSCIA, 2012a), que é utilizada no mundo. $O$ consumo de energia se acentua em países onde a população urbana ultrapassa a média mundial, a exemplo da China, onde as cidades comportam 89\% da população (ZHANG; ZHENG; FATH, 2014), Argentina, com 92\% ou Cingapura, onde toda a população vive em ambiente urbano. (POPULATION FUND, 2011)

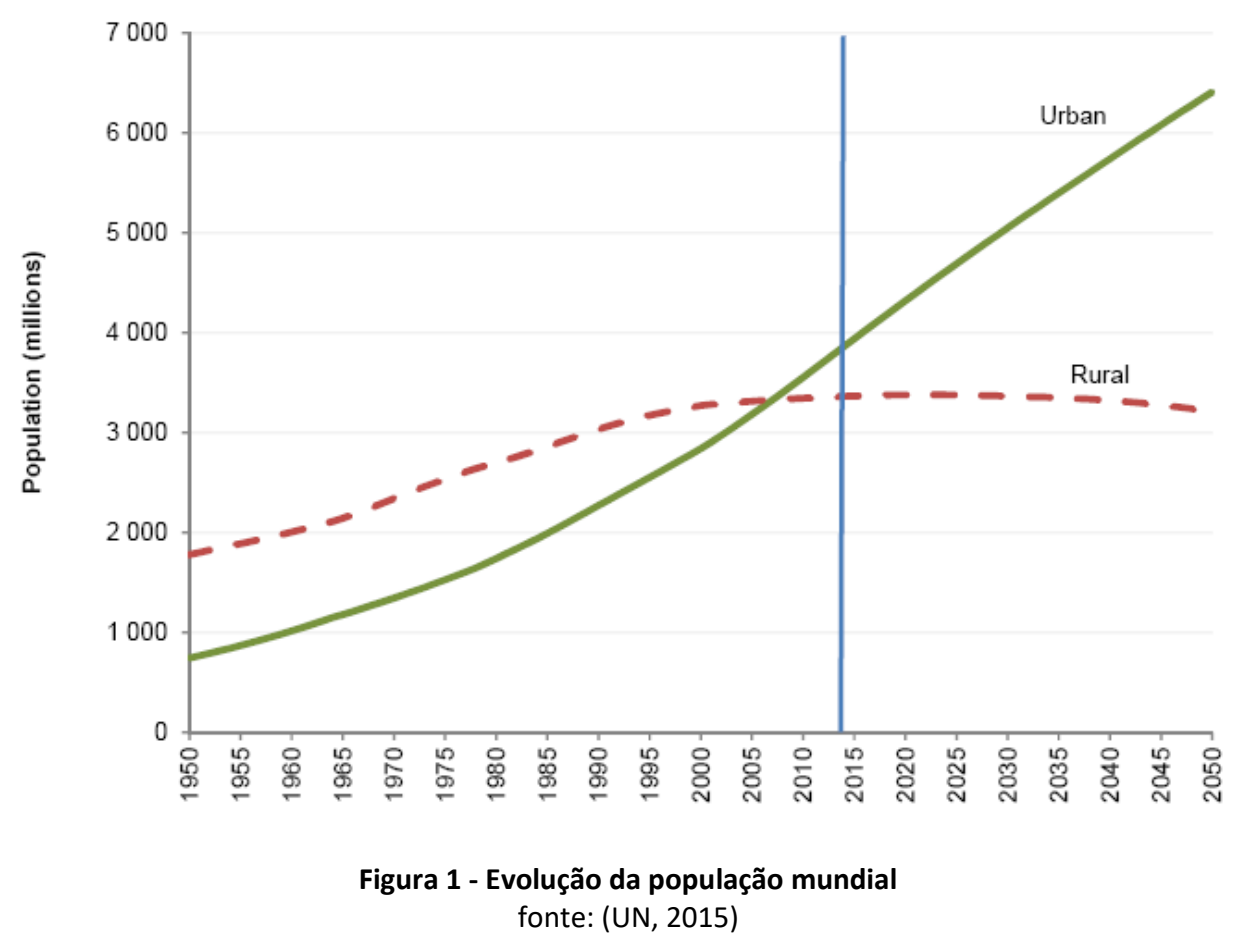

Segundo estimativas da Organização das Nações Unidas (ONU) (UN, 2015), até meados do século XXI a população mundial atingirá nove bilhões de habitantes (figura 1), sendo que em torno de seis bilhões e quinhentos milhões de pessoas habitarão no ambiente urbano, fato que culminará na expansão das cidades existentes e no surgimento de novas megalópoles.

Concomitante ao crescimento populacional mundial ocorre: (a) O aumento do percentual da população urbana: estendendo os benefícios da urbanização à maior parcela da população mundial, porém submetendo-a aos problemas inerentes das 
cidades; (b) o aumento do consumo de energia, que, por sua vez, se correlaciona com impactos ambientais. (c) O desenvolvimento tecnológico: proporcionando facilidades e racionalização para o cotidiano; (d) O crescimento econômico: ampliando o acesso a bens de consumo e serviços com potencial para melhoria da qualidade de vida.

Como consequência do crescimento populacional e econômico, surge o aumento da demanda por energia (ZUCARO et al., 2014). Mesmo considerando que o desenvolvimento tecnológico (GOLDEMBERG; LUCON, 2007), proporciona a adoção de medidas de eficiência energética, (T'SERCLAES et al., 2008; ZHAO; Ll; $M A, 2012)$ conforme figura 2 , pois a demanda per capita por energia tem sido crescente no decorrer da história. (CHEN et al., 2008; TSO, 2003; WANG, 2014)

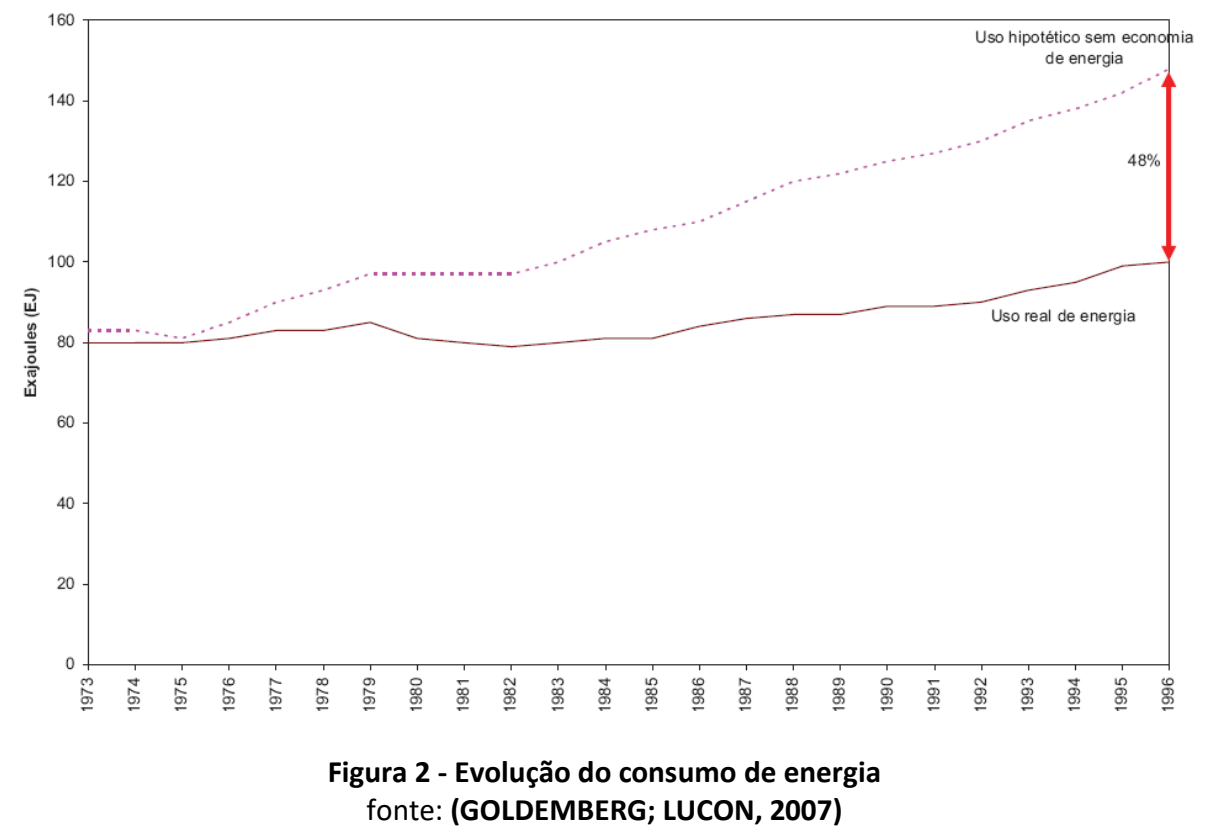

Ainda que seja crescente a participação das ofertaes energéticas limpas (com baixa emissão de gases de efeito estufa (GEE)) no suprimento da demanda energética mundial, grande parte da energia fornecida no mundo ainda é baseada em combustíveis fósseis (TSO, 2003).

Neste panorama, a diminuição da demanda per capita por energia é um objetivo fundamental a ser atingido nas cidades sustentáveis (GOLDEMBERG; LUCON, 2007; PAPASTAMATIOU et al., 2016), buscando o aumento da intensidade energética (LIU, 2013) e, consequentemente diminuindo o impacto da produção e do 
consumo de energia no meio ambiente, objetivando a redução das emissões de CO2 (IEA, 2016a).

Contudo o consumo direto de energia nas cidades é um assunto complexo e dependente de muitos fatores, como a morfologia da cidade e o contexto social (FERTNER; GROßE, 2016). Para fins de estudo e compreensão dos fenômenos, o consumo de energia nos centros urbanos se divide em duas categorias: (a) consumo direto de energia; (b) consumo indireto de energia.

O consumo direto de energia está vinculado ao uso de energia para deslocamento realizado em meio de transporte próprio e para a realização de tarefas domiciliares, como aquecimento e resfriamento ambiental ou de água, cozimento, iluminação, utilização de eletrodomésticos e outras tarefas inerentes ao cotidiano da população urbana. $O$ consumo indireto de energia está vinculado à energia necessária para produção de bens e serviços que são adquiridos ou consumidos pela população, não considerando a localização ou período em que o bem ou serviço consumido foi produzido. Os sistemas de transportes coletivos estão incluídos no grupo do consumo indireto. Diz-se do consumo indireto que a energia está "incorporada" ao bem ou ao serviço consumido.

Esta divisão teórica entre consumo direto e indireto de energia se justifica pela necessidade de identificação do local de origem da energia consumida quando há desempenho de alguma atividade. Com o advento da globalização e abertura dos mercados, não raras vezes, os produtos e serviços consumidos são produzidos em regiões distantes, ou mesmo em outros países, fato que pode levar a erros na compreensão da dinâmica de produção e consumo de energia quando analisados localmente.

Ainda no campo das relações entre ambiente urbano e consumo de energia, sabese que muitas das atividades cotidianas desenvolvidas no interior das cidades são influenciadas direta e indiretamente pelas características das cidades (formato urbano, desenho da implantação, distribuição do sistema de transporte, densidade, uso do solo, tamanho e formato das famílias, formato e altura das edificações e condições climáticas, entre outras). 
Considerando que algumas das características das cidades podem ser direcionadas em função de ações estratégicas de planejamento territorial urbano, é plausível afirmar que estas intervenções urbanísticas que controlam ou direcionam as características das cidades tem potencial para contribuir, de alguma forma, com as mudanças necessárias rumo às cidades sustentáveis.

Dentro deste panorama, partindo da revisão bibliográfica que engloba a identificação dos impactos ambientais negativos causados pelo consumo e produção de energia, buscando identificar (qualificação) e estimar (quantificação) a energia consumida nos centros urbanos e compreendendo a influência das características da cidade no consumo de energia, este trabalho propõe um modelo computacional que auxilia na compreensão das relações existentes entre o consumo direto de energia, incluindo os sistemas de transportes coletivos, nas cidades e as suas características, de forma sistêmica, permitindo a identificação dos resultados das intervenções urbanísticas no consumo da energia em áreas urbanizadas. Inclui-se ainda na análise, o efeito das características das cidades nas emissões de $\mathrm{CO} 2$, para os usos finais energéticos considerados. 


\subsection{OBJETIVO GERAL}

Analisar, sistemicamente, a influência das características das cidades no consumo direto de energia e nas emissões de gases do efeito estufa, incluindo o sistema de transporte coletivo, a partir de um modelo integrador proposto pelo autor.

\subsection{OBJETIVOS ESPECÍFICOS}

Compreender, através da revisão da bibliografia, a influência isolada de cada característica das cidades no consumo direto de energia, incluindo os sistemas de transporte coletivo;

Compreender a dinâmica de modelagem dos sistemas complexos que analisam o consumo direto de energia e o consumo de energia em sistemas de transporte coletivo baseado nos algoritmos adotados em cada estudo;

Conhecer e familiarizar-se com os modelos utilizados nas modelagens computacionais relacionados ao tema central deste trabalho;

Replicar os conceitos adotados nos modelos computacionais publicados na literatura utilizando a ferramenta NetLogo, permitindo a uniformização dos processos e rotinas dos modelos, sem alteração dos resultados finais;

Elaborar modelo único, integrado, englobando as características da cidade de forma sistêmica, permitindo o estudo, análise e compreensão da influência das características das cidades no consumo direto e no consumo indireto de energia em sistemas de transportes coletivo, em meios urbanos.

Realizar calibração do modelo com base em dados empíricos, permitindo alcançar confiabilidade nas cidades simuladas.

Analisar o efeito da variação do consumo de energia nas emissões dos gases do Efeito Estufa. 


\subsection{JUSTIFICATIVA}

A partir do conhecimento das relações entre as características da cidade, o consumo direto de energia e as emissões de $\mathrm{CO} 2$, em contexto sistêmico, a modelagem computacional das cidades tem potencial para orientar ações de planejamento urbano que diminuam o consumo de energia e as emissões de $\mathrm{CO} 2$, contribuindo para a construção do ambiente urbano sustentável.

Apesar do aumento do uso de energia renovável em todo o planeta, a maioria das ofertaes energéticas ainda está baseada em processos altamente poluentes e com índices elevados de emissão de GEE (Gases do Efeito Estufa). Hong Kong, em 2001, produzia grande parte da energia consumida em seu território através da queima de óleo e carvão, combustíveis fósseis, com altos valores relativos de emissão de poluentes e oriundos de fontes não renováveis. (TSO, 2003)

A edição do ano de 2016 do Balanço Energético Nacional indica que no ano de 2013, $81,4 \%$ da energia ofertada no mundo têm como fonte primária os combustíveis fósseis, figura 3 , cabendo ao petróleo a maior representatividade com $28,9 \%$ do total, o carvão mineral como segunda maior fonte, representando $28,9 \%$ e na terceira posição o Gás Natural (também extraído do petróleo) com 21,4\%.

2013

Total: $13.54110^{6}$ tep (toe)

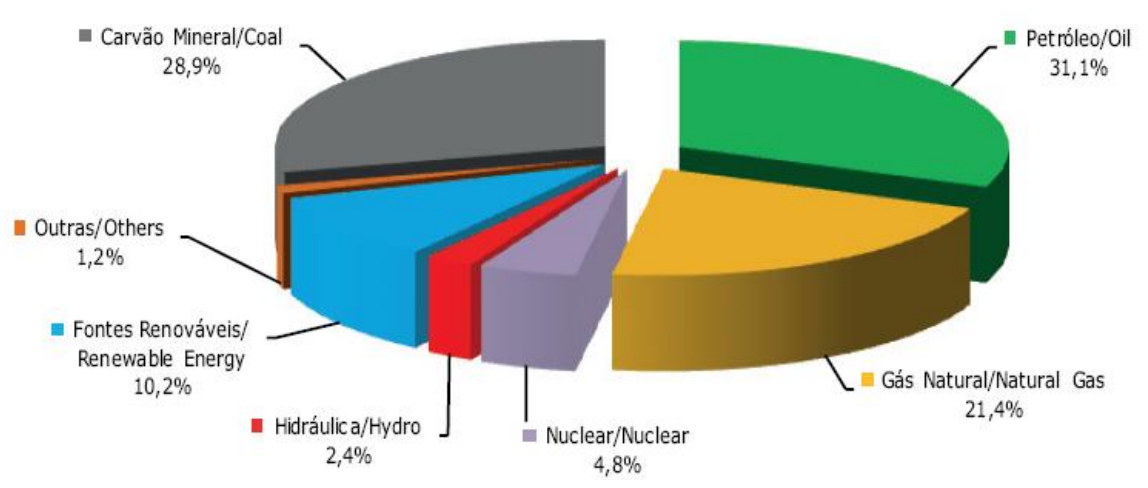

Figura 3 - Distribuição da oferta mundial de energia por fonte Fonte: BEN 2016

O volume de energia utilizado nos centros urbanos tem sido alvo de vários estudos, pois há evidências de que a produção e o consumo de energia têm relação direta com os impactos ao meio ambiente, principalmente no que se refere à emissão de 
CO2 e, por consequência, a acentuação da mudança climática global. (EGGLESTON et al., 2006; ZHANG; ZHENG; FATH, 2014)

Uma vez que as características das cidades apresentam correlação com o consumo de energia, o estudo e compreensão destas características e das interações entre elas podem resultar em embasamento teórico para propostas de planejamento de cidades com baixo consumo energético e baixa emissão de gases do efeito estufa (GEE), premissas para a caracterização das cidades sustentáveis.

Neste contexto, a originalidade deste trabalho está na proposta de um modelo computacional incluindo a análise simultânea das relações entre as características das cidades (abordagem sistêmica), o consumo direto de energia, incluindo a energia consumida nos sistemas de transporte coletivo (consumo indireto) e as emissões de $\mathrm{CO} 2$, permitindo o estudo das correlações e dos impactos resultantes da interação entre os agentes na influência pela demanda de energia e emissões nos centros urbanos.

Cabe ressaltar que atualmente as relações entre as características das cidades e o consumo de energia estão em discussão na literatura científica, contudo, durante a revisão bibliográfica, não foram localizados estudos publicados que tratem o tema de forma sistêmica e abrangente, principalmente no que diz respeito às ferramentas utilizadas (ferramenta única). Em muitos trabalhos, apesar da análise de duas ou três características das cidades em um mesmo estudo, por vezes não há foco no estudo do cruzamento destas interferências. No apêndice $A$, é possível visualizar a tabela 12 - resumo indicando que os trabalhos publicados apresentam abordagens isoladas.

Ainda, como parte da originalidade deste trabalho, está a construção do modelo computacional como ferramenta simuladora unificada, baseada em agentes (programa NetLogo) a qual permite o estudo do uso e ocupação do solo urbano, gerando dados a partir do comportamento da população em função das alterações das características da cidade virtual proposta. 


\section{REVISÃO BIBLIOGRÁFICA}

\subsection{ENERGIA E CIDADES}

Nos dois últimos séculos, o incremento da população mundial e o percentual de pessoas que habita em cidades apresentaram aumentos sem precedentes, (figura 4) fato que amplia a demanda por energia, (CHEN et al., 2008; TSO, 2003; WANG, 2014) tanto na fase de produção, quanto transformação, transporte e consumo em sua forma primaria ou transformada. $O$ aumento do consumo energético acentuou as emissões de $\mathrm{CO} 2$, alterando a composição da atmosfera e interferindo no efeito estufa, culminando na mudança climática global (EGGLESTON et al., 2006).

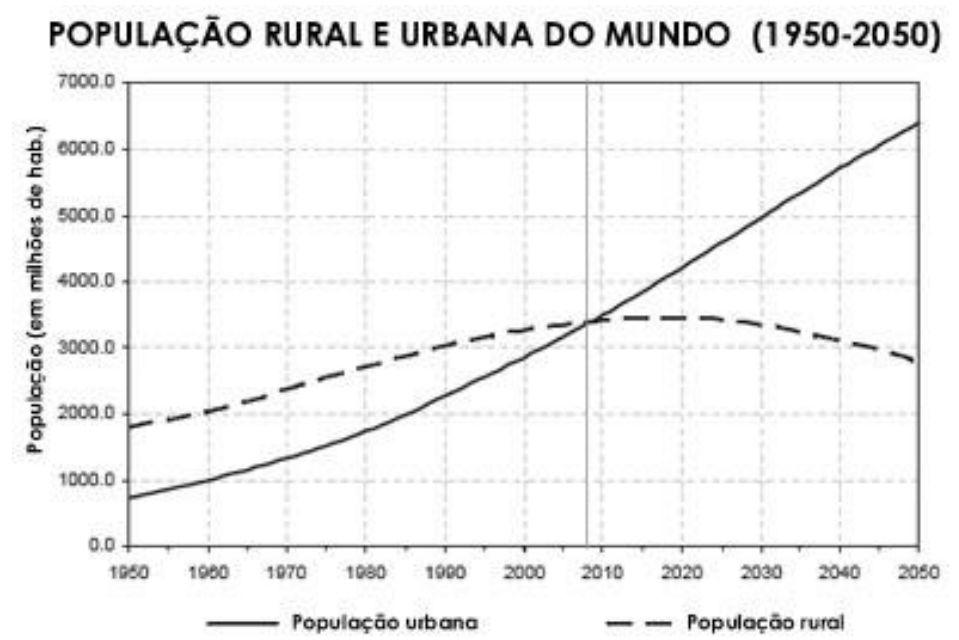

Figura 4 - Evolução temporal da população mundial urbana e rural (1950 - 2050) fonte: (UN, 2015)

Apesar de concentrar pouco mais de $50 \%$ da população (YIN; MIZOKAMI; MARUYAMA, 2013b), em aproximadamente $2 \%$ do território mundial, as cidades são responsáveis pelo consumo de aproximadamente $75 \%$ da energia que é consumida no mundo. (LAZAROIU; ROSCIA, 2012b) Em alguns países, como a China, este consumo chega a $89 \%$ (ZHANG; ZHENG; FATH, 2014). Outras regiões do mundo apresentam percentual de urbanização maior do que a média mundial, como o Brasil, onde $84 \%$ da população é urbana. (DE CASAS CASTRO MARINS; DE ANDRADE ROMÉRO, 2013), fato que pode aumentar o consumo per capita de energia.

Com a projeção da continuidade do aumento da população mundial e o incremento da população urbana, em termos numéricos e percentuais respectivamente, é necessário que o processo de desenvolvimento social, econômico e tecnológico 
continue, contudo o desenvolvimento econômico é dependente do aumento da demanda por energia (GOLDEMBERG; LUCON, 2007). A figura 5 apresenta o panorama de aumento de consumo de energia ocorrido desde o ano de 1990, com projeções para maiores elevações até o ano de 2040, com predominância de aumento para os países que não são membros do OECD (Organisation for Economic Cooperation and Development - Organização para cooperação e desenvolvimento econômico). A mesma figura 5 ainda apresenta a previsão de aumento do consumo para os cinco tipos de combustíveis analisados - combustíveis líquidos, carvão, gás natural, energia de fontes renováveis e energia nuclear.
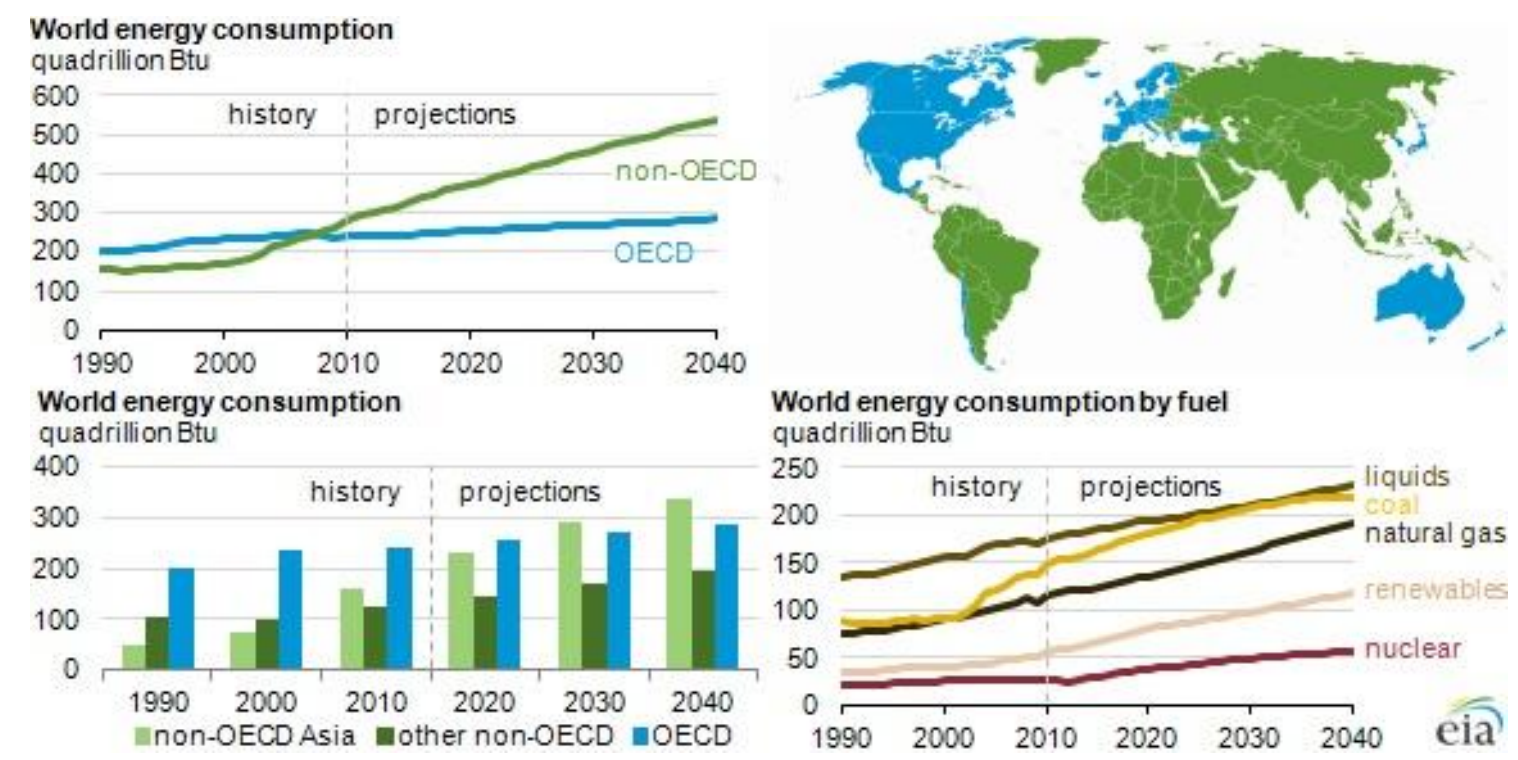

Figura 5 - Panorama e projeção do consumo de energia no mundo fonte: IEA, 2016

Com base na análise da figura 4 cabe ressaltar que, mesmo contabilizando os avanços tecnológicos que permitem o aumento da eficiência energética, quando considerando o aumento exponencial da população mundial, a demanda total por energia ainda é crescente.

O consumo de energia gera impactos diretos e indiretos no meio ambiente, independente da fonte primária de energia e do seu propósito de uso ou consumo, contudo há de se ressaltar que 0 atual cenário mundial de dependência dos combustíveis fósseis tem ampliado os impactos ambientais de maneira sem precedentes, de forma que as consequências ecológicas e socioeconômicas esperadas são de grande magnitude (WIEDENHOFER; LENZEN; STEINBERGER, 2013). 
Apesar dos esforços para mudanças nas formas de produção de energia, procurando meios alternativos e menos impactantes ao meio ambiente, como energia produzida a partir de fontes renováveis, a solução mais imediata ainda requer a necessidade de agregar os esforços na mudança de hábitos da população (WIEDENHOFER; LENZEN; STEINBERGER, 2013), (ALA-MANTILA; HEINONEN; JUNNILA, 2014), (WORLD WIDE FUND FOR NATURE., 2012) e na interferência do Estado (IEA, 2016a), buscando a redução do consumo de energia e a descarbonização do uso de energia.

No sentido da busca da redução do consumo de energia, estudos têm apontado que há correlação entre as características dos centros urbanos e o consumo de energia de seus habitantes. (ALA-MANTILA; HEINONEN; JUNNILA, 2014). Como características das cidades este trabalho destaca: o formato horizontal e vertical da mancha urbana, (YIN; MIZOKAMI; MARUYAMA, 2013b), englobando sua ocupação em termos de extensão territorial e em altura dos edifícios, a densidade populacional, localização e quantidade de áreas verdes, distribuição espacial dos pontos de oferta de comércios, serviços (polos atratores), entre outros.

O planejamento urbano de cidades sustentáveis e cidades inteligentes passa, necessariamente pela redução do consumo de energia (LAZAROIU; ROSCIA, 2012b), sendo necessário o avanço nos estudos e o entendimento sistêmico das características das cidades que influenciam diretamente no consumo energético. A cidade não pode ser vista apenas como uma soma de edifícios. A cidade é um organismo vivo que possui variáveis e influências cruzadas e o consumo de energia e as emissões de GEE estão inseridos nesta complexidade (ZUCARO et al., 2014). A cidade é complexa (ZHANG; ZHENG; FATH, 2014) e requer análise complexa.

\subsubsection{Consumo de energia nas cidades}

Em conjunto com a água, a energia elétrica passou a ser de fundamental importância para o bem estar do homem nos últimos séculos. (ZHANG; ANADON, 2013). Apesar de utilizada para diversas finalidades (industrial, comercial, residencial) a energia consumida pelas famílias que habitam as cidades, incluindo a energia necessária para transporte individual ou coletivo, representa em torno de $50 \%$ da energia consumida no ambiente urbano (STEPHAN; CRAWFORD; DE MYTTENAERE, 2012). Nas principais cidades do Estado de são Paulo, estudadas 
neste trabalho, o percentual de energia correspondente a energia direta varia entre 25\% e 35\% (SÃO PAULO, 2016a).

Para fins de estudo, o consumo de energia da população no meio urbano é dividido em dois grandes grupos: O primeiro grupo constitui-se do consumo direto - aquele que engloba a energia utilizada para funcionamento das residências (eletricidade para iluminação e aparelhos diversos, iluminação, controle interno de temperatura e combustível para abastecimento de veículos próprio) (CARLSSON-KANYAMA; ENGSTRÖM; KOK, 2008) - enquanto que o segundo grupo, o consumo indireto, é composto pela energia utilizada pela indústria para produção de todos os bens e serviços consumidos, incluindo o setor de transporte coletivo, o comércio varejista, (CARLSSON-KANYAMA; ENGSTRÖM; KOK, 2008; WIEDENHOFER; LENZEN; STEINBERGER, 2013). A energia indireta também é conhecida na literatura como "energia incorporada aos produtos e serviços". (CHEN; CHEN, 2011)(PETERS; HERTWICH, 2008). A tabela 1 apresenta o enquadramento das atividades em cada divisão.

Tabela 1 - Classificação do tipo de consumo de energia

\begin{tabular}{|c|c|c|}
\hline USO & ATIVIDADE & FONTE \\
\hline Direto & Iluminação Interna & $\begin{array}{lll}\text { (CARLSSON-KANYAMA; } & \text { ENGSTRÖM; KOK, 2008; } \\
\text { VRINGER; BLOK, 1995) } & & \\
\end{array}$ \\
\hline Direto & Aparelhos eletrodomésticos & $\begin{array}{l}\text { (CARLSSON-KANYAMA; ENGSTRÖM; KOK, 2008, } \\
\text { 2008) }\end{array}$ \\
\hline Direto & $\begin{array}{l}\text { Aquecimento e resfriamento } \\
\text { ambiental }\end{array}$ & $\begin{array}{l}\text { (CARLSSON-KANYAMA; ENGSTRÖM; KOK, 2008; } \\
\text { REINDERS; VRINGER; BLOK, 2003) }\end{array}$ \\
\hline Direto & Transporte particular & $\begin{array}{llll}\text { (ALA-MANTILA; HEINONEN; JUNNILA, } & \text { 2014; } \\
\text { CARLSSON-KANYAMA; ENGSTRÖM; KOK, 2008; } \\
\text { REINDERS; VRINGER; BLOK, 2003; VRINGER; BLOK, } \\
\text { 1995) }\end{array}$ \\
\hline Direto & Preparo de alimentos & $\begin{array}{l}\text { (CARLSSON-KANYAMA; ENGSTRÖM; KOK, 2008; } \\
\text { REINDERS; VRINGER; BLOK, 2003) }\end{array}$ \\
\hline Indireto & Iluminação pública & (CARLSSON-KANYAMA; ENGSTRÖM; KOK, 2008) \\
\hline Indireto & Transporte coletivo & $\begin{array}{l}\text { (ALA-MANTILA; HEINONEN; JUNNILA, } \\
\text { CARLSSON-KANYAMA; ENGSTRÖM; KOK, 2014; } \\
\text { VRINGER; BLOK, 1995) }\end{array}$ \\
\hline Indireto & Produção Industrial & $\begin{array}{l}\text { (CARLSSON-KANYAMA; ENGSTRÖM; KOK, 2008; } \\
\text { VRINGER; BLOK, 1995) }\end{array}$ \\
\hline Indireto & $\begin{array}{l}\text { Comercialização (atacado e } \\
\text { varejo) }\end{array}$ & (CARLSSON-KANYAMA; ENGSTRÖM; KOK, 2008) \\
\hline Indireto & Atividade Profissional Liberal & (CARLSSON-KANYAMA; ENGSTRÖM; KOK, 2008) \\
\hline Indireto & Cultura & $\begin{array}{l}\text { (ALA-MANTILA; HEINONEN; JUNNILA, 2014; } \\
\text { REINDERS; VRINGER; BLOK, 2003) }\end{array}$ \\
\hline Indireto & Saúde & (ALA-MANTILA; HEINONEN; JUNNILA, 2014) \\
\hline
\end{tabular}


Nota-se, portanto, que os dados tabelados direcionam, de forma clara, que o consumo direto está associado às atividades cotidianas desenvolvidas, sobretudo, no interior das residências.

É necessário ressaltar que, apesar de haver grande tendência de aceitação das definições descritas acima, a discussão não está completamente fechada, pois há corrente de pensamento que tende a atribuir parte do trânsito de bens e matérias primas utilizadas nos processos produtivos ao consumo direto (ZHANG; ZHENG; FATH, 2014), uma vez que o gasto energético para realização desta tarefa está relacionado às condições internas da cidade, como distâncias, parcelamento do solo e sistemas de transporte. Embora exista esta discussão de classificação do tipo de consumo, este fato reforça a afirmação de que o consumo de energia é influenciado pelas características e condições da cidade (trânsito, modal de transportes, zoneamento, entre outros).

Quando há cruzamento de dados entre o consumo energético das famílias, a literatura aponta que o crescimento da renda aumenta levemente o consumo de energia ligado ao primeiro grupo (consumo direto) e também aumenta, só que fortemente, o consumo de energia ligado ao segundo grupo (consumo indireto). (LENZEN, 1998; LENZEN; DEY; FORAN, 2004; MOLL et al., 2008; REINDERS; VRINGER; BLOK, 2003), por este motivo, os mesmo autores concluem que os fatores "renda" e "despesa" são fatores importantes (se não os principais) que influenciam o consumo de energia das famílias (tanto quantitativamente, quanto qualitativamente) e estão fortemente correlacionados.

A tabela 2 mostra valores para o consumo de energia per capita nas cidades.

\begin{tabular}{|l|l|l|l|}
\multicolumn{4}{l}{ Tabela 2 - Consumo per capita de energia em vários países } \\
\hline & $\begin{array}{l}\text { CONSUMO PER CAPITA } \\
\text { SOBRE A ENERGIA } \\
\text { TOTAL }\end{array}$ & $\begin{array}{l}\text { ANO } \\
\text { REFERÊNCIA }\end{array}$ & $\begin{array}{l}\text { REFERÊNCIA } \\
\text { BIBLIOGRÁFICA }\end{array}$ \\
\hline Bélgica & $287 \mathrm{GJ} /$ ano & 2003 & $\begin{array}{l}\text { (REINDERS; VRINGER; } \\
\text { BLOK, 2003) }\end{array}$ \\
\hline USA & $283 \mathrm{GJ} /$ ano & 2002 & $\begin{array}{l}\text { (HERTWICH, 2011) } \\
\text { Espanha }\end{array}$ \\
\hline Portugal & $242 \mathrm{GJ} /$ ano & 2003 & $\begin{array}{l}\text { (REINDERS; VRINGER; } \\
\text { BLOK, 2003) }\end{array}$ \\
\hline Brasil & $180 \mathrm{GJ} /$ ano & 2005 & $\begin{array}{l}\text { (CARLSSON-KANYAMA; } \\
\text { ENGSTRÖM; KOK, 2008) }\end{array}$ \\
\hline & $173 \mathrm{GJ} /$ família/ano & 2005 & $\begin{array}{l}\text { (CARLSSON-KANYAMA; } \\
\text { ENGSTRÖM; KOK, 2008) }\end{array}$ \\
\hline
\end{tabular}




\begin{tabular}{|l|l|l|l|}
\hline Reino Unido & $138 \mathrm{GJ} /$ ano & 1996 & (HERTWICH, 2011) \\
\hline & $135 \mathrm{GJ} /$ ano & 2005 & (MOLL et al., 2008) \\
\hline Noruega & $130 \mathrm{GJ} /$ ano & 2005 & (MOLL et al., 2008) \\
\hline Suécia & $123 \mathrm{GJ} /$ ano & 2005 & (MOLL et al., 2008) \\
\hline Holanda & $112 \mathrm{GJ} /$ ano & 2005 & (MOLL et al., 2008) \\
\hline Índia & $12 \mathrm{GJ} /$ ano & $1993-1995$ & (HERTWICH, 2011) \\
\hline
\end{tabular}

Os dados evidenciam que os países desenvolvidos consomem mais energia per capita do que os países em desenvolvimento.

O consumo energético direto da população urbana está quase que na sua totalidade, voltada para o funcionamento da residência (iluminação, eletrodomésticos, aquecimento e outros benefícios), para o transporte (individual ou coletivo) e para o trato com os alimentos (conservação, refrigeração e preparo) (WIEDENHOFER; LENZEN; STEINBERGER, 2013).

Neste momento, é necessário conceituar que o consumo indireto de energia, apesar de estar correlacionado com a renda local, não necessariamente ocorre localmente, pois a produção industrial dos bens consumidos em determinado centro urbano pode ocorrer a qualquer distância do ponto de consumo, até mesmo extrapolar os limites do país de consumo. (ALA-MANTILA; HEINONEN; JUNNILA, 2014). A este processo se dá o nome de externalização dos impactos, pois a energia consumida e os impactos ambientais do local de produção do produto são diferentes no local de consumo do bem.

Para que se compreenda a dinâmica do consumo de energia de um centro urbano é necessário que sejam compreendidos os fatores que determinam, ou influenciam, a demanda energética das cidades. (HOEKSTRA; VAN DEN BERGH, 2003). Métodos de análise da dinâmica de consumo de energia permitem que o montante de energia consumida seja dividido entre as categorias "consumo direto" e "consumo indireto". (ALCÁNTARA; DUARTE, 2004)

Ligado ao consumo direto está o montante de energia consumida no interior das residências, independente de seu uso final (aquecimento ambiental ou de água, iluminação, resfriamento ou aquecimento de alimentos, higiene ou lazer) e nos deslocamentos realizados em meios de transporte particular. Na China o consumo residencial representa aproximadamente $10 \%$ (dez por cento) do consumo total do país (ZHAO; LI; MA, 2012). Os mesmos autores indicam que 63\% (sessenta e três 
por cento) das residências chinesas estão inseridas no meio urbano. Nos Estados Unidos, o consumo residencial equivale a mais do que $20 \%$ (vinte por cento) do montante consumido pelo país (YUN; STEEMERS, 2011), este percentual sobe para $24 \%$ em estudo realizado em Hong Kong. (TSO, 2003)

Outra forma de identificação de consumo direto de energia está atrelada a forma de apresentação da energia, permitindo que a energia consumida diretamente pelos habitantes da cidade seja identificada e quantificada a partir do uso da energia elétrica e da energia potencial do carvão, petróleo e gás natural, adquiridos pelos habitantes da cidade. (SONG; WOO, 2008)

Entre os principais itens caracterizados como direto na totalização do consumo de energia nas cidades estão os meios particulares de transporte ou locomoção, incluindo todo meio utilizado para a mobilidade interna na cidade, (WIEDENHOFER; LENZEN; STEINBERGER, 2013). Esta fonte é responsável pela emissão de 33\% do total de emissões totais de gases do efeito estufa nos EUA (sendo composto por 95\% de dióxido de carbono) (LIU; SHEN, 2011).

$O$ aumento do consumo residencial tende a aumentar na medida em que se verifica aumento da renda e alteração de comportamento no que diz respeito à intensidade do uso de eletrodomésticos. Por outro lado, o consumo tende a diminuir quando se considera a tecnologia aplicada à eficiência energética de equipamentos (eletrodomésticos, iluminação, etc.) e a evolução das técnicas e materiais aplicados às novas edificações, maximizando a capacidade de aquecimento/arrefecimento internos. (ZHAO; LI; MA, 2012)

A definição mais resumida e amplamente utilizada na literatura para a energia indireta é "a energia consumida para produção de bens e serviços antes da utilização do item produzido" (SONG; WOO, 2008), (WIEDENHOFER; LENZEN; STEINBERGER, 2013), (ZHAO; LI; MA, 2012). A energia indireta, em muitas condições, é dita "energia incorporada" ao serviço ou ao produto.

A energia utilizada para fins industriais é a principal forma de consumo indireto de energia e corresponde, na China, a $71 \%$ (setenta e um por cento) do consumo total (ZHAO; LI; MA, 2012). 
Em um mundo globalizado, onde a evolução dos sistemas de transportes de mercadorias e de pessoas em escala internacional tem facilitado e permitido o aumento do consumo de mercadorias produzidas em regiões distantes, o consumo indireto de energia tem representado significativa relevância nos estudos acerca do comportamento da dinâmica de consumo de energia mundial, principalmente quando o objeto de estudo engloba os impactos ambientais causados pelo consumo da energia elétrica (CHEN; CHEN, 2011), pois o produto é consumido ou utilizado em local diferente de onde ocorre o impacto ambiental decorrente da produção/transformação de energia utilizada para a sua produção.

\subsubsection{Estudo do consumo direto de energia nos centros urbanos}

Apesar da divisão do consumo de energia em duas categorias (direto e indireto) (WIEDENHOFER; LENZEN; STEINBERGER, 2013), o metabolismo urbano (ZHANG; ZHENG; FATH, 2014) influencia o consumo direto (uso residencial e transporte individual), e o consumo indireto (transporte coletivo). Neste ponto tornase necessário ressalvar que a caracterização do transporte coletivo como consumo indireto é passível de contestação e não é consenso na literatura (ZHANG; ZHENG; FATH, 2014), onde, em alguns estudos, o transporte coletivo é considerado, em parte, como uso direto.

O consumo direto de energia está relacionado a várias atividades desenvolvidas em residências, entre elas (aquecimento, iluminação, uso de eletrodomésticos, etc.) (YAO; STEEMERS, 2005) e é amplamente estudado e discutido na literatura científica. Contudo os métodos aplicados para análise dos dados formam um grande conjunto heterogêneo, fato que dificulta a comparação direta dos estudos. (CHEN et al., 2008)

Os dados relativos ao montante de energia consumida diretamente no interior da cidade (assim como os outros dados de consumo de energia elétrica) são, geralmente, medidos pelos operadores dos sistemas de fornecimento de energia (principalmente elétrico e gás, através de medidores individuais instalados para leitura e posterior tarifação do consumo) e publicados oficialmente. Com a alteração de tecnologias, os métodos de medição dos índices evoluem e passam a ser cada vez mais apurados e em intervalos menores. (CHEN et al., 2008) Na tabela 3 é 
possível verificar o percentual de contribuição de cada grupo de atividades no consumo direto de energia em residências em alguns países do mundo.

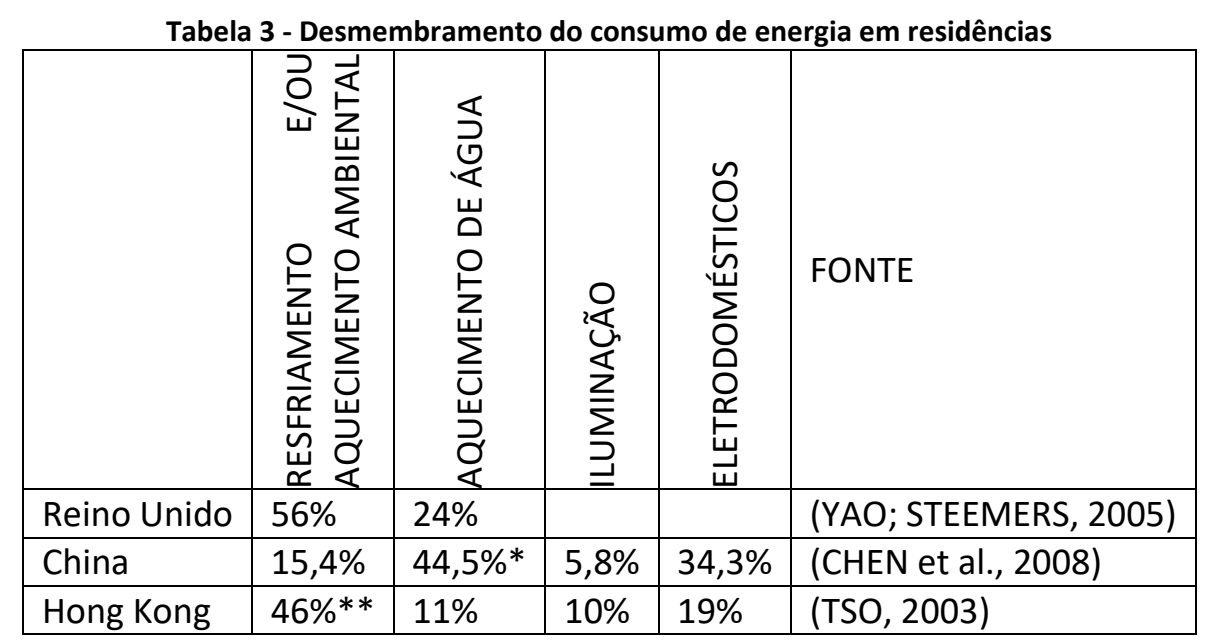

Quando o montante não for igual a 100\%, a diferença é utilizada para outras finalidades não incluídas na tabela.

${ }^{*}$ incluindo cozimento, ${ }^{* *} 66 \%$ durante o verão.

A tabela 3 evidencia que a cultura local e as condições climáticas determinam o percentual de uso de energia em relação às atividades cotidianas, pois os valores apresentam grande variação.

A determinação e quantificação da energia direta de energia é realizada através de métodos já estabelecidos em literatura.

De início deve-se ressaltar que 0 valor total de energia consumida em um determinado território é resultado da somatória da energia consumida diretamente e indiretamente, (WIEDENHOFER; LENZEN; STEINBERGER, 2013), logo se torna necessário apenas o conhecimento de um, entre os dois valores, para que se obtenha seu complemento. Esta informação torna-se relevante na medida em que alguns estudos disponíveis na literatura obtêm informações a partir desta simplificação, principalmente por falta de dados detalhados relativos ao consumo.

Para levantamento mais detalhado do consumo direto de energia, a entrevista ainda é o método mais aplicado. Apesar do baixo índice de retorno das entrevistas realizadas e da dificuldade de amplitude, este método tem sido replicado em função da viabilidade econômica (TSO, 2003). 


\subsubsection{Uso racional de energia direta em cidades}

Muitos estudos reconhecem que o entendimento da dinâmica de consumo de energia é premissa para a adoção de políticas de uso racional de energia, possibilitando ações norteadoras que mitigam os impactos ambientais oriundas da produção e consumo de energia. (CHEN et al., 2008; RICHARDSON; THOMSON; INFIELD, 2008; TSO, 2003; YAO; STEEMERS, 2005).

Muitas ações voltadas à racionalização do uso direto de energia estão direcionadas a necessidade de mudança comportamental dos habitantes, mais especificamente em hábitos isolados, como por exemplo, a orientação em acumular louças e lavá-las quando a ocupação da máquina de lavar estiver próxima da capacidade máxima dos equipamentos, diminuir o tempo dos banhos, fechando a saída de água para ensaboar-se, desligar a iluminação de ambientes desocupados, evitar utilizar carros em pequenas distâncias, etc., (CARLSSON-KANYAMA; ENGSTRÖM; KOK, 2008), ou seja, as ações têm como alvo a alteração do comportamento dependendo apenas da disposição do agente (habitante) em mudar suas rotinas.

Contudo muitas tarefas ou necessidades da população são influenciadas pelas características das cidades. A escolha do modal de transporte para locomoção depende, em parte, da distância a ser percorrida, da disponibilidade de transporte coletivo, das condições viárias e de tráfego, entre outras, portanto as condições físicas da cidade influenciam também na decisão da população. Além do exemplo acima, algumas outras características podem influenciar de forma direta ou indireta o consumo final de energia.

\subsubsection{Características das cidades e a influência no consumo energético}

Muitas são as características das cidades (WIEDENHOFER; LENZEN; STEINBERGER, 2013) com potencial de influência no consumo de energia. (MARIQUE et al., 2014) Entre elas podemos citar o formato urbano, que inclui a implantação (ou desenho urbano) e a elevação das edificações (gabarito de altura e formato), distribuição do sistema de transporte, densidade, uso do solo, tamanho, formato e poder aquisitivo das famílias, condições climáticas entre outros.

Muitas destas características resultam do processo histórico de construção da cidade, incluindo até as mais recentes intervenções no âmbito do planejamento 
urbano. Desde o início das cidades industriais (pós-revolução industrial) já se tem registros de amplas discussões sobre o formato ideal das cidades e sua composição, surgindo teorias antagônicas, como a centralização e a descentralização das regiões principais. (CHOAY, 2003)

Portanto, algumas das características das cidades cuja correlação com o consumo de energia já estão identificadas na literatura e serão brevemente abordadas neste trabalho com o intuito de solidificar os conceitos e apresentar qualitativamente as relações existentes. As correlações quantitativas são posteriormente empregadas no modelo desenvolvido. Para fins didáticos, os fatores que influenciam o consumo de energia nos centros urbanos foram agrupados em três grandes grupos: características físicas, características da população e atividades cotidianas.

\subsubsection{Características físicas}

As características físicas das cidades são aqueles que podem ser associadas com o uso e ocupação do espaço urbano construído ou natural, tanto na horizontalidade quanto na verticalidade.

A mancha urbana é uma das características mais marcantes dos centros urbanos. As relações entre a forma urbana e o consumo de energia têm sido amplamente discutidas na literatura científica (EWING; RONG, 2008; FILION, 2008; HORNER, 2013; KO, 2013), e verifica-se a grande aceitação da correlação existente entre ambos (KO, 2013), bem como os impactos ambientais causados em decorrência das emissões de GEE, oriundos do consumo e produção de energia (BROWNSTONE; GOLOB, 2009). Dentro do termo "forma urbana" deve-se considerar duas dimensões de ocupação: a implantação, também denominado de perfil horizontal e a elevação da cidade, denominado de perfil vertical.

A implantação, também conhecida como mancha urbana é delimitada pelo desenho formado em função do arranjo interno de ocupação da cidade por meio de edifícios, arruamentos, espaços verdes e espaços vazios, devendo ser consideradas suas dimensões, orientações e posicionamentos. $O$ formato da implantação tem relação direta com as distâncias e percursos a serem percorridos pela população em seus deslocamentos diários, com o formato da malha de distribuição de energia elétrica e 
com a circulação de ar no interior das cidades. Um exemplo de implantação, ou mancha urbana pode ver visualizado na figura 6.

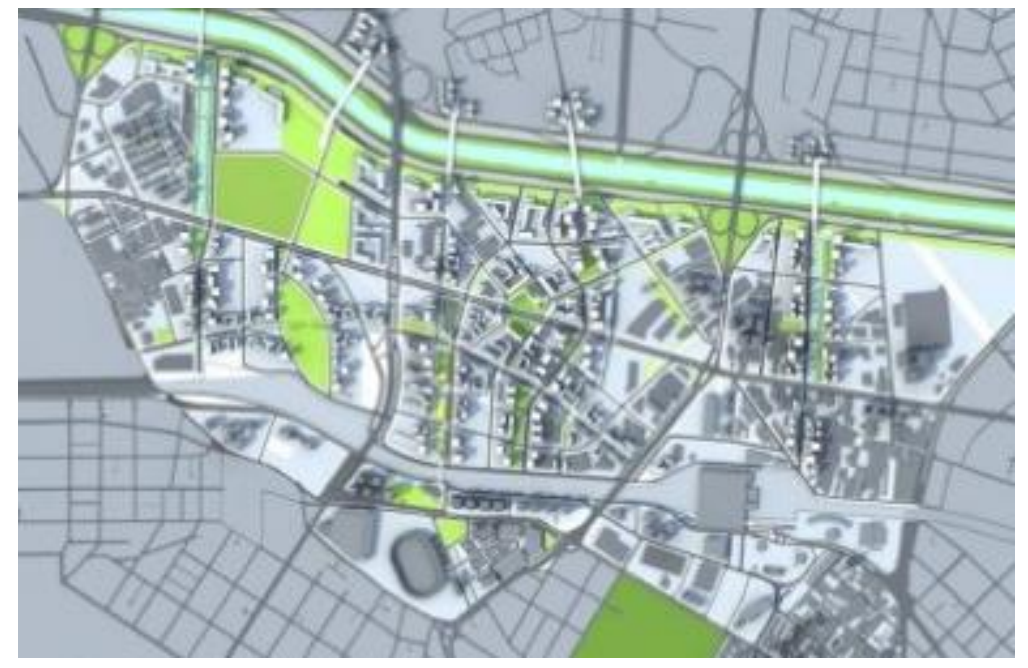

Figura 6 - Exemplo de mancha urbana fonte: site VITRUVIUS, editada pelo autor

A elevação é formada pela ocupação vertical da cidade, tendo relação direta com o processo de adensamento populacional. A densidade das cidades apresenta correlação negativa com o consumo energético da população (MINDALI; RAVEH; SALOMON, 2004). A verticalização também tem impacto direto com a circulação de ar no interior das cidades, pois tem a capacidade de formar corredores por onde circula o ar ou ainda pode formar barreiras, desviando os ventos e influenciando na formação das ilhas de calor (BIAS; BAPTISTA; LOMBARDO, 2003). Um exemplo de elevação, ou ocupação vertical do espaço da cidade pode ser visualizado na figura 7.

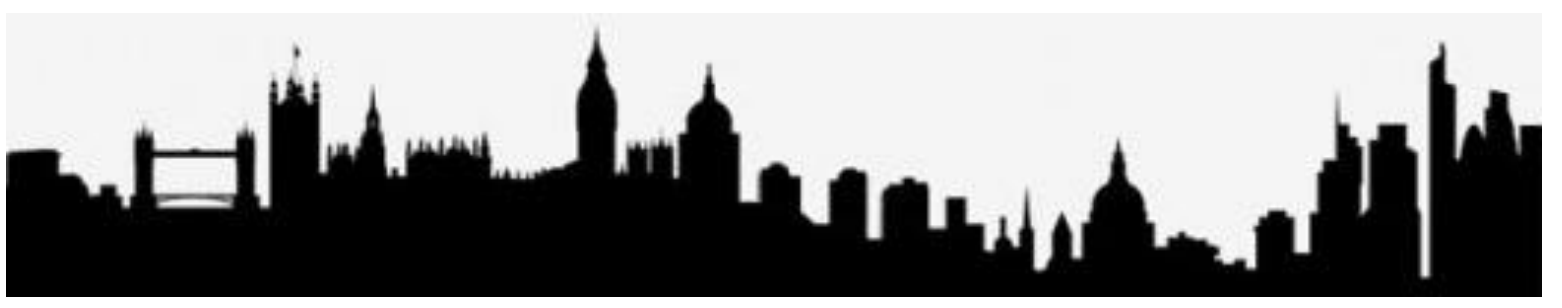

Figura 7 - Elevação ou perfil da cidade - ocupação vertical fonte: site VITRUVIUS, editada pelo autor

Portanto, ambas as características do formato urbano possuem correlações com o consumo direto e indireto de energia.

O formato urbano é uma característica da cidade que permite ser ajustada a partir de ações que utilizam os instrumentos de planejamento urbano (uso e ocupação do 
solo, coeficiente de aproveitamento, IPTU progressivo, etc.), permitindo, com isso, interferência no consumo de energia independente da mudança de hábitos da população.

Vinculado à formação de ilhas de calor, interferindo diretamente no fluxo de ar no interior das cidades, o formato, posicionamento e altura das edificações compõem uma característica importante das cidades que influenciam no consumo de energia, particularmente, e mais especificamente, na utilização de energia para resfriamento interno dos edifícios. (CAVAN et al., 2014)

A disposição dos edifícios, a existência de recuos entre as edificações e a altura das mesmas são características que permitem ou não incidência solar direta nas fachadas (seja na própria fachada ou na fachada contígua), conforme exemplificado na figura 8. Estas características podem definir a quantidade de radiação solar e o fluxo luminoso que adentra nos edifícios, impactando a demanda de energia necessária para os sistemas de resfriamento, aquecimento e iluminação interna. (DE CASAS CASTRO MARINS; DE ANDRADE ROMÉRO, 2013) Em microescala, o projeto e construção de edifícios que agregam técnicas de circulação de ar (circulação natural) e proteção auxiliar contra a insolação (aparadores e brisessoleils) são opções para diminuição do consumo de energia necessária para resfriamento interno de moradias. (YUN; STEEMERS, 2011)

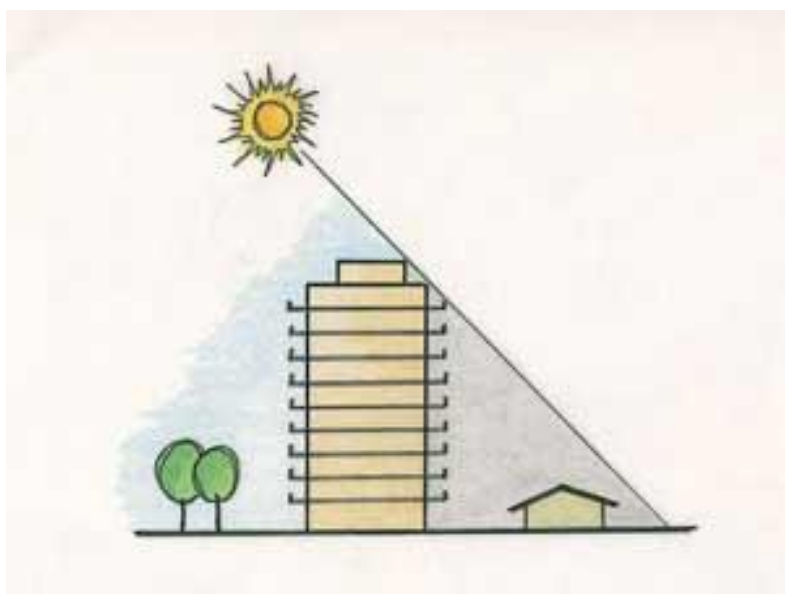

Figura 8 - Barreira para incidência solar em edificação fonte: site VITRUVIUS, editada pelo autor

Outra característica importante relacionada à altura e disposição das edificações nos centros urbanos é a alteração da dinâmica dos ventos na cidade. Os elementos que compõem a ocupação vertical formam barreiras desviando o trajeto dos ventos e 
impedindo a sua livre circulação. A figura 9 apresenta um exemplo simples desta dinâmica. Os ventos contribuem para troca de calor na atmosfera, amenizando o processo de formação de ilhas de calor, além de auxiliarem na dispersão de particulados poluentes que estão em fase de suspensão. O desvio do percurso natural dos ventos pode contribuir para alteração na demanda por energia nas cidades, principalmente nas atividades relacionadas aos sistemas de arrefecimento interno.

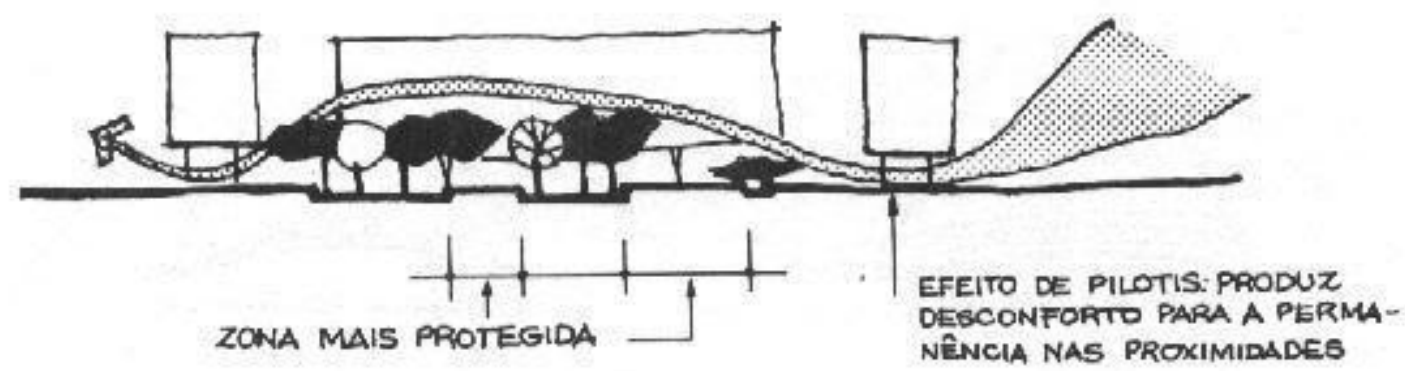

Figura 9 - Exemplo de interferência da ocupação vertical na dinâmica de ventos fonte: site VITRUVIUS, editada pelo autor

As ilhas de calor são regiões localizadas nos centros urbanos onde há elevação da temperatura em alguns graus acima dos níveis na zona rural, tanto no ar, quanto na superfície, devido à alteração da paisagem natural pelo homem, sobretudo a retirada de vegetação para construção de edifícios. O uso a que a edificação é destinada praticamente não impacta na formação das ilhas de calor. Seja o uso residencial, industrial, comercial ou misto, o fenômeno é semelhante. O que realmente contribui para o aquecimento é a substituição da vegetação por superfícies fabricadas pelo homem, (LI et al., 2014) prática que altera significativamente o albedo das superfícies.

Um aspecto prevalecente na formação de ilhas de calor é a morfologia urbana, ou seja, a forma urbana, ou o desenho adquirido pela implantação da cidade (horizontal e vertical), pois o vento é direcionado conforme as barreiras e corredores resultantes da ocupação urbana (THEEUWES et al., 2014), conforme figura 10. A circulação de ar tem papel fundamental na troca de calor entre a superfície, o ar, os edifícios, as áreas verdes, as pessoas e demais elementos urbanos, pois proporciona a mistura do ar uniformizando sua temperatura. (AMBROSINI et al., 2014) Neste aspecto, a 
altura das edificações também é de fundamental importância, pois interferem tanto na circulação de ar, quanto na incidência dos raios solares sobre as superfícies.

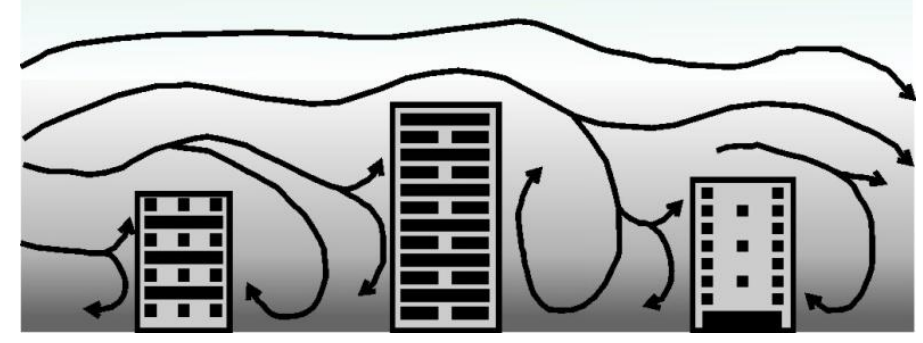

Figura 10 - Alteração na dinâmica de circulação de ar

fonte: (CRISTIANE CAMPOS TOLEDO; FILLIPE TAMIOZZO PEREIRA TORRES; LUIZ ALBERTO MARTINS, 1997)

A inserção de áreas arborizadas, áreas verdes e permeáveis e o aumento do albedo das superfícies cobertas são ações mitigadoras da formação de ilhas de calor nos centros urbanos, (AMBROSINI et al., 2014; TAHA, 1997). A verticalização, principalmente das áreas residenciais diminuiriam a ocupação do solo, permitindo maior disponibilidade para áreas verdes, podendo também diminuir o tamanho da mancha urbana, sendo estas, duas ações estratégicas de ocupação do solo que contribuiriam para a circulação do ar e dificultam a formação das ilhas de calor (LI et al., 2014). A adoção de telhados verdes tem baixo impacto na mitigação do fenômeno de formação de ilhas de calor. A funcionalidade de telhados verdes temse mostrado mais eficazes em edifícios baixos e cidades menos densas, ainda assim seriam necessárias grandes áreas de cobertura para que algum efeito perceptível fosse identificado. (AMBROSINI et al., 2014)

Aliado a outros fatores (socioeconômicos e culturais) as condições de clima e as estações do ano afetam diretamente o consumo de energia individual, (CHEN et al., 2008) repercutindo em todas as escalas de estudo (residência, bairro, cidades ou nação).(XU; ANG, 2014).

As mudanças no sistema climático do planeta, em decorrência das ações antrópicas, possui correlação positiva com o consumo de energia mundial. $O$ aquecimento da terra altera a necessidade do uso de equipamentos para os sistemas de aquecimento e resfriamento de ambientes internos (TSO, 2003). Este variação também está correlacionada com o tamanho das famílias, ou seja, famílias que possuem mais pessoas compartilham dos benefícios do uso da energia para o mesmo ambiente interno da residência (KENNEDY et al., 2009). Também está 
correlacionado com o tamanho dos ambientes construídos e com os aspectos comportamentais dos habitantes, uma vez que a percepção e necessidade do uso de condicionamento de ar são individuais (RICHARDSON; THOMSON; INFIELD, 2008; YAO; STEEMERS, 2005) Contudo os estudos desta relação ainda são incipientes. (RICKWOOD, 2009).

A principal característica da urbanização é a alteração da paisagem natural (LI et al., 2014). Dentro deste processo é necessário que haja distinção entre ocupação e uso do solo. O termo ocupação do solo está relacionado a qualquer tipo de alteração que altere ou desfigure o ambiente original, enquanto que $\mathrm{o}$ uso do solo refere-se a atividade que é desempenhada sobre o solo ocupado.

O uso e ocupação do solo é uma ação antrópica que impacta direta e indiretamente o meio ambiente ( $\mathrm{LI}$ et al., 2014). Inicialmente é possível afirmar que o consumo de energia é alterado em função da formação de ilhas de calor, fenômeno agravado pela alteração do albedo da superfície urbana e impermeabilização do solo (KO, 2013). Estudos ainda têm apontado que a disposição do uso dos solos e a criação de regiões de restrições, ou segregação do uso, tem impacto na mobilidade urbana, sobretudo nas viagens cotidianas de deslocamento residência - trabalho e viceversa (LIU; SHEN, 2011), pois a inserção de blocos "vazios", áreas verdes, lazer, espelhos d'água, etc., ampliam as distâncias a serem percorridas no interior das cidades, ocasionando o aumento do consumo energético para a mobilidade.

Atualmente o foco dos projetos de arquitetura tem-se voltado para o desempenho energético isolado dos edifícios, ignorando seu impacto no conjunto arquitetônico da cidade, desprezando suas características de ocupação do solo e alteração da paisagem natural $(K O, 2013)$.

Dentre as categorias de uso do solo possíveis nas regiões urbanas destacam-se: residencial, comercial e serviços, industrial e institucional. (LI et al., 2014), contudo cabe ressaltar que as cidades ocupam aproximadamente $2 \%$ do território mundial (YIN; MIZOKAMI; MARUYAMA, 2013b) e o uso agrícola representa grande parte da ocupação no globo, porém, neste trabalho o recorte da análise está nos centros urbanos. 
Desde a acentuação das externalidades decorrentes do uso do solo urbano, muitas foram às propostas que visavam à cidade ideal. Historicamente, esta busca já foi registrada em cidades gregas há quase três milênios (CHOAY, 2003).

A cobertura vegetal, tanto em termos de percentual de solo ocupado, quando em composição, formato e distribuição territorial, é agente de ação direta na mitigação de ilhas de calor (CAVAN et al., 2014), interferindo no uso de energia utilizada para sistemas de resfriamento.

Cabe ressaltar que as áreas verdes e arborizadas, sobretudo parques e praças, devem ser considerados como solo ocupado, pois, apesar de apresentar, na maioria das vezes, solo permeável, constitui-se de um ambiente alterado pela ação humana (LI et al., 2014) e estão inseridas no meio urbano, sendo, muitas vezes, influenciadas pelo meio em que estão inseridas.

No contexto urbano, as áreas verdes são de grande valor, pois propiciam condições para mitigação das ilhas de calor (AMBROSINI et al., 2014), são consideradas áreas permeáveis e umidificam o ar pelo processo de evapotranspiração (TAHA, 1997), permitem o uso para recreação e servem de morada para a vida animal de pequeno porte (TENG et al., 2011).

Mobilidade urbana é um termo que está relacionado com a capacidade de deslocamento no interior das cidades (KNEIB, 2012) e envolve uma série de fatores, como infraestrutura, tecnologia e processos de operações. (DE CASAS CASTRO MARINS; DE ANDRADE ROMÉRO, 2013). Estes deslocamentos ocorrem por quatro motivos principais: trabalho, estudo, lazer e compras e podem ocorrer pelos mais diversos modais: transporte particular, transporte coletivo ou a pé. (KEIRSTEAD; SIVAKUMAR, 2012), contudo, independente do objetivo do percurso, na maioria das vezes o deslocamento é realizado de forma motorizada, fato que demanda energia (DUJARDIN; MARIQUE; TELLER, 2014).

Associada à mobilidade realizada em modais de transporte movidos a motores à explosão está a emissão de GEE, pois em sua grande maioria, a energia utilizada é oriunda de fontes fósseis, fato que acentua o impacto no meio ambiente, como 0 agravamento do efeito estufa e acentuação da formação de ilhas de calor. 
(HICKMAN; HALL; BANISTER, 2013). Estes problemas geram reações em cadeia que na maioria das vezes são negligenciadas pelos planejadores urbanos.

Em cidades cuja densidade é alta, considera-se mais eficiente o sistema de transporte público, considerando que a maior parcela da população substitui o transporte individual por transporte de massa. (KENNEDY et al., 2009), fato que reduz a ocupação dos espaços de circulação de veículos e permite maior fluidez ao trânsito.

Nos países europeus, a energia consumida com a locomoção corresponde a $32 \%$ do consumo total de energia primária. (MARIQUE et al., 2014).

No Brasil a energia utilizada nos sistemas de transporte apresenta tendência de aumento nos últimos 10 anos (BRASIL, 2014), conforme tabela 4, e atualmente está na ordem de $32 \%$ do total de energia consumida em 2013 , e, apesar do aumento significativo da utilização de biocombustíveis, o setor de transportes contribui com a participação de $44 \%$ dos produtos derivados do petróleo incluídos no balanço energético nacional (BRASIL, 2014), conforme apresentado na figura 10. Este quadro justifica porque grande parte dos estudos de otimização dos sistemas de transporte em centros urbanos estão voltados as relações entre transportes e emissões de gases do efeito estufa. (HICKMAN; HALL; BANISTER, 2013).

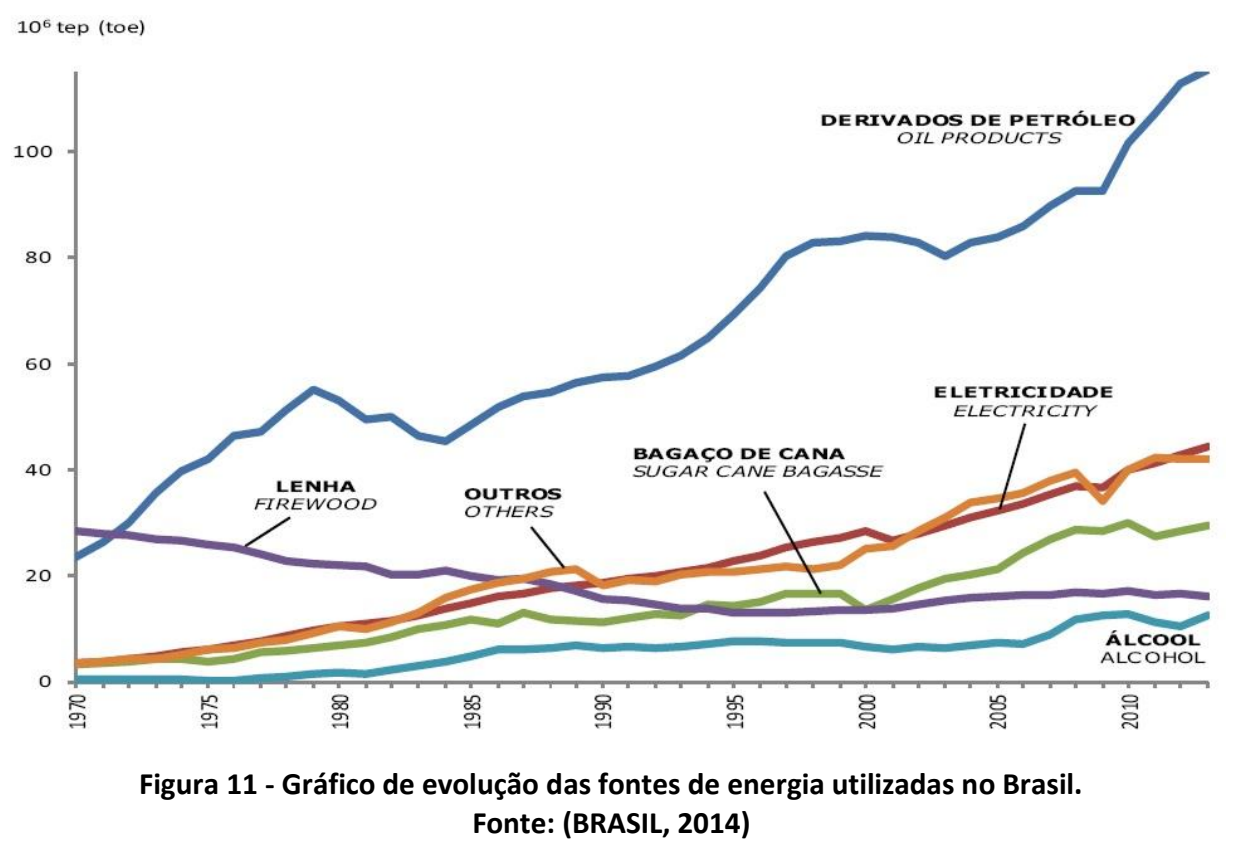


Nos grandes centros urbanos do Estado de São Paulo, a energia consumida para o deslocamento é ligeiramente mais alta, atingindo valores próximos a $60 \%$ (SÃO PAULO, 2016b).

O uso dos sistemas de transporte no interior das cidades é complexo (DE CASAS CASTRO MARINS; DE ANDRADE ROMÉRO, 2013) e seu estudo engloba vários fatores como, por exemplo, o objetivo do deslocamento, a forma utilizada para deslocar-se, as características dos usuários, entre outros. (HORNER, 2013), porém a diminuição das necessidades de viagens e a redução dos percursos em termos de distância e tempo podem contribuir para a melhoria do sistema de transporte das cidades e contribuir para a redução do consumo de energia, mitigando os impactos ambientais decorrentes do uso de combustíveis fósseis (MINDALI; RAVEH; SALOMON, 2004), visto que se estima que a contribuição do sistema de transporte para emissão de CO2 está na ordem de 25\%. (HICKMAN; HALL; BANISTER, 2013)

\begin{tabular}{|c|c|c|c|c|c|c|c|c|c|c|}
\hline & \multicolumn{10}{|c|}{ ANO } \\
\hline & 2004 & 2005 & 2006 & 2007 & 2008 & 2009 & 2010 & 2011 & 2012 & 2013 \\
\hline CONSUMO TOTAL DE ENERGIA & 190664 & 195491 & 202534 & 215197 & 226215 & 229732 & 241194 & 245860 & 253037 & 260149 \\
\hline USO RESIDENCIAL (TOTAL) & 21357 & 21827 & 22090 & 22271 & 22738 & 23129 & 23562 & 23267 & 23761 & 23730 \\
\hline USO RESIDENCIAL (\%) & 11,2 & 11,2 & 10,9 & 10,3 & 10,1 & 10,5 & 9,8 & 9,5 & 9,4 & 9,1 \\
\hline TRANSPORTES (TOTAL) & 51690 & 52720 & 53630 & 58019 & 62829 & 63041 & 69720 & 73989 & 79027 & 83153 \\
\hline TRANSPORTES (\%) & 27,1 & 27,0 & 26,5 & 27,0 & 27,8 & 28,6 & 28,9 & 30,1 & 31,2 & 32,0 \\
\hline & $10^{3} \operatorname{TEP}(T$ & & & & & & & & & \\
\hline
\end{tabular}

No âmbito da estrutura de ocupação e zoneamento, o incentivo a descentralização da ocupação urbana apresenta potencial para redução do uso de energia em deslocamentos internos, uma vez que a cidade que possui vários centros de interesses (cidades policêntricas) tem maior oferta de atrativos em regiões descentralizadas, permitindo ao usuário a escolha do polo mais próximo, diminuindo a distância a ser percorrida. Supõe-se ainda que o fluxo de deslocamento ocorra de forma dividida, podendo ocorrer melhor utilização da malha viária, aumentando a fluidez do tráfego e, por consequência, diminuição no tempo de deslocamento (HICKMAN; HALL; BANISTER, 2013) e aumento da eficiência na relação quilômetros/litro dos veículos automotores.

Outro ponto relevante está na criação de corredores expressos que permitam grandes travessias em velocidade superior à praticada internamente na cidade, sem a necessidade de parada em cruzamentos. Esta prática, apesar de não diminuir a 
distância da viagem, permite melhor aproveitamento do tempo e menor consumo de combustível na relação litros/quilômetro de combustível, reduzindo o gasto energético das viagens. (HICKMAN; HALL; BANISTER, 2013)

A oferta de rede integrada de transporte público, oferecendo ao usuário boas condições de deslocamento (incluindo conforto, tempo de deslocamento, custo acessível, etc.), permite a substituição (pelo menos em parte) do transporte particular - muitas vezes individualizado - por transporte coletivo. Esta condição favorece a diminuição da quantidade de veículos ocupando o sistema viário, permitindo maior fluidez ao tráfego, além do que o consumo per capita de combustível nos sistemas de transporte público, quando comparados com o transporte particular é substancialmente menor. (BUBECK; TOMASCHEK; FAHL, 2014; JAIN et al., 2014).

Partindo de ações integradas de planejamento urbano, como readequação do zoneamento permitindo e incentivando a criação de vários centros atrativos na cidade, a readequação viária, possibilitando melhoria no fluxo dos sistemas de transporte, e investimentos em estudos e implantação de sistemas de transporte coletivo, a alteração na dinâmica de deslocamento no interior das cidades pode contribuir para a diminuição da demanda por energia para os sistemas de transporte.

A implantação da cidade (disposição e uso do solo) é determinante para a implantação da malha de distribuição de energia elétrica, incluindo as bases de apoio ao sistema para transformação e derivações. O foco principal do estudo desta relação na racionalização de energia através da prevenção de perdas. (EWING; RONG, 2008). Partindo deste raciocínio, quanto mais ampla for a forma urbana, ou o espaço ocupado pela cidade, maiores serão as linhas de transmissão e distribuição, possibilitando, desta maneira, maior dificuldade no monitoramento do sistema, ampliando a possibilidade de perdas, independente do motivo que ela ocorra (falha, furto, queda de tensão, etc.).

Desta forma, o adensamento da ocupação urbana tende a minimizar as perdas e contribuir para a diminuição do gasto de energia. 


\subsubsection{Características da população}

A densidade populacional tem correlação fraca e negativa no consumo de energia das cidades (LENZEN et al., 2006; MINDALI; RAVEH; SALOMON, 2004). Este fenômeno está intimamente ligado à diminuição dos espaços ocupados por cada habitante, pressupõe que ambientes menores requerem quantidade de energia menor para serem aquecidos e/ou resfriados, além do que cidades mais densamente ocupadas requerem menores distâncias de deslocamento quando considerada a população como um todo (WIEDENHOFER; LENZEN; STEINBERGER, 2013)

A distribuição e fornecimento de saneamento básico e serviços públicos em cidades adensadas tendem a consumir menos energia per capita, pois na medida em que 0 adensamento populacional se eleva, o percurso para atendimento dos pontos de consumo de água torna-se menor, reduzindo a demanda de energia para bombeamento de água em sua distribuição, por exemplo. (FILION, 2008) e eliminando vazamentos na rede, evitando desperdício de água e eventual necessidade de maior volume a ser bombeado. (XU et al., 2014). Cabe ressaltar que o adensamento está relacionado com o gabarito de altura das edificações e que, em edificações altas, o bombeamento de água passa a ser uma necessidade interna da edificação.

Outro fator importante no adensamento populacional está no impacto direto da redução da mancha urbana. Cidades mais densas ocupam espaços menores para o mesmo número de habitantes. Desta forma, a diminuição dos percursos de viagem resulta em menor gasto energético com os sistemas de transporte particulares ou públicos (MINDALI; RAVEH; SALOMON, 2004). A figura 12 apresenta a correlação exponencial entre o consumo anual de gasolina por habitante e a densidade urbana para algumas cidades.

Ações de planejamento urbano que visem a verticalização da cidade incentivam o adensamento populacional e possuem potencial para reduzir o consumo de combustível para mobilidade nos centros urbanos. 


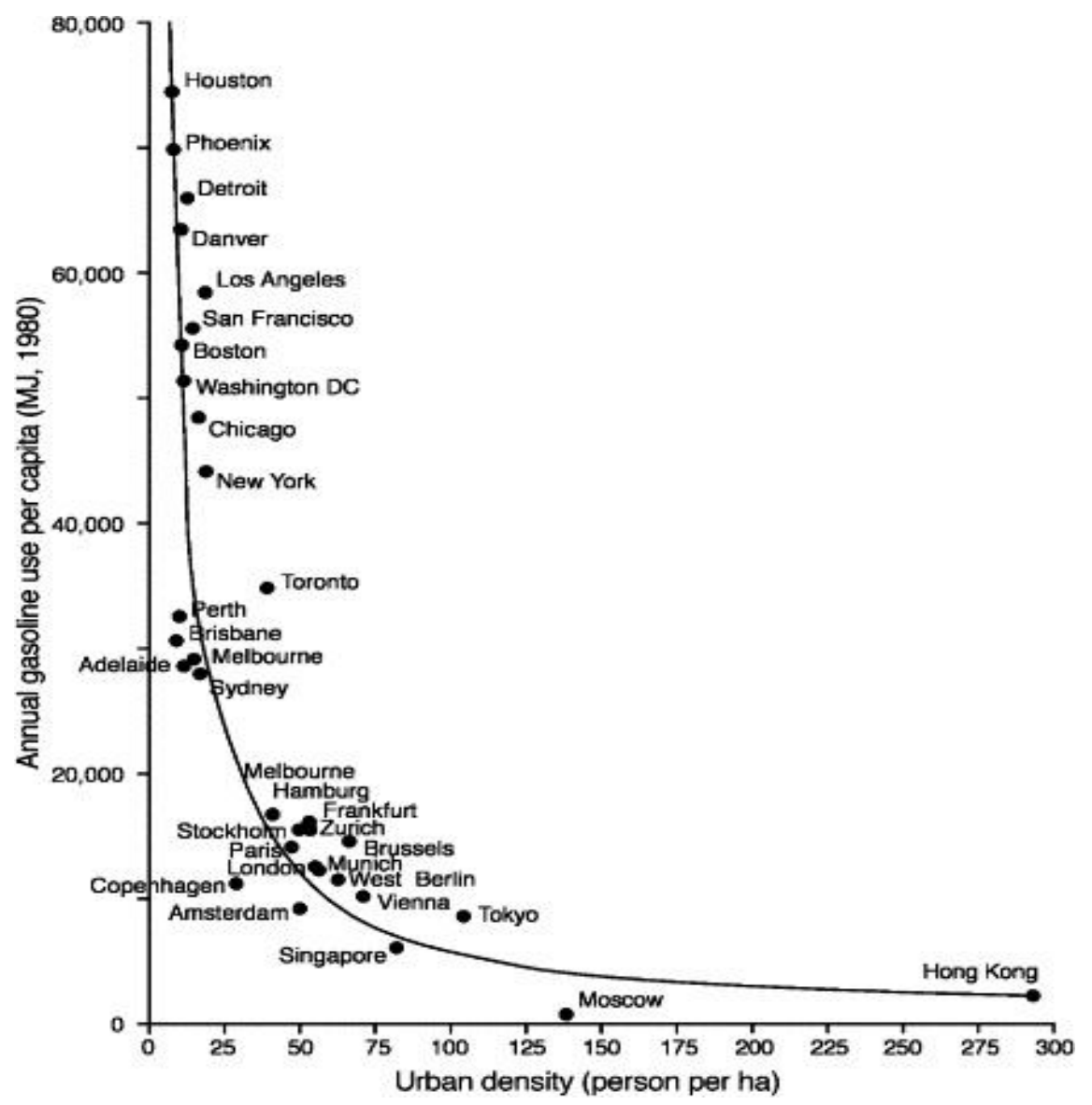

Figura 12 - Relação entre consumo de gasolina por habitante $x$ densidade urbana fonte: (MINDALI; RAVEH; SALOMON, 2004)

O formato e o tamanho das famílias estão relacionados, principalmente, com a relação renda e despesa per capita (WIEDENHOFER; LENZEN; STEINBERGER, 2013; WIER et al., 2001). Estas características influenciam diretamente no consumo de energia da cidade. (TSO, 2003). Na Europa, a média de consumo de energia de fontes primárias em edificações está na ordem de $40 \%$ do total produzido. (MARIQUE et al., 2014)

O número de ocupantes tem correlação negativa com o consumo de energia elétrica em unidades residenciais. Esta relação explica-se no compartilhamento que ocorre em atividades desenvolvidas no interior das residências onde há consumo direto de energia elétrica. Pessoas que habitam a mesma residência e, portanto desenvolvem atividades em um mesmo ambiente podem, por exemplo, compartilhar do mesmo sistema de resfriamento ou aquecimento do ambiente. Da mesma forma, caso a atividade seja desenvolvida no mesmo cômodo, podem também compartilhar o mesmo ponto de iluminação. Deste exemplo se pode afirmar que: quando comparada o consumo de energia de uma família com outra família com o dobro de 
membros, o consumo de energia certamente não será o dobro. Dado os usos comuns de ambientes, eletrodomésticos e demais atividades, é esperado que o consumo seja menor. (RICHARDSON; THOMSON; INFIELD, 2008)

A compreensão da dinâmica de consumo direto de energia elétrica no interior das residências permite ao operador do sistema identificar os picos e vales de consumo e elaborar estratégias para utilização das fontes de energia renováveis em tempo integral, apenas complementando a demanda de energia com a geração de energia pelos métodos mais poluentes. (YAO; STEEMERS, 2005)

Analisando os possíveis meios de utilização de energia no interior de residências é possível dividi-los em dois grupos: O primeiro grupo está relacionado com as o comportamento dos habitantes da residência e tem correlação muito fraca com o ambiente em que estão inseridos. São exemplos deste grupo: lavar, cozinhar, conservação de alimentos, entretenimento, higiene, etc. $O$ segundo grupo é composto pelo consumo de energia da forma direta relacionada com o meio físico e basicamente estão relacionados às condições ambientais e as características das edificações, destacando a aquecimento, resfriamento, iluminação do ambiente, transporte vertical, bombeamento de água (RICHARDSON; THOMSON; INFIELD, 2008; YAO; STEEMERS, 2005). Ressalvando que há autores que incluem a iluminação à condição comportamental e não ambiental. (CHEN et al., 2008)

Outro fator relevante é a renda percapita. Embora o fator renda/despesas não possa ser considerado uma característica da cidade, é necessário ressaltar que as condições econômicas dos habitantes têm forte relação com fatores que influenciam o consumo de energia, como a mobilidade urbana, a densidade populacional, 0 formato e tamanho das famílias, o formato da edificação entre outros. Esta ressalva toma importância na medida em que a relação entre a renda/despesas é um fator que apresenta forte correlação com o consumo de energia da cidade (ALAMANTILA; HEINONEN; JUNNILA, 2014), enquanto que as demais características citadas neste parágrafo ainda necessitam de estudos mais aprofundados. (KENNEDY et al., 2009)

A correlação entre renda familiar e impacto ambiental pode ser representada pela curva de Kuznets, amplamente divulgada pela literatura, porém apresentando 
algumas adaptações para as realidades mais atuais (STERN, 2004). O gráfico da figura 13 apresenta a curva de Kuznets.

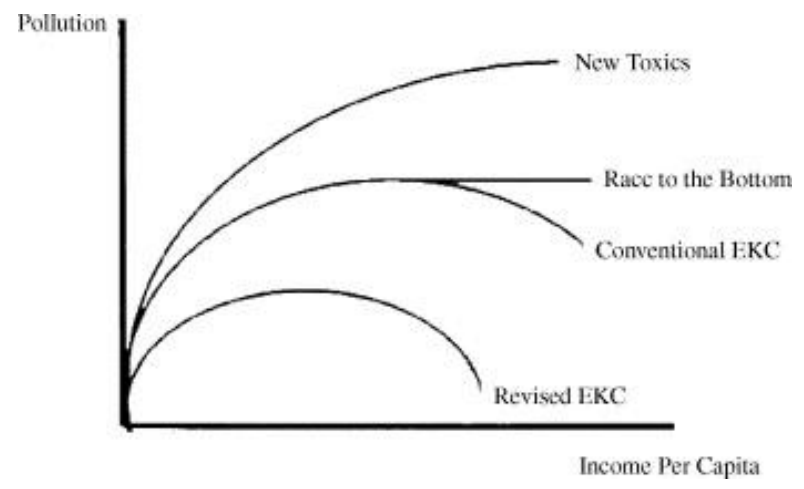

Figura 13 - Representação da curva de Kuznets fonte: (STERN, 2004)

O gráfico da figura 13 representa a correlação entre o avanço da renda e o avanço exponencial da poluição, cabendo ressaltar que a correlação é positiva até certo momento de aumento da renda, quando passa a ser negativa. Este fato se explica, basicamente, pela consciência ambiental adquirida pelos povos com renda alta (STERN, 2004) e pelo acesso à tecnologia e eficiência no uso da energia. Estudos apontam que, com a descoberta de novos tóxicos e com a alteração nos padrões de produção e consumo, a correlação possa ser positiva, porém exponencial, para qualquer faixa de renda (STERN, 2004).

\subsubsection{Atividades cotidianas e o consumo de energia}

A demanda de energia está vinculada ao tipo de atividade que é desenvolvida pelo homem (KEIRSTEAD; SIVAKUMAR, 2012). Partindo deste princípio, o consumo energético total pode ser estimado a partir do conhecimento do cotidiano da cidade (metabolismo urbano). Para esta finalidade há disponibilidade de programas computacionais que possuem a capacidade de transformar as informações disponíveis sobre as atividades desenvolvidas na cidade e o consumo energético, estimando o consumo energético em qualquer intervalo temporal.

O uso residencial de energia nos Estados Unidos corresponde a mais do que $20 \%$ (vinte por cento) do consumo total do país. Desta parcela, grande parte é consumida por sistemas de resfriamento em edifícios para fins de moradia, superando, inclusive, a quantidade de energia gasta por sistemas de aquecimento. Previsões apontam que estes valores podem ser ainda maiores, visto que se observa 0 
aumento da temperatura em todo o planeta em decorrência das mudanças climáticas. (YUN; STEEMERS, 2011)

No Reino Unido $56 \%$ da energia consumida diretamente em residências são empregadas no aquecimento de ambientes e $24 \%$ em aquecimento de água (para diversas finalidades) (YAO; STEEMERS, 2005). Na China, o percentual utilizado para aquecimento ambiental é estimado em 15,4 \%, enquanto que a energia consumida para cozimento e aquecimento de água está estimada em 44,5\% do total consumido. (CHEN et al., 2008)

Diversos são os fatores que influenciam na necessidade de controle interno de temperatura em edifícios, evidenciando a complexidade do sistema de consumo de energia.

A energia elétrica destinada para os sistemas de iluminação em residências, no Reino Unido, corresponde a $20 \%$ do montante consumido. (YAO; STEEMERS, 2005).

Os principais fatores que podem contribuir para a diminuição do consumo de energia nos sistemas de iluminação interna são: o avanço na tecnologia das lâmpadas e equipamentos de iluminação e os arranjos externos e internos que permitam melhor aproveitamento da luz natural.

\subsection{EMISSÕES E CIDADES}

Apesar de o avanço tecnológico favorecer o desenvolvimento de técnicas e equipamentos empregados na produção de energia a partir de fontes renováveis, a oferta energética mundial ainda está altamente apoiada no uso de combustíveis fósseis, a qual possui grandes valores de emissões de GEE. A relação entre a quantidade de emissões e a produção de uma sociedade pode ser medida através da intensidade de Carbono, dividindo-se a quantidade de carbono emitido para a atmosfera pelo Produto Interno Bruto (PIB) local.

No ano de $2013,81,4 \%$ da energia ofertada no mundo teve como fonte primária os combustíveis fósseis, cabendo ao petróleo a maior representatividade com $28,9 \%$ do total, o carvão mineral como segunda maior fonte, representando $28,9 \%$ e na 
terceira posição o Gás Natural (também extraído do petróleo) com 21,4\% (EPE, 2014).

2013

Total: $13.54110^{6}$ tep (toe)

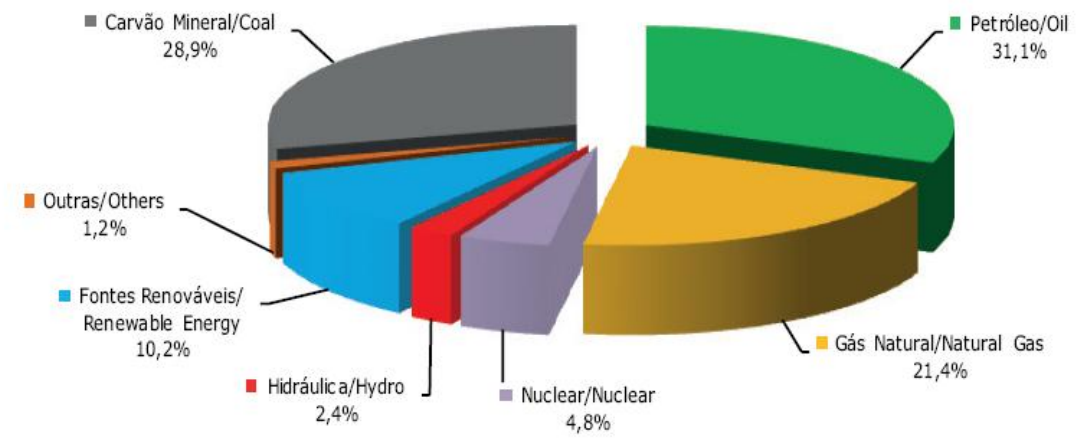

Figura 14 - Distribuição da oferta mundial de energia por fonte. fonte: (IEA, 2016)

No ano de $2014,66,4 \%$ da oferta de energia deu-se diretamente a partir dos combustíveis fósseis, sendo o petróleo responsável por 39,9\%, o gás natural por $15,1 \%$ e o carvão $11,4 \%$ da energia total consumida no mundo (OCDE, 2016). Ainda, se considerarmos que a energia elétrica foi responsável por suprir $18,1 \%$ da demanda energética mundial em 2014, e que 66,7\% energia elétrica mundial é gerada a partir de combustíveis fósseis (OCDE, 2016), calcula-se então que 78,5\% da energia consumida no mundo em 2014 teve como fonte primária de energia, os combustíveis fósseis.

Embora se verifique o declínio de 2,9\% entre 2013 informado pelo (EPE, 2014) e 2014 (OCDE, 2016), Nos próximos 35 anos a população mundial tende a aumentar em torno de 25\%, atingindo nove bilhões de habitantes. (UN, 2015), culminando no aumento da demanda energética (GOLDEMBERG; LUCON, 2007), tanto em função da quantidade absoluta de habitantes, quanto na demanda energética per capita (CHEN et al., 2008; TSO, 2003; WANG, 2014), mesmo se considerarmos que a evolução tecnológica agrega a eficiência energética nos meios de consumo (T'SERCLAES et al., 2008; ZHAO; LI; MA, 2012).

$75 \%$ do total da energia primária, após ser transformada, é consumida no ambiente urbano (DHAKAL, 2009; LAZAROIU; ROSCIA, 2012a), logo, 50\% da população mundial, que habita em cidades (GAUBE; REMESCH, 2013; PAGLIARA, 2010; YIN; 
MIZOKAMI; MARUYAMA, 2013a) e ocupa apenas 2\% da extensão territorial mundial é responsável por grande parte das emissões de $\mathrm{CO} 2$, contribuindo significativamente para o agravamento das mudanças climáticas globais (ZHANG; ZHENG; FATH, 2014).

Nas residências, onde há o consumo direto de energia, parte dos usos finais energéticos é alimentada por energia elétrica. Nos Estados Unidos a produção de energia elétrica tem sido a principal fonte de emissão de CO2 (ENERGY INFORMATION ADMINISTRATION, 2016). Além da energia elétrica, é comum, no uso direto de energia, a utilização de GLP e GN, além de fontes renováveis, como a energia solar. Embora utilizada em transportes, os combustíveis fósseis (gasolina, etanol, diesel) quando utilizados para transporte de passageiros (individual ou coletivo) também pertencem ao conjunto do consumo direto de energia.

Desta forma, ações concentradas nas cidades para redução das emissões tem grande potencial para redução da produção mundial de $\mathrm{CO} 2$, contribuindo para mitigação do efeito estufa. Dentre as ações possíveis, este trabalho destaca a otimização da cidade e do espaço urbano com o intuito de: (a) reduzir o consumo direto de energia e (b) alterar significativamente a oferta energética, visando especificamente o aquecimento de água, dando prioridade para fontes renováveis, em especial a energia solar.

\subsubsection{Emissões de co2 na cidade}

Estima-se que $68 \%$ das emissões dos gases de efeito estufa estejam diretamente ligados ao consumo de energia, sendo que $90 \%$ do montante destes gases é o Dióxido de Carbono - CO2 (IEA, 2016b). Conforme a figura 14 apresenta a oferta energética apoiada sobre os combustíveis fósseis agrava a situação, pois os fatores de emissão de CO2 por energia produzida são altos. Neste trabalho, os fatores adotados estão listados na tabela 13, onde também é possível compará-los com fatores de emissão de outras fontes de energia, incluindo as fontes renováveis. 


\section{MÉTODOS, MATERIAIS E FERRAMENTAS}

\subsection{MÉTODO}

A análise proposta por este trabalho deu-se em quatro etapas:

Processo de construção de um modelo baseado em agentes (MBA ou ABM AgentBased Model), incluindo a revisão da literatura; replicação de modelos existentes, montagem de um de modelo integrado e testes de estabilidade;

Análise multivariada de dados reais, extraídos de base de dados oficiais sobre o consumo de energia em cidades paulistas, através de modelo de regressão;

Calibração do modelo MBA (confronto de resultados das simulações com dados reais e análise de cidades paulistas);

Extração e análise de dados de cidades modeladas com alterações controladas nas características das cidades.

Algumas etapas foram desenvolvidas concomitantemente, mesmo que com pontos em comum. Para facilitar a apresentação do método e da sequência de produção deste trabalho, pode-se observar o fluxograma apresentado na figura 15. 


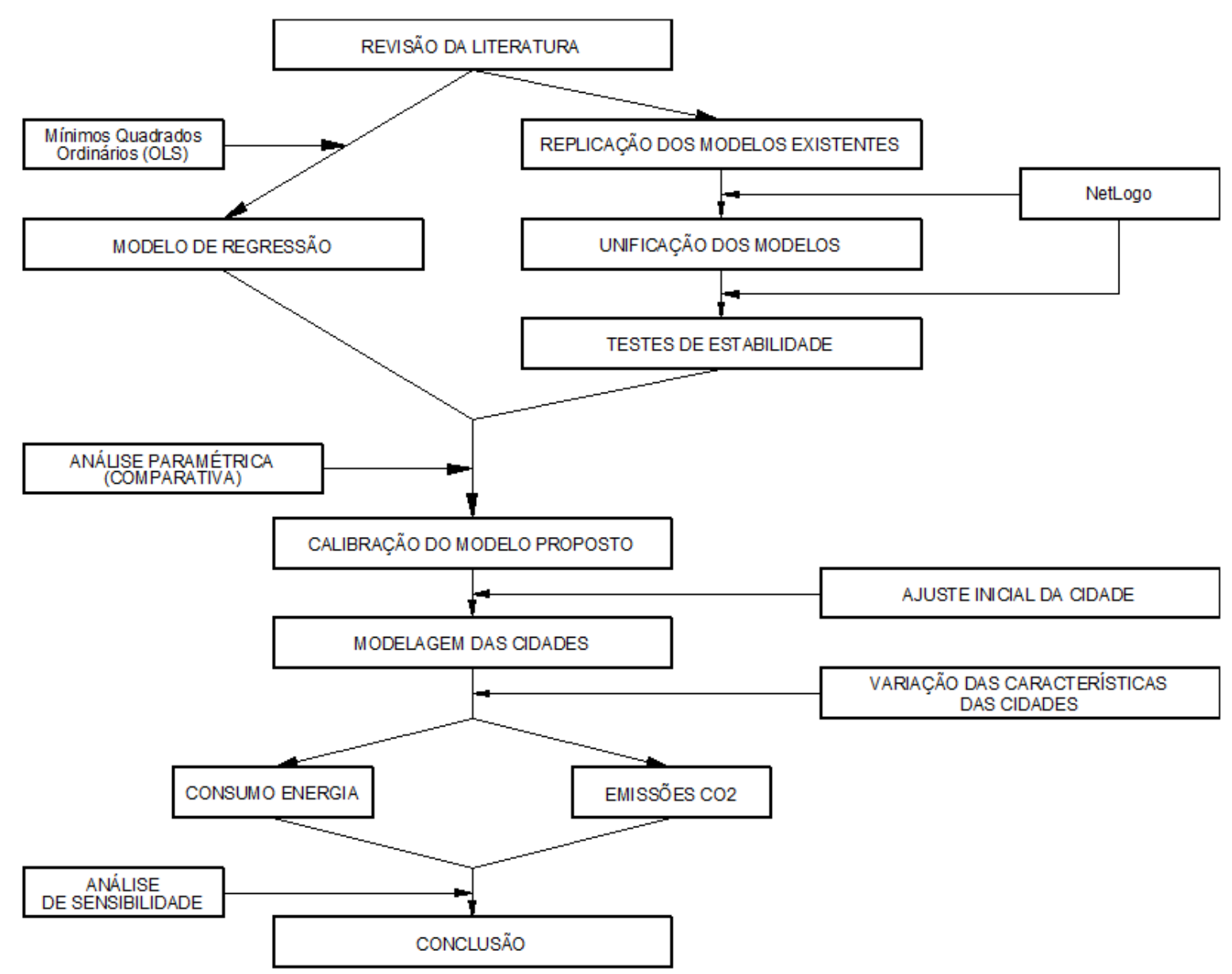

Figura 15 - Fluxograma de atividades do desenvolvimento do trabalho fonte: autor

A seguir, as etapas de produção do trabalho são detalhadas separadamente.

\subsubsection{Construção do modelo baseado em agentes}

Partindo da revisão da bibliografia foram estudados modelos similares ao que se pretendia para este trabalho, voltados à ocupação urbana e ao consumo direto de energia, contudo, não foram encontrados modelos integrados, mas sim, estudos isolados de cada assunto.

Os modelos estudados foram analisados e tiveram suas premissas e rotinas replicadas na mesma plataforma de software (NetLogo) para posterior integração e montagem de modelo único, incluindo as características das cidades, o consumo de energia e as emissões de GEE.

O detalhamento da estrutura, algoritmo e funcionamento do modelo estão apresentados na seção "MODELO PROPOSTO". 


\subsubsection{Análise multivariada de cidades paulistas}

Para executar a calibração e validação dos resultados obtidos no modelo de agentes proposto inicialmente foi realizado estudo do consumo energético de dez cidades do Estado de São Paulo utilizando-se o modelo STIRPAT (YORK; ROSA; DIETZ, 2003), variante do modelo IPAT (EHRLICH; HOLDREN, 1971), através de análise multivariada, considerando parâmetros socioeconômicos e as características das cidades extraídas direta e indiretamente do conjunto de dados disponíveis no Anuário Energético do Estado de São Paulo (SÃO PAULO, 2016b).

A análise multivariada foi realizada por uma regressão linear, ajustado para o modelo STIRPAT, admitindo as emissões finais como o impacto ambiental em função das demais variáveis consideradas.

\subsubsection{Calibração dos resultados}

Para calibração dos resultados do modelo proposto (MBA), foram simuladas 345 possíveis arranjos de ocupação de cidades, representando 345 cidades criadas pelo programa de simulação, variando-se os ajustes iniciais das cidades, permitindo a extração do conjunto de dados para cada uma das ocupações resultantes da evolução do modelo.

Para todas as cidades simuladas, após a auto-organização da ocupação espacial, foram medidos o consumo de energia e as emissões de GEE, bem como as demais variáveis resultantes do MBA (condições socioeconômicas da população e características das cidades).

Os dados resultantes da análise dos dados disponíveis no banco de dados consultado e nos resultados do modelo de regressão foram comparados com os dados resultantes do MBA, considerando o fator de impacto das variáveis nas emissões e suas respectivas correlações.

Os ajustes iniciais das cidades simuladas nesta fase de calibração do modelo, bem como a comparação dos resultados obtidos estão apresentados na seção "CALIBRAÇÃO DO MODELO". 


\subsubsection{Análise das cidades modeladas}

Após a validação do modelo, foram realizadas simulações (evidenciando as alterações nas características das cidades) com extração do conjunto de dados, permitindo a construção de elementos gráficos e figuras bidimensionais (mapas) que serão estudados a partir da análise de sensibilidade. A base para modelagem será a análise do tipo input-output, alimentando o modelo com dados controlados e extraindo dados que permitam a confrontação com a realidade.

Partindo da variação das variáveis estudadas, foi possível realizar projeções da dinâmica de consumo direto de energia e emissões de $\mathrm{CO} 2$ em função das alterações das características das cidades modeladas, permitindo inferir sobre 0 impacto simultâneo das características das cidades sobre o consumo de energia e as emissões de $\mathrm{CO} 2$.

\subsection{MATERIAIS E FERRAMENTAS}

A primeira etapa iniciou-se com a revisão da literatura, realizada em livros e artigos científicos publicados (impressos ou digital) em português, inglês ou espanhol. A pesquisa preliminar foi realizada com a utilização de buscadores WebofKnowledge, e Google Acadêmico. Inicialmente a busca foi restrita às publicações com recorte temporal entre 2010 e 2016, contudo os trabalhos publicados anteriormente ao ano de 2010, quando citados repetidas vezes nos textos inicialmente selecionados, foram agrupados na revisão da literatura. As buscas partiram de palavras chaves genéricas inseridas nos tópicos ou títulos dos artigos e posteriormente "refinadas" com termos que direcionaram a pesquisa para o tema. As principais buscas realizadas e seus resultados quantitativos, na data de início do trabalho de revisão bibliográfica estão apresentados na tabela 5 .

Tabela 5 - Resultado quantitativo das buscas realizadas para pesquisa bibliográfica com recorte temporal entre 20102015

\begin{tabular}{|l|l|l|}
\hline PALAVRA(S) INICIAL(IS) & REINADORES DA BUSCA & $\begin{array}{l}\text { QUANT. DE ARTIGOS } \\
\text { ENCONTRADOS }\end{array}$ \\
\hline urbanform"+ energy & \multicolumn{1}{|c|}{} \\
\hline & Energy + consumption & 8312 \\
\hline & $\begin{array}{l}\text { Energy + consumption + } \\
\text { direct }+260\end{array}$ \\
\hline & $\begin{array}{l}\text { Energy + consumption + } \\
\text { direct + city }\end{array}$ \\
\hline & $\begin{array}{l}\text { Energy + consumption + } \\
\text { indirect }\end{array}$ \\
\hline
\end{tabular}




\begin{tabular}{|l|l|l|}
\hline Residential + energy +consumption & & 126 \\
\hline Urban form + transport & & 22 \\
\hline Environmental impact & & 3231 \\
\hline & + energy & 31 \\
\hline & + production + energy & 37 \\
\hline & + consumption + energy & 40 \\
\hline
\end{tabular}

A seleção inicial dos trabalhos foi realizada a partir da leitura prévia do resumo, considerando o alinhamento com o tema da pesquisa. A seleção final foi realizada a partir da disponibilidade de acesso ao conteúdo integral do artigo e seu alinhamento com o tema do trabalho.

O objetivo da revisão da bibliografia foi compreensão da influência "isolada" das características dos centros urbanos no consumo direto de energia, no consumo indireto de energia em transportes coletivos e nas emissões de $\mathrm{CO} 2$, além do foco exploratório, buscando aprofundar o conhecimento relativo aos temas envolvidos (CERVO; BERVIAN; SILVA, 2007). As publicações estudadas e seus respectivos temas abordados estão compilados na tabela no apêndice $A$.

Os dados levantados nas publicações estudadas foram organizados e agrupados considerando o grupo, tema e indicador utilizados, conforme mostra a figura 15.

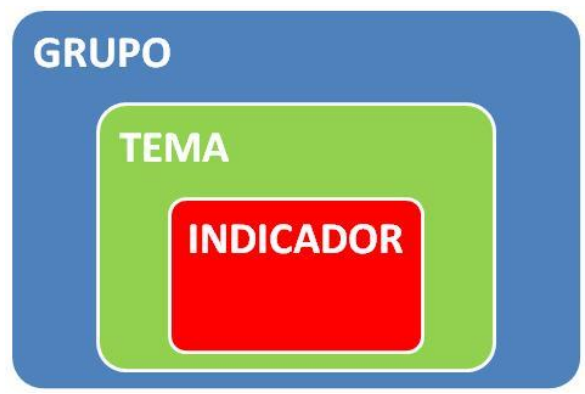

Figura 16 - Organização dos indicadores em temas e grupos, proposta pelo autor. fonte: autor

A partir da revisão da literatura realizada, os indicadores mais utilizados foram agrupados conforme o grupo principal a que se referem, resultando em quatro grandes grupos: características das cidades, características da população, atividades cotidianas e emissões. No conjunto dos trabalhos analisados, indicados no apêndice $A$, a frequência da abordagem de cada grupo está descrita no gráfico da figura 16. 


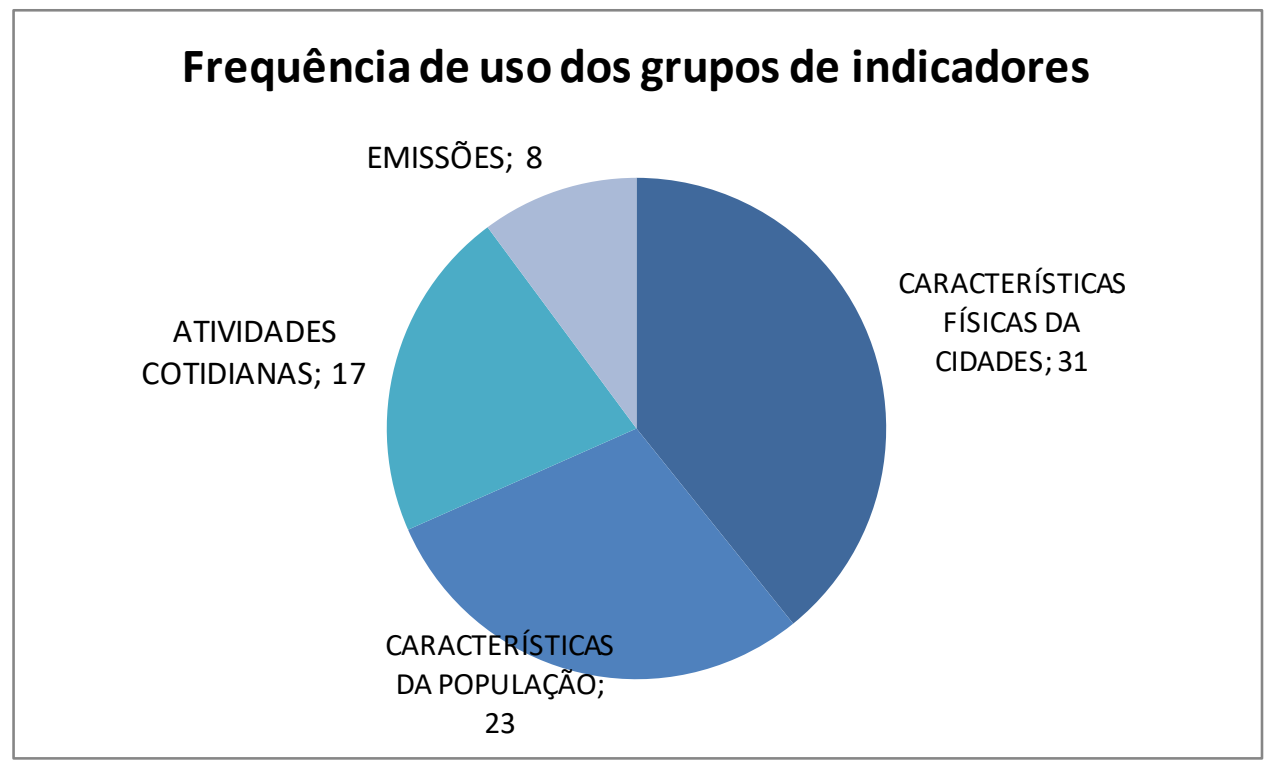

Figura 17 - Gráfico de frequência de uso dos grupos de indicadores fonte: autor

Cada grupo é composto por temas que influenciam no consumo de energia da cidade. A lista de temas e a frequência com que são citadas nos trabalhos que compõem a revisão da literatura são apresentadas na tabela 6.

\begin{tabular}{|c|c|}
\hline \multicolumn{2}{|l}{ Tabela $\mathbf{6}$ - Lista de temas e frequência verificada na revisão da literatura } \\
\hline TEMA RELACIONADO & $\begin{array}{c}\text { FRENQUÊCIA DE USO VERIFICADA NA } \\
\text { REVISÃO DA LITERATURA - APENDICE A }\end{array}$ \\
\hline TRANSPORTES & 12 \\
\hline FORMA URBANA & 8 \\
\hline USO E OCUPAÇÃO DO SOLO & 8 \\
\hline EMISSÕES & 8 \\
\hline RENDA & 7 \\
\hline DENSIDADE POPULACIONAL & 6 \\
\hline COMPORTAMENTO & 6 \\
\hline AQUECIMENTO / RESFRIAMENTO & 5 \\
\hline INFRAESTRUTURA URBANA & 5 \\
\hline ILHA DE CALOR & 4 \\
\hline AREAS VERDES & 4 \\
\hline CONSUMO & 4 \\
\hline ALBEDO & 2 \\
\hline
\end{tabular}

Analisando os dados tabelados, fica evidente a preocupação crescente com o consumo energético associado aos meios de transporte.

A classificação proposta nesta metodologia teve por finalidade facilitar a organização das informações, pois no modelo a ser proposto foi realizado o cruzamento de todas 
as variáveis de forma sistêmica. Em terceiro nível, cada tema é composto pelas variáveis que assumem valores (abordagem quantitativa) para serem inseridos nos modelos. A tabela 7 apresenta a classificação proposta e sua hierarquia em grupo, tema e indicador.

Tabela 7 - Classificação hierárquica dos indicadores mais utilizados em estudos relacionados as características das cidades e o consumo de energia

\begin{tabular}{|c|c|c|}
\hline GRUPO & TEMA & INDICADOR \\
\hline \multirow{17}{*}{$\begin{array}{c}\text { CARACTERÍSTICAS } \\
\text { FÍSICAS DAS } \\
\text { CIDADES }\end{array}$} & \multirow{4}{*}{ FORMA URBANA } & formato geométrico \\
\hline & & expansão urbana \\
\hline & & dimensões da mancha urbana \\
\hline & & policentrismo \\
\hline & \multirow{3}{*}{$\begin{array}{l}\text { USO E OCUPAÇÃO DO } \\
\text { SOLO }\end{array}$} & densidade de edifícios \\
\hline & & \% de área ocupada \\
\hline & & densidade residencial \\
\hline & \multirow{4}{*}{$\begin{array}{l}\text { INFRAESTRUTURA } \\
\text { URBANA }\end{array}$} & \% de área ocupada por arruamento \\
\hline & & rede de distribuição de água \\
\hline & & rede de distribuição de energia elétrica \\
\hline & & rede de distribuição de gás \\
\hline & \multirow{2}{*}{ ILHA DE CALOR } & circulação de ar \\
\hline & & composição atmosférica \\
\hline & \multirow{2}{*}{ AREAS VERDES } & $\%$ de área verde \\
\hline & & \% de área verde por habitante \\
\hline & \multirow{2}{*}{ ALBEDO } & albedo natural \\
\hline & & albedo alterado \\
\hline \multirow{9}{*}{$\begin{array}{l}\text { CARACTERÍSTICAS } \\
\text { DA POPULAÇÃO }\end{array}$} & \multirow[t]{2}{*}{ RENDA } & $\begin{array}{l}\text { consumo residencial em } \\
\text { eletrodomésticos }\end{array}$ \\
\hline & & renda per capita \\
\hline & \multirow{2}{*}{$\begin{array}{l}\text { DENSIDADE } \\
\text { POPULACIONAL }\end{array}$} & densidade populacional \\
\hline & & verticalização de cidades \\
\hline & \multirow{3}{*}{ COMPORTAMENTO } & $\begin{array}{l}\text { tempo empregado em atividades no } \\
\text { decorrer do dia }\end{array}$ \\
\hline & & atividades de lazer \\
\hline & & atividades de compras \\
\hline & \multirow{2}{*}{ CONSUMO } & ciclo de vida de bens \\
\hline & & uso de serviços \\
\hline \multirow{5}{*}{$\begin{array}{l}\text { ATIVIDADES } \\
\text { COTIDIANAS }\end{array}$} & \multirow{5}{*}{ TRANSPORTES } & $\begin{array}{l}\text { média anual do consumo energético em } \\
\text { transportes }\end{array}$ \\
\hline & & distância de percursos e viagens \\
\hline & & $\begin{array}{l}\text { passageiros de sistemas de transporte } \\
\text { (público, privado e pedestres) }\end{array}$ \\
\hline & & modal de transporte \\
\hline & & eficiência energética da frota \\
\hline
\end{tabular}




\begin{tabular}{|c|c|c|}
\hline & \multirow{4}{*}{$\begin{array}{l}\text { AQUECIMENTO / } \\
\text { RESFRIAMENTO }\end{array}$} & \\
\hline & & $\begin{array}{l}\text { consumo energético específico de } \\
\text { edifícios }\end{array}$ \\
\hline & & insolação em fachadas \\
\hline & & iluminação natural \\
\hline \multirow{3}{*}{ EMISSÕES } & \multirow{3}{*}{ EMISSÕES DE GEE } & consumo de combustíveis fósseis \\
\hline & & consumo de biocombustíveis \\
\hline & & consumo de biomassa \\
\hline
\end{tabular}

$\mathrm{Na}$ segunda etapa da pesquisa, a revisão bibliográfica passou a ter foco experimental (CERVO; BERVIAN; SILVA, 2007), quando foram replicadas as modelagens computacionais procurando uniformizar (ou padronizar) os resultados, permitindo a compreensão da dinâmica evolutiva do consumo direto de energia nos centros urbanos e no consumo indireto, especificamente em transporte coletivo. Esta uniformização da base dos modelos teve por finalidade facilitar a união dos diversos estudos isolados na etapa seguinte do trabalho.

No terceiro estágio da fase inicial do trabalho, foi elaborado modelo computacional no software NetLogo, possibilitando a inclusão de todas as características das cidades que foram inicialmente estudadas em separado, permitindo o ajuste independente para cada item. Esta união dos modelos permitiu verificar as interações entre as variáveis, considerando a cidade como um sistema complexo (MILLER, 2007; PORTUGALI, 2011) e o impacto da ação concomitante das características das cidades no consumo de energia direta e nas emissões de GEE em centros urbanos.

O MBA foi desenvolvido no software NetLogo por ser adequado a proposta deste trabalho. O modelo desenvolvido é do tipo "estoques e fluxos" e tem abordagem bottom-up. Os dados foram inseridos no modelo considerando o tratamento estatístico PCA (Análise dos Componentes Principais), capturado dos modelos estudados, permitindo o agrupamento e a diminuição dos dados inseridos no modelo final, melhorando o desempenho de produção de dados, visto que há limite de processamento de informações nos computadores pessoais utilizados nas modelagens. A simplificação somente ocorreu em situações em que a ação de agrupamento foi nula ou pouco relevante no resultado final. 
Após a montagem do modelo, foi realizada a calibração do mesmo. As áreas de estudo para calibração do modelo considerou os dados estatísticos de dez cidades do Estado de São Paulo com população superior a 400 mil habitantes, capazes de formar centro urbano.

Após a realização da calibração do modelo, serão realizados estudos de caso em cidades hipotéticas, permeando pelas diversas escalas de abordagem dentro dos limites territoriais (quarteirão, bairro, distrito, cidade, região metropolitana e outras). Os detalhamentos das fases de construção do modelo baseado em agentes, da calibração e da análise final do MBA estão detalhados nas próximas seções deste trabalho. 


\section{MODELAGEM COMPUTACIONAL}

A preocupação dos efeitos da produção e consumo de energia é crescente. Pesquisas têm sido realizadas, com o uso de modelagem computacional procurando a racionalização do uso de energia, (FERRARI; GUIGOU; LAREO, 2013) principalmente voltada aos sistemas de transporte e aos sistemas de aquecimento e resfriamento de edificações. Parte destas pesquisas procura entender 0 comportamento individual, buscando a compreensão do conjunto para propor soluções. (MARIQUE et al., 2014)

Entre as vantagens do uso da modelagem computacional está a possibilidade da inclusão de muitas variáveis na simulação, permitindo o cruzamento das mesmas, analisando as influências de forma sistêmica. (FERRARI; GUIGOU; LAREO, 2013) Além da possibilidade de alimentação do modelo com muitas variáveis, ainda é necessário ressaltar a possibilidade da modelagem incluindo diversos cenários, possibilitando a adaptação do modelo para locais diversos, o que resulta em grande quantidade de formas possíveis para testar combinações de cenários e verificar os resultados finais obtidos. (MARIQUE et al., 2014)

Apesar de amplamente utilizada e útil, a modelagem computacional voltada ao uso racional da energia ainda apresenta lacunas a serem preenchidas, como por exemplo, a adaptação de edifícios existentes para uso racional de energia, a relevância de cruzar dados entres local de trabalho, de residência e de serviços em deslocamentos internos da cidade e, sobretudo, a aplicação prática dos resultados de modelagem em políticas públicas. (MARIQUE et al., 2014)

\subsection{ABORDAGENS DA SIMULAÇÃO COMPUTACIONAL}

Com o avanço da tecnologia, o aumento da capacidade de processamento dos equipamentos portáteis e a popularização dos equipamentos de informática, a modelagem computacional tem ocupado importante papel no cenário científico.

Aplicado a diversos campos das ciências a modelagem computacional de sistemas energéticos possui duas abordagens básicas: top-down ou bottom-up. (REITER; MARIQUE, 2012) 
A abordagem top-down (de cima para baixo) parte de dados gerais, indicadores e demais valores que representam a totalidade de uma característica ou fenômeno (preço da gasolina, índice de desenvolvimento, etc.), portanto tem pouca capacidade de detalhamento dos processos e não permite a verificação das emergências decorrentes da interação entre os agentes do processo. (CHIACCHIO et al., 2014, p.)

A abordagem bottom-up (de baixo para cima) é alimentada com dados específicos de cada uma das partes envolvidas (respeitando a escala adotada) e representam as características individuais (idade, hábitos, opiniões, área construída, nível de renda, tecnologias empregadas), possui grande capacidade de detalhamento, mas grande necessidade de processamento. É utilizada para compreender o resultado a partir do comportamento das partes. Entre as dificuldades encontradas para aplicação desta abordagem está a necessidade de grande volume de dados de entrada. (REITER; MARIQUE, 2012). Esta abordagem é necessária para sistemas complexos (CHIACCHIO et al., 2014), onde o resultado final é fruto da interação das partes e não da somatória dos resultados parciais.

\subsection{ALGUMAS PREMISSAS DE MODELAGEM EM USO DIRETO DE ENERGIA EM CIDADES APLICADAS ÀOS MODELOS PUBLICADOS}

\subsubsection{Uso residencial}

Comprovadamente há alguns fatores que influenciam o consumo direto de energia no interior das residências (WIEDENHOFER; LENZEN; STEINBERGER, 2013), entre ele destaca-se o tamanho e a composição das famílias (RICHARDSON; THOMSON; INFIELD, 2008), contudo grande parte dos modelos considera apenas a quantidade de energia consumida na residência, desprezando a forma e, sobretudo, os períodos de utilização.

Além do tamanho e composição das famílias é necessário entender a dinâmica ou rotina das famílias que compõem a cidade, para que se possa compreender a forma de utilização (tempo de uso, simultaneidade, momento de uso, etc.) e seus impactos diretos no sistema energético e impacto direto e indireto no meio ambiente. (RICHARDSON; THOMSON; INFIELD, 2008). As atividades desenvolvidas pelos 
habitantes determinam a quantidade de energia consumida nas cidades (KEIRSTEAD; SIVAKUMAR, 2012; MARIQUE et al., 2014).

Em busca do entendimento desta dinâmica é possível a aplicação do Time-Use Survey (TUS) (IPSOS-RSL AND OFFICE FOR NATIONAL STATISTICS, 2003), possibilitando modelar o uso a partir dos horários de consumo direto de energia elétrica. Em estudo realizado no Reino Unido, no ano de 2000 é possível verificar a menor utilização de energia elétrica no período compreendido entre 00:00h - 7:00h e a maior utilização durante a parte final da manhã, entre 8:00h - 12:00h, repetindo-se no começo da noite (18:00h as 22:00h), onde há maior consumo direto de energia (RICHARDSON; THOMSON; INFIELD, 2008). No mesmo estudo é mencionado que os dados da pesquisa realizada coincidem, corroborando a pesquisa, com os dados do sistema energético do país.

A importância da análise da correlação está relacionada à oferta energética de cada região estudada, visto que, quando a capacidade de produção é excedida pelo consumo, torna-se necessária que o suprimento da demanda seja realizado com a produção de energia em ofertaes alternativas que, em muitos casos, são mais poluentes do que as tradicionalmente utilizadas, ampliando assim os impactos ao meio ambiente. Muitos países já recorrem a fontes alternativas para suprimento da demanda de energia e uma das tendências mundiais consolida-se nesta mesma premissa, onde o viés econômico prevalece sobre a responsabilidade ambiental. 0 Brasil tem sido exemplo desta aplicação. Pais com oferta energética predominantemente hídrica, que lança programas incluindo incentivos governamentais à construção de termoelétricas. (CONFEDERAÇÃO NACIONAL DA INDÚSTRIA, 2007)

\subsubsection{Ferramentas de modelagem}

A modelagem computacional apresenta diversas utilidades nos mais variados campos do conhecimento. Com grande capacidade de reproduzir sistemas e processar dados tem sido utilizada como auxilio nas tarefas recorrentes e nos estudos onde há influência de diversas variáveis. Por apresentar várias formas de abordagem, neste trabalho haverá o recorte de uma ferramenta útil para estudos de sistemas complexos, consumo de energia e planejamento urbano. A escolha da 
ferramenta adequada surgirá da análise dos modelos existentes e das características oferecidas pelos programas disponíveis.

\subsection{DESCRIÇÃO DOS MODELOS ESTUDADOS}

A modelagem computacional possui ampla possibilidade de abordagens e inclusão de variáveis, portanto, são diversas as ferramentas existentes e disponíveis para construção dos modelos. A escolha de um modelo existente, ou a proposta de um novo modelo, passa necessariamente pelo conhecimento das ferramentas existentes. Nesta seção serão estudados três modelos relacionados ao tema central deste trabalho, com ênfase na abordagem e identificação das premissas do modelo estudado, servindo como embasamento para a escolha da ferramenta, das variáveis, da abordagem e demais características do modelo a proposto.

\subsubsection{Modelo 1 - estudo integrado do uso de energia, considerando a morfologia e} mobilidade urbana e os edifícios.

Não é possível desassociar as correlações existentes entre os fatores que influenciam o consumo de energia no interior da cidade. O estudo do consumo de energia passa, necessariamente, pela análise da complexidade dos fatores que influenciam o cotidiano do homem. (DE CASAS CASTRO MARINS; DE ANDRADE ROMÉRO, 2013)

Após a acentuação do processo de urbanização ocorrido na segunda metade do século $X X, 84 \%$ da população brasileira habita os centros urbanos. A falta de planejamento tornou as cidades ineficientes, acarretando no consumo elevado de energia e aumento da emissão de poluentes e GEE, trazendo inúmeros problemas de saúde à população. Identificar e compreender o processo de consumo de energia no interior das cidades é necessário para orientar o planejamento de novas cidades.

O objetivo do modelo é demonstrar e avaliar o potencial do planejamento urbano integrando à morfologia, mobilidade urbana, características e eficiência energética das construções.

A metodologia consiste no desenvolvimento de um modelo matemático de equações, com visão bottom-up e abordagem quantitativa, que trabalha em escala de bairro (local), agregando informações da morfologia urbana. O modelo é executado no programa excel com os dados disponíveis para o bairro da Água 
Branca, São Paulo. Os autores entendem que a morfologia urbana é composta por vários cenários (áreas ocupadas ou livres, impermeabilizadas ou permeáveis, volumes - altura - que ocupam o espaço, materiais empregados e cores que compõem o espaço urbano) e que estes cenários possuem características bem definidas (densidade, uso) que afetam as condições ambientais (mobilidade, meio ambiente, conforto, consumo energético, circulação de luz e ar).

O modelo é desenvolvido em dois módulos subsequentes que se realimentam. $\mathrm{Na}$ primeira etapa é realizada, através do embasamento bibliográfico da literatura, a correlação entre a estrutura física urbana e o consumo de energia. Nesta etapa são considerados: o clima local, densidade populacional, densidade de edifícios, uso e ocupação do solo, mobilidade urbana, e características físicas das edificações. $\mathrm{Na}$ segunda etapa, após serem determinadas as correlações, são simuladas diferentes morfologias urbanas envolvendo a demanda energética para avaliação das estratégias a serem adotadas relativas à composição do espaço, incluindo as emissões decorrentes do consumo de energia. Os dados resultantes podem ser transformados para interfaces gráficas (mapas e gráficos) que permitem maior facilidade de interpretação aos planejadores urbanos.

O funcionamento do modelo foi dividido em 5 etapas, conforme tabela 8.

Tabela 8 - Sequencia de etapas do funcionamento do modelo proposto por (DE CASAS CASTRO MARINS; DE ANDRADE ROMÉRO, 2013)

\begin{tabular}{|c|c|}
\hline $1 \mathfrak{a}$ & $\begin{array}{l}\text { Identificação do uso e ocupação do solo; } \\
\text { Determinação das características dos edifícios (porte e posicionamento) e consequente } \\
\text { densidade populacional; } \\
\text { Esta etapa permite a extração da demanda potencial de transporte para cada região } \\
\text { analisada, independente da escala de abordagem. }\end{array}$ \\
\hline $2 \underline{a}$ & $\begin{array}{l}\text { Determinação da mobilidade local através da demanda potencial de transporte (mínimo e } \\
\text { máximo potencial), incluindo transporte à pé e por bicicletas (população que utiliza } \\
\text { transporte não motorizado); } \\
\text { Comparação da capacidade existente (larguras das vias) com a capacidade necessária das } \\
\text { vias locais. Esta análise é realizada com base no passo anterior; } \\
\text { Adoção do maior valor (existente ou necessário) como sendo o ideal para o planejamento do } \\
\text { bairro. }\end{array}$ \\
\hline $3 \underline{a}$ & $\begin{array}{l}\text { Recalculo dos resultados quantitativos (população, uso e ocupação do solo e outros) de } \\
\text { acordo com a capacidade viária adotada na segunda fase; } \\
\text { Recalculo da demanda potencial de transporte; }\end{array}$ \\
\hline $4 \underline{a}$ & $\begin{array}{l}\text { Quantificação das áreas com potencial para serem iluminadas e ventiladas naturalmente, em } \\
\text { função da morfologia urbana; } \\
\text { Estratégias para diminuição da demanda energética para fins de iluminação e ventilação } \\
\text { (albedo, circulação natural de ar, brises e demais tecnologias disponíveis). } \\
\text { Cálculo da demanda energética para diversas situações adotadas; }\end{array}$ \\
\hline
\end{tabular}


\begin{tabular}{|l|l|}
\hline 5 & Calculo da demanda energética para transportes, considerando modo, tecnologia aplicada e
\end{tabular} tipo de combustível.

Nota-se, com base na análise da tabela 8, que o modelo acrescenta de forma subsequente as variáveis envolvidas no processo de consumo de energia na cidade, destacados na tabela 9, iniciando com a entrada de dados físicos sobre o ambiente construído e posteriormente inserindo informações relativas aos habitantes.

\begin{tabular}{|c|c|}
\hline INDICADOR & UNIDADE \\
\hline Densidade populacional & Habitantes $/ \mathrm{km}^{2}$ \\
\hline Densidade de edifícios & $\mathrm{m}^{2}$ de área construída $/ \mathrm{m}^{2}$ de área urbana \\
\hline \% ocupada & $\mathrm{m}^{2}$ de área ocupada $/ \mathrm{m}^{2}$ de área urbana \\
\hline \% ocupada por arruamento & $\mathrm{m}^{2}$ de área ocupada por vias $/ \mathrm{m}^{2}$ de área urbana \\
\hline \% área verde & $\mathrm{m}^{2}$ de área verde pública $/ \mathrm{m}^{2}$ de área urbana \\
\hline \% área verde por habitante & $\mathrm{m}^{2}$ de área verde pública /habitantes \\
\hline Densidade residencial & Residências $/ \mathrm{m}^{2}$ \\
\hline Consumo energético específico de edifícios & $\mathrm{kWh} / \mathrm{m}^{2} /$ ano e $\mathrm{kWh} /$ pessoa/ano \\
\hline $\begin{array}{l}\text { Média anual do consumo energético em } \\
\text { transportes }\end{array}$ & kWh/passageiro/ano e kWh/habitante/ano \\
\hline
\end{tabular}

Com o intuito de facilitar o cruzamento e análise, os dados dos indicadores são previamente tratados e compatibilizados em unidades iguais. No caso do modelo analisado a unidade $\mathrm{m}^{2}$ prevalece sobre as demais, conforme mostra a tabela 9.

O consumo de energia em sistemas de transporte é maior do que em edifícios. Em situação ideal, o consumo de energia pode ser diminuído para muitas das atividades, em até $45 \%$. Adoção de sistemas passivos de ventilação e iluminação e a escolha adequada do meio de locomoção contribuem para a redução no consumo per capita de energia.

A conclusão aponta que a orientação correta e o uso do volume adequado dos edifícios contribuem para a diminuição da demanda de energia da cidade. Os transportes devem seguir a seguinte escala de prioridade: pedestre, transporte público de massa e particular, reduzindo o consumo de energia, atentando para o espaço necessário para todos os modos de circulação.

O modelo apresentado tem potencial para ser utilizado em fase de planejamento de bairros ou cidades.

O modelo apresentado corrobora as indicações da literatura sobre consumo de energia, onde estão consolidadas as informações de que percorrer o trajeto à pé ou 
de bicicleta demanda menos energia do que o trajeto por transporte coletivo, que, por sua vez, demanda menor energia do que o transporte particular.

Ainda no modelo é discutida e apresentada a disposição das fachadas, insolação e ventilação naturais de edifício em substituição à sistemas mecânicos para o arrefecimento interno é também consenso amplo na literatura.

O trabalho não realiza a analise cruzada dos indicadores utilizados, apenas une no mesmo trabalho dois conjuntos de fatores que contribuem para o consumo de energia no interior das cidades, tanto que no resultado final apresenta dois resultados separados, um para o sistema de transportes e outro para os edifícios estudados.

\subsubsection{Modelo 2 - cidades com baixo consumo de energia}

Entre as premissas de uma cidade sustentável está a busca pela redução no consumo energético. Embora os avanços tecnológicos tenham contribuído para a melhoria da eficiência energética nos mais variados aspectos, a demanda por energia tem sido crescente, ora pelo aumento exponencial da população, ora pelo aumento do uso de energia per capita, conforme mostra a figura 13. (GOLDEMBERG; LUCON, 2007)

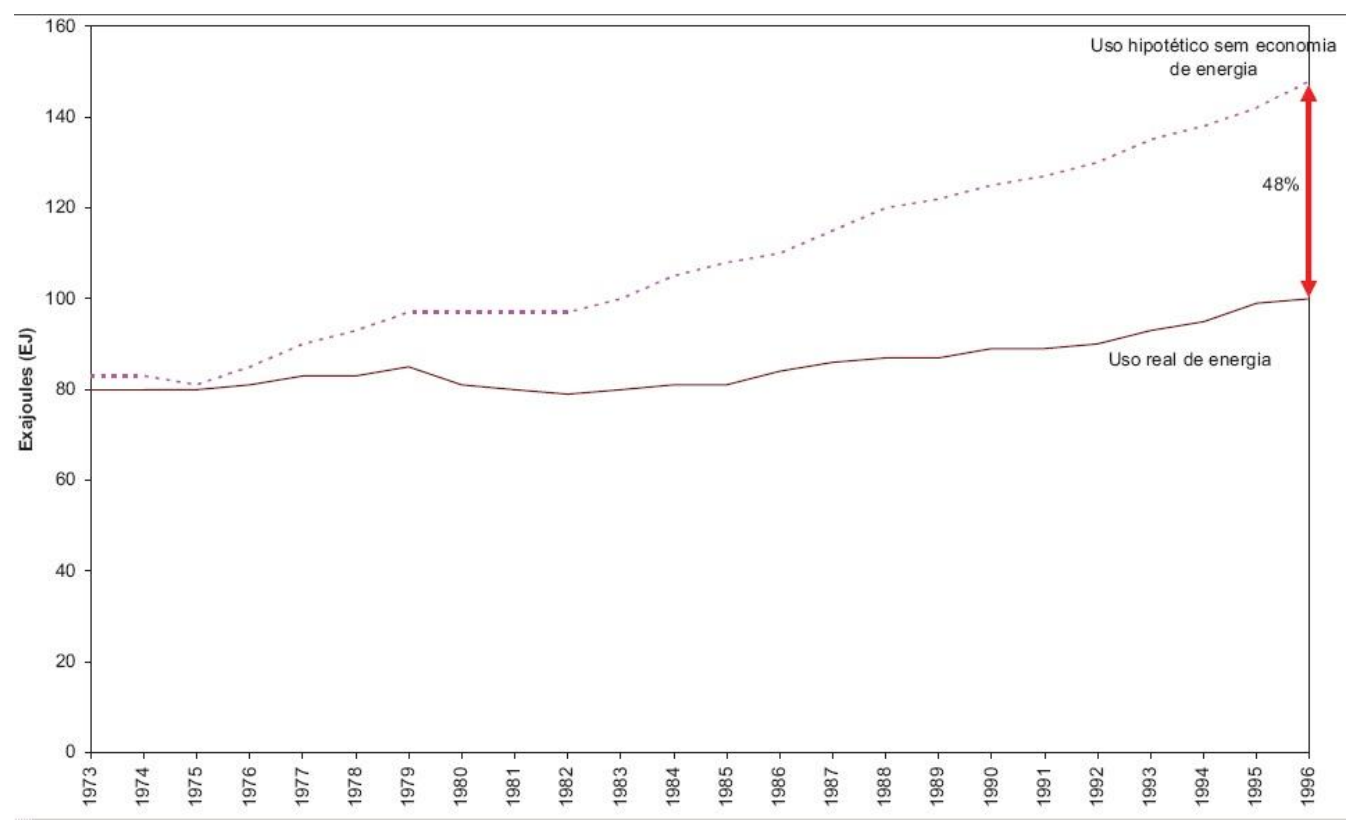

Figura 18 - Demanda mundial por energia - com e sem economia.

fonte: (GOLDEMBERG; LUCON, 2007) 
Agindo em diversas áreas a busca por uma cidade com baixo consumo de energia passa necessariamente pela proposta de novas tecnologias e adequação dos componentes existentes na cidade, como, por exemplo, a adaptação de edifícios com técnicas, materiais e tecnologias que permitam a melhoria na eficiência energética. (REITER; MARIQUE, 2012)

A redução do consumo de energia nas cidades, sobretudo na mobilidade urbana e no uso em edifícios é dada como excelente estratégia de preservação do meio ambiente, contribuindo para o avanço no desenvolvimento das cidades sustentáveis.

Análise do consumo de energia em escala de cidade, considerando a demanda energética em edifícios residenciais e mobilidade urbana.

A metodologia empregada para esta analise, surge a partir da adaptação de propostas anteriores (KAVGIC et al., 2010; RATTI; BAKER; STEEMERS, 2005), incluindo Sistema de Informação Georeferenciada (SIG), permitindo ampliar a escala do modelo para o nível de cidade, considerando os edifícios e o consumo energético em transportes a partir da abordagem mista (ou abordagem híbrida) bottom-up e top-down, dependendo do nível de detalhe da informação que alimenta o modelo. 0 modelo foi alimentado pela base de dados PICC (Projet Informatique de Cartographie Continue) e as informações básicas estão relacionadas à: densidade da rede de transportes, tipos de edifícios, densidade dos edifícios, área dos quarteirões, data das construções, consumo energético dos meios de transportes e previsão de oferta de transporte alternativo aos veículos particulares.

Devido à variedade e quantidade de dados disponíveis, preliminarmente os mesmos foram tratados estatisticamente por PCA (Análise dos componentes principais), permitindo o agrupamento e a diminuição dos dados a serem inseridos no modelo. Para agrupamento dos dados considerou-se: data de construção e reforma dos edifícios, quantidade de fachadas, tipo de uso (individual ou coletivo), índice de desempenho da viagem casa-trabalho e casa- escola, pois, na região de estudo, existem dados de consumo de energia para edifícios a partir destas características.

Dadas às características, o "índice de performance energética" de cada pessoa foi calculado considerando a distância percorrida, o meio de transporte utilizado e sua taxa específica baseada no tipo de combustível utilizado. A utilização de SIG 
permitiu a extração de dados estatísticos e, paralelamente, a impressão visual em forma de gráficos e mapas, auxiliando na leitura e interpretação dos resultados.

$\mathrm{Na}$ análise da demanda energética no interior das residências considerou-se: uso de eletrodomésticos, aquecimento de água e cozimento. Foram realizadas as comparações entre seis possibilidades de consumo energético em edifícios,conforme mostra a figura 19 posteriormente foram previstos dois cenários para o sistema de transporte para modelagem do consumo de energia. O resumo dos cenários simulados pode ser verificado na tabela 10.

Tabela 10 - Cenários simulados no modelo.

\begin{tabular}{|c|c|c|}
\hline 1 & $\begin{array}{l}\text { Novos edifícios seguem as diretivas de desempenho energéticas com vistas a } \\
\text { redução do consumo; }\end{array}$ & \multirow{6}{*}{ EDIFÍCIOS } \\
\hline 2 & Fortalecimento da política energética em edifícios novos; & \\
\hline 3 & 40\% de redução de consumo de energia em edifícios antigos; & \\
\hline 4 & $\begin{array}{l}\text { Adaptação dos edifícios antigos para atendimento a política de consumo } \\
\text { energético atual; }\end{array}$ & \\
\hline 5 & $\begin{array}{l}\text { Renovação de TODOS os edifícios existentes para atendimento a política de } \\
\text { consumo energético atual; }\end{array}$ & \\
\hline 6 & $\begin{array}{l}\text { Renovação de TODOS os edifícios existentes para atendimento a política de } \\
\text { consumo energético atual e NOVOS edifícios com consumo "passivo" } \\
\text { (muitíssimo baixo). }\end{array}$ & \\
\hline 7 & Aumento gradual do uso de transportes e do gasto energético & \multirow[b]{2}{*}{ TRANSPORTES } \\
\hline 8 & $\begin{array}{l}\text { Aumento gradual do uso de transportes SEM aumento do gasto energético } \\
\text { devido ao avanço tecnológico }\end{array}$ & \\
\hline
\end{tabular}

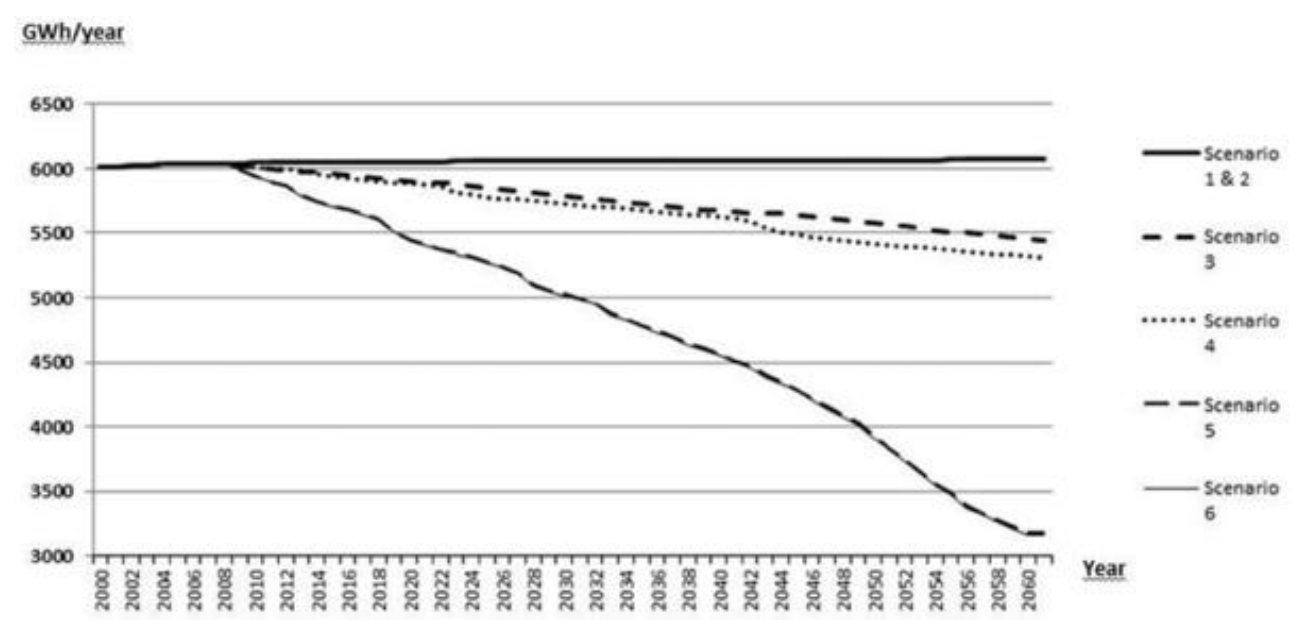

Figura 19 - Projeção do consumo de energia até o ano de 2060 para os cenários simulados. fonte: (GOLDEMBERG; LUCON, 2007)

$\mathrm{Na}$ análise cruzado da tabela 10 e do gráfico 14 nota-se o papel da eficiência energética aplicada em novas edificações, através do emprego de equipamentos, métodos e técnicas para redução do consumo de energia. Quanto maior a 
quantidade de edifícios projetados com a preocupação da eficiência energética, menor o consumo total de energia, o que contribui para o fortalecimento do ideal das cidades com baixo consumo energético.

O modelo mostra que as regiões periféricas do perímetro estudado apresentam maior consumo energético nas viagens com finalidade de estudos.

Na região estudada, considerando o uso final, a energia consumida em edifícios está na ordem de $6048 \mathrm{GWh}$, enquanto se verifica o consumo de $941 \mathrm{GWh}$ consumido em transportes (considerando apenas viagens para escola e trabalho).

Para os cenários simulados, a situação 5 e 6 foram as que apresentaram maior redução no consumo de energia, conforme mostra a figura 14, indicando a necessidade de renovação das edificações antigas atendendo aos padrões de consumo de energia das atuais políticas. Ressalta-se ainda que a adequação dos edifícios antigos também apresenta resultados satisfatórios quanto a redução no consumo energético, contudo, estas ações demandam grande período de tempo para serem implementadas.

Quanto aos sistemas de transportes, o adensamento populacional pode ser uma alternativa atrativa, quando promove a diminuição do trajeto das viagens, reduzindo o consumo de energia a cada viagem.

Como conclusão, aponta-se que o consumo energético da região estudada está fortemente ligado ao uso residencial, sendo que as ações de planejamento para redução do consumo energético devem focar neste recorte. Programas de aplicação de alternativas tecnológicas e melhorias em edificações novas e reformadas tem sido alvo das políticas públicas procurando aumentar a eficiência energética dos edifícios.

Apenas 0 adensamento populacional, proposto pela literatura, tem impacto modesto na redução do consumo de energia para o local estudado. Talvez o adensamento populacional possa ser estudado com a criação de núcleo adensados. É necessária a criação de uso e ocupação do solo misto, de forma a diminuir as distâncias percorridas nas viagens estudadas. 
Outro fator isolado que apresenta impacto modesto é a aplicação de política de redução de consumo de energia apenas para edifícios novos.

O modelo proposto não estuda as relações cruzadas. Os assuntos implantação e modernização de edifícios e sistemas de transporte são tratados de forma separada, contudo, dada a complexidade da cidade é necessário que os estudos abordem as correlações existentes entre os temas.

\subsubsection{Modelo 3 - consumo de energia e atividades cotidianas}

Em modelos onde há falta de dados referente ao consumo energético da cidade, é possível que a abordagem bottom-up seja realizada através da estimativa do consumo energético em função das atividades desenvolvidas pela população no decorrer do dia, em escala temporal de até 5 minutos. (KEIRSTEAD; SIVAKUMAR, 2012)

Visto que o metabolismo urbano é composto pelo conjunto de ação antrópicas, a análise deste conjunto pode determinar o fluxo de energia necessário para o metabolismo urbano.

O objetivo do modelo é demonstrar que a demanda energética de uma cidade pode ser estimada através da análise das atividades urbanas.

Como método, utiliza-se a microsimulação baseada nas atividades desenvolvidas pelos habitantes das cidades. A partir da análise das atividades são estimados os fluxos de recursos necessários para darem suporte às ações executadas. Dentre estes recursos encontram-se os recursos energéticos. Esta simulação é baseada em modelos de uso da terra e sistemas de transporte, simulando as viagens realizadas, cruzando a simulação com informações do uso do solo e tem por finalidade prever a consequência de ações pontuais ou regionais (escala de abrangência do modelo), norteando o processo de planejamento urbano. É um modelo estatístico de equações, geralmente do tipo input-output e a grande quantidade de dados a serem tratados são aplicados em regras simples e diretas, favorecendo que a simulação seja realizada em menor tempo de processamento.

A abordagem utiliza indicadores como localização (e relocalização) das famílias, de ambientes de trabalhos e de negócios (comércio e serviço), estágio de 
desenvolvimento local, proprietários de veículos, entre outros. Na terceira geração dos modelos similares, eles são desenvolvidos pela abordagem de modelagem baseada em agentes, incorporando o comportamento populacional como vetor de direcionamento das escolhas e ações.

O modelo proposto foi dividido em três etapas: Delimitação do espaço e coleta de dados para alimentação do modelo; execução do modelo para determinação das atividades dos habitantes e conversão das atividades em demanda de recursos, com foco em energia. Para estas etapas foram utilizados dois modelos: TASHA ( $2^{2}$ etapa) e LTS (MILLER; ROORDA, 2003). Os dados foram extraídos do modelo LTS e do Departamento de Energia e Mudanças Climáticas do Reino Unido.

A seção resultados apresentam as duas simulações distintas, a primeira foi suportada em uma situação real e a segunda houve alteração no horário de pico da cidade. A intenção desta alteração está relacionada à mudança no comportamento dos congestionamentos inerentes dos centros urbanos, que causam aumento no consumo de energia. A partir das atividades geradas em ambos os cenários, foram determinadas as demandas energéticas para cada situação simulada.

Como conclusão, as demandas observadas e similares são ligeiramente semelhantes. A elaboração de mapas facilita a visualização dos resultados, conforme pode ser verificada na figura 15.
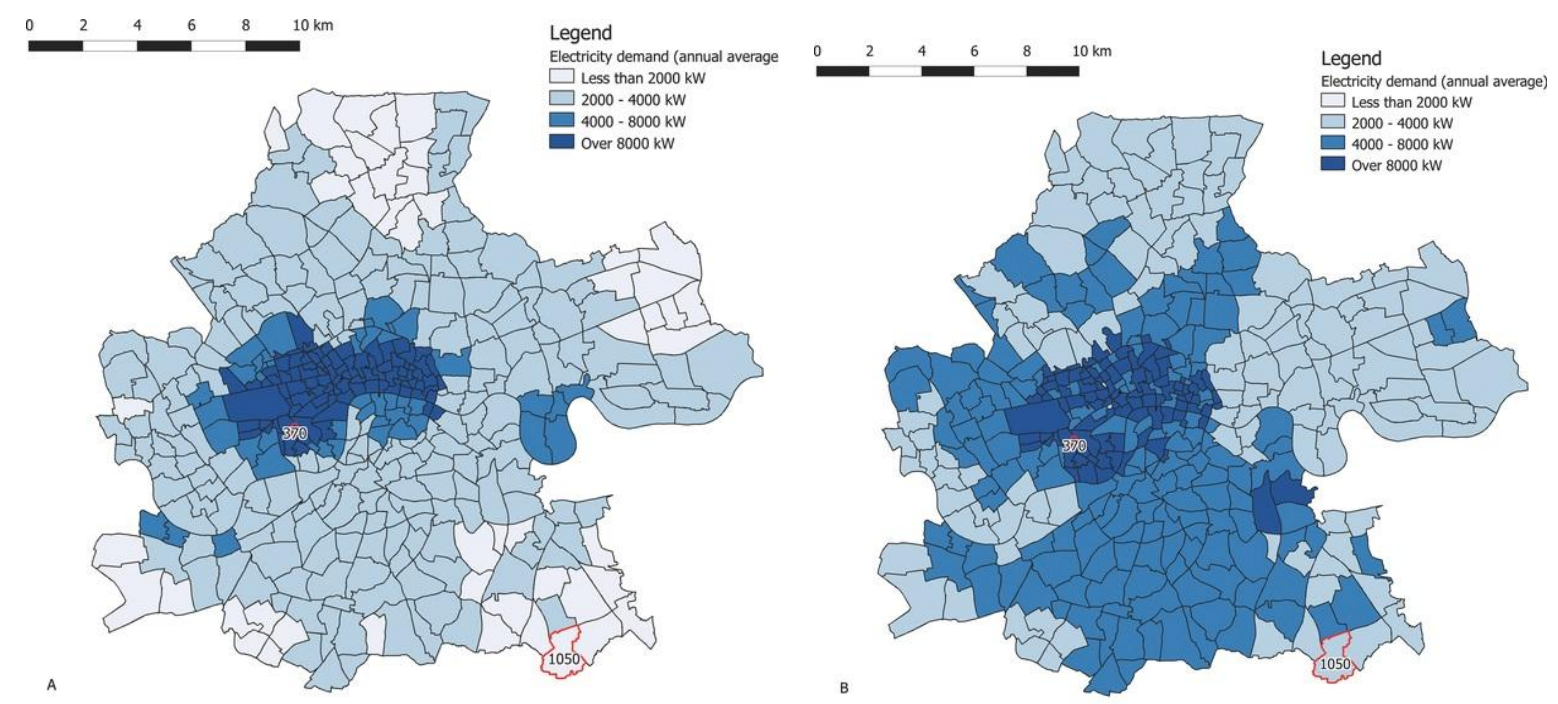

Figura 20 - Comparativo entre a condição empírica e a condição simulada fonte: (KEIRSTEAD; SIVAKUMAR, 2012) 
Os dados oficiais sobre demanda de energia, muitas vezes anuais, não são suficientes para embasamento de propostas de ações de intervenções. A simulação computacional a partir da análise das atividades da cidade pode reduzir o período de análise para escala temporal reduzida, permitindo uma análise mais aprofundada sobre o metabolismo urbano e sua relação com a demanda de recursos, entre eles a energia.

O diferencial do modelo estudado está na forma de obtenção dos dados para a abordagem bottom-up, mas não há estudo da correlação dos fatores que influenciam o consumo de energia nas cidades.

\subsubsection{Análise geral dos modelos estudados}

Apesar de apresentarem o mesmo foco - estudo que engloba o consumo de energia e algumas características das cidades - e objetivos semelhantes, os trabalhos estudados apresentam abordagens, variáveis e etapas diferentes, conforme apresentado na tabela 11. Contudo pode-se verificar que a utilização da modelagem computacional possui aceitação no meio científico e apresenta-se como uma ferramenta eficiente na tarefa de processamento de informações.

Os modelos apresentados seguem padronização e uniformização para entrada de dados, não permitindo ajustes individuais para cada variável, limitando as possibilidades de ajuste, simulação e análise do comportamento das variáveis incluídas no modelo.

Tabela 11 - Análise Comparativa dos modelos descritos

\begin{tabular}{|c|c|c|c|}
\hline & (EPE, 2014) & $\begin{array}{c}\text { (REITER; MARIQUE, } \\
\text { 2012) }\end{array}$ & $\begin{array}{c}\text { (KEIRSTEAD; } \\
\text { SIVAKUMAR, 2012) }\end{array}$ \\
\hline $\begin{array}{l}\text { OBJETIVO } \\
\text { GERAL }\end{array}$ & $\begin{array}{l}\text { Avaliar o potencial do } \\
\text { planejamento urbano }\end{array}$ & $\begin{array}{l}\text { Avaliar a possibilidade de } \\
\text { reduzir o consumo de } \\
\text { energia em edifícios e } \\
\text { sistemas de transporte } \\
\text { urbano }\end{array}$ & $\begin{array}{l}\text { Estimar o consumo } \\
\text { energético de uma cidade } \\
\text { através da análise das } \\
\text { atividades desenvolvidas } \\
\text { pela população }\end{array}$ \\
\hline $\begin{array}{l}\text { FERRAMENTA } \\
\text { UTILIZADA }\end{array}$ & MS-Excel & $\begin{array}{l}\text { Modelo próprio, acoplado } \\
\text { a módulo SIG, adaptado } \\
\text { de uma série de outros } \\
\text { modelos propostos na } \\
\text { literatura. }\end{array}$ & $\begin{array}{c}\text { Modelo TASHA para } \\
\text { estimar as atividades e } \\
\text { suas durações e modelo } \\
\text { LTS, acoplado com DECC } \\
\text { para cálculo da demanda } \\
\text { energética. }\end{array}$ \\
\hline $\begin{array}{c}\text { TEMAS } \\
\text { INSERIDOS } \\
\text { NO MODELO }\end{array}$ & $\begin{array}{l}\text { a) Transportes } \\
\text { b) Características físicas } \\
\text { da cidade }\end{array}$ & $\begin{array}{l}\text { a) Mobilidade Urbana } \\
\text { b) Características físicas } \\
\text { dos edifícios }\end{array}$ & $\begin{array}{l}\text { a) Tipo de atividades } \\
\text { b) Duração das } \\
\text { atividades }\end{array}$ \\
\hline
\end{tabular}




\begin{tabular}{|c|c|c|c|}
\hline $\begin{array}{l}\text { VARIÁVEIS } \\
\text { ESTUDADAS }\end{array}$ & $\begin{array}{l}\text { a) Morfologia Urbana } \\
\text { b) Mobilidade Urbana } \\
\text { c) Características físicas } \\
\text { das edificações } \\
\text { d) Eficiência energética } \\
\text { das edificações }\end{array}$ & $\begin{array}{l}\text { a) Características da } \\
\text { frota } \\
\text { b) Distâncias percorridas } \\
\text { c) Modais de transportes } \\
\text { d) Quantidade de dias } \\
\text { trabalhados } \\
\text { e) Data de construção } \\
\text { dos edifícios } \\
\text { f) Data de reforma dos } \\
\text { edifícios } \\
\text { g) Tipos de edifícios }\end{array}$ & $\begin{array}{l}\text { a) Uso do solo } \\
\text { b) Modal de transporte } \\
\text { c) Percursos percorridos }\end{array}$ \\
\hline ETAPAS & $\begin{array}{l}\text { a) Identificação de uso e } \\
\text { ocupação do solo } \\
\text { b) Identificação da } \\
\text { mobilidade urbana } \\
\text { c) Calculo da situação } \\
\text { real } \\
\text { d) Simulação do } \\
\text { potencial de } \\
\text { conservação de } \\
\text { energia em edifícios } \\
\text { e) Simulação do } \\
\text { potencial de } \\
\text { conservação de } \\
\text { energia nos } \\
\text { transportes }\end{array}$ & $\begin{array}{l}\text { a) Tratamento dos dados } \\
\text { por PCA } \\
\text { b) Cálculo do "índice de } \\
\text { performance } \\
\text { energética" } \\
\text { c) Integração SIG } \\
\text { d) Modelagem do } \\
\text { consumo de energia } \\
\text { e) Simulação de } \\
\text { diferentes cenários } \\
\text { para as cidades }\end{array}$ & $\begin{array}{l}\text { a) Estimativa das } \\
\text { atividades realizadas } \\
\text { durante o período de } \\
24 \text { hrs } \\
\text { b) Identificação dos } \\
\text { recursos necessários } \\
\text { para as atividades } \\
\text { c) Cálculo da demanda } \\
\text { energética para que } \\
\text { as atividades sejam } \\
\text { realizadas }\end{array}$ \\
\hline RESULTADOS & $\begin{array}{c}\text { Tanto os sistemas de } \\
\text { transportes, quanto os } \\
\text { edifícios apresentam } \\
\text { potencial para } \\
\text { conservação de energia } \\
\text { quando inseridos como } \\
\text { meta no planejamento } \\
\text { urbano. }\end{array}$ & $\begin{array}{c}\text { O arranjo físico e as } \\
\text { características das } \\
\text { edificações influenciam no } \\
\text { consumo energético das } \\
\text { cidades. A variação das } \\
\text { características afeta o } \\
\text { consumo energético. }\end{array}$ & $\begin{array}{l}\text { Realizado cálculo de } \\
\text { recursos necessários para } \\
\text { o suporte Às atividades } \\
\text { desenvolvidas pela } \\
\text { população, entre os } \\
\text { recursos é possível } \\
\text { estimas a demanda } \\
\text { energética }\end{array}$ \\
\hline CONCLUSÃO & $\begin{array}{c}\text { O planejamento urbano } \\
\text { contribui para a } \\
\text { diminuição da demanda } \\
\text { por energia nos centros } \\
\text { urbanos }\end{array}$ & $\begin{array}{l}\text { É possível a busca de } \\
\text { cidades com baixo } \\
\text { consumo de energia } \\
\text { através de interferências } \\
\text { nas características } \\
\text { estudadas neste modelo }\end{array}$ & $\begin{array}{l}\text { A demanda energética de } \\
\text { uma cidade pode ser } \\
\text { estimada a partir das } \\
\text { atividades desenvolvidas } \\
\text { pela população local. }\end{array}$ \\
\hline
\end{tabular}

A tabela 11 apresenta a modelagem computacional como ferramenta para processamento de grande volume de informações. O uso de modelos integrados, ou modelos diferentes em determinadas etapas é uma prática comum, sobretudo quando os modelos utilizados são limitados quanto à possibilidade de programação personalizada do modelo. As etapas da modelagem e a escolha das ferramentas são determinadas em função dos tipos de dados disponíveis e do objetivo a ser alcançado.

Como resultado de pesquisa os modelos analisados reforçam as corelações existentes entre as características das cidades e o consumo de energia, porém para a análise sistêmica é necessário que o programa a ser utilizado não possua 
qualquer tipo de restrição para inserção de dados e análise dos resultados e seja completamente configurável e adaptável, conforme a necessidade da simulação.

\subsection{NetLogo COMO FERRAMENTA DE MODELAGEM}

Com base nas premissas necessárias para modelagem computacional e análise sistêmica das relações entre o consumo de energia, as emissões de $\mathrm{CO} 2$ e as características das cidades a replicação das premissas básicas de alguns modelos identificados na literatura foi realizada com o programa NetLogo, pois o mesmo não apresenta pré-condições, nem limites, de inserção de dados. Inicialmente foi realizada a programação do software, montando-se o painel de entrada de dados e o algoritmo (código) do modelo. Posteriormente o modelo foi alimentado com os dados dos modelos existentes para verificação dos resultados.

O programa NetLogo é um ambiente gráfico de modelagem computacional a partir da modelagem baseada em agentes (ABM) com grande capacidade de modelar sistemas pela abordagem bottom-up para investigar a performance individual e do conjunto final de agentes, propiciando ajustes capazes de avaliar o resultado de intervenções, podendo ser utilizado para planejamento de ações. Possui capacidade de modelar a realidade, simular processos simplificados e elaborar previsões dos cenários em tempo previamente determinado (MUSCALAGIU; EMIL; NEGRU, 2014).

A interface com o usuário programador é simplificada e apresenta comando préconfigurados, conforme apresentada na figura 21, contudo o uso conjunto destes comandos resulta em inúmeras possibilidades para a modelagem. A interface com o usuário é bem intuitiva e de fácil ajuste, através de barras deslizantes ou botões do tipo "liga/desliga" totalmente configuráveis. 


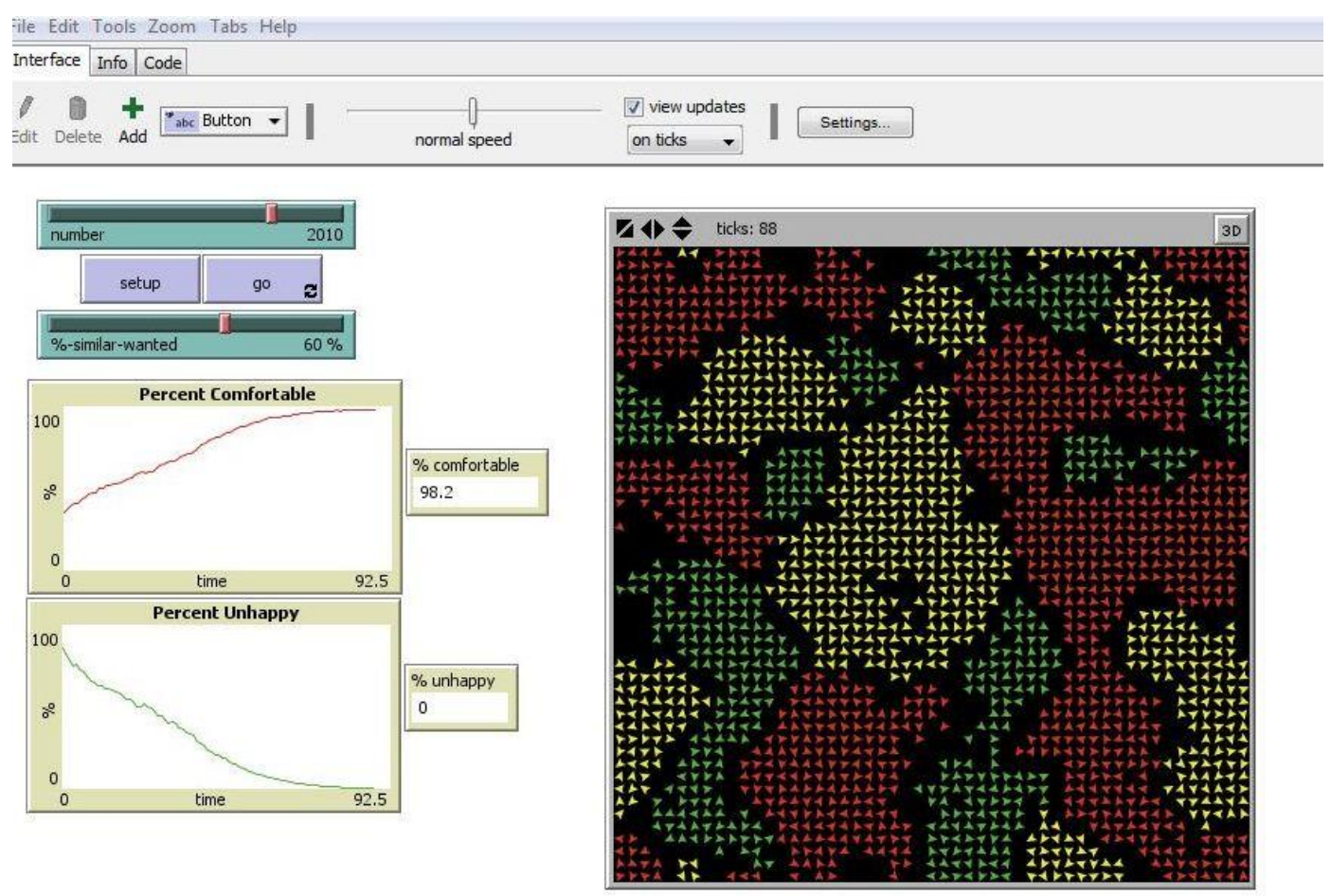

Figura 21 - Captura da tela do software NetLogo. Interface com o usuário. Modelos de segregação espacial. fonte: autor

Por ser um software de código aberto e apresentar facilidade de programação (utiliza a linguagem logo) permite a troca de informações com banco de dados ou outros programas, tornando possível a utilização simultânea de outros programas no auxílio da modelagem, seja em paralelo ou de forma acoplada ao NetLogo. O carregamento de imagens e dados simultaneamente atribui ao NetLogo a capacidade de acoplamento com SIG, característica com grande potencial para aplicação em planejamento urbano, uma vez que as cidades podem ser facilmente representadas em mapas georeferenciados.

O banco de dados e a capacidade de trabalhar com equações matemáticas e realimentação do sistema permitiram o desenvolvimento do modelo tipo "estoque e fluxo" fato que viabilizou a aplicação em processos complexos e evolutivos, característicos das cidades. 


\section{O MODELO PROPOSTO}

O modelo proposto busca estimar o consumo de energia para 7 categorias de usos finais energéticos: iluminação, eletrodomésticos, conforto térmico ambiental, aquecimento de água, cozimento, mobilidade urbana (transporte público e privado) e serviços auxiliares (incluindo iluminação externa, bombeamento de água e transporte vertical - elevadores). A partir da estimativa do consumo, em função das características das cidades simuladas e da escolha entre os vetores de energia disponíveis para atendimento ao serviço energético, é estimado o montante de $\mathrm{CO} 2$ emitido pelas atividades modeladas.

O ajuste inicial é realizado considerando a quantidade de polos atratores na cidade, a quantidade de famílias que habitam a cidade, a quantidade de vínculos entre os habitantes e os polos atratores, distribuição de classes sociais, ocupação do solo e resolução do mapa em metros.

A distribuição aleatória das famílias, da área comercial e industrial, bem como o posicionamento dos polos atratores ocorre na configuração inicial da cidade, representando uma cidade de baixa densidade, pois apresenta elevada quantidade de espaços não ocupados entre as famílias e relativa baixa ocupação de cada célula. A distribuição inicial é regulamentada pela taxa de ocupação máxima de cada célula que compõem a cidade e pela segregação de classes sociais.

Após a disposição inicial dos agentes é iniciada a simulação de evolução da cidade. A dinâmica de evolução é baseada na auto-organização da cidade (Choay 2003), onde os agentes procuram ocupar o melhor espaço da cidade, maximizando seus benefícios. No modelo proposto a melhor posição para um agente é aquela que minimiza a somatória das distâncias entre o ponto que o mesmo ocupa e cada um dos polos atrativos dos quais possui vínculo, respeitando a condição social e a disponibilidade de espaço nas células da cidade.

O consumo de energia de cada agente é medido com periodicidade, na medida em que a auto-organização ocorre, permitindo medidas em diversas situações de ocupação, de mancha urbana e de densidade populacional. Devido a autoorganização as famílias tendem a formar grupos, aumentando a densidade 
populacional da cidade, contudo a densidade é limitada pela taxa de ocupação do solo (características da cidade que relacionada a área ocupada com a área total construída sobre o solo), valor que é estabelecido por uma ação de planejamento urbano, através do plano diretor de desenvolvimento da cidade.

Durante a dinâmica de auto-organização promovida pelo modelo, as características da cidade (uso do solo, percentual de ocupação do solo, área construída, densidade, áreas verdes e temperatura local) variam de acordo com o posicionamento das famílias. Esta variação afeta as características das famílias (distâncias de viagens até os polos atratores, demanda por usos finais energéticos e consumo de energia).

Para que o consumo de energia seja estimado, possibilitando a avaliação das relações entre as características das cidades e o consumo de energia, o modelo proposto considera a evolução da ocupação urbana o metabolismo urbano.

Durante o processo de auto-organização da cidade é possível ajustar os parâmetros iniciais do cenário modelado, sendo possível: (a) inserir áreas verdes, ajustando seu tamanho e posição na cidade; (b) alterar a taxa de ocupação do solo. Ambos os ajustes podem interferir no arranjo da cidade e são ditados por políticas públicas de planejamento urbano.

A inserção de áreas verdes na cidade afeta diretamente o ambiente construído, resultando em mudanças no uso e ocupação do solo e temperatura local. (CAVAN et al., 2014; THEEUWES et al., 2014b). Estas alterações tem potencial para influenciar o consumo direto de energia, pois alteram as distâncias percorridas na cidade e o conforto térmico em edifícios (STEPHAN; CRAWFORD; DE MYTTENAERE, 2012b).

$\mathrm{Na}$ inserção das áreas verdes, as famílias que ocupam o espaço proposto para posicionamento das mesmas são redistribuídas aleatoriamente na cidade. Esta premissa do modelo é utilizada para replicar o processo de gentrificação. Contudo, as famílias expulsas para a implantação das áreas verdes entram novamente no processo de auto-organização, procurando novamente o melhor posicionamento na cidade, respeitando as mesmas regras iniciais já explicadas. 
A alteração da taxa de ocupação está diretamente relacionada com a possibilidade de verticalização das cidades, ampliando a ocupação por célula, diminuindo a mancha urbana e aumentando a densidade da cidade.

\subsection{ESTIMATIVA DO CONSUMO DIRETO DE ENERGIA}

Com base nas regras de auto-organização da cidade, o consumo de energia pode ser estimado a qualquer momento da simulação. O consumo é calculado para cada agente e estimado para cada dia de consumo, considerando um dia típico da família.

A partir da revisão da literatura acerca do consumo direto de energia, realizada basicamente em publicações dos últimos cinco anos, o consumo de energia foi dividido em sete grupos de usos finais energéticos: iluminação interna, eletrodomésticos, conforto térmico, aquecimento de água, cozimento, mobilidade urbana e serviços auxiliares.

\subsubsection{Iluminação}

O montante de energia consumida para o primeiro grupo de usos finais energéticos representa a demanda energética para iluminação interna e está relacionada ao tamanho da família, quantidade de dormitórios da residência, classe social e o período de ocupação da residência. $O$ consumo de energia elétrica consumida na iluminação interna é calculada baseada na equação 1. (REN; PAEVERE; MCNAMARA, 2012)

$$
\text { Cons ilum }=\frac{n \text { ilum }}{\text { ef ilum }} \times h \times A \text { piso } \times \frac{N P}{N r} \times(1 \sim 1.1) \div 1000 \times 3,6 \frac{M J}{k W h}
$$

Onde Consilum é o montante diário de energia elétrica consumida para iluminação interna expresso em MJ/dia, nilum é a iluminância requerida $\left(200 \mathrm{~lm} / \mathrm{m}^{2}\right.$, conforme ABNT), efilum é a eficiência da iluminação $(\mathrm{Im} / \mathrm{W}), h$ representa o período necessário de iluminação durante um dia (em horas), Apiso é a área da residência em $\mathrm{m}^{2}, N P$ representa a quantidade de membros da família que ocupa a residência, e $N R$ é a quantidade de dormitórios da residência. $O$ índice "1 1.1" é aplicado conforme a densidade local. Ainda foi aplicado um fator de conversão de 3.6 MJ/kWh para que o resultado final seja expresso em MegaJoules (MJ).

O período de utilização da iluminação (h) é vinculado a dois atributos da família: quantidade de membros e classe social. (REN et al., 2013). O modelo considera 
uma média de 4 horas de utilização por dia (12 horas de intervalo sem sol, subtraindo-se 8 horas de sono por noite).

\subsubsection{Eletrodomésticos}

O segundo grupo de usos finais energéticos é composto pelos eletrodomésticos. Incluindo: refrigerador (até $24 \mathrm{~h}$ por dia), televisão (até $12 \mathrm{~h}$ por dia) secadora de roupas (até $1 \mathrm{~h}$ por dia), ventiladores (até $12 \mathrm{~h}$ por dia) e ferro de passar roupas (até 0,5h por dia). O tempo médio de uso para cada eletrodoméstico foi estimado com base nos períodos de utilização disponíveis na literatura em estudo realizado na Austrália (REN; PAEVERE; MCNAMARA, 2012).

A potência média utilizada para cada eletrodoméstico foi de: 100W $250 \mathrm{~W}$ para televisores, 70W para refrigeradores, 4000W $\sim 5000 \mathrm{~W}$ para secadora de roupas, $100 \mathrm{~W}$ para ventiladores e $1500 \mathrm{~W}$ para ferro de passar. Os valores foram estimados com base em documentos da ANEEL (AGÊNCIA NACIONAL DE ENERGIA ELÉTRICA, 2001). A quantidade de cada eletrodoméstico por residência é distribuído aleatoriamente, no início da simulação, considerando a classe de renda e o tamanho da família (AZEVEDO; CHAPMAN; MULLER, 2016).

O cálculo do consumo energético do segundo grupo é realizado com base na equação 2a, adaptada de (REN et al., 2013), desprezando-se o período de consumo em modo de espera.

$$
\text { Cons elet }=\sum_{i-j}^{n} \text { pot. aparelho } \times \text { tempo de uso } \times 3,6 \frac{M J}{K W h}
$$

Como correção inicial, foi utilizado um fator de correção de uso específico para cada aparelho, o qual é afetado por fatores considerados no modelo. Devido ao tempo disponível para permanecer em casa, influenciado pelas distâncias percorridas na cidade, foi aplicado o fator calculado pela formula $2 \mathrm{~b}$ para o uso de televisores.

$$
F c d=\frac{\max d i s t-\min d i s t}{2 \times \sum \text { dist }}
$$

Onde Fcd é o fator de ajuste, maxdist é a máxima distância percorrida para alcançar o polo atrator mais distante, mindist é a distância entre a residência e o polo atrator mais perto e $\Sigma$ dist é a somatória de todas as distâncias até todos os polos atratores com os quais a família possui vínculos. 
Além o fator distância, a temperatura local influencia diretamente o período de uso dos refrigeradores, secadoras de roupas e ventiladores. O efeito da temperatura no uso destes eletrodomésticos é corrigido pelo fator calculado na fórmula 2c.

$$
F c t=\frac{\text { temperatura local }}{\text { menor temperatura na cidade }}
$$

Por fim, o coeficiente Cuse foi aplicado ao período de utilização de todos os eletrodomésticos, considerando a probabilidade de utilização dos mesmos, considerando o tamanho da família. O coeficiente foi calculado conforme equação $2 d$.

$$
\text { C use }=\frac{\text { tamanha da família }}{\text { tamanho da maior família da simulação }}
$$

\subsubsection{Conforto térmico ambiental}

O conforto térmico ambiental interno é o terceiro grupo de usos finais energéticos considerado no modelo. É necessário ressaltar que para cada região estudada as características climáticas devem ser consideradas no cálculo da demanda energética para este grupo de serviços, variando entre a necessidade de resfriamento de ar para as regiões quentes e aquecimento de ar para as regiões frias (AZEVEDO; CHAPMAN; MULLER, 2016). Neste estudo foi considerada a necessidade resfriamento do ar, adaptando-o, portanto a regiões tropicais, a exemplo de grande parte do Brasil.

Independente do clima local, a temperatura interna ideal no interior de uma edificação está em torno de 20ำ (MARIQUE et al., 2014), valor este considerado nas simulações deste estudo.

A demanda por energia para garantir o conforto térmico ambiental interno é definido para cada família conforme sua posição relativa na cidade, e a densidade local, fator que influencia na formação das ilhas de calor. O cálculo do consumo de energia é dado pela equação 3 .

$$
\begin{aligned}
\text { Consumo }- \text { ar } & =\sum_{i-j}^{n} \text { área do piso com temp controlada } \times 2,5 \times \Delta t \times 1,23 \frac{M J}{\mathrm{~m}^{3}} \\
& \times \frac{\text { tempo de uso }}{\text { dia }} \times 0.8 \sim 0.02
\end{aligned}
$$

Onde é considerado que o pé direito médio dos ambientes é de $2.5 \mathrm{~m}, \Delta \mathrm{t}$ representa a diferença entre a temperatura interna e externa, 1,2309192 MJ/m³ é o calor 
específico do ar (ar seco à pressão de 1 atm). O termo "(.8 0,02)" representa a possibilidade da família em possuir sistema de resfriamento na residência e varia conforme a classe social.

A diferença de temperatura interna e externa $(\Delta t)$ corresponde a diferença entre $o$ resultado da ação das ilhas de calor e a temperatura considerada ideal no interior das edificações, a qual corresponde à $20^{\circ} \mathrm{C}$.

\subsubsection{Aquecimento de água para banho}

O quarto grupo de serviços energético se refere ao aquecimento de água para banho, o qual é realizado por aquecedores elétricos de passagem ou acumulação (chuveiros ou caldeiras) com potência fixa. Portanto o consumo energético destes equipamentos é calculado conforme a potência e o período de uso dos mesmos. $O$ período de utilização é variado, conforme o tamanho da família.

Com base na faixa de renda em que a família se encaixa, ocorre a variação da potência dos equipamentos utilizados no aquecimento de água, variando entre 3500W, 4400W ou 6000W (AGÊNCIA NACIONAL DE ENERGIA ELÉTRICA, 2001). O tempo médio de utilização por banho está distribuído automaticamente pelo modelo, variando entre 5 e 20 minutos.

\subsubsection{Mobilidade urbana}

O quinto serviço energético considerado no modelo é a mobilidade urbana. $O$ consumo energético estimado para este serviço está correlacionado com a densidade local, pois a mesma afeta o tempo e consumo de combustível quando se considera o deslocamento entre a residência e os polos atrativos relacionados com cada família. (YE et al., 2015).

A necessidade de locomover-se na cidade está diretamente relacionada às distâncias percorridas pelos membros da família (YE et al., 2015). A distância total percorrida é calculada com base na quantidade de membros da família, na resolução do mapa e no potencial calorífico do combustível líquido, conforme apresenta a equação 6 .

A demanda energética é estimada para cada família, a partir da distância total percorrida por todos os membros em um dia, considerando os valores mencionados 
por (MARIQUE et al., 2014), onde o consumo energético é dado em kWh. O cálculo é efetuado de acordo com a equação 4:

$$
\text { Cons }=\sum_{i-j}^{n} \text { dist. vinculos } \times 2 \times \frac{\text { tamanho }- \text { familia }}{n \text { vinculos }} \times 2,196 \mathrm{MJ} \times(1 \sim 1.3)
$$

O valor do consumo de energia média adotado foi de 0,61 $\mathrm{kWh} /$ person $/ \mathrm{km}_{\text {traveled }}$ (MARIQUE et al., 2014). O fator de correção de "1 1.3" (entre 1 e 1,3) é aplicado para locais com mínima densidade e máxima densidade respectivamente, a título de compensar o gasto adicional em virtude dos congestionamentos.

\subsubsection{Cozimento}

Cozimento é o sexto grupo de usos finais energéticos considerado no modelo. Estimar o consumo de energia utilizada em cozimento em uma cidade é uma tarefa difícil, pois há uma gama extensa de técnicas aplicadas nesta prática. (HAGER; MORAWICKI, 2013), além de uma série de equipamentos e fontes energéticas utilizadas (GHEDAMSI et al., 2016). Além do que, quando considerado o comportamento humano, pode-se aumentar em até $100 \%$ o consumo de energia para preparo da mesma alimentação (HAGER; MORAWICKI, 2013).

Desta forma, uma abordagem "bottom-up", baseada em (GHEDAMSI et al., 2016; HAGER; MORAWICKI, 2013) foi considerada para estimar o montante de energia consumido para cozimento. O cálculo da demanda energética é realizado com base na equação 5.

$$
E c o z=1746 M J \times 3 \times \text { tamanho da família } \times \frac{\text { máx_dist }}{\text { min_dist }+ \text { máx_dist }}
$$

- Onde 1746 MJ é a quantidade mínima de energia consumida para preparo de uma refeição, 3 refere-se à quantidade de refeições preparadas por dia.

\subsubsection{Serviços auxiliares}

O sétimo e ultimo grupo considerado no modelo corresponde aos usos finais energéticos auxiliares nas residências que se enquadram no consumo direto de energia, sendo eles: iluminação externa, bombeamento de água e transporte vertical (elevadores).

A iluminação externa refere-se à iluminação disponível na área externa da edificação, porém ainda em área privada (exclui-se a iluminação pública) e está 
relacionada ao tamanho da área a ser iluminada. Para cálculo foi considerado o consumo de $5 \mathrm{~W} / \mathrm{m}^{2}$ (equação 6).

$$
\text { CilmExt }=\text { external area }[m 2] \times \frac{5 W}{m^{2}} \times 3,6 \frac{J}{K W h}(6)
$$

Para o bombeamento de água e uso dos elevadores foi considerado apenas para edifícios que possuem mais do que dois pavimentos. O consumo energético depende da altura da edificação e da quantidade de usuários dos serviços e é calculado conforme a equação 7 .

Cserv $=N$ pisos $\times$ tamanho da família $\times(2 \sim 7) \frac{\text { viagens }}{\text { pessoa }} \times, 05 \frac{k w}{\text { floor }} \times 3,6 \frac{\mathrm{J}}{\mathrm{kWh}}(7)$

- Onde $N$ pisos é a quantidade de pavimentos da edificação e (2 7) é a quantidade de viagens realizadas por cada membro da família utilizando-se do elevador e distribuída aleatoriamente no modelo.

\subsubsection{Consumo energético total}

O consumo de energia direta da cidade é dado a partir da soma do consumo individual de cada família para cada um dos 7 usos finais energéticos considerados na simulação.

Com o intuito de avaliar as relações entre as características das cidades e 0 consumo direto de energia, para cada cidade modelada, o modelo assume que a população da cidade e a área construída são fixas. Desta forma, algumas características da cidade emergem na medida em que a auto-organização ocorre, permitindo acompanhar o consumo energético a cada momento e analisar a causa e consequência das variações.

\subsection{ESTIMATIVA DAS EMISSÕES DE CO2}

A estimativa de emissões de $\mathrm{CO} 2$ decorre da estimativa do consumo energético da cidade simulada.

Para cada um dos sete usos finais energéticos considerados no modelo, foram verificadas as possibilidades reais de fontes energéticas a serem utilizadas, considerando a realidade brasileira. As opções de utilização das fontes de energia estão relacionadas na tabela 12 . 
Tabela 12 - Usos finais energéticos e possíveis fontes de alimentação de energia

\begin{tabular}{|c|c|}
\hline SERVIÇO ENERGÉTICO & FONTE DE ENERGIA \\
\hline Iluminação & Eletricidade \\
\hline Eletrodomésticos & Eletricidade \\
\hline Conforto térmico ambiental & Eletricidade \\
\hline Aquecimento de água, & Eletricidade, GN, Energia Solar \\
\hline Transportes & Gasolina automotiva, óleo diesel, GNV, Etanol \\
\hline Cozinha & GLP, GN \\
\hline Serviços & Energia elétrica \\
\hline
\end{tabular}

Para cada fonte de energia, até o seu uso final, foi adotado o fator de emissão conforme preconizado pelo Ministério da Ciência, Tecnologia e Inovação para a produção de energia elétrica (BRASIL, 2017), divulgado no Balanço energético Nacional, para o GN (EPE, 2014) e pelo IPCC para as demais fontes de energia (EGGLESTON et al., 2006). Os fatores de emissão adotados para estimativa das emissões de CO2 estão apresentados na tabela 13.

Tabela 13 - Fatores de emissão por tipo de fonte energética

\begin{tabular}{|l|l|l|}
\hline FONTE DE ENERGIA & EMISSÕES DE CO2 & UNIDADE \\
\hline Eletricidade & Média de 63,62 (min. 29,3 e Max 135,5 & $\mathrm{gCO}_{2} / \mathrm{kWh}$ \\
\hline GN & 56,1 & $\mathrm{KgCO}_{2} / \mathrm{TJ}$ \\
\hline GNV & 56,1 & $\mathrm{KgCO}_{2} / \mathrm{TJ}$ \\
\hline Gasolina Automotiva & 69,3 & $\mathrm{KgCO}_{2} / \mathrm{TJ}$ \\
\hline Óleo diesel & 74,10 & $\mathrm{KgCO}_{2} / \mathrm{TJ}$ \\
\hline Etanol & ZERO & \\
\hline GLP & 63,1 & $\mathrm{KgCO}_{2} / \mathrm{TJ}$ \\
\hline Energia Solar & ZERO & \\
\hline
\end{tabular}

Na próxima seção serão apresentados os resultados das simulações realizadas. 


\section{ANÁLISE dE REGRESSÃo E CALIBRAÇÃo DO MBA PROPOSTO}

\subsection{STIRPAT - MODELO DE REGRESSÃO MULTIVARIADA}

Com o intuito de confrontar os resultados obtidos nas modelagens, foi realizado estudo de regressão. Para o estudo das relações entre os dados estatísticos levantados foi utilizado o modelo STIRPAT (YORK; ROSA; DIETZ, 2003), adaptado a partir do modelo IPAT (EHRLICH; HOLDREN, 1971) o qual preconiza que o impacto (I), é decorrente da população local $(P)$, da riqueza $(A)$ e da tecnologia $(T)$, conforme equação 1. Neste modelo buscou-se adaptar a abordagem STIRPAT a fim de incluir características das cidades (população urbana, quantidade de pontos atratores).

$I=P \times A \times T$

Buscando estimar o peso relativo de cada variável sobre o impacto, o modelo STIRPAT atribuiu coeficientes às variáveis do modelo, resultando na equação 2 .

$I i=a P_{i}^{b} \times A_{i}^{c} \times T_{i}^{d} \times e_{i}$

Sendo: "a" constante da escala do modelo, "b", "c" e "d" expoentes da população (P - Population), das riquezas (A - Afluence) e da tecnologia ( $T$ - Thecnology), os quais indicam a relação entre os fatores e o impacto. Por fim "e" é o termo de erro e "i" indica que as variáveis I, P, A, T e "e" podem ser divididas em mais do que uma variável.

Como objeto de estudo foram selecionadas as dez cidades no Estado de São Paulo com mais do que 400 mil habitantes (IBGE, 2017b): São Paulo, Guarulhos, Campinas, São Bernardo do Campo, Santo Andre, Osasco, são José dos Campos, Sorocaba, Mauá e São José do Rio Preto. Foram analisados os dados referentes ao intervalo de 2006 a 2015.

As emissões de $\mathrm{CO} 2$ de cada município foram estimadas em função do consumo energético municipal (SÃO PAULO, 2014). Para o cálculo do CO2 emitido, foram considerados fatores de emissão adotados pelo IPCC (EGGLESTON et al., 2006) para os combustíveis líquidos, Ministério das Ciências, Tecnologia e Inovação (BRASIL, 2017) para a eletricidade e pelo Balanço Energético Nacional (EPE, 2014) para o Gás Natural, considerando as características do gás natural distribuído na rede do Estado de São Paulo. 
No caso da eletricidade, apesar do caráter regional da análise, foram utilizados fatores de emissão do sistema interligado nacional (BRASIL, 2017), pois grande parte da energia consumida no estado é gerada fora. Os valores adotados denotam a participação significativa da energia hidráulica na oferta brasileira, porém o fator de emissão médio anual foi utilizado para o respectivo ano, conforme a figura 22. Notase que em dez anos o fator de emissão da eletricidade triplicou. A variação explicase em função da fonte de energia primária utilizada para produção da energia elétrica, principalmente pela complementação da energia hidráulica com termoelétricas, para a realidade brasileira.

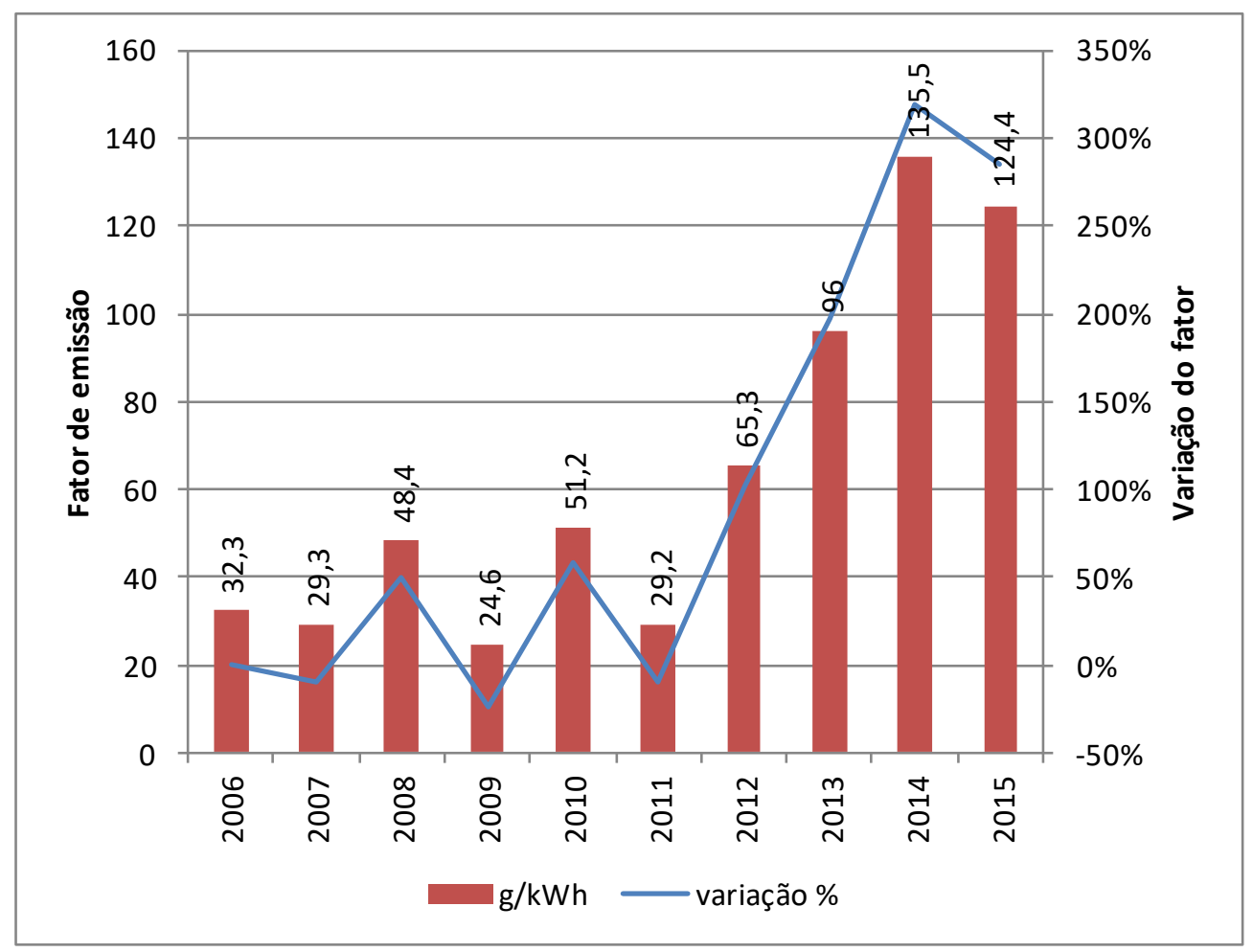

Figura 22 - Variação do fator de emissão para produção de energia elétrica no Brasil fonte: autor

Nas cidades em que há aeroportos implantados foram desprezados os consumos de combustíveis para aviação, considerando que, apesar do abastecimento das aeronaves serem realizados nos municípios, as emissões extrapolam os limites das cidades. Ainda considerou-se que os aeroportos atendem regiões mais amplas do que os municípios em que se encontram.

O foco principal do estudo está direcionado para as emissões oriundas do consumo direto de energia. $O$ consumo direto de energia engloba a energia utilizada no interior das edificações (para qualquer finalidade) e a energia utilizada na locomoção 
(para o ambiente de trabalho, lazer, educação, etc.). Exclui-se, do consumo direto de energia, os deslocamentos realizados com fins comerciais. Neste contexto, foram consideradas como vetores energéticos a eletricidade, gás natural ( $G N)$, gás natural veicular (GNV), gasolina automotiva, óleo diesel, gás liquefeito de petróleo (GLP) e etanol.

Como dados populacionais, foi adotado o valor absoluto da população (SÃO PAULO, 2016a). A descrição da variável populacional está descrita no grupo $\mathrm{P}$ da tabela 15. Os fatores econômicos utilizados no modelo foram extraídos das bases de dados do IBGE (IBGE, 2017a). Como variáveis associadas com a riqueza da população, utilizou-se o produto interno Bruto (PIB), a renda, o consumo de eletricidade, a oferta de indústrias, comércios e serviços e o volume de combustível utilizado no deslocamento (consumo direto). As descrições das variáveis econômicas (riquezas) estão descritas no grupo A da tabela 15.

A tecnologia foi agregada ao modelo relacionando o total de emissões de $\mathrm{CO} 2 \mathrm{com}$ as residências do município e com o PIB estadual, bem como através da intensidade energética considerando o consumo direto e o consumo total de energia no estado. As descrições das variáveis tecnológicas estão descritas no grupo T da tabela 15.

\begin{tabular}{|c|c|c|c|c|}
\hline GRUPO & VARIÁVEL & SÍMBOLO & DEFINIÇÃ̃O & UNIDADE \\
\hline I & Emissões $\mathrm{CO}_{2}$ & I & $\begin{array}{l}\text { Emissões } \mathrm{CO}_{2} \text { do } \\
\text { consumo direto } \\
\text { de energia }\end{array}$ & Toneladas \\
\hline $\mathrm{P}$ & População & Pt & $\begin{array}{l}\text { Quantidade de } \\
\text { habitantes do } \\
\text { município }\end{array}$ & pessoas \\
\hline \multirow{3}{*}{ A } & PIB per capita & $A \$$ & $\begin{array}{l}\text { Produto Interno } \\
\text { Bruto dividido } \\
\text { pelos habitantes }\end{array}$ & $\mathrm{R} \$ / \mathrm{hab}$ \\
\hline & $\begin{array}{l}\text { Eletricidade per } \\
\text { capita }\end{array}$ & $\mathrm{Ae}$ & $\begin{array}{c}\text { Consumo direto } \\
\text { de eletricidade } \\
\text { dividido pelos } \\
\text { habitantes }\end{array}$ & $\mathrm{MJ} / \mathrm{hab}$ \\
\hline & $\begin{array}{l}\text { Densidade de } \\
\text { polos atratores }\end{array}$ & Ap & $\begin{array}{c}\text { Somatória dos } \\
\text { polos atratores } \\
\text { dividido pela área } \\
\text { do município }\end{array}$ & $\mathrm{un} / \mathrm{Km}^{2}$ \\
\hline \multirow[t]{2}{*}{$\mathrm{T}$} & $\begin{array}{l}\text { Emissões diretas } \\
\text { por residência }\end{array}$ & $\operatorname{Tr}$ & $\begin{array}{c}\text { Emissões } \mathrm{CO}_{2} \text { do } \\
\text { consumo direto } \\
\text { dividido pela } \\
\text { quantidade de } \\
\text { residências no } \\
\text { município }\end{array}$ & T CO2/residência \\
\hline & $\begin{array}{c}\text { Intensidade } \\
\text { Energética } \\
\text { (consumo direto) }\end{array}$ & $\mathrm{Td}$ & $\begin{array}{l}\text { Energia direta } \\
\text { consumida } \\
\text { dividida pelo } \\
\text { Produto Interno }\end{array}$ & $\mathrm{MJ} / \mathrm{R} \$$ \\
\hline
\end{tabular}




\begin{tabular}{|c|c|c|c|c|}
\hline & $\begin{array}{c}\text { Intensidade } \\
\text { energética } \\
\text { (consumo total) }\end{array}$ & $\mathrm{Tt}$ & $\begin{array}{c}\text { Energia total } \\
\text { consumida } \\
\text { dividida pelo } \\
\text { Produto Interno } \\
\text { Bruto }\end{array}$ & $\mathrm{MJ} / \mathrm{R} \$$ \\
\cline { 2 - 5 } & $\mathrm{CO} / \mathrm{PIB}$ & $\mathrm{Tc}$ & $\begin{array}{c}\text { Total de emissões } \\
\text { de } \mathrm{CO}_{2} \text { dividido } \\
\text { pelo PIB }\end{array}$ & $\mathrm{T} \mathrm{CO2} \mathrm{/} \mathrm{R \$}$ \\
\cline { 2 - 5 } & $\begin{array}{c}\text { Fator de emissão } \\
\text { da eletricidade }\end{array}$ & $\begin{array}{c}\text { Total de emissões } \\
\text { de } \mathrm{CO}_{2} \text { emitido } \\
\text { para produção de } \\
1 \mathrm{MJ} \text { de energia }\end{array}$ & $\mathrm{TCO} / \mathrm{MJ}$ \\
\hline
\end{tabular}

Todos os dados primários foram coletados para determinar o consumo direto de energia e relacionar as atividades antropogênicas com as emissões de CO2 (AGUIR BARGAOUI; LIOUANE; NOURI, 2014; RASKIN, 1995), sendo:

I corresponde ao total de $\mathrm{CO} 2$ emitido resultante do consumo direto de energia, incluindo a eletricidade, GN, GNV, gasolina automotiva, óleo diesel, GLP e etanol (CARLSSON-KANYAMA; ENGSTRÖM; KOK, 2008), calculada a partir do consumo direto de energia de cada município (SÃO PAULO, 2016a), aplicando-se percentuais para estimativa do consumo direto, sendo $100 \%$ da eletricidade, $100 \%$ do GN residencial, $5 \%$ do GNV, $50 \%$ da gasolina, $40 \%$ do etanol (DETRAN-SP, 2017), $6 \%$ do óleo diesel (PMSP, 2017) e 40\% do GLP. Para o consumo energético considerado, as emissões foram calculadas com base nos fatores de emissão de cada tipo de combustível considerando o consumo residencial estacionário ou para mobilidade urbana (EGGLESTON et al., 2006). Para as emissões relativas ao uso do etanol foi considerada emissão zero de CO2 (DEMIRBAS, 2009);

P corresponde ao total de população, contabilizando todos os residentes no município conforme estimativa do Balanço Energético do Estado de São Paulo (SÃO PAULO, 2016a);

PIB per capita corresponde ao PIB do município dividido pela população local. Considerando que o PIB do ano de 2015 ainda não foi oficialmente divulgado, o mesmo foi estimado com base no desenvolvimento do PIB nacional (redução de $3,77 \%$ relativa ao ano de 2014 );

Eletricidade per capita corresponde ao consumo residencial, dividida pela população local; 
Polos atratores $/ \mathrm{km}^{2}$ : São considerados polos atratores todos os espaços que atraem as pessoas e geram deslocamento urbano (KHAKPOUR; $R \emptyset D, 2016$ ) e consequente consumo de combustível. A quantidade de polos atratores foi calculada somando-se os consumidores comerciais, de serviços e industriais, disponibilizados no BEESP (SÃO PAULO, 2016a). Os deslocamentos (particular ou público) com a finalidade de transitar para o posto de trabalho, locais de lazer, consumo e serviços enquadramse no consumo direto de energia e fazem parte do escopo deste trabalho. A variável relaciona a oferta dos polos atratores com a extensão territorial do município, entendendo que o aumento na densidade de polos atratores reduz as distâncias percorridas e o consumo de energia.

Emissões diretas por residências: Relaciona o valor da variável "I" com o total de residências no município, conforme quantidade de instalações de medidores de eletricidade instaladas para fins residenciais (SÃO PAULO, 2016a). Esta variável buscar integrar ao modelo o avanço tecnológico aplicado no interior das residências, considerando a diminuição do consumo energético em função do aumento da eficiência dos equipamentos (exemplo: iluminação a led) e a redução das emissões relativas as substituições nos processos (exemplo: troca de fogão GLP por forno de microondas);

Intensidade energética (consumo direto de energia): Relaciona as emissões relativas ao consumo direto com o PIB do município. Considera-se que a intensidade energética reflete o desenvolvimento tecnológico, uma vez que o aumento do PIB representa $\mathrm{O}$ aumento das atividades econômicas e consequente aumento da demanda energética. A diminuição da intensidade energética pode refletir a eficiência energética influenciada pelo avanço tecnológico.

Fator de emissão da eletricidade: Valor médio de $\mathrm{CO} 2$ emitido na produção da eletricidade, considerando as diversas fontes de produção distribuídas no país e as variações anuais.

Com o objetivo de quantificar e analisar as relações lineares das variáveis do modelo, a partir da adaptação do STIRPAT, o impacto é quantificado a partir da equação 3.

$\log I=a+b \ln P t+c \ln A \$+d \ln A e+e \ln A p+f \ln T r+g \ln T d+h \ln T t+i \ln T c+j \ln T e+\omega$ 
Onde a é a intercessão, b, c, d, e, f, g, h, i, j são os coeficientes das variáveis (tabela 1) e $\omega$ é o erro.

Os parâmetros foram analisados em de duas formas distintas, sendo que no primeiro modelo foi considerado o período de 10 anos e os dados das 10 cidades e no segundo modelo foi considerado o mesmo intervalo de tempo, porém a regressão foi realizada separadamente para cada cidade.

A evolução acumulada dos principais dados primários utilizados no modelo está apresentada nas figuras 23 à 27 . Na figura 23 verifica-se a queda da população entre os anos de 2009 e 2010 em todas as cidades, exceto São Paulo, porém, em todos os demais anos abrangidos pelo estudo (2006-2015), a população é crescente, bem como o resultado acumulado, comparando o ano de 2006 ao de 2015, a população aumentou em todas as cidades, com exceção da cidade de Osasco.

\section{EVOLUÇÃO DA POPULAÇÃO}

ref. ano de 2006

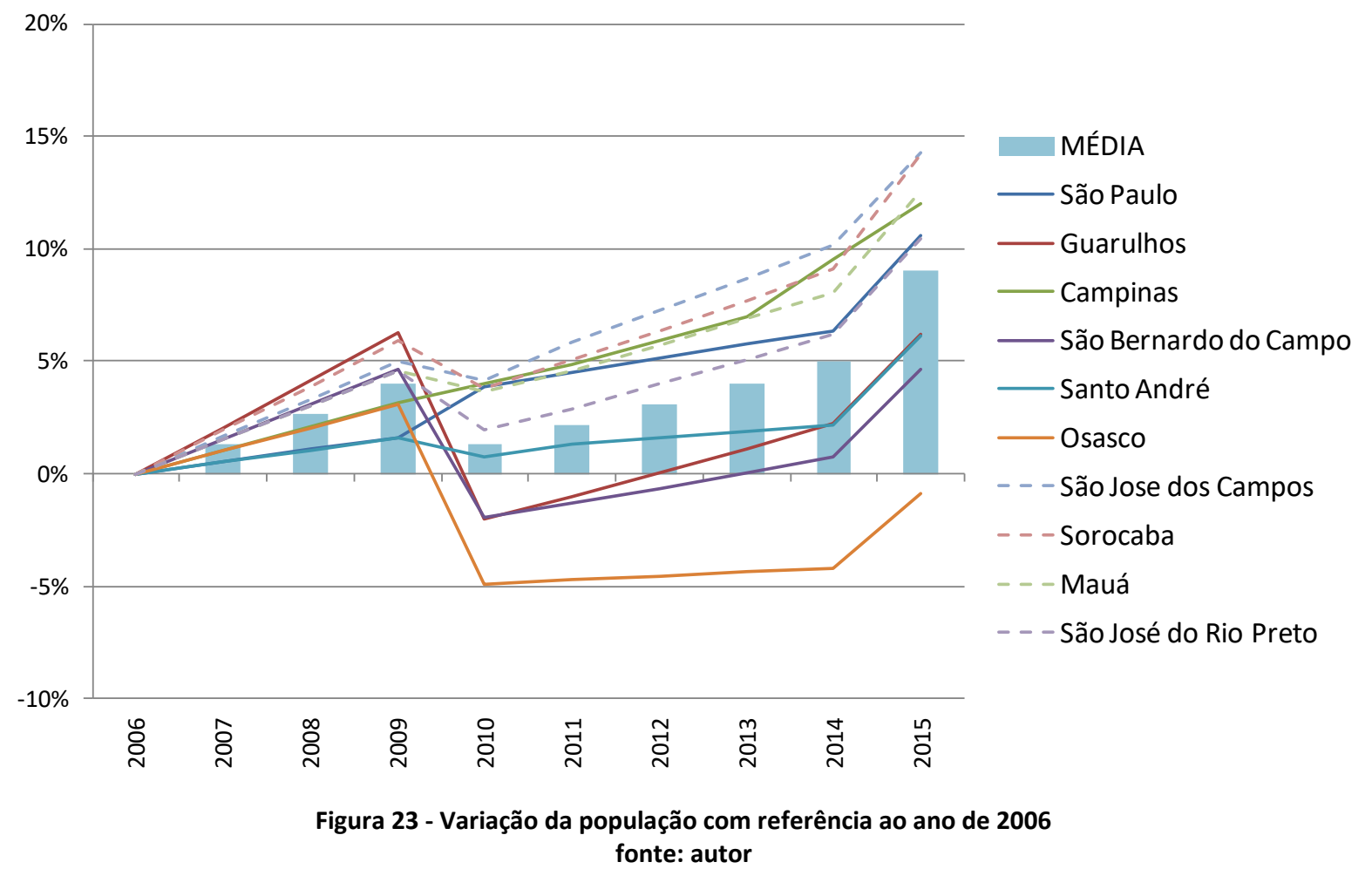

O PIB elevou-se no decorrer do tempo, exceto para o ano de 2015 , onde o PIB nacional sofreu queda, causando reação em cadeia para todos os municípios. Considerando que os dados do PIB de cada município ainda não foram divulgados 
oficialmente, a tendência de queda foi adotada para todos os municípios estudados. A evolução do PIB municipal, bem como a variação da média dos valores de todos os PIB's considerados, está apresentada na figura 24.

\section{EVOLUÇÃO DO PRODUTO INTERNO BRUTO MUNICIPAL} ref. ano de 2006

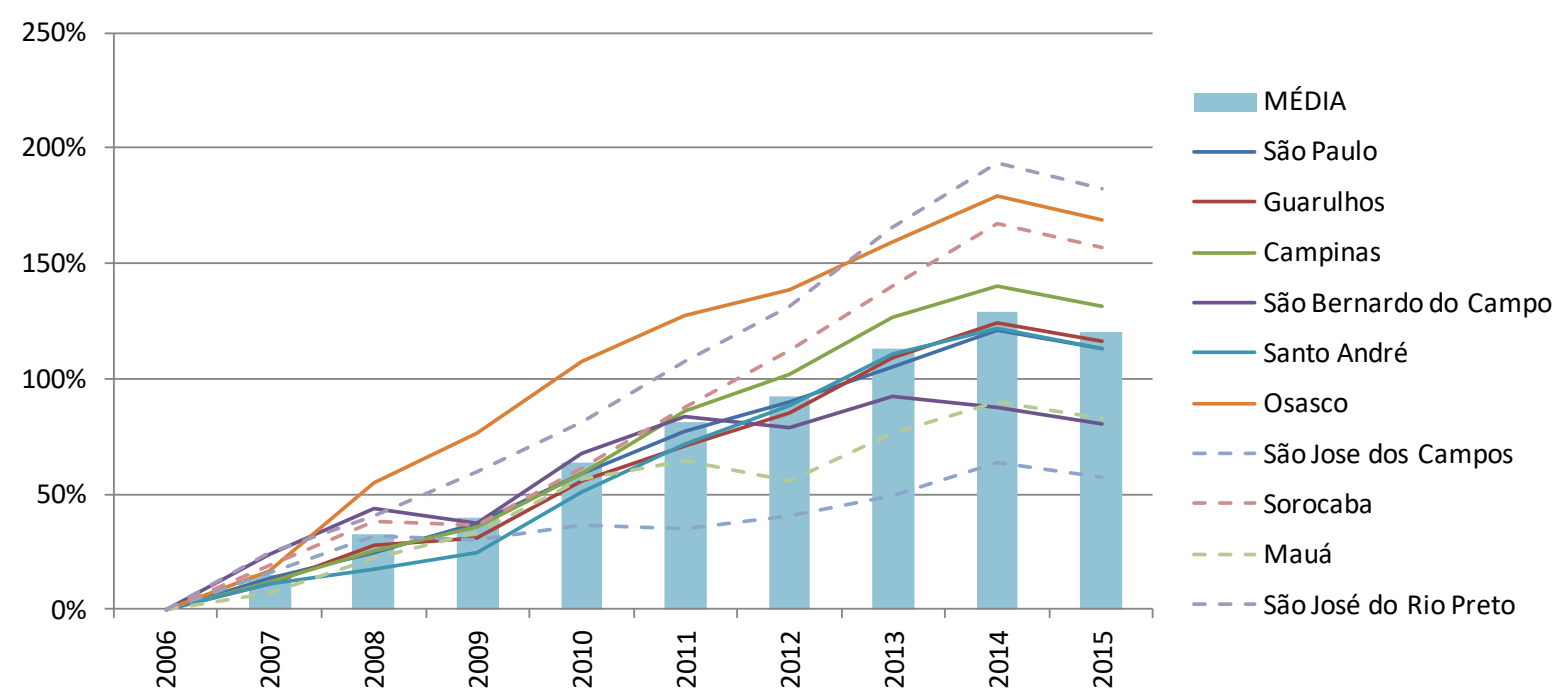

Figura 24 - Variação do PIB municipal com referência ao ano de 2006 fonte: autor

O consumo direto de eletricidade é crescente a cada ano até 2013 , com queda em 2014 e retomada de crescimento, ainda que discreto, no ano de 2015 . Somente na cidade de Sorocaba o fenômeno não se repete, onde o crescimento do consumo direto de energia é crescente durante todo o período analisado pelo estudo. A variação do consumo direto de energia, com referência ao ano de 2006, está apresentada na figura 25. 


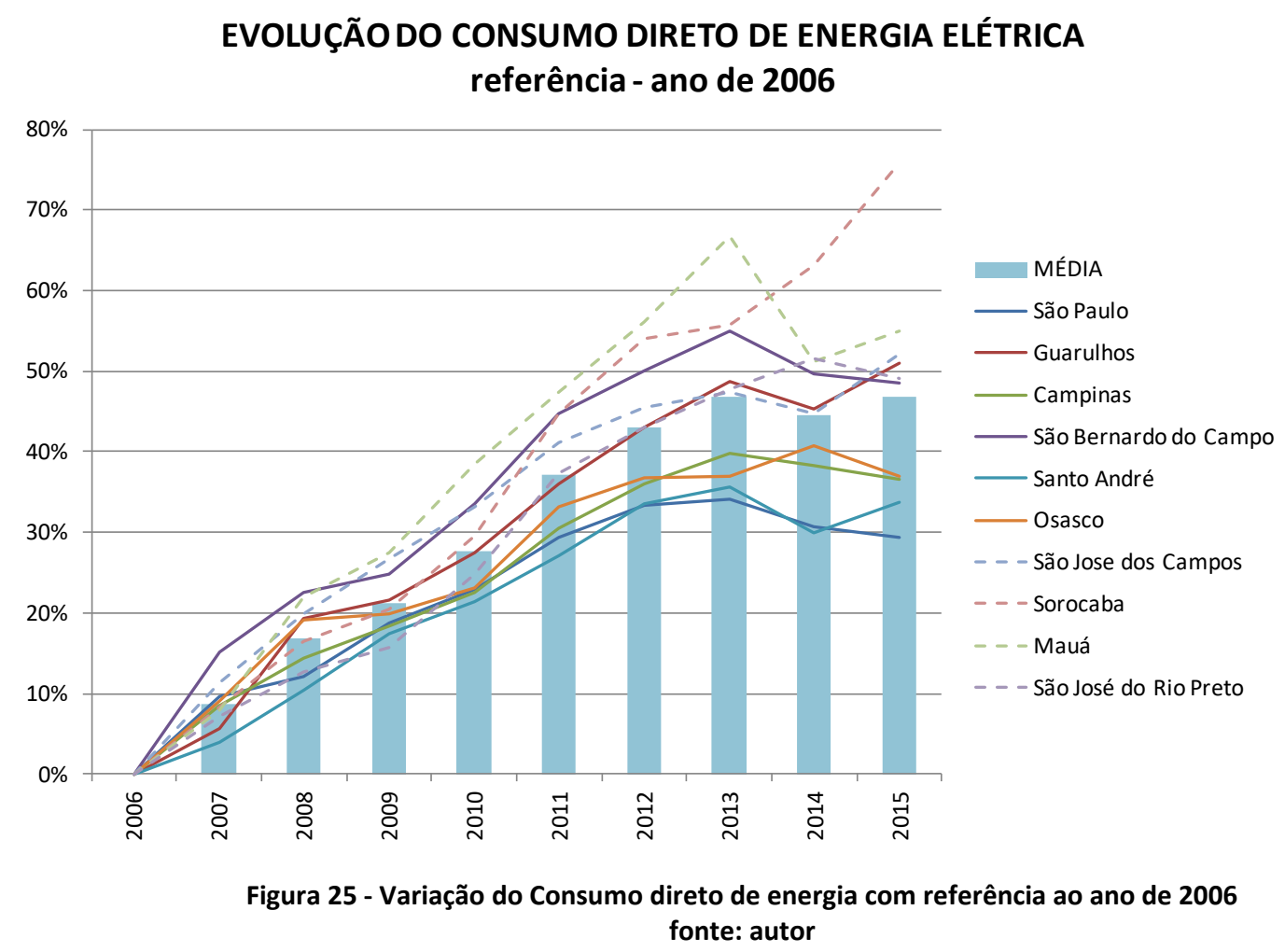

O consumo total de energia nas cidades estudadas segue a tendência do consumo direto, com exceção da cidade de Mauá, onde ocorreu declínio de $23 \%$ no consumo energético no ano de 2007. A cidade de Mauá um polo petroquímico que reúne diversas empresas do setor. Em função da alteração de processos de produção, o GN deixou de ser utilizado em grande escala, ocasionando o declínio do consumo desta fonte energética refletindo no consumo total de energia do município. Para os demais anos estudados, a cidade de Mauá seguiu a tendência de consumo das demais cidades. Como a cidade de Mauá apresenta pouco peso relativo no consumo total das dez cidades, a média do consumo total, verificado na figura 26 , segue o padrão de crescimento do consumo direto de energia, contudo apresentando valores percentuais menores. 
EVOLUÇÃO DO CONSUMO TOTAL DE ENERGIA (direto e indireto) referência - ano de 2006

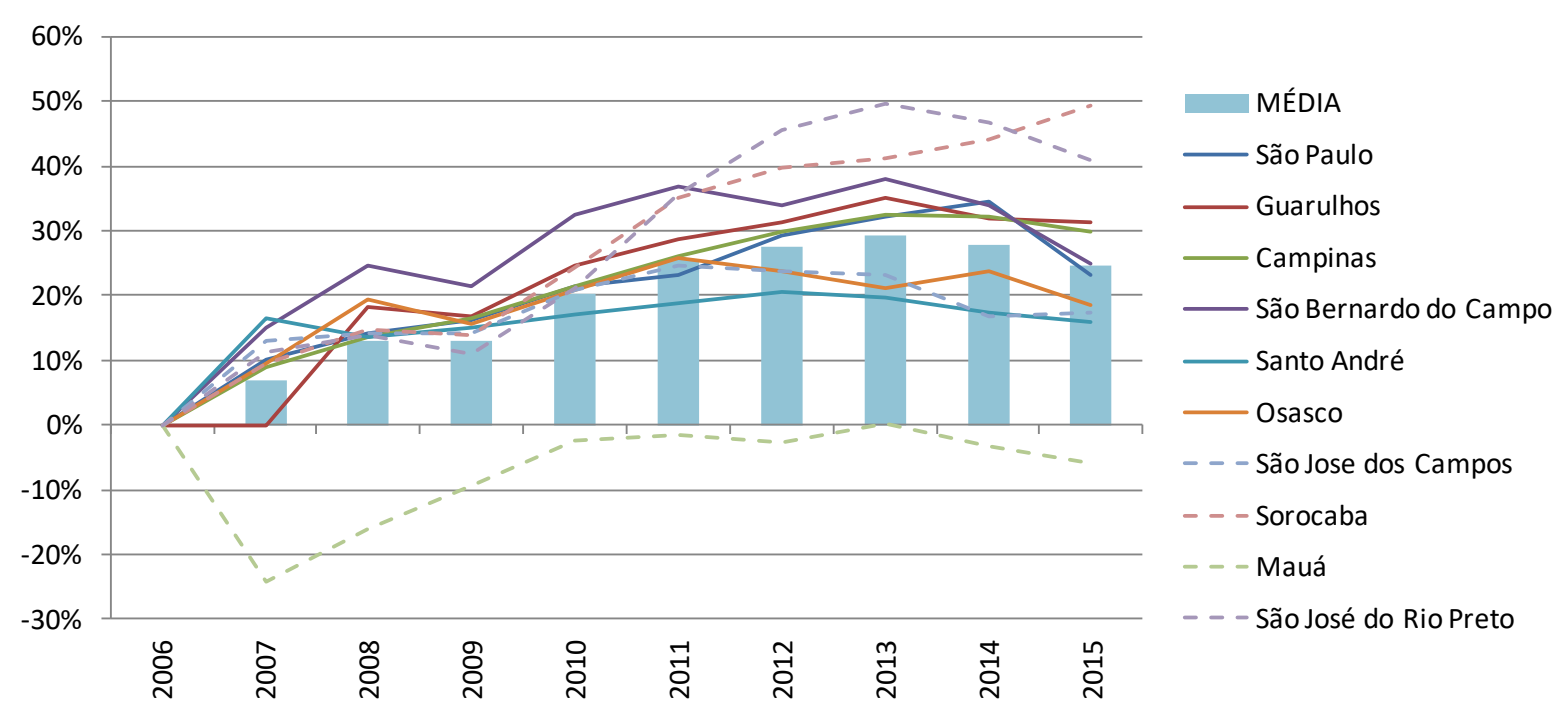

Figura 26 - Variação do Consumo total de energia com referência ao ano de 2006 fonte: autor

As emissões totais passam por forte declínio no ano de 2009. A média das emissões de todas as cidades no ano de 2009 aproxima-se da média das emissões do ano de 2006. Dentre os dados primários, cabe ressaltar o comportamento da do consumo energético da cidade de Mauá apresenta alto impacto nas emissões da cidade, porém teve impacto moderado na média das emissões de 2007. Quanto às emissões do município, elas ficaram abaixo do valor de 2006 até o ano de 2010, contudo sofreram aumentos anuais, nos padrões das demais cidades estudadas. Com exceção do ano de 2009, todos os demais anos apresentaram alta nas emissões quando comparados com o ano referência de 2006. Verifica-se, por fim, o aumento gradual das emissões até $\mathrm{o}$ ano de 2014, com ligeira queda no ano de 2015. 


\section{EVOLUÇÃO DAS EMISSÕES TOTAIS \\ referência - ano de 2006}

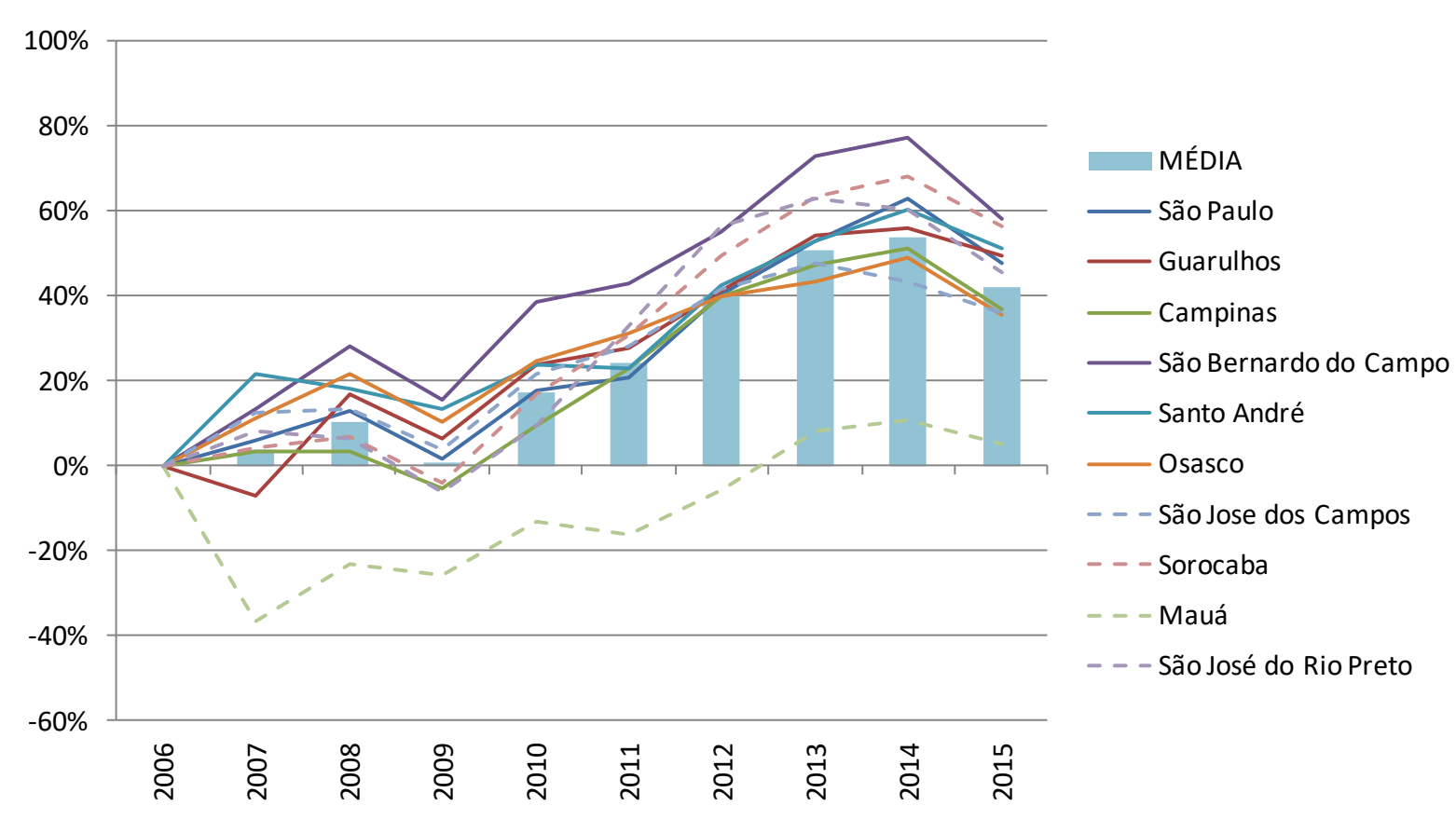

Figura 27 - Variação das emissões totais de $\mathrm{CO} 2$ com referência ao ano de 2006 fonte: autor

\subsubsection{Resultados do modelo stirpat}

Além da análise do comportamento dos dados primários e das variáveis isoladas, as relações entre as variáveis também foram estudadas, tomando como base os dados dos 10 municípios alvos do estudo (modelo 1) e isoladamente para cada município (modelo 2), considerando o período de 10 anos (entre 2006 e 2015), através da regressão de mínimos quadrados ordinários. Os resultados do modelo 1 apresentam maior robustez sobre o modelo 2 devido à quantidade de amostras analisadas (10 vezes maior), contudo os resultados do modelo 2 possibilitam inferir os resultados das flutuações das variáveis, através da analise dos parâmetros do modelo 1 , visto que para cada cidade analisada as características específicas são diferentes.

A tabela 15 apresenta os resultados dos modelos. No modelo 1 (primeira coluna de resultados) observa-se a população é o coeficiente que apresenta a maior influência nas emissões $(0,996)$, com elasticidade unitária positiva, corroborando a essência do IPAT (EHRLICH; HOLDREN, 1971).

Apenas dois coeficientes apresentam relação negativa com as emissões, sendo que a mais significativa é a intensidade energética $(-0,216)$, corroborando o princípio de 
que o avanço tecnológico é favorável à diminuição do consumo energético e a mitigação das emissões de CO2 (GOLDEMBERG; LUCON, 2007). O segundo coeficiente com relação negativa é a densidade dos polos atratores. Apesar de apresentar coeficiente relativamente baixo $(-0,0218)$, a condição negativa indica que o aumento da oferta de polos atratores tem a capacidade de oferecer mais opções de viagem. Com a escolha de polos atratores mais próximos das residências, os percursos tendem a diminuir em distância e, consequentemente, em consumo energético (seja por transporte particular ou transporte público). A diminuição do consumo de energia para deslocamento reduz as emissões.

Todas as demais variáveis modeladas apontam coeficientes positivos (aumentam as emissões), porém todos os valores ficaram abaixo de 1,0 (um). As emissões de CO2 oriundas do consumo direto por residência apresentam coeficiente 0,846 , apontando para a importância do ambiente doméstico e dos sistemas de transportes nas emissões de $\mathrm{CO} 2$.

Semelhante às emissões do consumo direto, o consumo direto de energia per capita aponta coeficiente positivo de influência nas emissões $(0,481)$. Esta variável indica o aumento das emissões na medida em que o consumo direto individual aumenta (independente do aumento da população). Dado que o consumo de eletricidade corresponde a aproximadamente $38 \%$ do consumo direto de energia, conforme se verifica na figura 28 , onde se pode verificar também que a flutuação é irrelevante, mantendo-se estável em todo o período, e que o fator de emissão tem sido crescente nos últimos dois anos, conforme pode ser verificado na figura 22 , elevando a participação das emissões da produção de eletricidade nas emissões totais, observada na figura 29, é justificável que a elevação do consumo per capita de eletricidade colabora para a elevação das emissões proveniente do consumo direto de energia. 


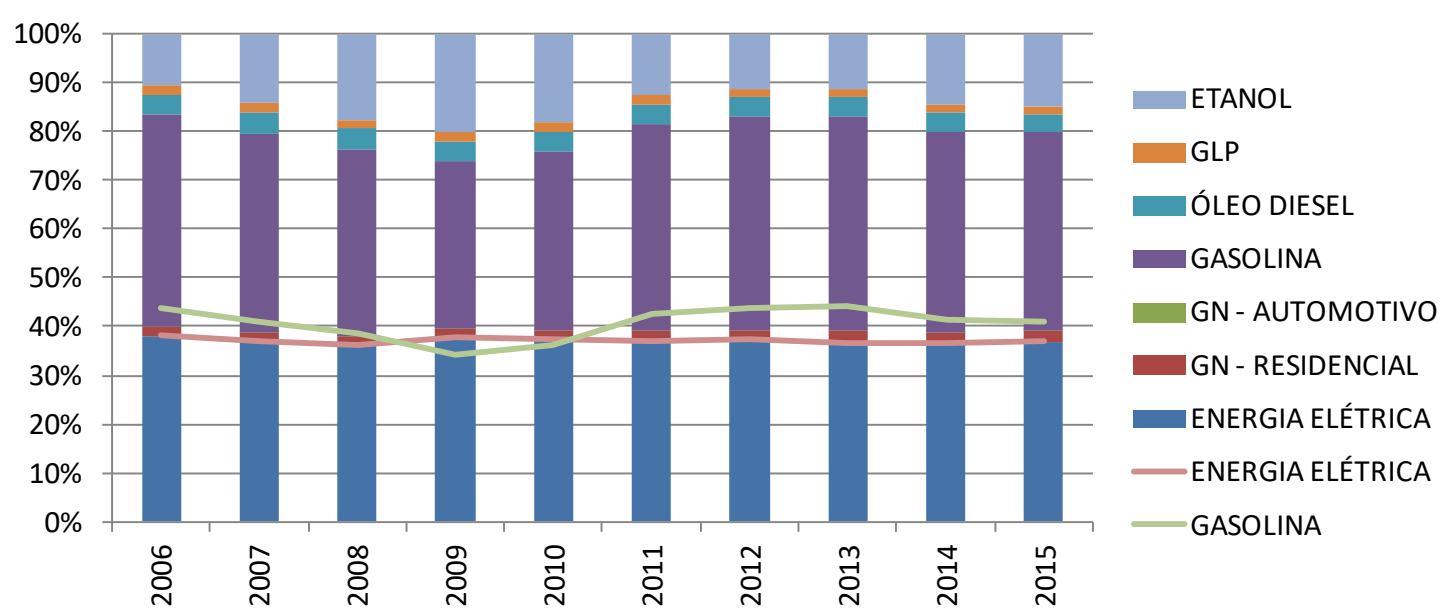

Figura 28 - Distribuição percentual do consumo de energia por fonte para as 10 cidades estudadas fonte: autor

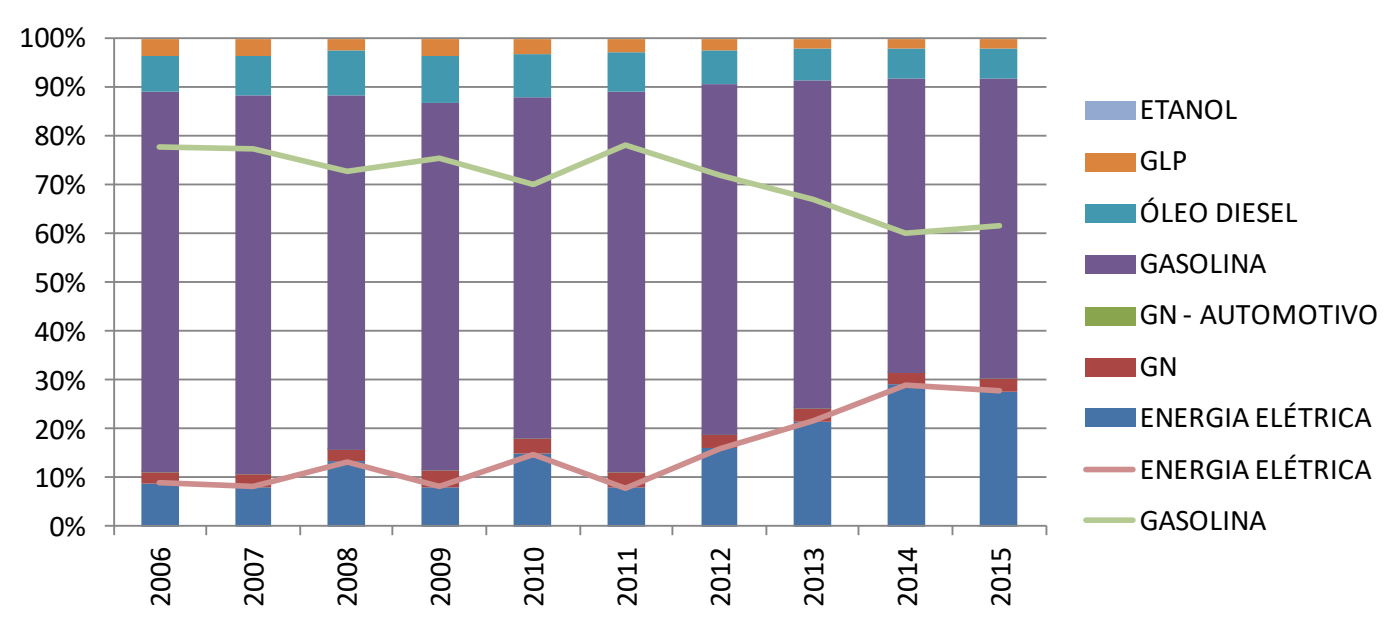

Figura 29 - Distribuição percentual das emissões oriundas do consumo direto de energia, separados por fonte energética, para as $\mathbf{1 0}$ cidades estudadas. fonte: autor

A relação $\mathrm{CO} 2 / \mathrm{PIB}$ apresenta coeficiente 0,2 , influenciando positivamente, ainda que menos intensamente, as emissões de CO2. Quando considerado apenas o consumo direto de energia, a intensidade energética do conjunto de cidades apresenta coeficiente positivo de 0,186 , opondo-se à intensidade energética calculada para a energia total da cidade $(-0,216)$.

Apesar das variáveis "intensidade energética" e "intensidade de carbono (CO2/PIB)" representarem o avanço tecnológico no sistema IPAT, verifica-se que, mesmo com seus valores médios em queda (figura 30 ), confirmando o avanço da tecnologia na produção e consumo de energia, sua influência positiva nas emissões reflete que a tecnologia aplicada não acompanha a mesma evolução do desenvolvimento econômico (medido pelo PIB), corroborando a tese de que, apesar do avanço 
tecnológico diminuir as emissões totais, o aumento das emissões per capita ainda é crescente, e seria maior, caso não houvesse o avanço da tecnologia. Os reais motivos deste fenômeno carecem de investigação detalhada, a qual foge do objetivo deste trabalho.

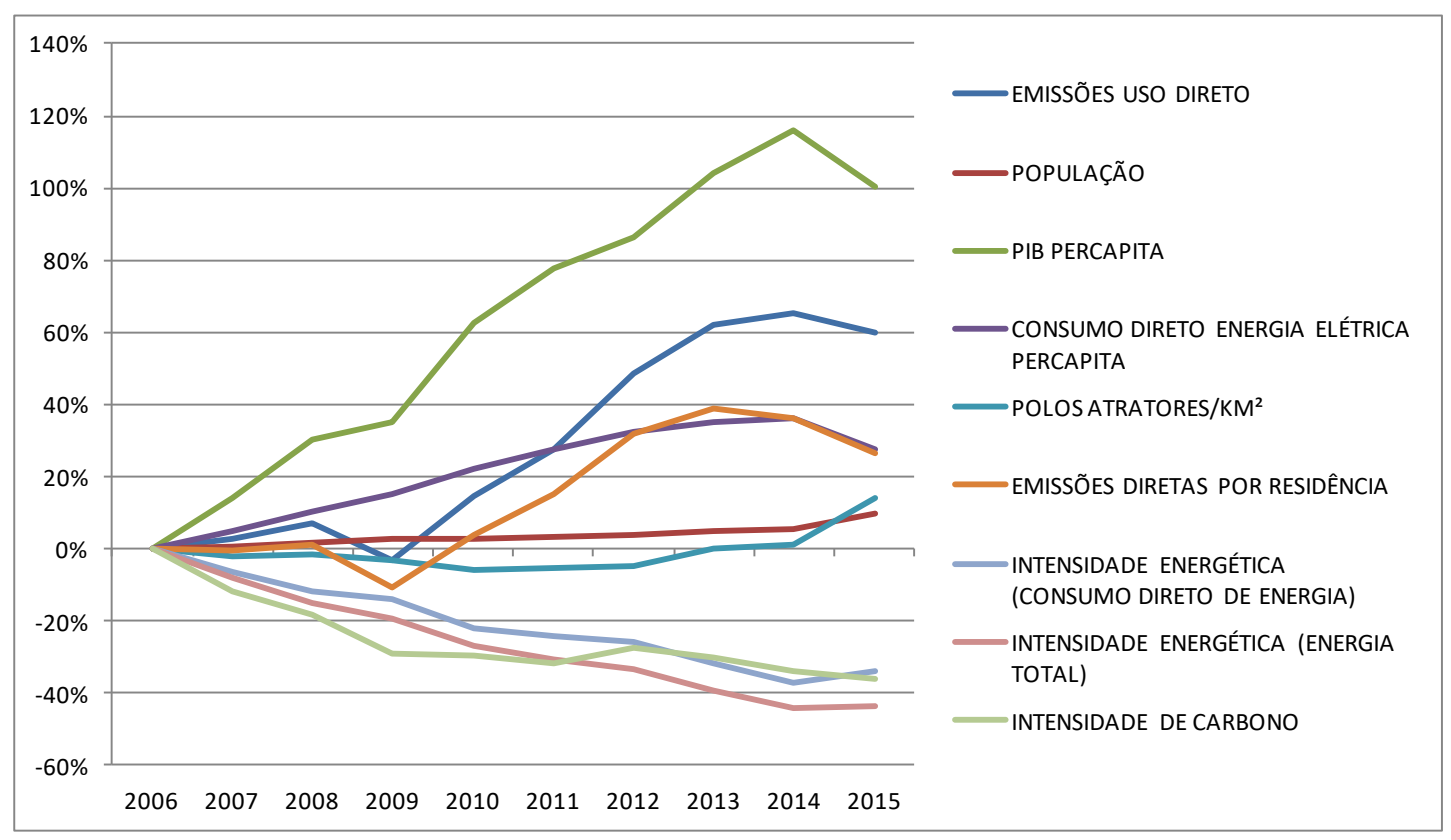

Figura 30 - Variação anual dos indicadores do IPAT com base no ano de 2006 fonte: autor

O PIB per capita é outra variável que apresenta influência positiva nas emissões. Apesar do fator relativamente baixo $(0,161)$ os resultados corroboram para a curva ambiental de Kuznets (KUZNETS, 1955), pois o aumento do PIB per capita indica o aumento da "riqueza" da população, culminando no aumento do consumo e consequente aumento da degradação ambiental, especificamente, para este estudo, com o aumento das emissões de $\mathrm{CO} 2$.

O menor coeficiente encontrado no modelo está relacionado ao fator de emissão de CO2 na produção de eletricidade $(0,017)$. Nota-se que o percentual representado pelo consumo direto de eletricidade é estável para todos os anos analisado, mantendo-se em aproximadamente $38 \%$ do total consumido, contudo o total de energia consumida é decrescente nos últimos três anos analisados (2013 - 2015), contribuindo, ainda, para a queda do consumo direto de eletricidade. A diminuição do total de energia direta consumida coincide com o aumento do fator de emissão, equilibrando o impacto analisado (emissões do uso direto de energia). Esta redução, apesar de necessitar de investigação mais aprofundada, sugere a eficiência da ação 
do Governo brasileiro no aumento da taxa de eletricidade em função da crise hídrica enfrentada a partir do ano de 2012.

Tabela 15 - Coeficientes resultados da regressão realizados para o modelo 1 e 2

\begin{tabular}{|c|c|c|c|c|c|c|c|c|c|c|c|}
\hline & \multirow{2}{*}{$\begin{array}{c}\text { MODELO } 1 \\
\text { ก } \\
\circ \\
\circ \\
\vdash\end{array}$} & \multicolumn{10}{|c|}{ MODELO 2} \\
\hline & & $\begin{array}{l}\frac{0}{3} \\
\pi \\
0 \\
0 \\
2 \pi \\
\sim\end{array}$ & 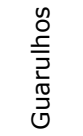 & 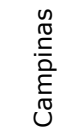 & $\begin{array}{l}u \\
\text { un }\end{array}$ & 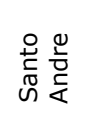 & 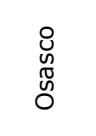 & U & 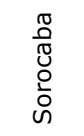 & $\begin{array}{l}\frac{\sqrt{0}}{3} \\
\sum^{\frac{\pi}{2}}\end{array}$ & $\begin{array}{l}\text { 㞻 } \\
\text { ज }\end{array}$ \\
\hline MUNICÍPIO & \multicolumn{11}{|c|}{ Coeficientes } \\
\hline Interseção & $-3,905$ & 14,507 & 15,725 & $-3,604$ & 9,635 & $-9,510$ & 19,095 & $-134,22$ & 13,101 & $-12,764$ & 18,132 \\
\hline POPULAÇÃO & 0,996 & 0,729 & 0,340 & 1,319 & 0,442 & 1,576 & 0,175 & 8,436 & 0,616 & 1,293 & 0,569 \\
\hline PIB PERCAPITA & 0,161 & 1,080 & 0,703 & 0,318 & 0,515 & $-0,099$ & 0,460 & $-2,203$ & 0,341 & $-1,116$ & 1,212 \\
\hline $\begin{array}{c}\text { CONSUMO DIRETO } \\
\text { ELETRICIDADE PERCAPITA }\end{array}$ & 0,481 & $-0,290$ & $-0,247$ & 0,073 & $-0,181$ & 0,380 & $-0,601$ & 3,346 & $-0,098$ & 1,218 & $-0,476$ \\
\hline POLOS ATRATORES/KM² & $-0,018$ & $-0,192$ & 0,053 & $-0,015$ & $-0,018$ & $-0,014$ & $-0,021$ & 0,122 & $-1,650$ & 0,246 & $-0,023$ \\
\hline EMISSÕES DIRETAS POR RESIDÊNCIA & 0,846 & $-0,234$ & 0,394 & 0,680 & 0,646 & 0,871 & 0,819 & 2,282 & 0,366 & 1,716 & $-0,076$ \\
\hline $\begin{array}{c}\text { INTENSIDADE ENERGÉTICA } \\
\text { (CONSUMO DIRETO DE ENERGIA) }\end{array}$ & 0,186 & 1,377 & 1,191 & 0,637 & 0,701 & $-0,099$ & 0,129 & $-5,278$ & 0,609 & $-1,415$ & 1,884 \\
\hline $\begin{array}{c}\text { INTENSIDADE ENERGÉTICA } \\
\text { (ENERGIA TOTAL) }\end{array}$ & $-0,216$ & $-2,147$ & $-1,733$ & $-0,861$ & $-1,057$ & $-0,264$ & $-1,048$ & 6,484 & $-1,104$ & 0,869 & $-2,830$ \\
\hline $\mathrm{CO} / \mathrm{PIB}$ & 0,200 & 1,780 & 1,240 & 0,511 & 0,675 & 0,123 & 1,024 & $-2,718$ & 0,512 & $-0,599$ & 1,968 \\
\hline $\begin{array}{l}\text { FATOR DE EMISSÃO } \\
\text { ELETRICIDADE }\end{array}$ & 0,017 & $-0,035$ & $-0,050$ & $-0,012$ & $-0,041$ & 0,005 & $-0,070$ & 0,255 & 0,014 & $-0,028$ & 0,005 \\
\hline
\end{tabular}

Os resultados do modelo 2 estão apresentados na tabela 15, separados para cada cidade. A análise deste modelo procura explicar as variações abruptas nos coeficientes, em função das alterações nas variáveis, corroborando as análises realizadas para o modelo 1 , visto que grande parte dos valores encontrados no modelo 2 aproximam-se dos valores encontrados no modelo 1.

Para todas as cidades a população apresenta relação positiva com as emissões. 0 menor coeficiente está atribuído à cidade de Osasco $(0,175)$, queda em sua população em 2010. A cidade de São José dos Campos apresenta maior coeficiente $(8,436)$ e maior desenvolvimento populacional entre as cidades e foi a única a qual, em todo o período analisado, não sofreu diminuição na população. Desta forma fica corroborada a literatura analisada que afirma que o aumento da população amplia as emissões per capitas (AGUIR BARGAOUI; LIOUANE; NOURI, 2014; EHRLICH; HOLDREN, 1971; LIDDLE, 2013).

A flutuação no indicador PIB per capita está relacionada ao movimento econômico e populacional das cidades. A cidade de São Jose dos Campos apresenta o menor coeficiente $(-2,203)$, contrariando a curva de Kuznets, contudo verifica-se que a cidade teve o menor aumento do PIB, ficando, pelo menos $50 \%$ abaixo da média, porém a população subiu acima da média, resultando em baixo aumento do PIB per 
capita. Já a cidade de São José do Rio Preto apresenta o maior coeficiente $(1,212)$, devido ao maior aumento do PIB entre todas as cidades.

Na cidade de Mauá destaca-se a relevância do consumo direto de energia (índice 1,218) devido à queda significativa do consumo total de energia influenciado pela interrupção do uso de gás natural por um único (e grande) consumidor localizado no polo petroquímico instalado na cidade. A influência dos polos atratores, apesar de relativamente baixa para todas as cidades, mantêm a tendência de da influência negativa nas emissões em $70 \%$ dos casos analisados.

As emissões de CO2 oriundas do uso direto de energia mantém a tendência de influência positiva com coeficientes abaixo de um (1), conforme o conjunto de todas as cidades, sendo mais elevado apenas na cidade de São José dos Campos. A intensidade energética, ligada ao consumo direto de energia é muito variável para cada cidade, contudo mantém a tendência da influência positiva em 7 cidades, enquanto a intensidade energética calculada a partir da energia total, mantém a influência negativa. Para todas as cidades, exceto para a cidade de Santo André, as intensidades apresentam influências opostas (positiva e negativa), seguindo a tendência da análise do modelo 1. A intensidade de carbono é negativa apenas para as cidades de Mauá, em função da alteração da sua oferta energética e São Jose dos Campos devido seu baixo desenvolvimento do PIB.

O fator de emissão da produção da eletricidade flutua positivamente ou negativamente à coeficientes muito baixos, visto que a variação no consumo de eletricidade tende a diminuir à medida que os fatores de emissão aumentam. Cabendo ressaltar que esta relação ocorre pelo mesmo motivo, a saber: diminuição dos recursos hídricos e consequente alteração da fonte de produção, agregado à política de elevação das taxas de energia adotada pelo Governo brasileiro.

\subsubsection{Discussão e análise do modelo stirpat}

Os resultados demonstram que, assim como em outros estudos, a variável população é a que mais se destaca. Nesse sentido o estado deve buscar desacelerar o crescimento das cidades e buscar uma maior distribuição da população no território. 
O segundo coeficiente mais importante está associado com as emissões diretas por residência, o qual é superior ao coeficiente do consumo direto de energia, fato que indica a diminuição do uso de energia "limpa" no ambiente doméstico, independente da escolha do consumidor final, pois a substituição da fonte geradora é uma decisão governamental. Em comparação com o coeficiente da intensidade energética, estes dois coeficientes demonstram que a escolha de vetores energéticos menos poluentes pelos consumidores pode acarretar uma redução nas emissões. Isto demonstra a relevância de políticas que incentivem a busca por alternativas baseadas em energias renováveis. O aumento dos polos atratores apresenta um impacto moderado nas emissões, indicando que incentivar o aumento destes polos para buscar uma redução na emissão não é uma ação muito efetiva. Ou seja, o impacto do planejamento urbano é moderado quando comparado com alternativas de substituição de combustíveis, tecnologias de uso final e geração descentralizada de energia.

As variáveis impactantes analisadas ( $P, A$ e $T)$ são sensíveis as características inerentes de cada cidade, apresentando influências diversificadas para conjunto de dados. Verifica-se também, que os desvios dos valores médios, impactam (positivamente ou negativamente) nas emissões dos Gases de Efeito Estufa. A partir da verificação da sensibilidade das variáveis é possível o emprego de políticas públicas procurando a diminuição das emissões e mitigação do efeito estufa.

Cabe destacar que a mitigação das emissões passa necessariamente pela intervenção governamental e pela escolha individual das famílias que habitam a cidade. Ações conjuntas tornam-se mais eficientes na redução das emissões, como a oferta e uso de transporte público, incentivos para geração descentralizada de energia a partir de fontes renováveis (eólica, solar) e uso de biocombustíveis.

\subsection{ANÁLISE COMPARATIVA DOS RESULTADOS INICIAIS DOS MODELOS STIRPAT E MBA}

Após tratar, analisar e estabelecer as relações entre as variáveis colhidas das 10 cidades reais do Estado de São Paulo, através do modelo STIRPAT, foram simuladas a ocupação ideal para 216 cidades através do Modelo Baseado em agentes proposto neste trabalho, procurando coletar dados iguais ou semelhantes aos dados reais, com o intuito de analisá-los através do modelo STIRPAT. 
Nesta fase, o MBA foi configurado inicialmente com as características semelhantes as cidades estudadas, mantendo-se as relações entre as famílias, população, polos atratores, e áreas urbanas. As relações foram estabelecidas a partir dos dados empíricos e reproduzidas no arranjo das cidades simuladas. As relações, bem como o valor de r $^{2}$ estão apresentadas na tabela 31.

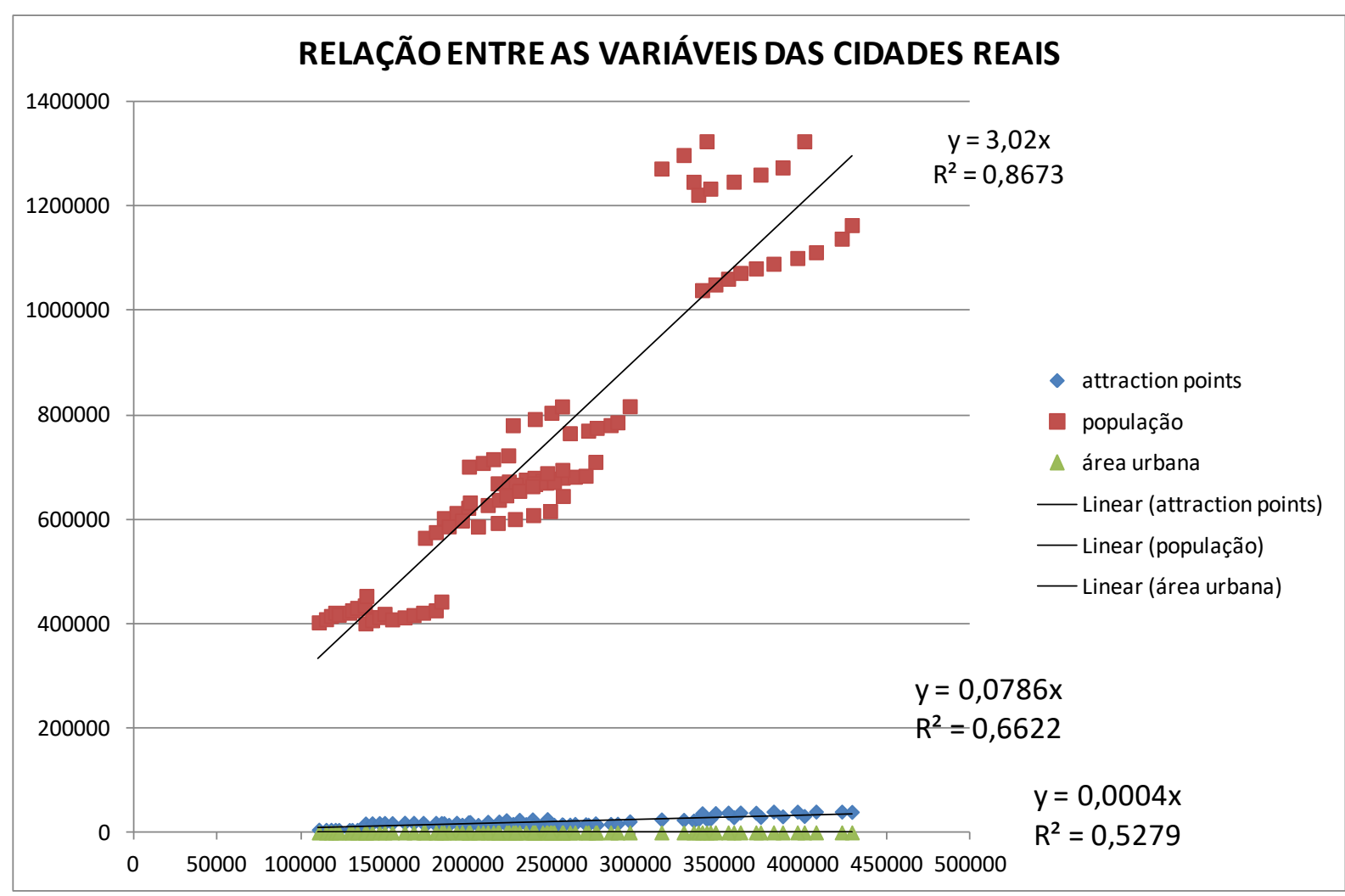

Figura 31 - Relação das variáveis polos atratores, população e área urbana em função da quantidade de famílias que habitam nas 10 cidades estudadas pelo modelo STIRPAT fonte: autor

Foram simuladas a auto-organização da ocupação urbana nas premissas estipuladas no MBA e, posteriormente foi realizada a extração dos dados resultantes das 216 simulações realizadas. Com os dados extraídos, foi realizada análise de regressão, resultando nos dados apresentados na tabela 16, os quais foram confrontados com o resultado da análise de regressão realizada para as 10 cidades do Estado de são Paulo.

Tabela 16 - resultado da análise de regressão das 216 cidades simuladas pelo MBA

\begin{tabular}{|c|c|}
\hline & Coeficientes \\
\hline Interseção & 3,70675083 \\
\hline POPULAÇÃO(hab) & 0,86368998 \\
\hline RENDA PER CAPITA (R\$/hab) & 0,17860782 \\
\hline
\end{tabular}




\begin{tabular}{|c|c|}
\hline DENSIDADE (hab/ $\left./ \mathrm{km}^{2}\right)$ & $-0,1521598$ \\
\hline PA / KM & $-0,5073512$ \\
\hline E COMBUSTÍVEL LIQ / P. A. (MJ/un) & 0,75590406 \\
\hline
\end{tabular}

Para análise comparativa entre os resultados, torna-se necessário salientar que em ambos os modelos, procurou-se trabalhar com unidades, montantes, proporções e indicadores iguais, sempre que possível.

O fator tecnológico foi retirado da análise, pois o MBA não é um modelo que evolui no tempo, mas sim, auto-organiza a cidade através da alteração de suas características. Desta forma, compreende-se que o fator tecnológico é o mesmo para o início e final da auto-organização da cidade.

A partir da tabela 17 é possível observar que a o tamanho da população tem relação positiva com as emissões de CO2 próximos da proporção de 1:1, em ambos os modelos. O fator de renda, apesar de ter proporção próxima de 0,2:1, ainda influencia as emissões positivamente em ambos os modelos. Esta condição corrobora a tese de Kuznets. A relação de combustível gasto por polo atrator existente são fatores com relação positiva com as emissões, pois, uma vez que a quantidade de combustível aumenta para que se atinjam os polos atratores (aumento das distancias a serem percorridas), as emissões tendem a aumentar. Em ambos os modelos os coeficientes são próximos.

A densidade populacional apresenta diferença substancial entre os modelos, contudo, ambos apresentam relação negativa com as emissões, sendo os fatores 0,15 para o MBA e 0,75 para o modelo STIRPAT. A relação polos atratores por quilômetro quadrado $\left(\mathrm{PA} / \mathrm{Km}^{2}\right)$ foi o único indicador cuja relação foi oposta nos modelos, apresentando relação positiva no modelo STIRPAT e relação negativa no MBA. A correlação negativa apresentada no MBA explica-se através da diminuição das distâncias a serem percorridas no interior das cidades. Considerando o aumento da oferta de polos atratores, os agentes da cidade têm mais possibilidades de destinos, permitindo vincular-se aos pontos mais próximos, o que resulta em menor gasto energético nos deslocamentos. Já no modelo STIRPAT, a quantidade de polos atratores resultou da somatória dos consumidores comerciais, industriais, serviços e poder público, quantidade de consumidores que podem refletir a flutuação do mercado, impossibilitando a análise isolada da variável. 
Tabela 17 - Comparação da influência das variáveis nos modelos MBA e STIRPAT

\begin{tabular}{|c|c|c|c|}
\hline \multicolumn{2}{|l|}{ MBA } & \multicolumn{2}{|r|}{ STIRPAT } \\
\hline Variável & Coeficientes & Coeficientes & Variável \\
\hline Interseção & 3,70675 & $-8,79415$ & Interseção \\
\hline POPULAÇÃO (hab) & 0,86369 & 0,97430 & POPULAÇÃO \\
\hline RENDA PER CAPITA (R\$/hab) & 0,17861 & 0,21685 & PIB PERCAPITA \\
\hline DENSIDADE POPULACIONAL (hab/km²) & $-0,15216$ & $-0,75330$ & DENSIDADE POPULACIONAL \\
\hline PA / KM ${ }^{2}$ & $-0,50735$ & 0,82484 & $\mathrm{PA} / \mathrm{Km}^{2}$ \\
\hline E COMBUSTÍVEL LIQ / P. A. (MJ/un) & 0,75590 & 0,67112 & E COMBUSTÍVEL LIQ / P. A. \\
\hline
\end{tabular}

A análise comparativa dos dados reais com os dados extraídos do MBA permite deduzir que o MBA reflete as cidades estudadas, permitindo, a partir da alteração das variáveis, verificar quais são as consequências no consumo energético e nas emissões de $\mathrm{CO} 2$ a partir de alterações nas características das cidades. Esta condição será explorada no capítulo seguinte. 


\section{RESULTADOS DA MODELAGEM}

Foram selecionados quatro cenários possíveis para as simulações com o intuito de avaliar as relações entre as características das cidades, o consumo direto de energia e as emissões de $\mathrm{CO} 2$. Em cada um dos cenários foram mantidas fixas as quantidades de polos atratores, famílias e vínculos entre as famílias e os polos atratores, variando-se a taxa de ocupação do solo e a quantidade de áreas verdes. A resolução do mapa foi ajustada conforme proporção apresentada na figura 31. A condição inicial de cada um dos cenários simulados é dado com a variação da taxa de ocupação do solo (entre 1 e 4) e da quantidade de áreas verdes de cada cidade (entre 0 e 3), totalizando 64 cenários possíveis para que a análises do conjunto possibilite alcançar o objetivo do trabalho. A tabela 18 apresenta os 4 cenários possíveis e seus respectivos valores considerados no ajuste inicial.

\begin{tabular}{|l|l|l|l|l|}
\multicolumn{7}{|c|}{ Tabela 18 - Características dos arranjos das cidades simuladas } \\
\hline & Cenário 1 & Cenário 2 & Cenário 3 & Cenário 4 \\
\hline Polos atratores & 460 & 612 & 766 & 460 \\
\hline Famílias & 6.000 & 8.000 & 10.000 & 8.000 \\
\hline Famílias / polo atrator & 13,05 & 13,07 & 13,05 & 17,39 \\
\hline Vínculos com polos atratores & 3 & 3 & 3 & 3 \\
\hline & 1 & 1 & 1 & 1 \\
Taxa de ocupação do solo & 2 & 2 & 2 & 2 \\
& 3 & 3 & 3 & 3 \\
\hline Resolução do mapa & 4 & 4 & 4 & 4 \\
\hline & $9,8 \mathrm{~m}$ & $11,4 \mathrm{~m}$ & $12,7 \mathrm{~m}$ & $11,4 \mathrm{~m}$ \\
Áreas verdes & 0 & 0 & 0 & 0 \\
(10 km ${ }^{2}$ / unidade) & 1 & 1 & 1 & 1 \\
& 2 & 2 & 2 & 2 \\
& 3 & 3 & 3 & 3 \\
\hline
\end{tabular}

A auto-organização inicia-se a partir da distribuição aleatória dos habitantes na cidade (Fig. 32a), e evolui para a melhor acomodação de todas as famílias, respeitando as premissas do modelo (Fig. 32d). Configurações espaciais intermediárias são registradas conforme figuras 32b e 32c. O retângulo representa o espaço da cidade considerada pelo modelo (alvo de estudo). Os pontos cinza são ocupados pelas empresas e indústrias e os pontos coloridos (brancos, vermelhos, amarelos e azuis) representam as famílias. Os polos atratores são representados por círculos. A figura 33 permite a melhor visualização da localização dos polos atratores . 


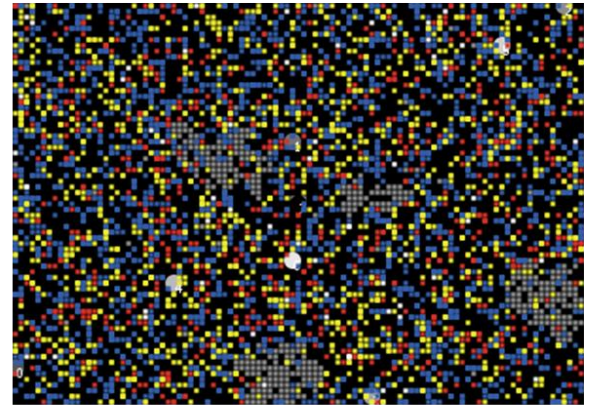

a)

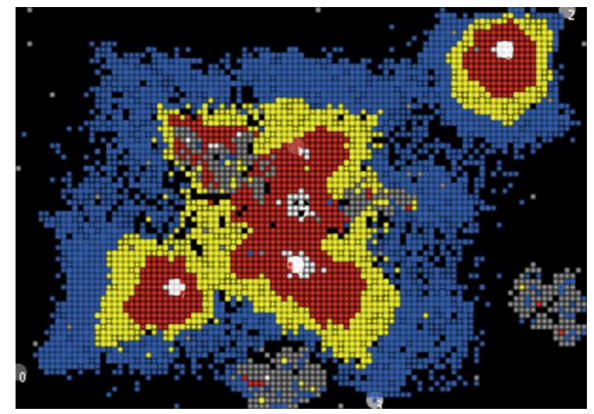

c)

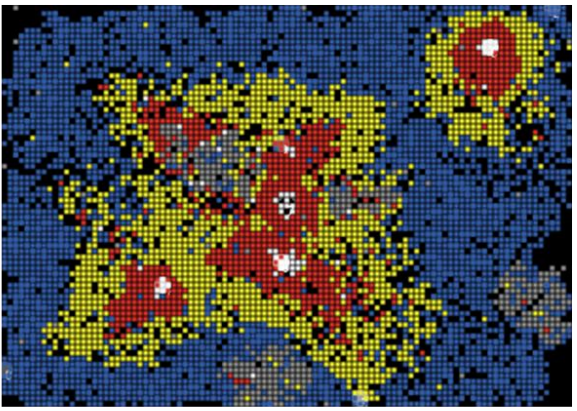

b)

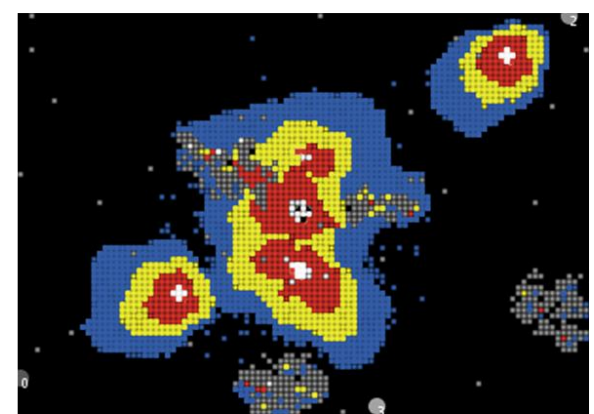

d)

Figura 32 - exemplo de evolução do processo de auto-organização da cidade fonte: autor

A auto-organização da cidade leva ao aumento da densidade populacional até o limite máximo, limitado pela taxa de ocupação do solo. O aumento da densidade leva a intensificação das ilhas de calor (SU; GU; YANG, 2010). A evolução das ilhas de calor é apresentada nas figuras $33 \mathrm{a}, \mathrm{b}, \mathrm{c}$ e $\mathrm{d}$. A temperatura de cada célula é calculada tomando como base sua posição relativa na cidade, sua densidade, o gabarito de altura das edificações ao seu redor e a densidade da vizinhança no raio de 300m de distância (CHENG et al., 2015).

A Fig. 34 apresenta a distribuição das áreas comerciais e industriais (células cinza), polos atratores (círculos brancos) e as áreas verdes para os cenários com 0, 1, 2 e 3 áreas verdes. As áreas verdes são posicionadas com formatos e posições aleatórias, determinados nas condições iniciais do modelo, respeitando 0 estabelecido para cada cenário conforme a tabela 18. 


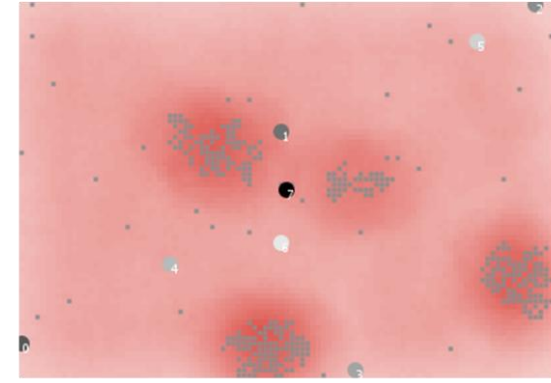

a)

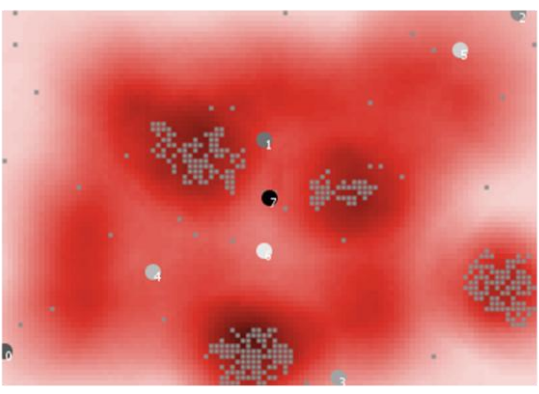

c)

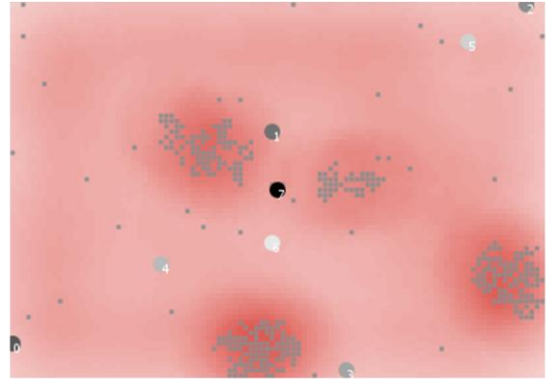

b)

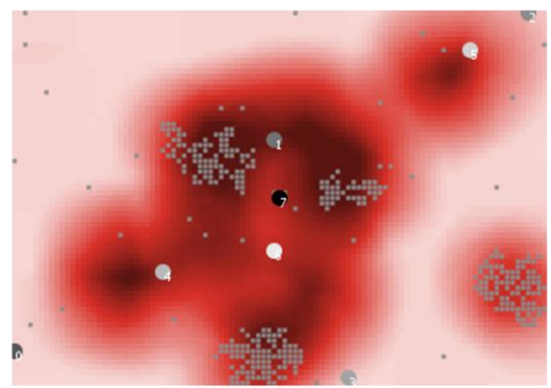

d)

$t+7$ ㅇc

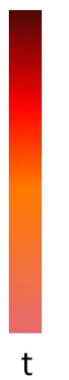

Figura 33 - exemplo da formação das ilhas de calor no decorrer da auto-organização da cidade fonte: autor

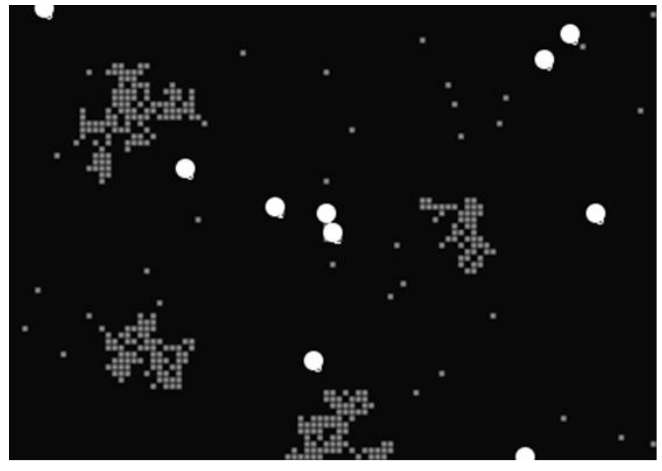

a) 0 green area $\Sigma 0.0 \mathrm{~km}^{2}$

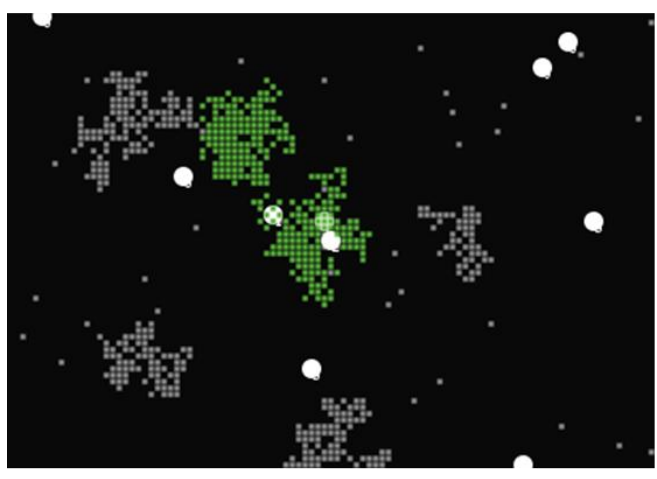

c) 2 green areas $\Sigma 1.0 \mathrm{~km}^{2}$

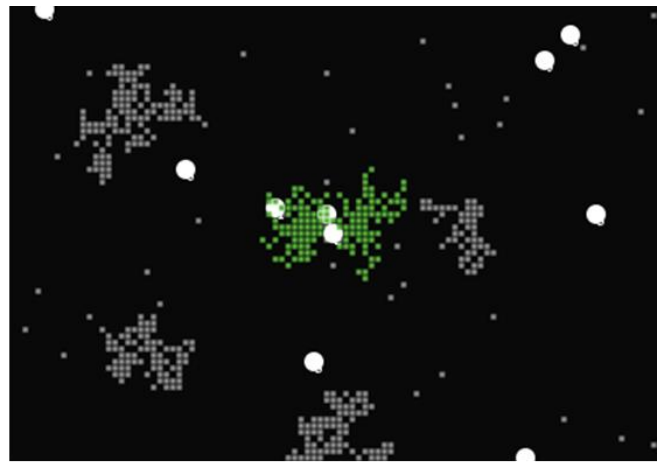

b) 1 green area

$$
\Sigma 0.5 \mathrm{~km}^{2}
$$

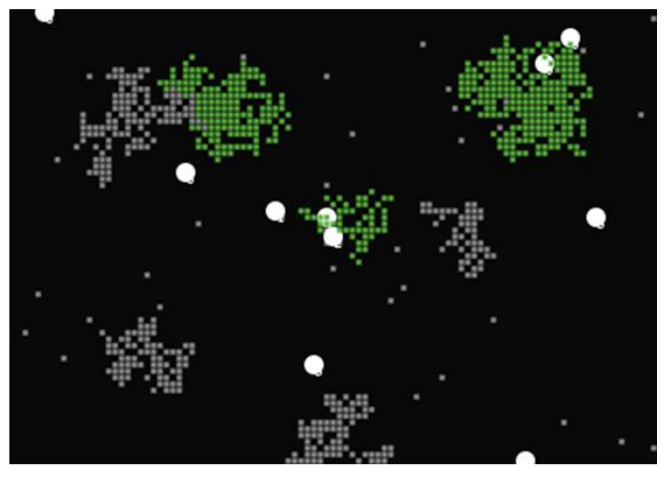

d) 3 green areas $\Sigma 1.5 \mathrm{~km}^{2}$

Figura 34 - Exemplo de posicionamento das áreas verdes nas cidades simuladas para o cenário 1 (pontos verdes no mapa) e as respectivas áreas.

fonte: autor 


\subsection{CONSUMO DE ENERGIA}

O menor valor diário per capita de energia direta consumida nas 64 simulações realizadas neste trabalho foi de 14,28 MJ por dia, por pessoa (cenário 1, taxa de ocupação é 4 e 3 áreas verdes), e o maior valor encontrado foi de 18,92 MJ por dia, por pessoa (cenário 3, taxa de ocupação é 1 e 3 áreas verdes). A diferença, em termos percentuais, entre os valores encontrados está em tono de $30 \%$.

Considerando a cidade como um sistema complexo (LIU; SWEENEY, 2012), o seu comportamento segue a lei da escala, onde, mantendo-se a proporção entre os agentes envolvidos é possível alterar o "tamanho" do sistema (PENNA; OLIVEIRA, 2008), portanto, alterando-se a quantidade de famílias e, proporcionalmente, ajustando o tamanho da população, dos polos atratores, dos vínculos e demais condições iniciais, é esperado que todos os resultados finais apresentem valores similares (consumo per capita). Contudo é necessário considerar que as condições de posicionamento das partes integrantes dos cenários também afetam os resultados finais obtidos. E nesse caso, a aleatoriedade na distribuição dos agentes afeta o resultado final.

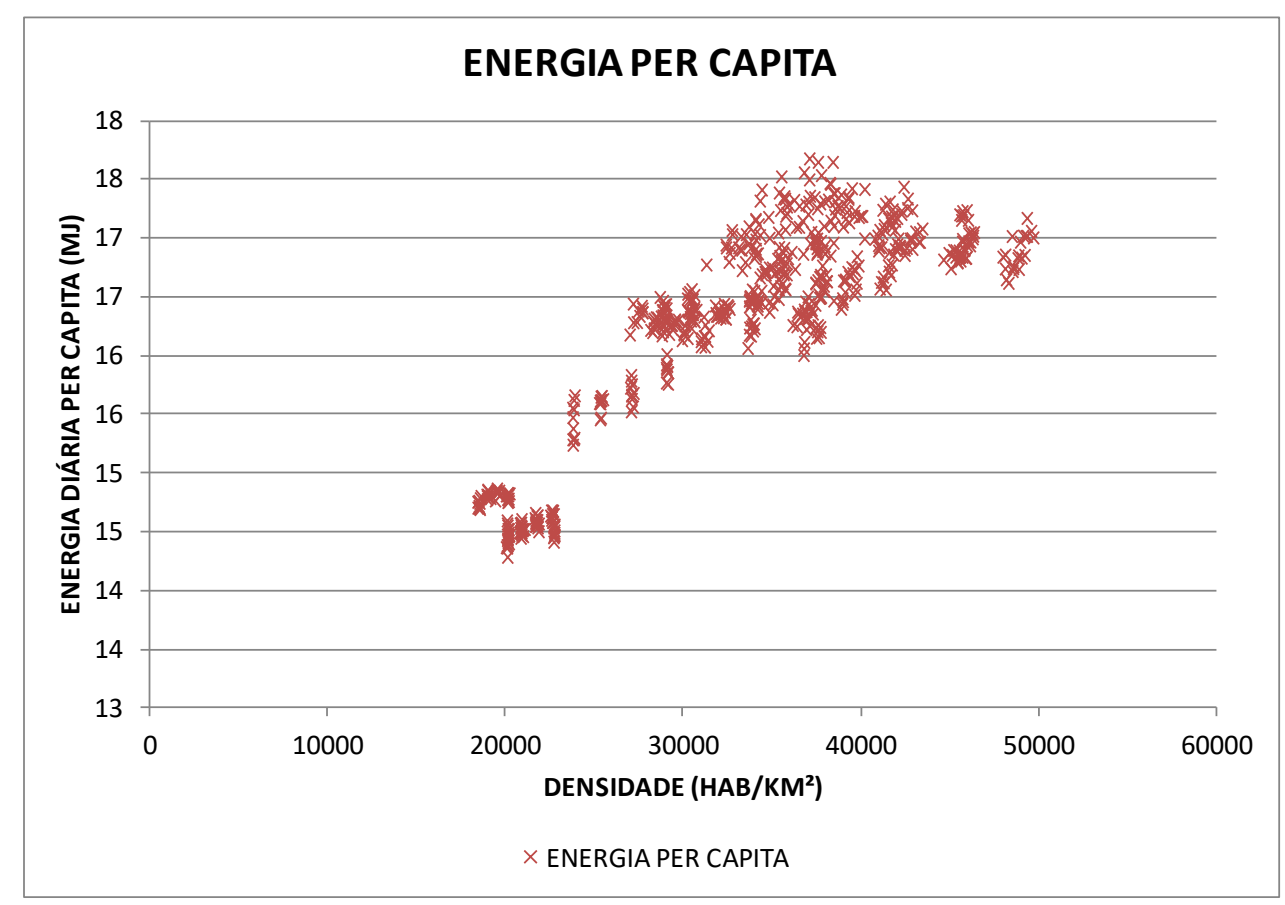

Figura 35 - Consumo diário de energia per capita em função da densidade da cidade fonte: autor

A figura 36 apresenta o consumo diário de energia per capita por serviço energético. As observações principais devem estar ligadas ao consumo de energia para 
mobilidade, que é decrescente $(49,5 \%)$ na medida em que a densidade aumenta (62\%), enquanto que o consumo de energia para os "serviços auxiliares" é crescente $(463,5 \%)$.

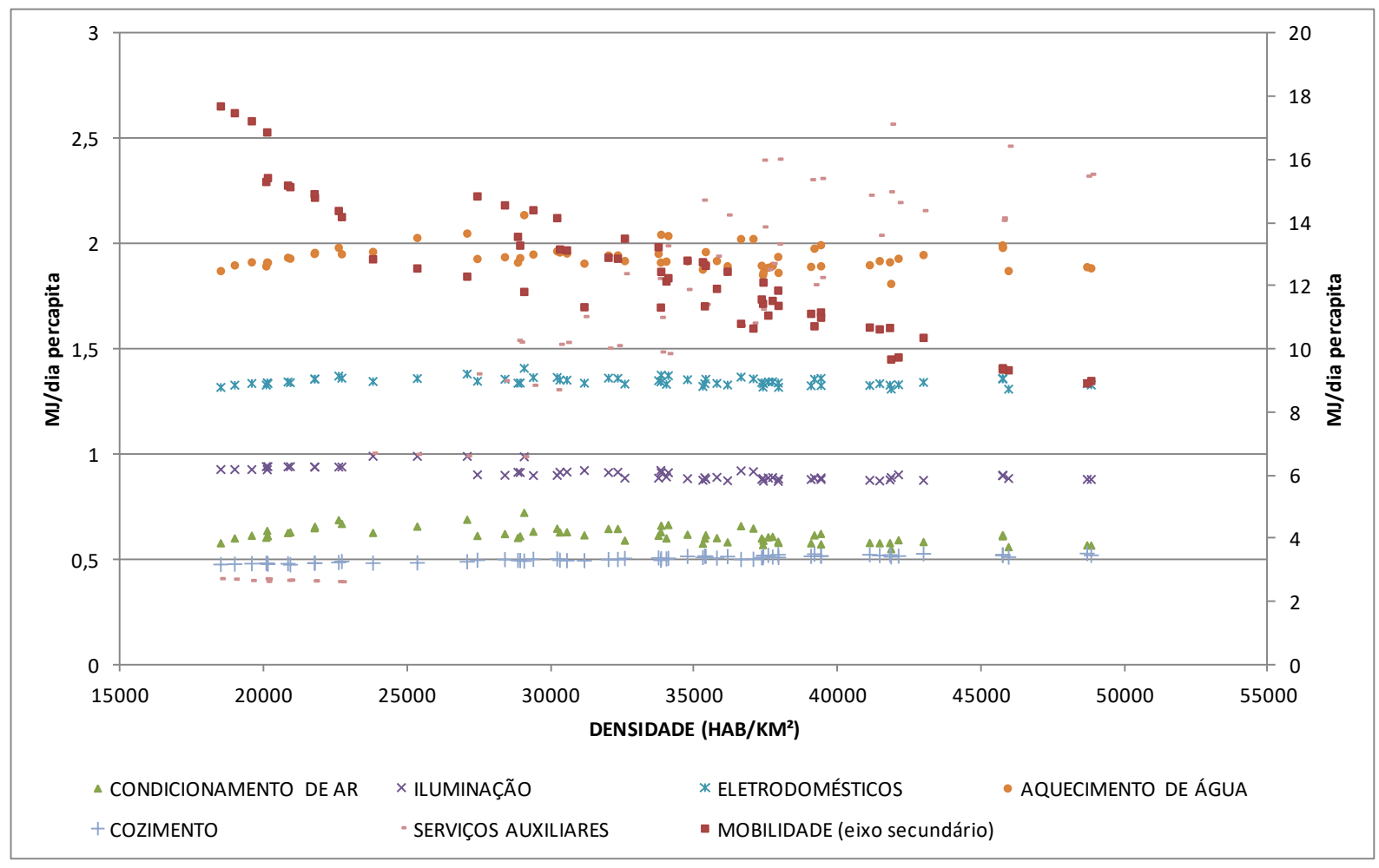

Figura 36 - Consumo energético diário per capita (MJ) por serviço energético.

fonte: autor

\subsubsection{Efeito da taxa de ocupação do solo no consumo energético}

A figura 37 apresenta os valores médios obtidos para as 160 simulações realizadas para o cenário 1 . O consumo direto final de energia per capita aumenta com o aumento da taxa de ocupação do solo, responsável pelo aumento da densidade populacional. Condição semelhante ocorre com os cenários 2, 3 e 4, onde os resultados estão expressos nas figuras 38 (variação máxima 14,5\%), 39 (variação máxima 13,7\%) e 40 (variação máxima 17,2\%), respectivamente, porém, observa-se maior amplitude nos resultados para cada taxa de ocupação adotada. 


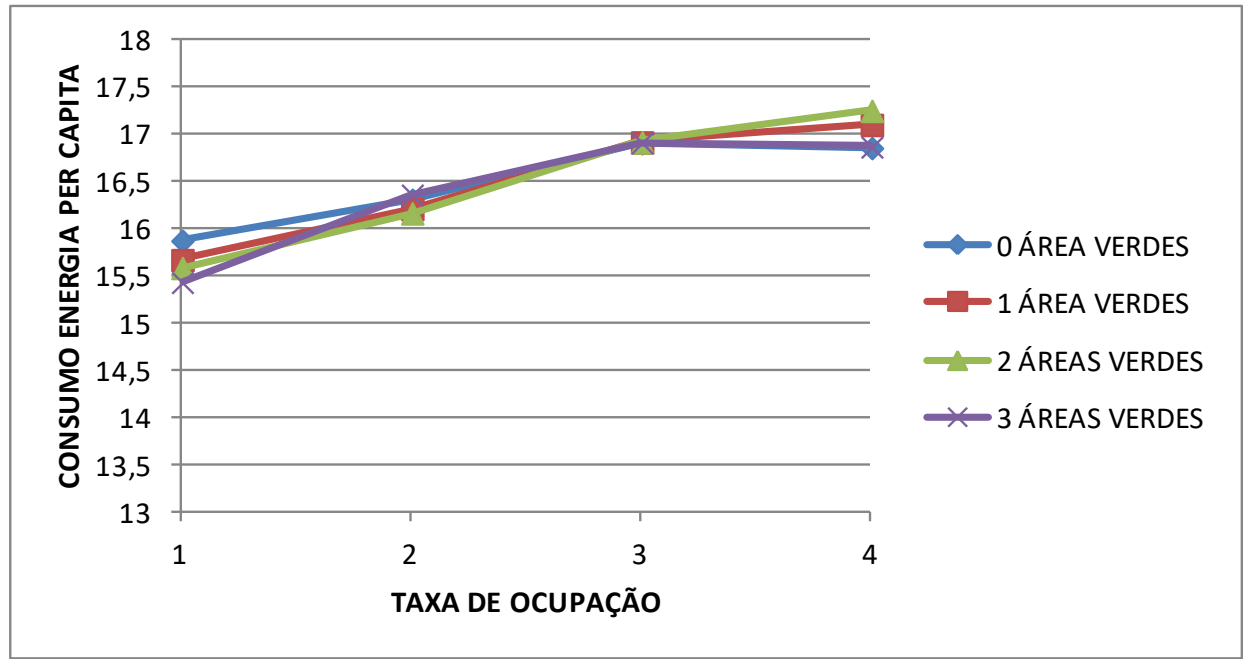

Figura 37 - Média do consumo diário per capita de energia (MJ) para o cenário 1. fonte: autor

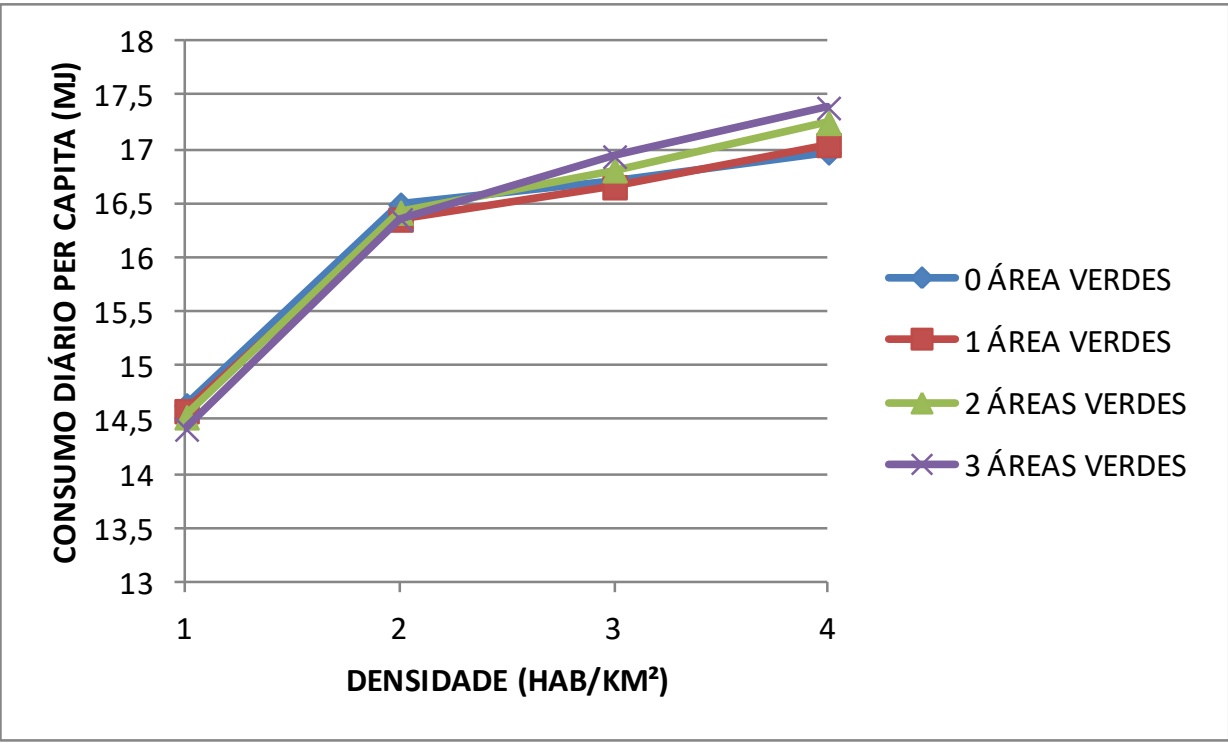

Figura 38 - Média do consumo diário per capita de energia (MJ) para o cenário 2.

fonte: autor 


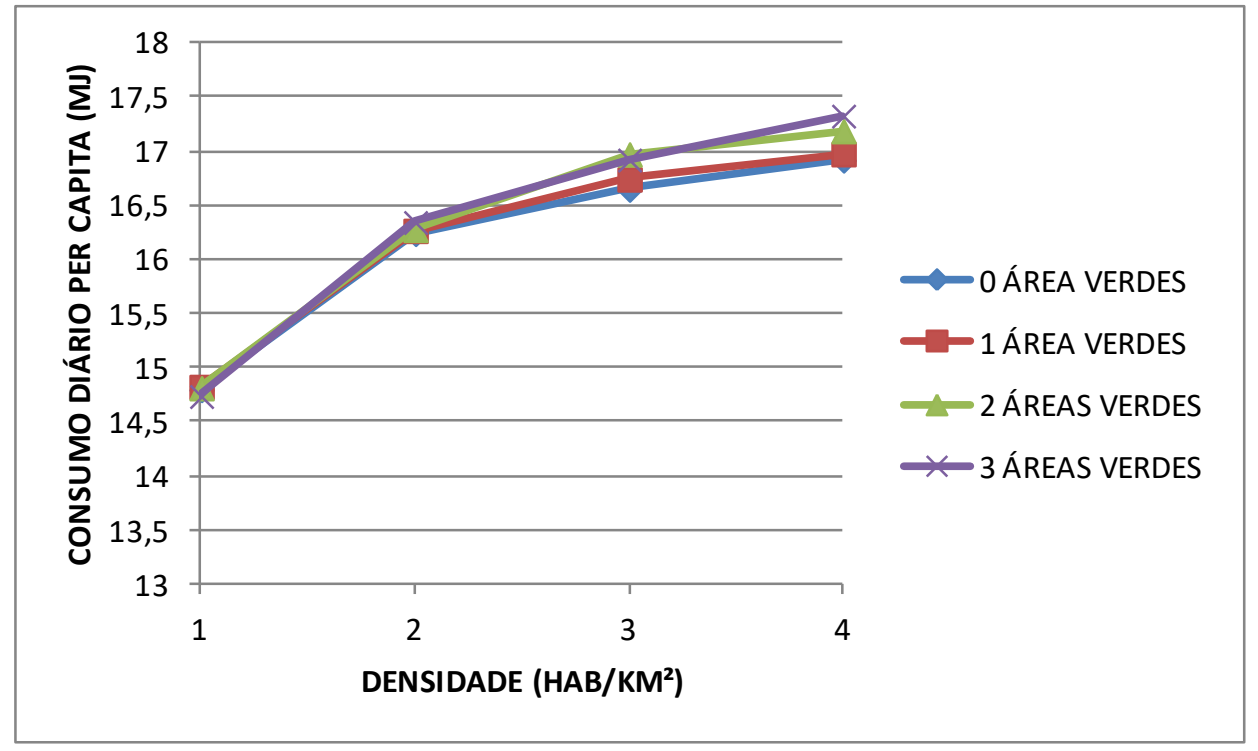

Figura 39 - Média do consumo diário per capita de energia (MJ) para o cenário 3. fonte: autor

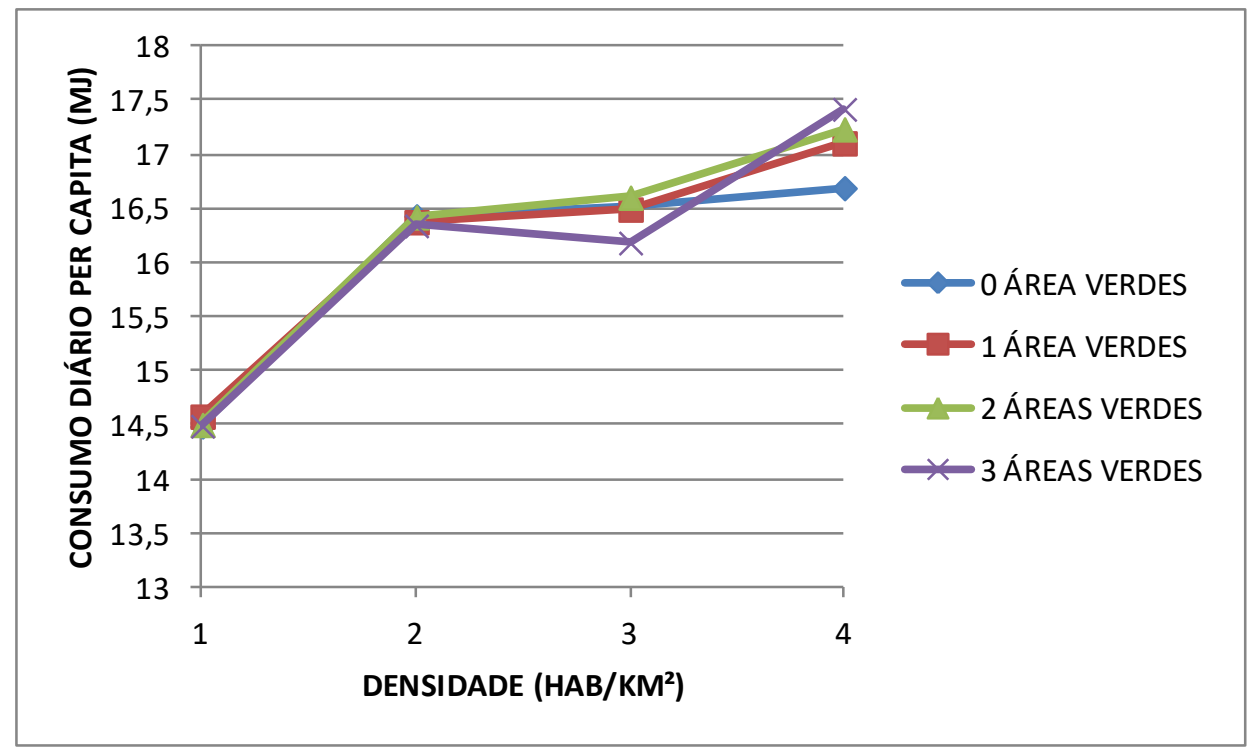

Figura 40 - Média do consumo diário per capita de energia (MJ) para o cenário 4. fonte: autor

\subsubsection{Efeito das áreas verdes na demanda energética}

A inserção de áreas verdes nas cidades simuladas afeta pouco o consumo per capita de energia.

Para o cenário 1, apresentado na figura 41, quando a taxa de ocupação é ajustada para um (1) a inserção das áreas verdes provoca a diminuição do consumo per capita de energia na ordem de 2,79 \%. Para a taxa de ocupação ajustada em 2 (média densidade) a inserção de 1 e 2 áreas verdes provoca a redução do consumo, 
porém a inserção de 3 áreas verdes eleva o consumo per capita acima das demais condições analisadas para T.O = 2. Para a taxa de ocupação ajustada em três, a presença das áreas verdes se apresenta insignificante, pois não altera o consumo per capita de energia. Finalmente, quando a taxa de ocupação é ajustada em "4", representando a cidade com grande densidade, o efeito, no cenário 1, é de elevação do consumo per capita para 1 e 2 áreas verdes, enquanto que a inserção de 3 áreas verdes diminui significativamente o consumo energético (2,23\%), provavelmente pelo efeito conjunto do arrefecimento, oferecido pelas áreas verdes e pela diminuição das distâncias a serem percorridas na cidade, proveniente do adensamento populacional.

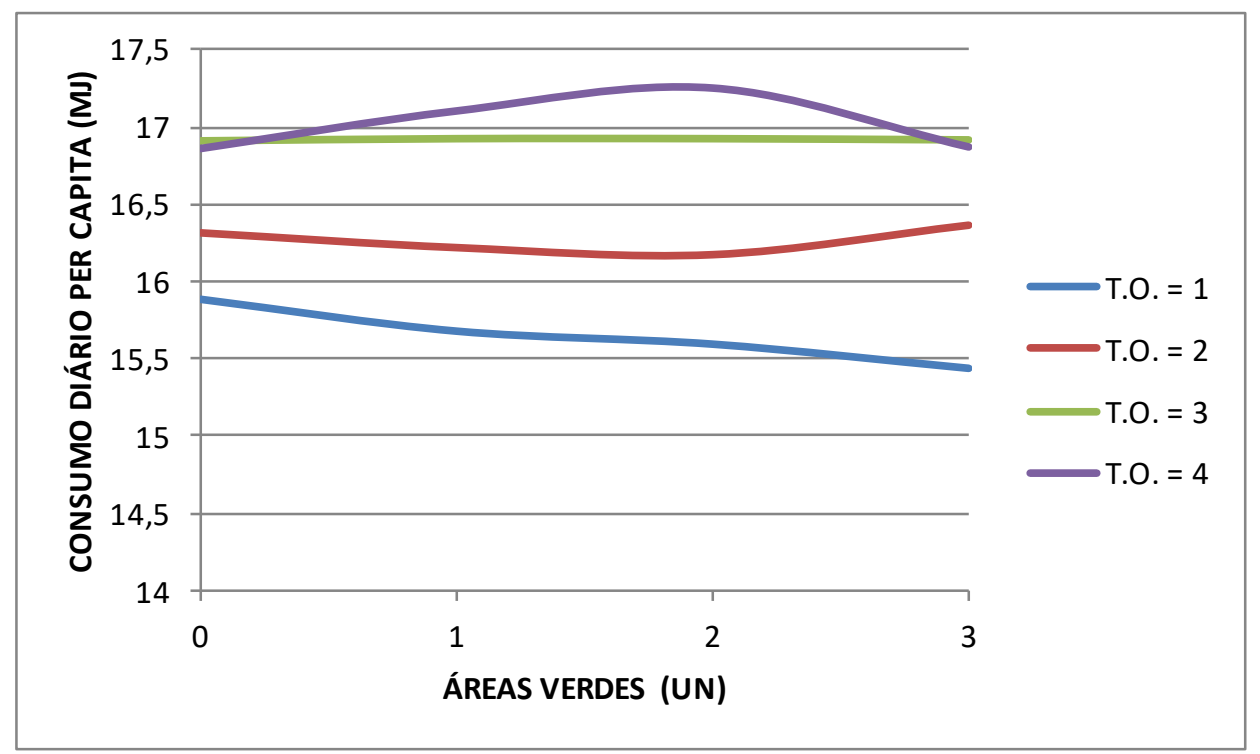

Figura 41 - Média do consumo diário per capita de energia (MJ) em função das áreas verdes para o cenário 1. fonte: autor

Para o cenário 2, representado na figura 42, quando a taxa de ocupação é ajustada em 1 e 2 a inserção das áreas verdes apresenta tendência de queda no consumo energético (1,5\%), enquanto que o ajuste para as taxas de ocupação 3 e 4, que representam as cidades com maiores densidades, a inserção das áreas verde aumenta o consumo de energia (2,3\%). 


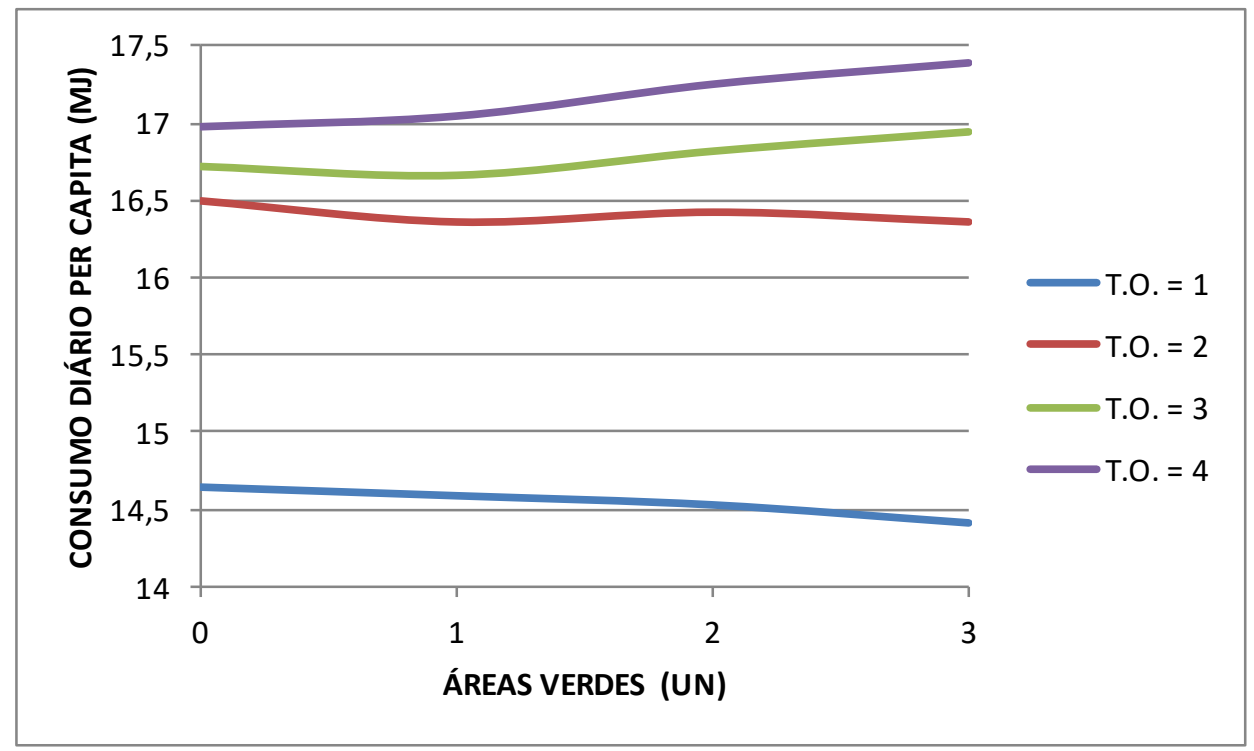

Figura 42 - Média do consumo diário per capita de energia (MJ) em função das áreas verdes para o cenário 2. fonte: autor

A figura 43 representa o comportamento médio do consumo per capita de energia para as cidades simuladas no cenário 3. Somente para as cidades com baixa densidade (taxa de ocupação ajustada em "1") a inserção das áreas verdes diminui o consumo de energia (0,6\%). Para as demais condições (T. O. ajustada em 2, 3 ou 4) a inserção das áreas verdes elevam o consumo per capita. Nas mais altas densidades a elevação do consumo com a inserção de 3 áreas verdes, quando comparadas as cidades sem áreas verdes, está na ordem de 2,37\%.

No cenário 4, com resultados apresentados na figura 44, onde a quantidade de polos atratores é o igual ao cenário 1 (460 polos atratores) e a quantidade de famílias e a resolução do mapa são iguais ao cenário 2 (8000 famílias e 11,4m/célula) nas cidades com baixa e baixa-média densidades (T.O. 1 e 2) a inserção das áreas verdes apresentou-se sem efeito, pois a variação no consumo de energia foi baixo, sendo $0,62 \%$ e $0,54 \%$, respectivamente. Para a taxa de ocupação ajustada em 3, o comportamento do consumo de energia cai abruptamente quando são inseridas 3 áreas verdes (queda de 2,52\%). Para as cidades altamente adensadas (T.O. = 4) o consumo se eleva na medida em que as áreas verdes são inseridas (com exceção do cenário 1, com 3 áreas verdes e densidade máxima - fig. 41), apresentando a maior elevação entre todos os resultados $(4,18 \%$ quando comparado com a T. O =1). 


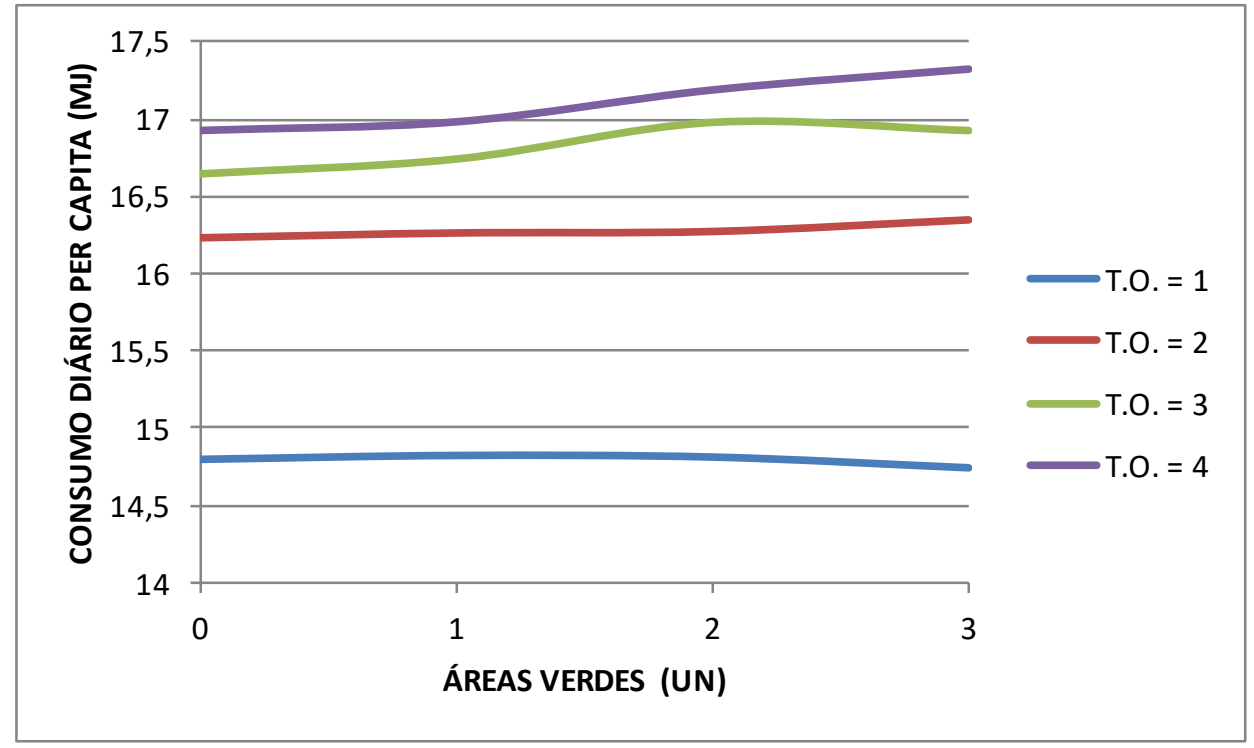

Figura 43 - Média do consumo diário per capita de energia (MJ) em função das áreas verdes para o cenário 3. fonte: autor

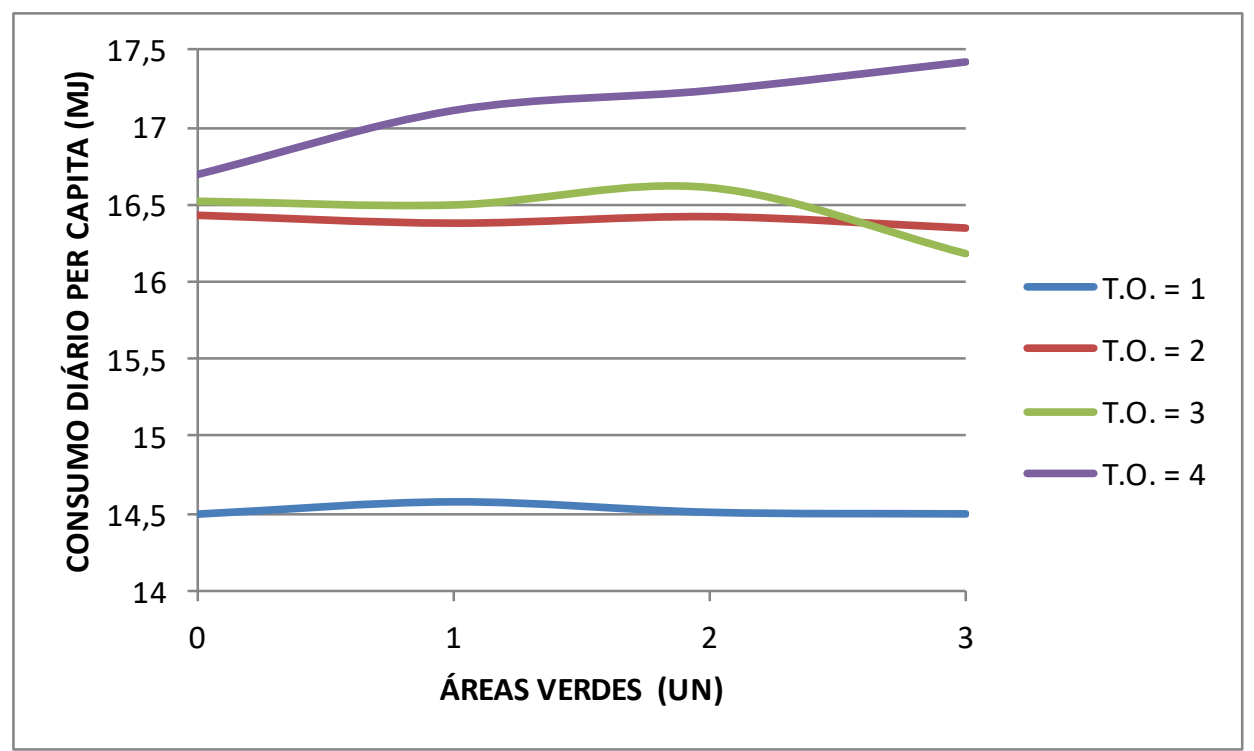

Figura 44 - Média do consumo diário per capita de energia (MJ) em função das áreas verdes para o cenário 4. fonte: autor

\subsubsection{Efeito dos polos atratores na demanda energética}

A posição e a quantidade de polos atratores alteram o metabolismo urbano (DILLON; SAPHORES; BOARNET, 2015), especialmente no que se refere às distâncias a serem percorridas, devido à estratégia das famílias em habitar no ponto mais próximo dos polos atratores com os quais possuem vínculos. A figura 45 compara o cenário 2 e 4, onde há variação apenas da quantidade de polos atratores (ver tabela 18). Para as cidades de baixa densidade (T.O. = 1 ou 2) a variação da 
quantidade de polos atratores proposta no modelo não se apresentou significativa, obtendo 1,01\% como maior valor, porém em algumas condições, verificou-se aumento de $0,36 \%$ no consumo. Contudo na medida em que a densidade aumenta, a correlação entre consumo de energia e a quantidade de polos atratores passa a ser negativa, ou seja, aumentando-se a quantidade de polos atratores, o consumo de energia tende a diminuir. A maior diminuição foi apresentada na taxa de ocupação 3 com 3 áreas verdes, onde se verificou queda de 4,44 \% no consumo. A única condição de aumento do consumo de energia foi de $0,19 \%$ para as cidades com maiores densidades.

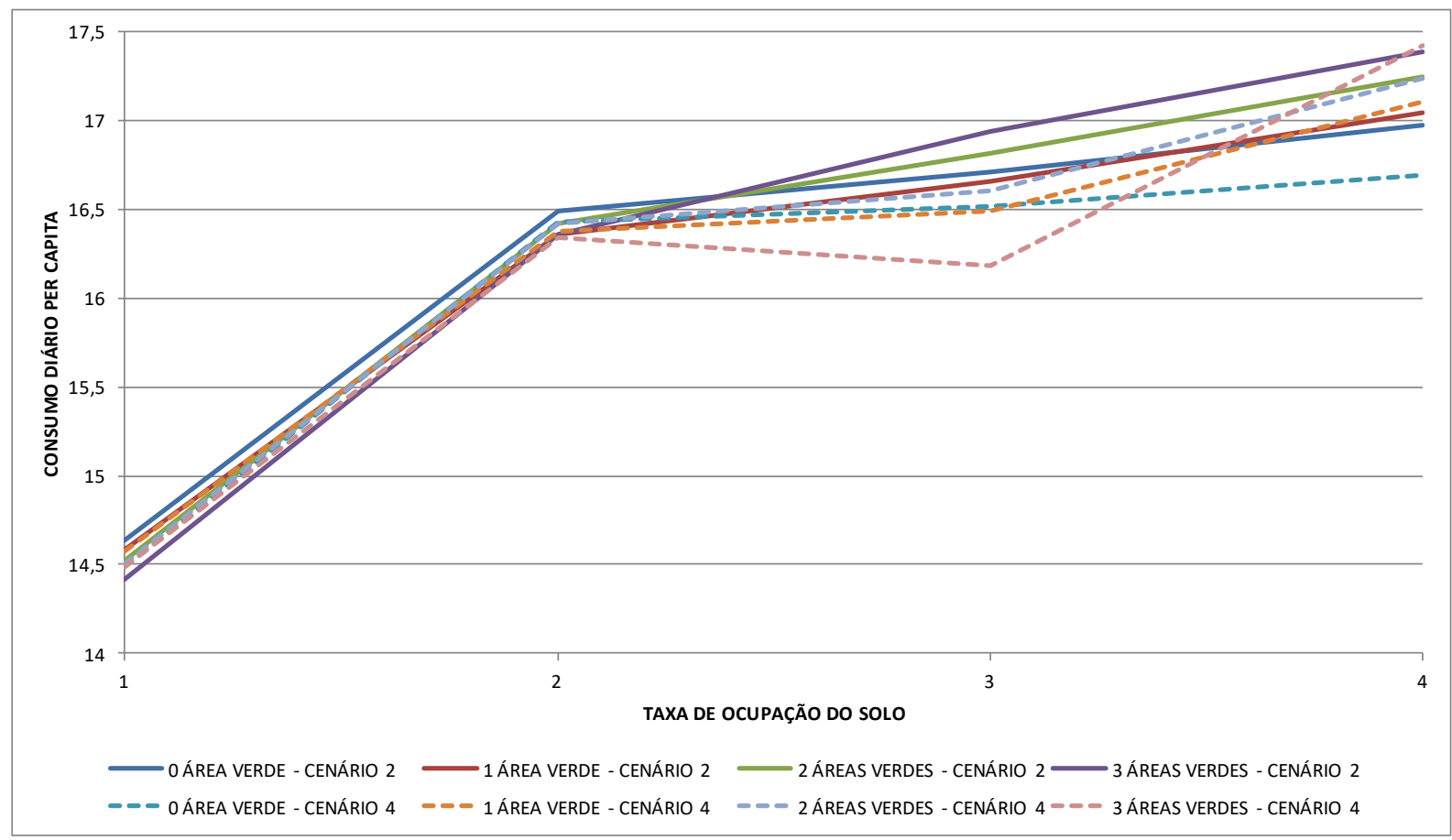

Figura 45 - Média do consumo diário per capita de energia para os cenários 2 e 4, em função da taxa de ocupação do solo.

fonte: autor

\subsection{EMISSÕES DE CO2}

O cálculo das emissões de CO2 é decorrente do consumo energético e sua respectiva fonte, considerando a realidade brasileira, conforme fatores de emissão apresentados na tabela 13. As cidades simuladas no MBA seguem as relações e arranjos estabelecidos na tabela 18 e os valores obtidos representam as emissões diárias para o melhor arranjo possível dada as premissas do MBA proposto neste trabalho. 
Dentre os valores médios dos 64 arranjos de cidades simuladas o valor máximo estimado para as emissões de $\mathrm{CO} 2$ foi de $1,54 \mathrm{gCO} 2$ per capita para o cenário 3 , com taxa de ocupação ajustado em 1 e a inserção de 3 áreas verdes, enquanto o menor valor estimado foi de 1,1043 gCO2 per capita para o cenário 1 , taxa de ocupação 4 e 3 áreas verdes. A diferença de valores corresponde a diminuição de $28 \%$ nas emissões.

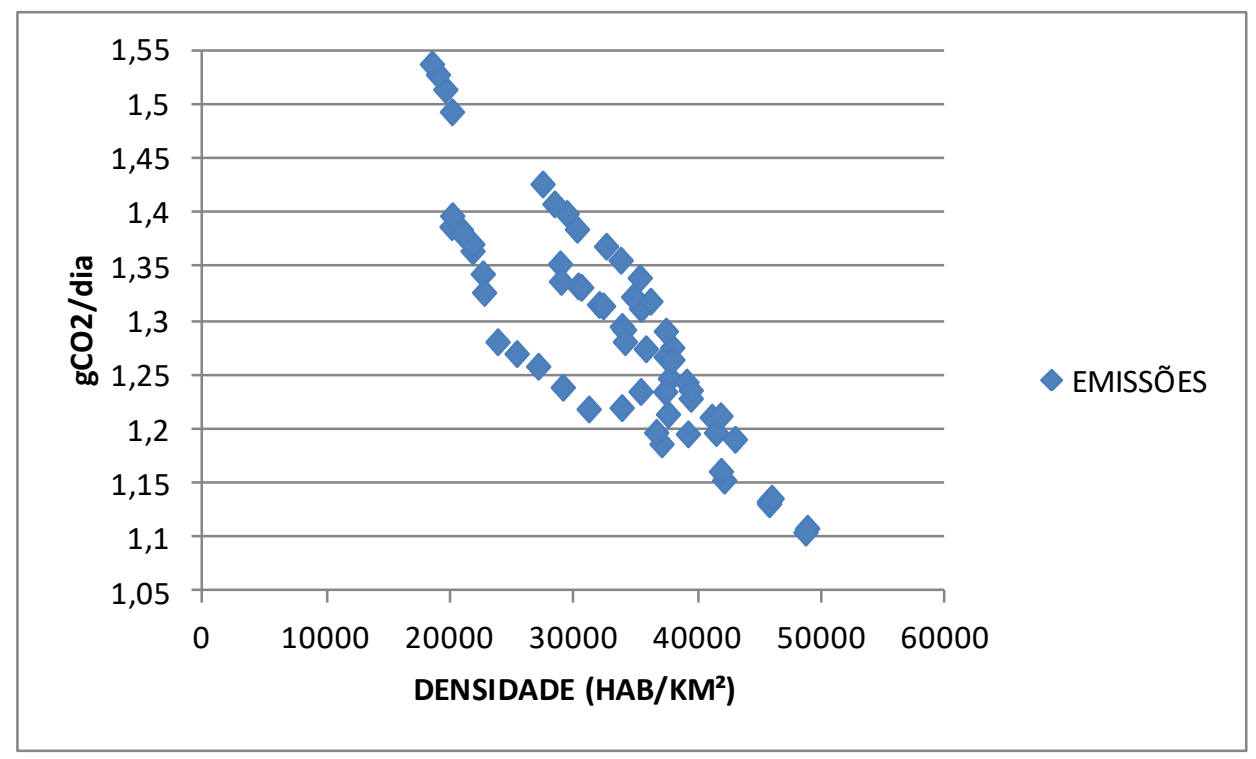

Figura 46 - Emissão diária per capita de $\mathrm{CO}_{2}$ em função da densidade da cidade.

fonte: autor

A figura 47 apresenta os valores médios estimados, para cada um dos 64 ajustes simulados (tabela 18) separados por usos finais energéticos. As emissões variam conforme a densidade populacional, contudo também são sensíveis aos fatores resultantes do adensamento populacional, como a formação das ilhas de calor, a alteração nas distâncias percorridas, o tempo gasto no deslocamento, a circulação de ar e de luz no interior da cidade e a necessidade de deslocamentos verticais. Estas influências são exploradas pontualmente neste trabalho.

Para estudo das interferências das características das cidades nas emissões de CO2 a partir do consumo direto de energia, serão apresentados os resultados direcionados a variação da taxa de ocupação do solo, da inserção de áreas verdes e da oferta dos polos atratores. 


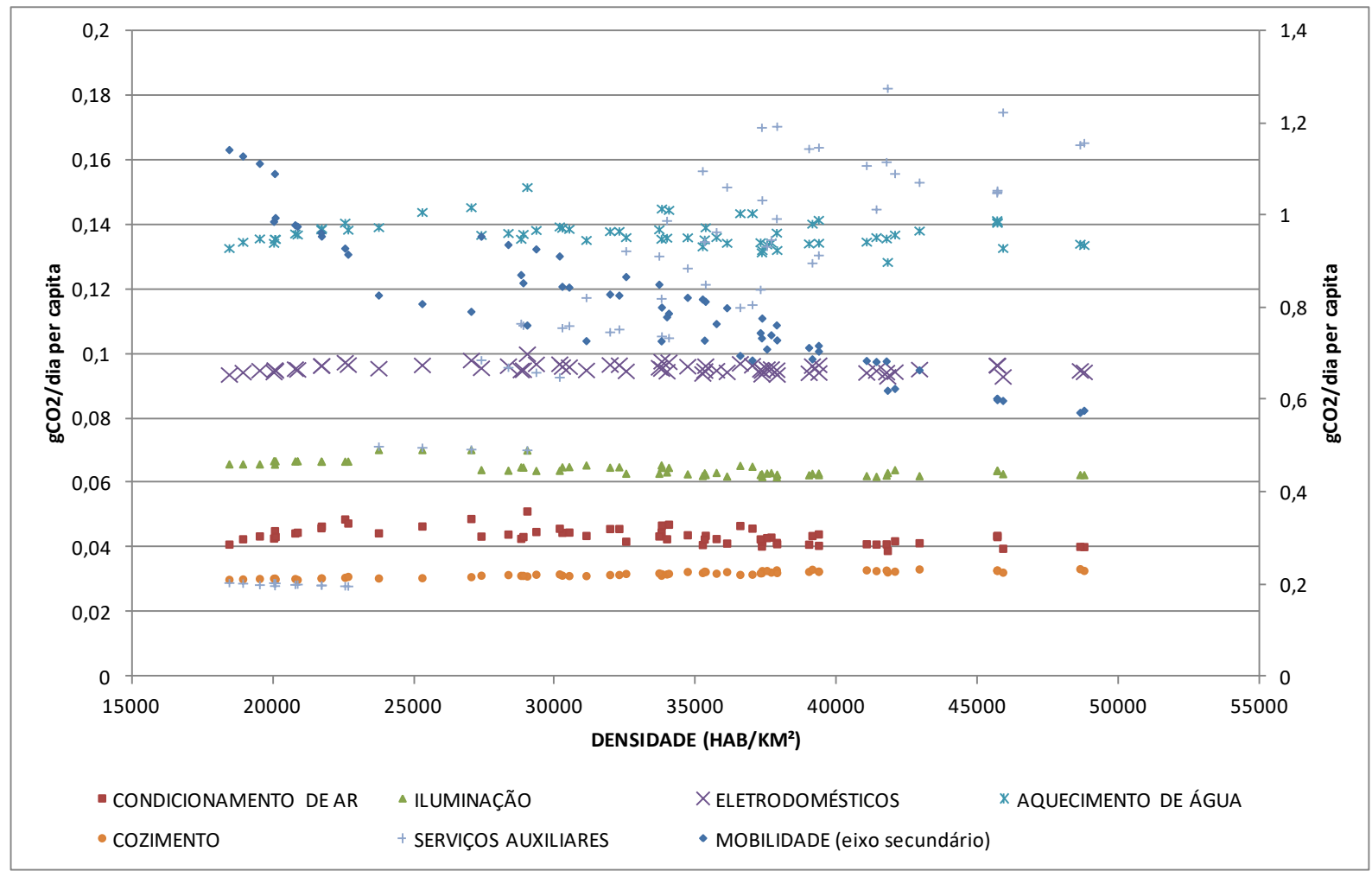

Figura 47 - Emissões diárias per capita de $\mathrm{CO2}$ (g) por serviço energético. fonte: autor

\subsubsection{Efeito da taxa de ocupação do solo nas emissões de $\mathrm{CO}_{2}$}

A taxa de ocupação do solo é o fator do planejamento urbano que permite o adensamento da cidade, logo, quanto maior o valor da taxa, maior a área construída permitida e, por consequência, maior a densidade local.

A figura 48 apresenta os valores médios estimados de CO2 emitido para as 160 simulações realizadas para o cenário 1 (tabela 18). Para todos os casos (exceção para a taxa de ocupação 4 com 2 áreas verdes), as emissões caem na medida em que a taxa de ocupação do solo aumentam.

A situação de queda se repete para todos as simulações realizadas nos cenários 2 , apresentado na figura 49, cenário 3 - figura 50 - e no cenário 4, conforme figura 51 . 


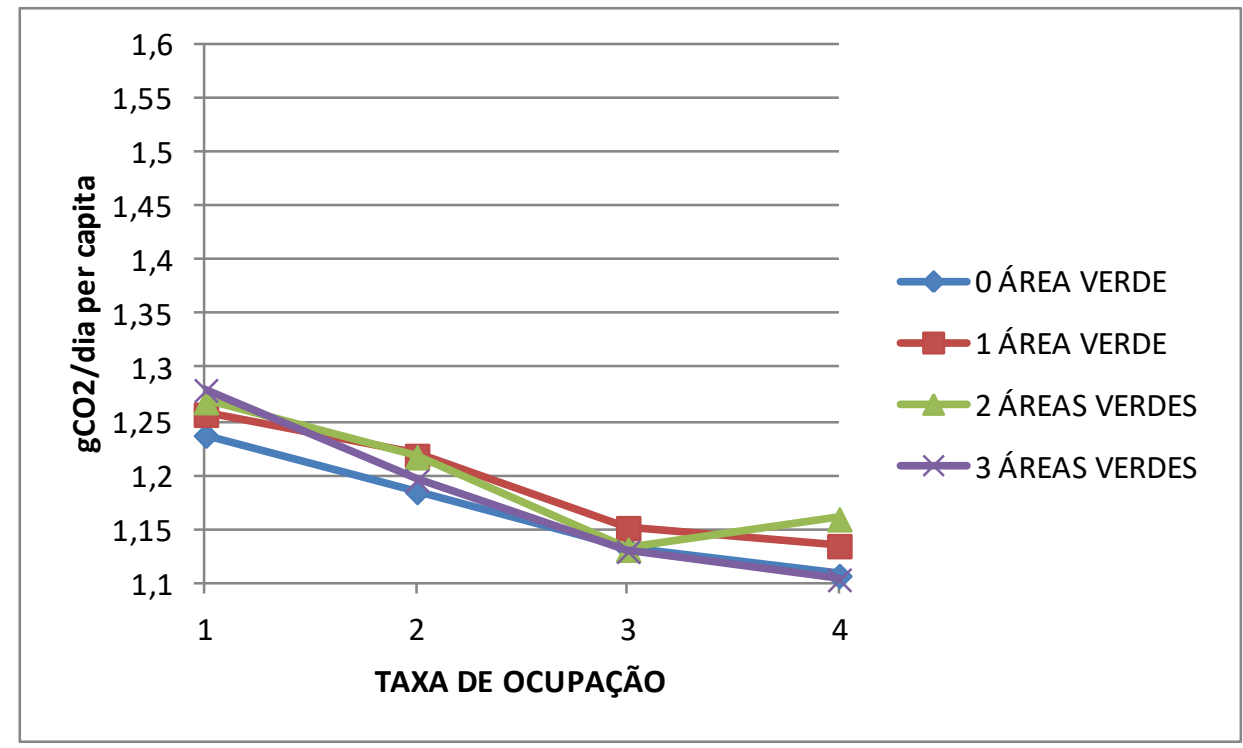

Figura 48 - Média das emissões diárias per capita de $\mathrm{CO}$ (g) em função da taxa de ocupação do solo para o cenário 1. fonte: autor

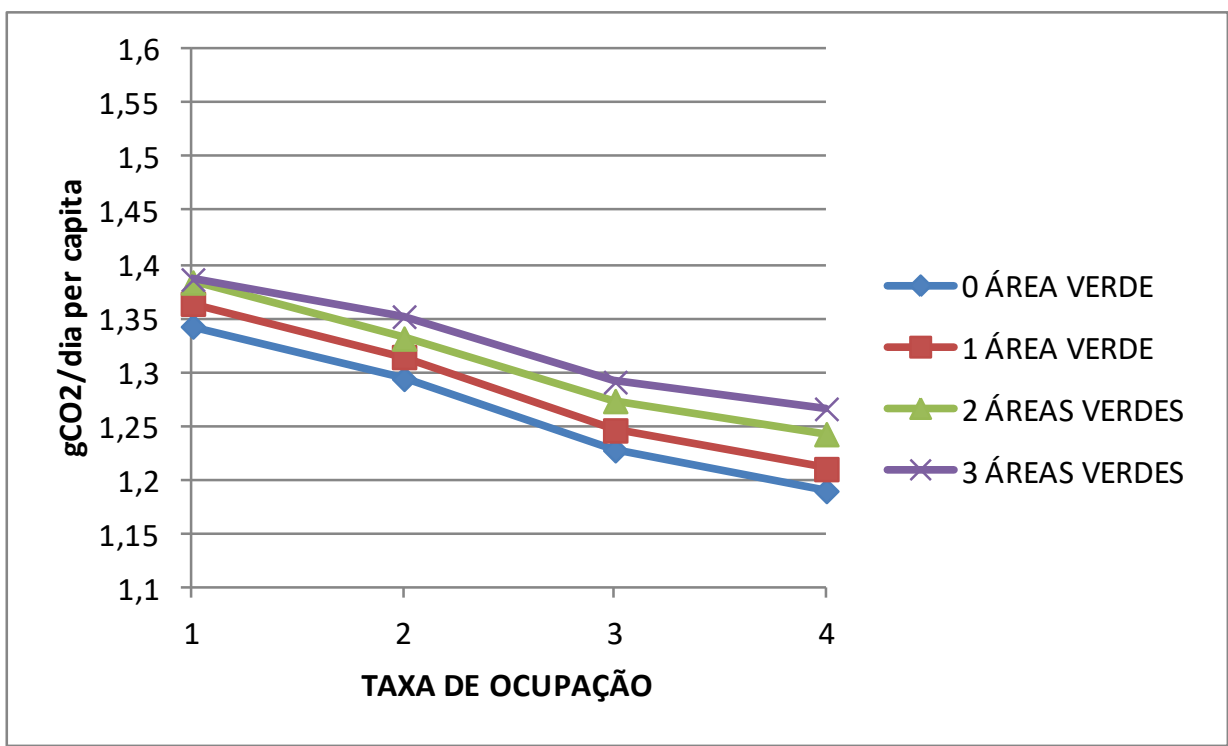

Figura 49 - Média das emissões diárias per capita de $\mathrm{CO}$ (g) em função da taxa de ocupação do solo para o cenário 2. fonte: autor

Para os três cenários (2, 3 e 4) fica evidente na visualização dos gráficos, a hierarquização das áreas verdes. Na medida em que há inserções de áreas verdes, a emissões aumentam, porém cabe ressaltar que o modelo não considera a captura de CO2 pelas áreas verdes inseridas na cidade, contudo já é conhecido que existem muitas variáveis que influenciam na capacidade de captura de carbono pelas áreas verdes, principalmente no que se refere ao tipo de cobertura e espécies utilizadas nas áreas verdes (FUNG; JIM, 2017). Os valores verificados em estudo podem ser superiores a 0,44 gCO2/ano/m² (MARCHI et al., 2015) 


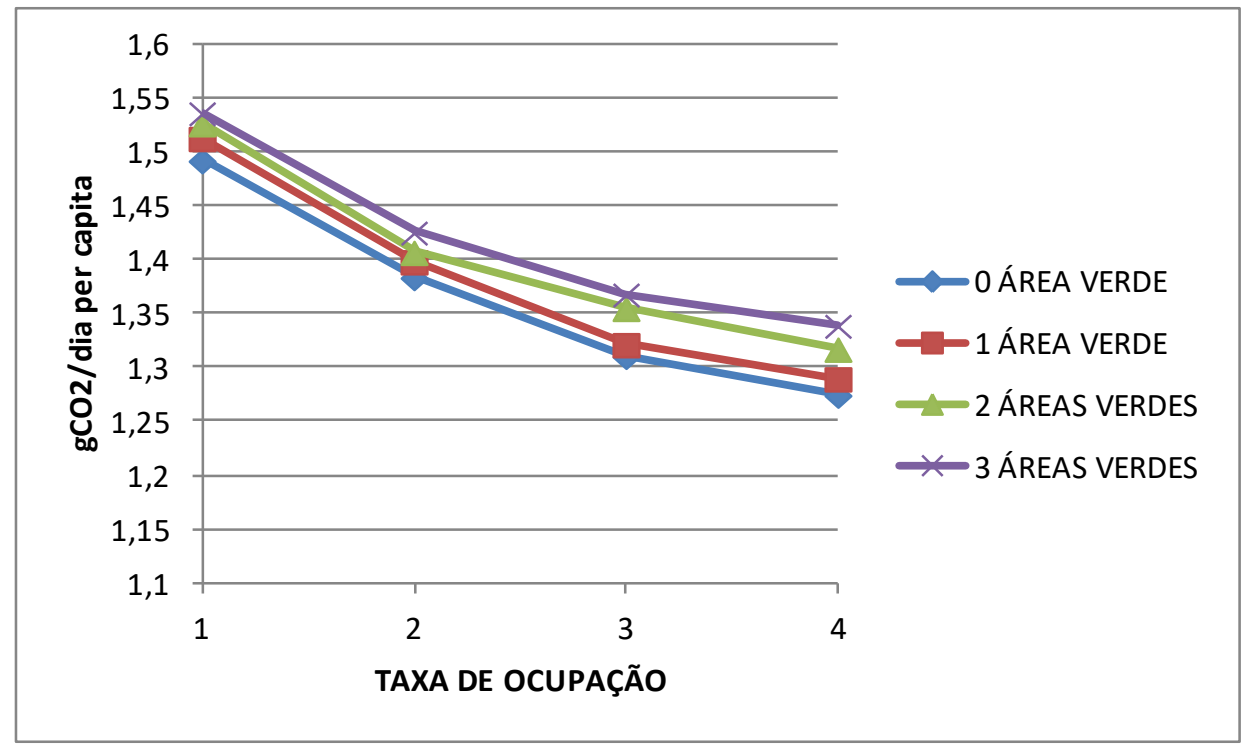

Figura 50 - Média das emissões diárias per capita de $\mathrm{CO}$ (g) em função da taxa de ocupação do solo para o cenário 3. fonte: autor

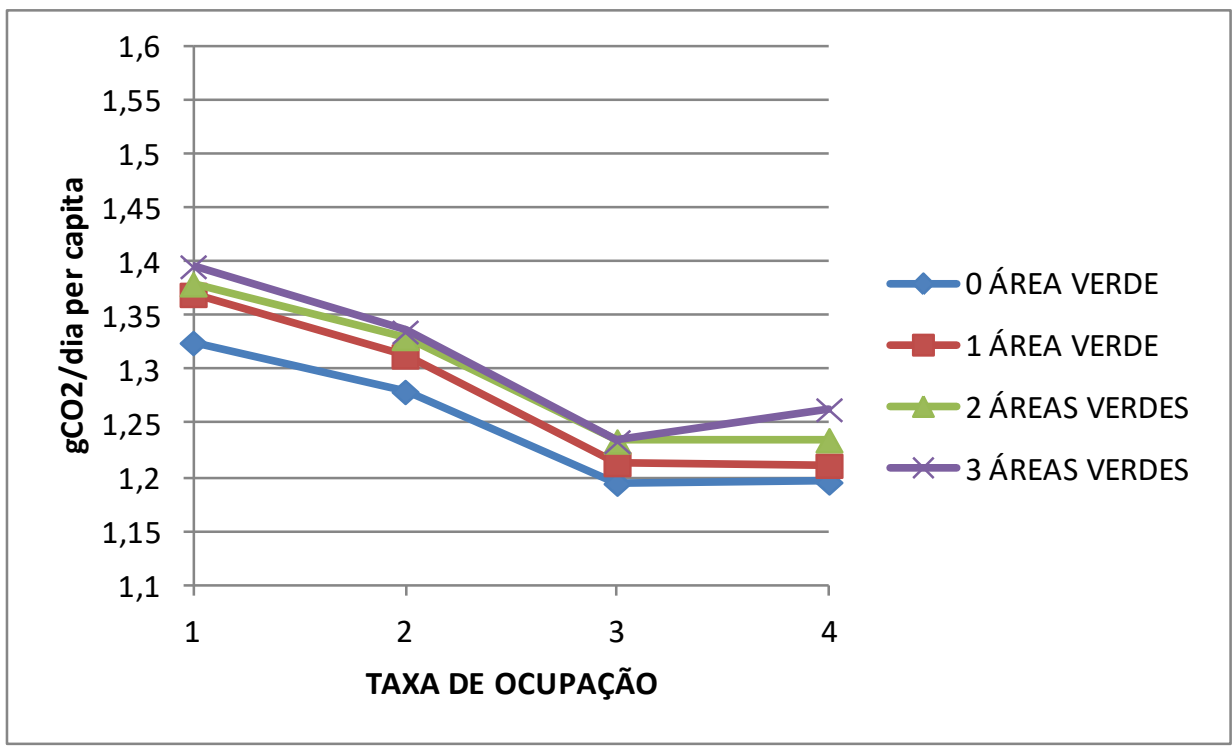

Figura 51 - Média das emissões diárias per capita de $\mathrm{CO}$ (g) em função da taxa de ocupação do solo para o cenário 4. fonte: autor

\subsubsection{Efeito das áreas verdes nas emissões de $\mathrm{CO}_{2}$}

As áreas verdes alteram significativamente o ambiente construído. Sua inserção, considerando a extensão territorial e a quantidade de pontos inseridos alteram 0 metabolismo urbano, o consumo de energia e consequentemente as emissões de CO2.

A figura 52 apresenta os valores médios estimados das 160 simulações realizadas para as cidades do cenário 1 (tabela 18). Para o cenário 1, as emissões aumentam na medida em que as áreas verdes são inseridas, diminuindo apenas para as 
cidades altamente adensadas (alta taxa de ocupação) e com grande quantidade de áreas verdes.

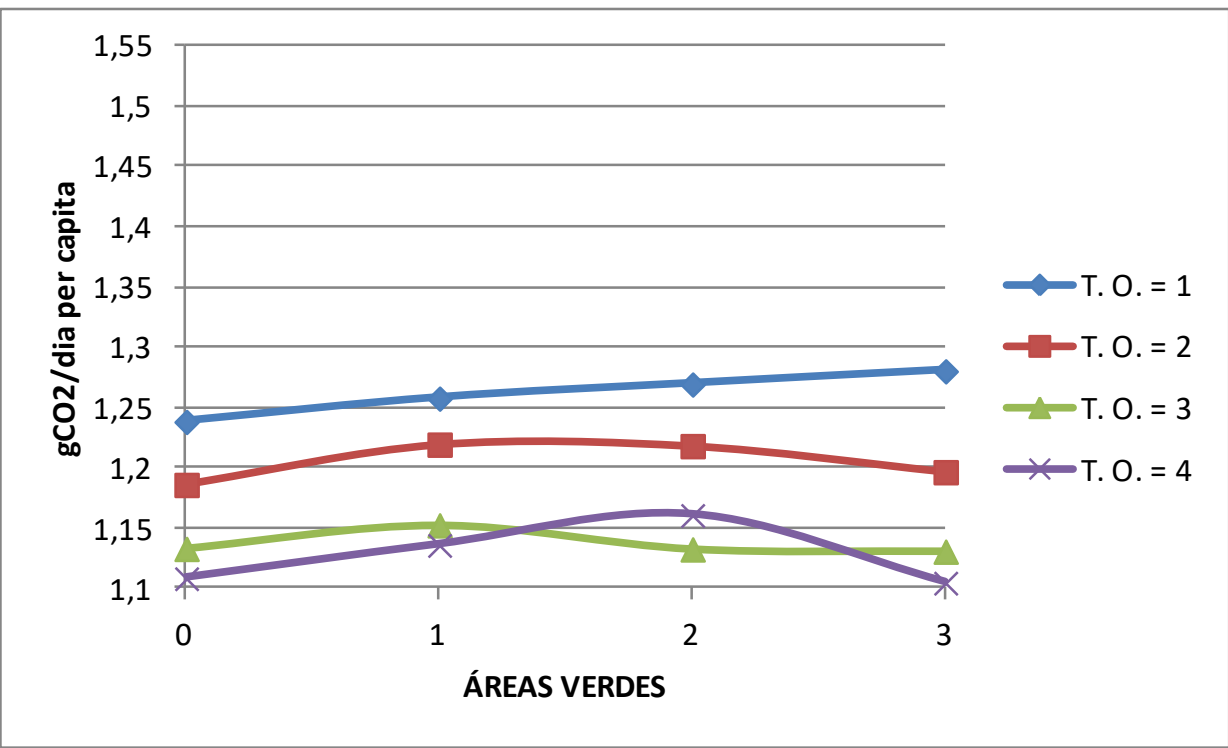

Figura 52 - Média das emissões diárias per capita de $\mathrm{CO2}$ (g) em função das áreas verdes para o cenário 1. fonte: autor

Para o cenário 2 e 3 (figuras 53 e 54 respectivamente) os efeitos da inserção das áreas verdes se assemelham, ficando evidente a hierarquização da taxa de ocupação do solo nas emissões, sendo que, na medida em que a taxa de ocupação aumenta, a cidade torna-se mais densa, contudo as emissões tendem a serem diminuídas.

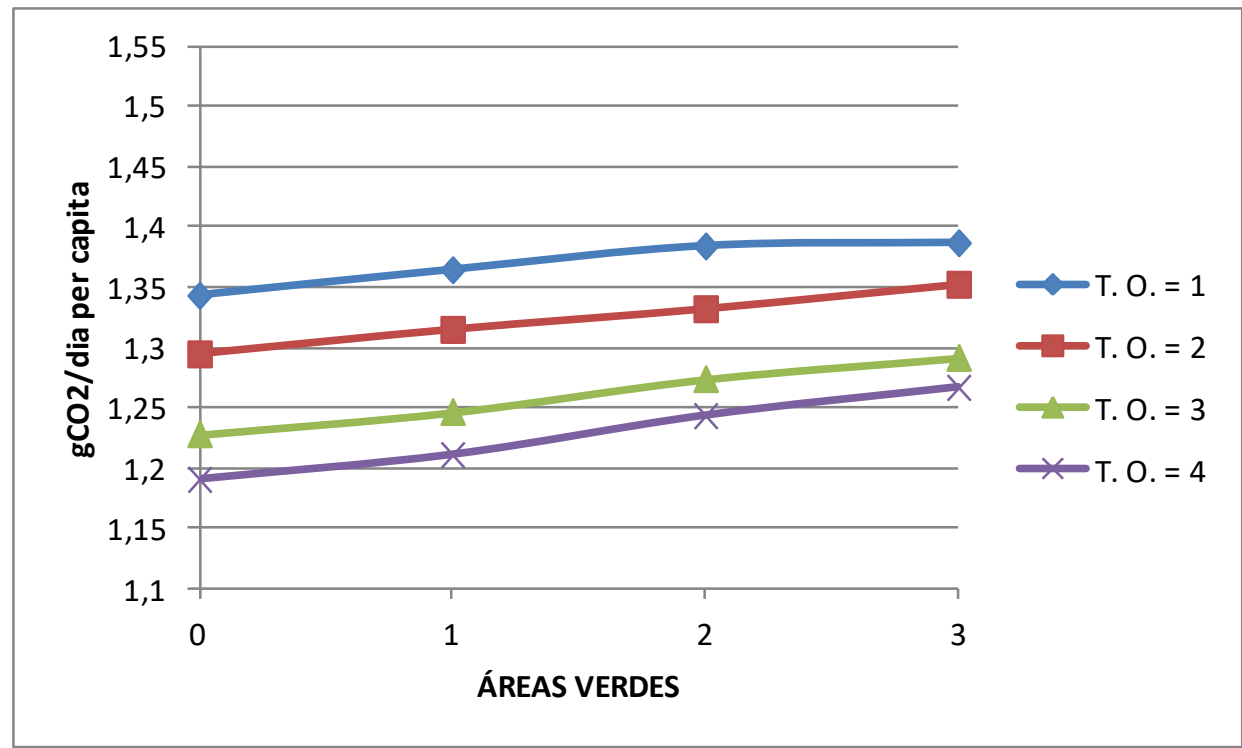

Figura 53 - Média das emissões diárias per capita de $\mathrm{CO2}$ (g) em função das áreas verdes para o cenário 2. fonte: autor 


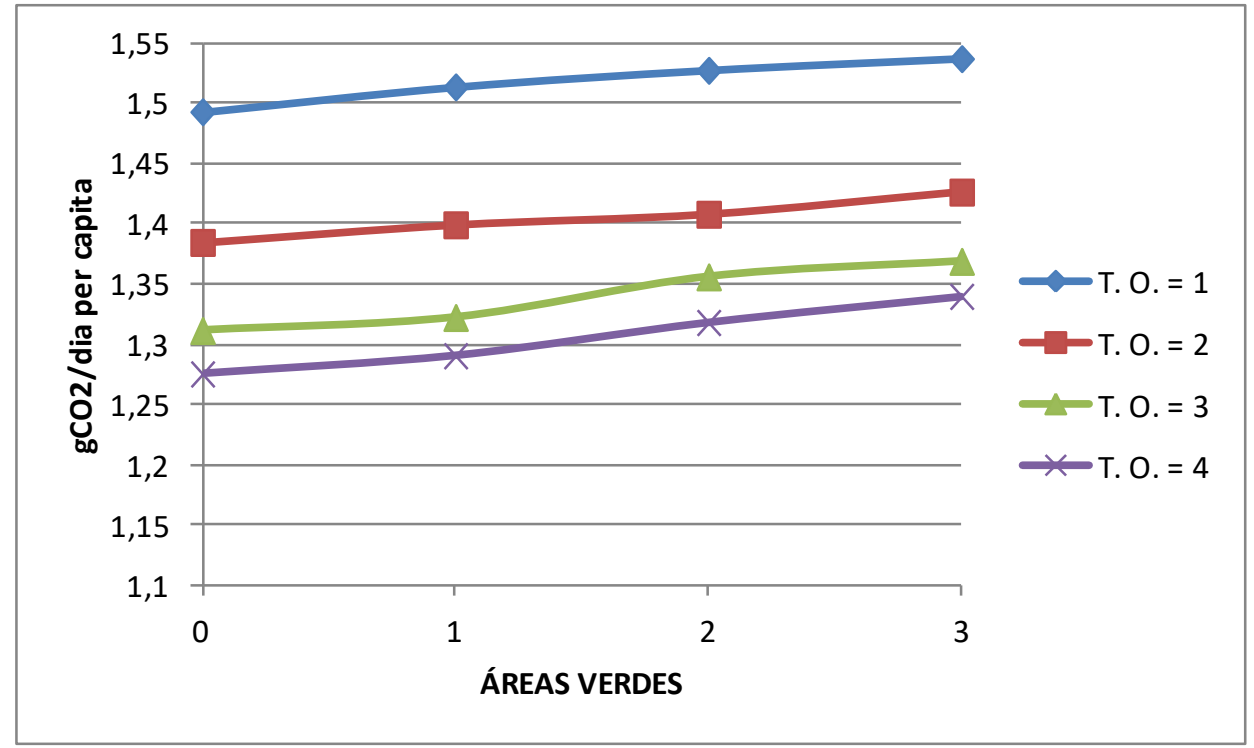

Figura 54 - Média das emissões diárias per capita de $\mathrm{CO}$ (g) em função das áreas verdes para o cenário 3. fonte: autor

A figura 55 apresenta os valores médios das estimativas de emissões para as 160 cidades simuladas. Neste cenário, em altas densidades, com taxa de ocupação do solo ajustada em 3 ou 4, verifica-se igualdade nos valores das emissões. Para baixas densidades, as emissões tendem a aumentar.

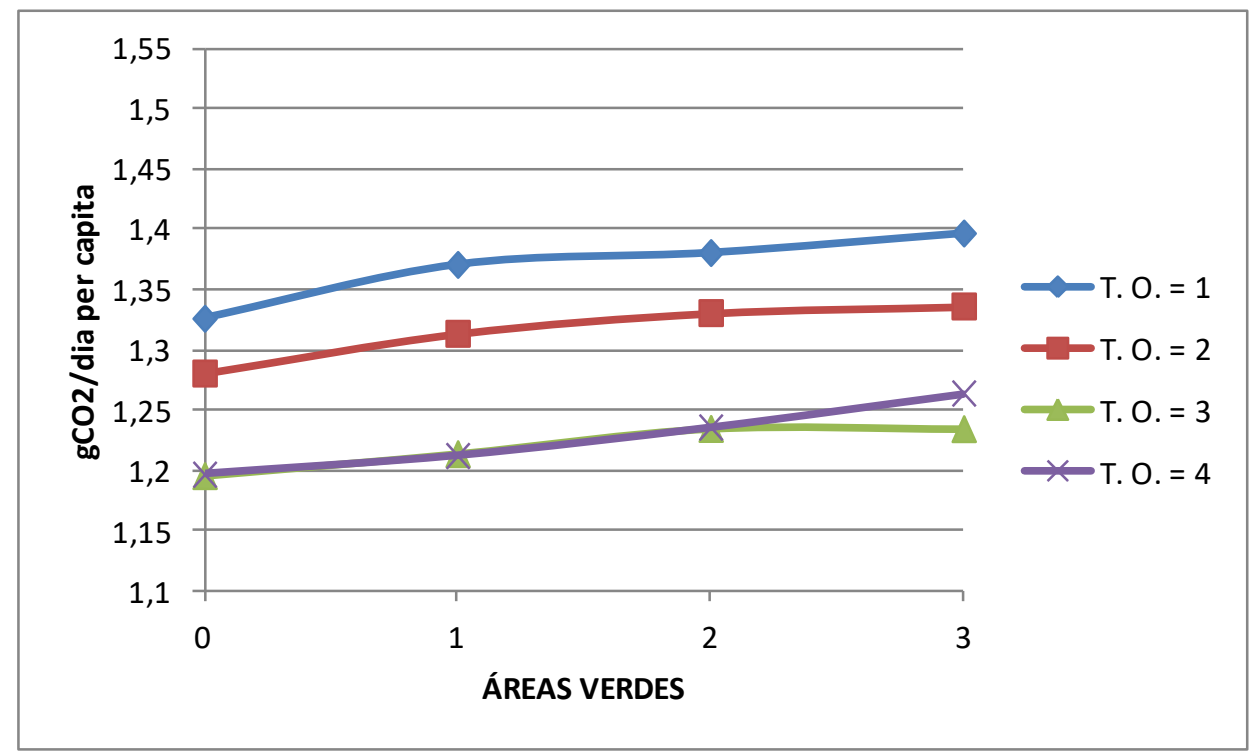

Figura 55 - Média das emissões diárias per capita de $\mathrm{CO} 2$ (g) em função das áreas verdes para o cenário 4. fonte: autor

\subsubsection{Efeito dos polos atratores nas emissões de $\mathrm{CO}_{2}$}

Para teste do efeito da oferta de polos atratores sobre as emissões de CO2 foram comparados os cenários 2 e 4 nas 16 combinações possíveis para cada cenário 
(tabela 18), considerando que a diferença entre os dois cenários está apenas na oferta de polos atratores.

Para as densidades médias e altas (taxa de ocupação em 2, 3 ou 4), quando comparados os mesmos ajustes para as cidades, variando-se apenas a oferta dos polos atratores, em todas as situações os valores das emissões são inferiores para as cidades que possuem maior oferta de polos atratores. Apenas para as cidades com baixa densidade (T. O. = 1) com a inserção de 1 ou 3 áreas verdes (apenas para estes dois casos) as emissões aumentam com o aumento da oferta de polos atratores. A figura 56 apresenta os valores e a tendência de cada um dos ajustes estudos para o cenário 2 e 4.

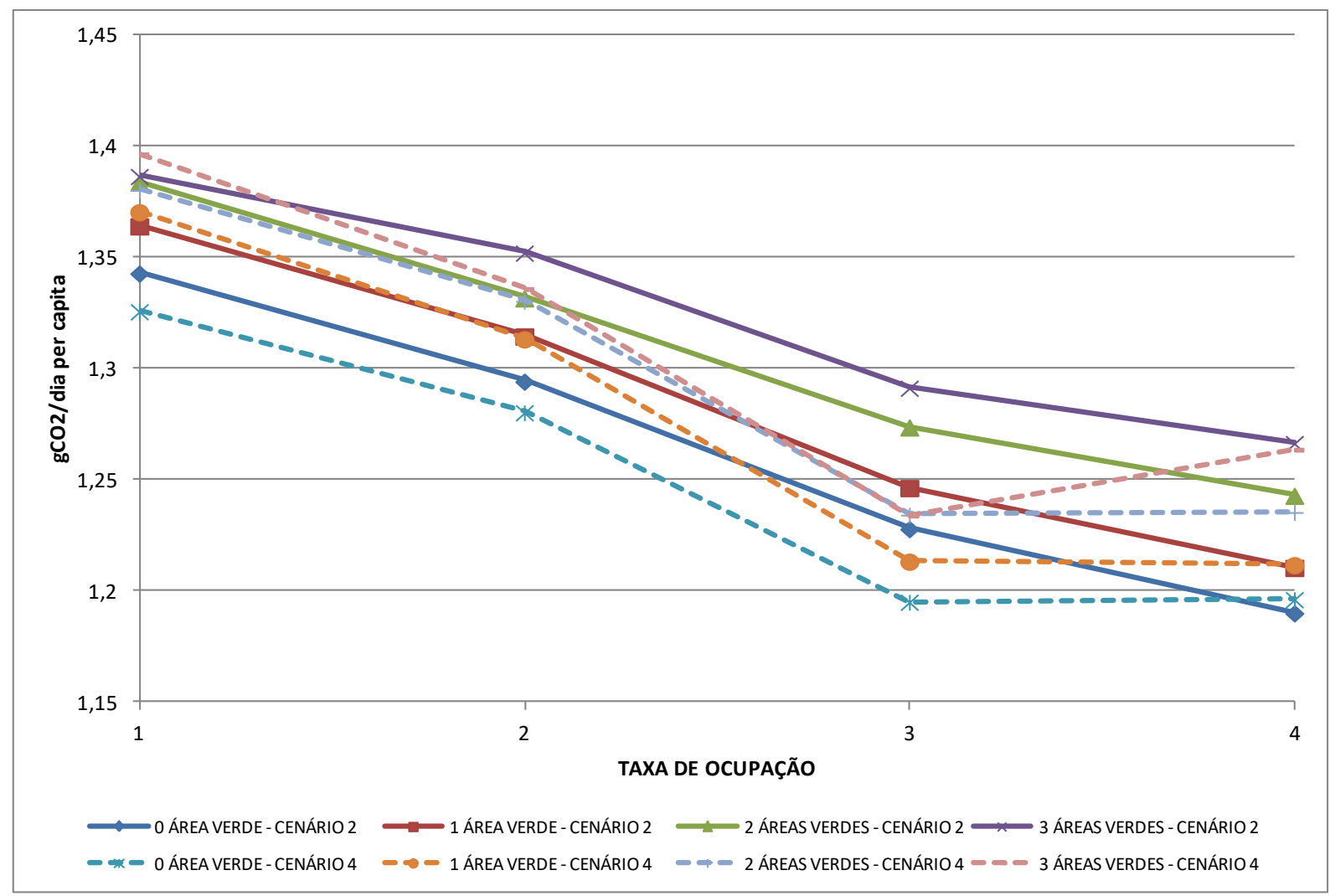

Figura 56 - Média da emissão diária per capita de energia para os cenários 2 e 4, em função da taxa de ocupação do solo. fonte: autor 


\section{DISCUSSÃO DOS RESULTADOS}

Embora o modelo proposto esteja baseado na integração das características das cidades, a análise inicial é realizada separadamente, permitindo a compreensão das partes (inseridas no conjunto) e posteriormente avançando para a compreensão das relações entre as características das cidades, o consumo direto de energia e as emissões de $\mathrm{CO}_{2}$ de forma sistêmica. Os resultados obtidos, analisados e discutidos neste trabalho refletem as condições da base de dados utilizadas na calibração do MBA, referente às 10 cidades do Estado de São Paulo, com população superior a 400 mil habitantes, onde mais do que $90 \%$ da população habita em centros urbanos, portanto, as diferenças entre os resultados deste trabalho e os demais estudos citados podem oriundos das divergências em questões regionais, condições climáticas, culturas e tradições, desenvolvimento social, políticas públicas de oferta e distribuição de energia e demais fatores que possam interferir no consumo energético e emissões de $\mathrm{CO}_{2}$ da comunidade local.

A auto-organização da cidade é influenciada pelos princípios norteadores do planejamento urbano, o qual possui capacidade para direcionar a forma urbana (fig. 32), o ambiente construído da cidade, o uso e ocupação do solo, as áreas verdes ou vazias, etc.. Estas características, por sua vez, afetam a ocupação da cidade e a densidade populacional influenciando na formação das ilhas de calor nas cidades (Fig. 33).

Os resultados das simulações apontam que a maximização do uso e ocupação do solo (direcionada pela taxa de ocupação do solo) aumenta a densidade urbana (podendo elevá-la em até 104\%, no caso do cenário 1 com 3 áreas verdes) que culmina na redução do consumo de energia para a mobilidade urbana (redução de 30,5\% para o mesmo cenário) (Fig. 36), corroborando a literatura sobre o assunto. (LENZEN et al., 2006; MINDALI; RAVEH; SALOMON, 2004). Esta redução ocorre pelo fato de que o aumento da densidade diminui as distâncias a serem percorridas no interior da cidade, (WIEDENHOFER; LENZEN; STEINBERGER, 2013) reduzindo o consumo de combustíveis líquidos em 18,5\%.

Porém os estudos de Lenzen et.al. (2006) e Mindali, Raveh e Salomon (2004) sobre a correlação entre densidade e consumo de combustíveis líquidos trata o assunto de 
forma isolada, não abrangendo as consequências indiretas do adensamento sobre os demais usos finais energéticos. A partir da analise sistêmica, o MBA proposto neste trabalho indica que o percentual economizado de energia depende das áreas verdes da cidade, da quantidade de polos atrativos disponíveis e da densidade populacional. Sem a presença das áreas verdes a diferença entre o consumo total de energia das cidades de baixa densidade e as cidades adensadas, com a otimização da ocupação do solo varia em até $49,5 \%$ quando a taxa de ocupação do solo varia entre 1 e 4 , respectivamente.

Ainda é necessário destacar que, nos resultados do MBA proposto verifica-se que o aumento da densidade urbana proporciona a formação das ilhas de calor (KOTHARKAR; SURAWAR, 2016) (Fig. 33), promovendo o aumento da demanda energética para os sistemas de condicionamento de ar. (SANTAMOURIS, 2014). A diferença entre o consumo de energia das cidades com baixa densidade e alta densidade, com a otimização da ocupação do solo varia em até $23,78 \%$.

No cenário 1, com a maior taxa de ocupação do solo (4), e a inserção de 2 áreas verdes onde foi medida a densidade próxima de $41.800 \mathrm{hab} / \mathrm{km}^{2}$, os serviços auxiliares, no ápice do adensamento foram responsáveis pelo aumento de $84,54 \%$ no consumo de energia para o serviço energético "serviços auxiliares" quando comparado com o menor valor encontrado nos 64 arranjos simulados.

Ainda foi possível verificar que o aumento da densidade urbana reflete em aumento do consumo de energia utilizada para os eletrodomésticos e cozimento. Este aumento resulta também da diminuição das distâncias percorridas, visto que as menores distâncias são percorridas em tempo menor, resultando em mais tempo disponível para as atividades no interior da residência, incluindo atividades que envolvem o uso dos eletrodomésticos e cozimento. Este resultado parte do pressuposto de que ao permanecerem mais tempo em casa as pessoas tendem a utilizar mais eletrodomésticos e prepararem sua alimentação. $O$ consumo para eletrodomésticos aumentou $7,03 \%$ e o consumo para cozimento aumentou $10 \%$.

As áreas verdes afetam discretamente o consumo direto de energia, pois possuem a capacidade de mitigar a formação das ilhas de calor (SUSCA; GAFFIN; DELL'OSSO, 2011). Tanto o tamanho das áreas verdes, quanto suas localizações 
no plano da cidade são relevantes, pois o raio de ação de mitigação das ilhas de calor considerado no modelo foi de $300 \mathrm{~m}$. Contudo, os estudos de Susca, Gaffin e Dell'Osso (2012) não consideraram que a inserção das áreas verdes nas cidades ocupa e segrega o espaço urbano, aumentando as distâncias a serem percorridas, aumentando o consumo de energia para a mobilidade urbana, o consumo de combustíveis líquidos e, consequentemente as emissões de $\mathrm{CO} 2$. O efeito direto e indireto da inserção de áreas verdes é identificado nas simulações realizadas neste trabalho, a partir da visão sistêmica. Ressalva-se que as áreas verdes trazem diversos benefícios às cidades, sobretudo os serviços ambientais, contudo os resultados apresentados pelo MBA proposto neste trabalho mostra que a inserção das áreas verdes tem pouco efeito final sobre o consumo de energia nas cidades com alta densidade, porém aumentam o consumo energético na medida em que as cidades tornam-se mais densas, com variação máxima de 4,2\%. (Fig. 41 até 44).

Ainda como resultado das análises das simulações, o aumento da oferta de polos atratores tende a criar cidades policêntricas, reduzindo o consumo de energia (Fig. 45), devido a diminuição significativa das distâncias percorridas. A maior economia verificada nas simulações da alteração dos polos atratores foi de $4,44 \%$ para o acréscimo de $24,59 \%$ dos polos atratores.

Embora o consumo de energia e as emissões de $\mathrm{CO} 2$ estejam relacionados, o comportamento das emissões de $\mathrm{CO} 2$ estimadas pelo modelo se contrapõe ao consumo de energia, pois decaem com o aumento da densidade populacional das cidades (figura 46). Analisando a figura 47 verifica-se que as emissões relativas à mobilidade diminuem com o aumento da densidade, enquanto os demais usos finais energéticos apresentam pequena elevação, com exceção dos "serviços auxiliares" que apresentam elevação expressiva, na ordem de $575 \%$, pois serviços de bombeamento de água e transporte vertical (elevadores) são praticamente inexistentes em regiões com baixa densidade, onde as edificações são mais baixas.

Em todos os cenários simulados (figura 48 a 51 ) verifica-se a diminuição das emissões em função da elevação da taxa de ocupação do solo (e consequente elevação da densidade urbana). A inserção das áreas verdes apresenta discreta elevação no montante das emissões. As figuras 52, 53, 54 e 55 apresentam o 
comportamento das emissões em todas as taxas de ocupação, para cada quantidade de áreas verdes adotadas no modelo.

A oferta de polos atratores diminuem as emissões, pois tem potencial para diminuir as distâncias das viagens diárias, encurtando os deslocamentos e reduzindo o consumo do serviço energético "mobilidade", porém, foi capturado no modelo que os menores percursos demandam menor tempo de trajeto e, portanto, maior tempo disponível no interior das residências, elevando a possibilidade de consumo dos demais usos finais energéticos.

Quando as variáveis são analisadas em conjunto as emissões de CO2 diminuem na medida em que o adensamento populacional aumenta. Este fenômeno ocorre em função da alteração da oferta energética, pois o arranjo da cidade reduz o consumo de combustíveis líquidos, derivados de petróleo, com altos fatores de emissão e aumentam o consumo de energia elétrica, a qual, na realidade brasileira, possui baixo fator de emissão, quando comparados com os combustíveis fósseis. Esta troca de vetor energético provoca a redução das emissões, mesmo com o aumento do montante de energia consumido nas cidades com altas densidades.

Cabe ressaltar que a correlação negativa entre o consumo de energia e as emissões de $\mathrm{CO} 2$ verificadas em função do adensamento populacional resultam do MBA proposto neste trabalho a partir de uma visão sistêmica e do seu caráter abrangente, provocando alterações pontuais nas características da cidade (ações de planejamento urbano), capturando suas consequências diretas e indiretas e considerando os resultados finais. 


\section{CONCLUSÃO}

A variação da taxa de ocupação do solo, a inserção de áreas verdes e a oferta de polos atrativos nas cidades afetam o consumo direto de energia e são fatores relevantes a serem considerados no planejamento e gestão das cidades sustentáveis, onde o baixo consumo de energia se torna essencial.

A alteração da taxa de ocupação afeta a densidade populacional, diminuindo as distâncias a serem percorridas entre as residências e os pontos de interesse dos habitantes, reduzindo, portanto o consumo de energia para mobilidade urbana e as emissões oriundas dos combustíveis líquidos, predominantemente derivados de fontes fósseis.

Contudo o aumento da densidade propicia a formação das ilhas de calor, aumentando a demanda de energia para sistemas de conforto térmico ambiental interno das residências, além de aumentar, o consumo de energia para os serviços auxiliares, como o bombeamento de água e uso de elevadores, ambos em edifícios altos, porém, a oferta energética brasileira direcionada a produção de energia elétrica é predominantemente hidráulica e relativamente pouco poluente (baixo fator de emissão).

De forma oposta à taxa de ocupação do solo, a inserção de áreas verdes no ambiente urbano mitiga a formação das ilhas de calor, diminuindo a necessidade de resfriamento dos ambientes e reduzindo a demanda energética para o conforto térmico ambiental interno. Contudo a inserção das áreas verdes segrega a cidade, ocupando o espaço urbano e aumentando as distâncias a serem percorridas entre as residências e os pontos de interesse dos habitantes, resultando no aumento da demanda de energia para a mobilidade urbana. Esta condição eleva as emissões de CO2 pela troca da oferta energética, diminuindo o uso de energia elétrica e aumentando o uso de combustíveis líquidos. Portanto, a implementação de áreas verdes deve ser acompanhada de uma análise do impacto das mesmas na mobilidade urbana.

Independente da densidade populacional, o aumento da oferta de polos atratores, criando cidades policêntricas, diminui as distâncias a serem percorridas pelos 
habitantes até seus pontos de interesse, reduzindo o consumo de energia para mobilidade, sem que haja impacto direto na formação de ilhas de calor e reduzindo as emissões de $\mathrm{CO} 2$, especificamente daquelas oriundas dos combustíveis fósseis (com alto fator de emissão).

Baseado nas premissas consideradas no modelo proposto, as características das cidades, que podem ser orientadas pelo planejamento urbano, influenciam o consumo direto de energia e nas emissões de CO2. Sobretudo, o aumento da densidade urbana implica no aumento do consumo direto total das cidades, mas reduz as emissões de $\mathrm{CO} 2$ em função da troca da fonte de energia, substituindo as ofertaes fósseis pelas ofertaes com grande participação de energia hidráulica, para a realidade brasileira.

Neste sentido é necessário que seja considerado o efeito bumerangue das ações de planejamento e gestão das cidades, pois o resultado final das ações pode divergir daquele que foi pretendido inicialmente, principalmente quando não há análise sistêmica e complexa entre as características das cidades e o consumo direto de energia. Assim a construção de modelos como o proposto neste trabalho é fundamental para avaliar o desdobramento de políticas públicas.

A ação dos urbanistas deve ser adequada à realidade atual, abandonando a prática da busca da cidade ideal, perseguida até meados do século $X X$, onde a estratégia era adequar o morador à cidade, limitando a quantidade de habitantes e determinando as condições de vida da sociedade. A cidade atual extrapola seus limites territoriais e interage com as demais cidades. As fronteiras das cidades apenas delimitam seu território político, mas não o campo de interação.

Este trabalho demonstra que o adensamento populacional, possível de ser alcançado por estratégias de planejamento urbano, apesar de resultar em elevação no consumo de energia, amplia o consumo energético, mas reduz as emissões, através da introdução de fontes de produção de energia limpa na oferta energética. Para a realidade brasileira, a substituição dos derivados de petróleo (largamente utilizados para a mobilidade urbana) pela energia elétrica (predominantemente proveniente de hidrelétricas), minimizam os fatores de emissão e contribuem para a redução das emissões e para a mitigação das mudanças climáticas. 
Por fim, cabe ressaltar que o uso de energia com níveis de emissões praticamente nulas (energia solar e eólica) devem ser considerados na oferta energética, minimizando ainda mais as emissões de $\mathrm{CO}_{2}$, quando utilizadas para produção de energia elétrica, buscando, assim, o processo de descarbonização dos processos de produção de energia. 


\section{LIMITES DO TRABALHO E TRABALHOS FUTUROS}

Embora o MBA proposto neste trabalho trate o assunto de forma sistêmica, as simulações estão limitadas as cidades cujas características assemelhem-se as cidades brasileiras, mais especificamente, as cidades do Estado de São Paulo, pois a calibração do modelo foi realizada com os parâmetros disponibilizados pelo Governo do Estadual (SÃO PAULO, 2014).

O uso de energia eólica e solar não foi testado no modelo, fato que certamente poderá influenciar nas emissões de $\mathrm{CO} 2$, visto que o fator de emissão para estas fontes de energia são considerados zero.

O serviço ecológico de captura do CO2 realizado pelas áreas verdes não foi incorporado ao modelo. Embora as áreas verdes inseridas no modelo não determinam o tipo de cobertura e, portanto, não mensuram a capacidade de captura de $\mathrm{CO} 2$, a inclusão desta variável pode interferir no resultado final das emissões, porém deve considerar a sazonalidade das espécies consideradas.

Como trabalho futuro, pretende-se a adaptação do MBA para um leque maior de cidades, considerando a condição climática local e os hábitos da população local, bem como a inclusão do uso de energia solar (incorporada ao pré-aquecimento de água e geração de energia local) e energia eólica, como componente da oferta energética. Ainda será estudada a inclusão do consumo indireto de energia, consumida pelas indústrias, comércios e serviços públicos e privados, e a contabilização da energia incorporada aos produtos produzidos fora da região consumida. Módulos de SIG (Sistema de Informação Georeferenciada) também poderão ser agregados ao modelo, principalmente as informações referentes ao uso, ocupação e topografia do território estudado. Por fim o trabalho futuro deve considerar a captura de $\mathrm{CO} 2$ pelas áreas verdes inseridas na cidade e dimensionar o impacto deste serviço ecológico no montante das emissões de $\mathrm{CO} 2$. 


\section{BIBLIOGRAFIA}

AGÊNCIA NACIONAL DE ENERGIA ELÉTRICA. A sua conta de luz por sua conta. Brasília: ANEEL, 2001.

AGUIR BARGAOUI, S.; LIOUANE, N.; NOURI, F. Z. Environmental Impact Determinants: An Empirical Analysis based on the STIRPAT Model. Procedia - Social and Behavioral Sciences, v. 109, p. 449-458, jan. 2014.

ALA-MANTILA, S.; HEINONEN, J.; JUNNILA, S. Relationship between urbanization, direct and indirect greenhouse gas emissions, and expenditures: A multivariate analysis. Ecological Economics, v. 104, p. 129-139, ago. 2014.

ALCÁNTARA, V.; DUARTE, R. Comparison of energy intensities in European Union countries. Results of a structural decomposition analysis. Energy Policy, v. 32, n. 2, p. 177-189, jan. 2004.

AMBROSINI, D. et al. Evaluating Mitigation Effects of Urban Heat Islands in a Historical Small Center with the ENVI-Met ${ }^{\circledR}$ Climate Model. Sustainability, v. 6, n. 10, p. 7013-7029, 10 out. 2014a.

AMBROSINI, D. et al. Evaluating Mitigation Effects of Urban Heat Islands in a Historical Small Center with the ENVI-Met ${ }^{\circledR}$ Climate Model. Sustainability, v. 6, n. 10, p. 7013-7029, 10 out. 2014b.

AZEVEDO, J. A.; CHAPMAN, L.; MULLER, C. L. Urban heat and residential electricity consumption: A preliminary study. Applied Geography, v. 70, p. 59-67, maio 2016.

BIAS, E. DE S.; BAPTISTA, G. M. DE M.; LOMBARDO, M. A. ANÁLISE DO FENÔMENO DE ILHAS DE CALOR URBANAS, POR MEIO DA COMBINAÇÃO DE DADOS LANDSAT E IKONOS. Anais XI SBSR, Anais...Belo Horizonte: INPE, 2003

BRASIL. PORTAL DO MINISTÉRIO DA CIÊNCIA, TECNOLOGIA E INOVAÇÃO. Institucional. Disponível em: <http://www.mct.gov.br/index.php/content/view/321144.html>. Acesso em: 28 fev. 2017.

BRASIL, E. DE P. E. Balanço Energético Nacional 2014: ano base 2013. Rio de Janeiro: [s.n.].

BROWNSTONE, D.; GOLOB, T. F. The impact of residential density on vehicle usage and energy consumption. Journal of Urban Economics, v. 65, n. 1, p. 91-98, jan. 2009.

BUBECK, S.; TOMASCHEK, J.; FAHL, U. Potential for mitigating greenhouse gases through expanding public transport services: A case study for Gauteng Province, South Africa. Transportation Research Part D: Transport and Environment, v. 32, p. 57-69, out. 2014a.

BUBECK, S.; TOMASCHEK, J.; FAHL, U. Potential for mitigating greenhouse gases through expanding public transport services: A case study for Gauteng Province, South Africa. Transportation Research Part D: Transport and Environment, v. 32, p. 57-69, out. 2014b.

CARLSSON-KANYAMA, A.; ENGSTRÖM, R.; KOK, R. Indirect and Direct Energy Requirements of City Households in Sweden: Options for Reduction, Lessons from Modeling. Journal of Industrial Ecology, v. 9, n. 1-2, p. 221-235, 8 fev. 2008.

CAVAN, G. et al. Urban morphological determinants of temperature regulating ecosystem services in two African cities. Ecological Indicators, v. 42, p. 43-57, jul. 2014. 
CERVO, A. L.; BERVIAN, P. A.; SILVA, R. DA. Metodologia cientifica. São Paulo: Pearson Prentice Hall, 2007.

CHEN, S. et al. A statistical method to investigate national energy consumption in the residential building sector of China. Energy and Buildings, v. 40, n. 4, p. 654-665, jan. 2008.

CHEN, Z. M.; CHEN, G. Q. An overview of energy consumption of the globalized world economy. Energy Policy, v. 39, n. 10, p. 5920-5928, out. 2011.

CHENG, X. et al. Influence of Park Size and Its Surrounding Urban Landscape Patterns on the Park Cooling Effect. Journal of Urban Planning and Development, v. 141, n. 3, p. A4014002, set. 2015.

CHIACCHIO, F. et al. Agent-Based Modeling of the Immune System: NetLogo, a Promising Framework. BioMed Research International, v. 2014, p. 1-6, 2014.

CHOAY, F. O urbanismo utopias e realidades, uma antologia. São Paulo: Perspectiva, 2003.

CONFEDERAÇÃO NACIONAL DA INDÚSTRIA. Oferta energética: cenários, oportunidades e desafios. Brasília: Confederação Nacional da Indústria, 2007.

DE CASAS CASTRO MARINS, K. R.; DE ANDRADE ROMÉRO, M. Urban and Energy Assessment from a Systemic Approach of Urban Morphology, Urban Mobility, and Buildings: Case Study of Agua Branca in Sao Paulo. Journal of Urban Planning and Development, v. 139, n. 4, p. 280-291, dez. 2013.

DEMIRBAS, A. Political, economic and environmental impacts of biofuels: A review. Applied Energy, v. 86, p. S108-S117, nov. 2009.

DETRAN-SP, D. E. DE T. DO E. DE S. P. Estatísticas de Trânsito. Institucional. Disponível em: $<$ https://www.detran.sp.gov.br/wps/wcm/connect/portaldetran/detran/detran/EstatisticasTransito/ >. Acesso em: 28 fev. 2017.

DHAKAL, S. Urban energy use and carbon emissions from cities in China and policy implications. Energy Policy, v. 37, n. 11, p. 4208-4219, nov. 2009.

DILLON, H. S.; SAPHORES, J.-D.; BOARNET, M. G. The impact of urban form and gasoline prices on vehicle usage: Evidence from the 2009 National Household Travel Survey. Research in Transportation Economics, v. 52, p. 23-33, out. 2015.

DUJARDIN, S.; MARIQUE, A.-F.; TELLER, J. Spatial planning as a driver of change in mobility and residential energy consumption. Energy and Buildings, v. 68, p. 779-785, jan. 2014.

EGGLESTON, H. S. et al. 2006 IPCC guidelines for national greenhouse gas inventories. [s.l: s.n.].

EHRLICH, P. R.; HOLDREN, J. P. Impact of Population Growth. Science, v. 171, n. 3977, p. 1212-1217, 26 mar. 1971.

ENERGY INFORMATION ADMINISTRATION. INTERNATIONAL ENERGY OUTLOOK 2016: with projections to 2040. S.I.: ENERGY INFORMATION ADMINI, 2016.

EPE. Balanço Energético Nacional 2014: Ano base 2013 - Relatório Final. Rio de Janeiro: Ministério de Minas e Energia, 2014. 
EWING, R.; RONG, F. The impact of urban form on U.S. residential energy use. Housing Policy Debate, v. 19, n. 1, p. 1-30, jan. 2008a.

EWING, R.; RONG, F. The impact of urban form on U.S. residential energy use. Housing Policy Debate, v. 19, n. 1, p. 1-30, jan. 2008b.

FERRARI, M. D.; GUIGOU, M.; LAREO, C. Energy consumption evaluation of fuel bioethanol production from sweet potato. Bioresource Technology, v. 136, p. 377-384, maio 2013.

FERTNER, C.; GROßE, J. Compact and Resource Efficient Cities? Synergies and Trade-offs in European Cities. European Spatial Research and Policy, v. 23, n. 1, 1 jan. 2016.

FILION, Y. R. Impact of Urban Form on Energy Use in Water Distribution Systems. Journal of Infrastructure Systems, v. 14, n. 4, p. 337-346, dez. 2008 a.

FILION, Y. R. Impact of Urban Form on Energy Use in Water Distribution Systems. Journal of Infrastructure Systems, v. 14, n. 4, p. 337-346, dez. 2008 b.

FUNG, C. K. W.; JIM, C. Y. Assessing the Cooling Effects of Different Vegetation Settings in a Hong Kong Golf Course. Procedia Environmental Sciences, v. 37, p. 626-636, 2017.

GAUBE, V.; REMESCH, A. Impact of urban planning on household's residential decisions: An agentbased simulation model for Vienna. Environmental Modelling \& Software, v. 45, p. 92-103, jul. 2013.

GHEDAMSI, R. et al. Modeling and forecasting energy consumption for residential buildings in Algeria using bottom-up approach. Energy and Buildings, v. 121, p. 309-317, jun. 2016.

GOLDEMBERG, J.; LUCON, O. Energia e meio ambiente no Brasil. Estudos Avançados, v. 21, n. 59, p. 7-20, abr. 2007.

GRUBLER, A. et al. Chapter 18 - Urban Energy Systems. In: Global Energy Assessment - Toward a Sustainable Future. Cambridge University Press, Cambridge, UK and New York, NY, USA and the International Institute for Applied Systems Analysis, Laxenburg, Austria: [s.n.]. p. 1307-1400.

HAGER, T. J.; MORAWICKI, R. Energy consumption during cooking in the residential sector of developed nations: A review. Food Policy, v. 40, p. 54-63, jun. 2013.

HERTWICH, E. G. THE LIFE CYCLE ENVIRONMENTAL IMPACTS OF CONSUMPTION. Economic Systems Research, v. 23, n. 1, p. 27-47, mar. 2011.

HICKMAN, R.; HALL, P.; BANISTER, D. Planning more for sustainable mobility. Journal of Transport Geography, v. 33, p. 210-219, dez. 2013a.

HICKMAN, R.; HALL, P.; BANISTER, D. Planning more for sustainable mobility. Journal of Transport Geography, v. 33, p. 210-219, dez. 2013b.

HOEKSTRA, R.; VAN DEN BERGH, J. C. J. M. Comparing structural decomposition analysis and index. Energy Economics, v. 25, n. 1, p. 39-64, jan. 2003.

HORNER, M. W. Exploring the linkages between transportation, urban form, and energy. Journal of Transport Geography, v. 33, p. 207-209, dez. 2013a. 
HORNER, M. W. Exploring the linkages between transportation, urban form, and energy. Journal of Transport Geography, v. 33, p. 207-209, dez. 2013b.

IBGE. IBGE :: Instituto Brasileiro de Geografia e Estatística. Institucional. Disponível em: <http://www.ibge.gov.br/home/estatistica/pesquisas/pesquisa_resultados.php?id_pesquisa=46>.

Acesso em: 12 jan. 2017a.

IBGE. IBGE I Cidades I São Paulo. Institucional. Disponível em: <http://cidades.ibge.gov.br/xtras/uf.php?coduf=35>. Acesso em: 8 jan. 2017b.

IEA, I. E. A. Energy Technology Perspectives 2016: Towards sustainable Urban Energy Systems Sumário Executivo. Paris: [s.n.].

IEA, I. E. A. CO2 emissions from fuel combustion - Highlights, $2016 \mathrm{~b}$.

IPSOS-RSL AND OFFICE FOR NATIONAL STATISTICS. United Kingdom Time Use Survey, 2000Colchester, Essex: UK Data Archive, , 2003. Disponível em: <http://dx.doi.org/10.5255/UKDASN-4504-1>. Acesso em: 25 dez. 2014

JAIN, S. et al. Identifying public preferences using multi-criteria decision making for assessing the shift of urban commuters from private to public transport: A case study of Delhi. Transportation Research Part F: Traffic Psychology and Behaviour, v. 24, p. 60-70, maio 2014.

KAVGIC, M. et al. A review of bottom-up building stock models for energy consumption in the residential sector. Building and Environment, v. 45, n. 7, p. 1683-1697, jul. 2010.

KEIRSTEAD, J.; SIVAKUMAR, A. Using Activity-Based Modeling to Simulate Urban Resource Demands at High Spatial and Temporal Resolutions: Activity-Based Modeling of Urban Resource Demands. Journal of Industrial Ecology, v. 16, n. 6, p. 889-900, dez. 2012.

KENNEDY, C. et al. Greenhouse Gas Emissions from Global Cities. Environmental Science \& Technology, v. 43, n. 19, p. 7297-7302, out. 2009.

KHAKPOUR, M.; RØD, J. K. An attraction-based cellular automaton model for generating spatiotemporal population maps in urban areas. Environment and Planning B: Planning and Design, v. 43, n. 2, p. 297-319, mar. 2016.

KNEIB, E. C. MOBILIDADE URBANA E QUALIDADE DE VIDA: DO PANORAMA GERAL AO CASO DE GOIÂNIA. Revista UFG, v. Ano XIII, n. 12, p. 71-78, jul. 2012.

KO, Y. Urban Form and Residential Energy Use: A Review of Design Principles and Research Findings. Journal of Planning Literature, v. 28, n. 4, p. 327-351, 1 nov. 2013.

KOTHARKAR, R.; SURAWAR, M. Land Use, Land Cover, and Population Density Impact on the Formation of Canopy Urban Heat Islands through Traverse Survey in the Nagpur Urban Area, India. Journal of Urban Planning and Development, v. 142, n. 1, p. 04015003, mar. 2016.

KUZNETS, S. Economic Growth and Income Inequality. The American Economic Review, v. 45, n. 1, p. 1-28, mar. 1955.

LAZAROIU, G. C.; ROSCIA, M. Definition methodology for the smart cities model. Energy, v. 47, n. 1, p. 326-332, nov. 2012a. 
LAZAROIU, G. C.; ROSCIA, M. Definition methodology for the smart cities model. Energy, v. 47, n. 1, p. 326-332, nov. 2012b.

LENZEN, M. Energy and greenhouse gas cost of living for Australia during 1993/94. Energy, v. 23, n. 6, p. 497-516, jun. 1998.

LENZEN, M. et al. A comparative multivariate analysis of household energy requirements in Australia, Brazil, Denmark, India and Japan. Energy, v. 31, n. 2-3, p. 181-207, fev. 2006.

LENZEN, M.; DEY, C.; FORAN, B. Energy requirements of Sydney households. Ecological Economics, v. 49, n. 3, p. 375-399, jul. 2004.

LI, W. et al. Discrepant impacts of land use and land cover on urban heat islands: A case study of Shanghai, China. Ecological Indicators, v. 47, p. 171-178, dez. 2014 a.

LI, W. et al. Discrepant impacts of land use and land cover on urban heat islands: A case study of Shanghai, China. Ecological Indicators, v. 47, p. 171-178, dez. 2014b.

LIDDLE, B. Urban density and climate change: a STIRPAT analysis using city-level data. Journal of Transport Geography, v. 28, p. 22-29, abr. 2013.

LIU, C.; SHEN, Q. An empirical analysis of the influence of urban form on household travel and energy consumption. Computers, Environment and Urban Systems, v. 35, n. 5, p. 347-357, set. 2011a.

LIU, C.; SHEN, Q. An empirical analysis of the influence of urban form on household travel and energy consumption. Computers, Environment and Urban Systems, v. 35, n. 5, p. 347-357, set. 2011 b.

LIU, X.; SWEENEY, J. Modelling the impact of urban form on household energy demand and related CO2 emissions in the Greater Dublin Region. Energy Policy, v. 46, p. 359-369, jul. 2012.

LIU, Y. Relationship between industrial firms, high-carbon and low-carbon energy: An agent-based simulation approach. Applied Mathematics and Computation, v. 219, n. 14, p. 7472-7479, mar. 2013.

MARCHI, M. et al. Carbon dioxide sequestration model of a vertical greenery system. Ecological Modelling, v. 306, p. 46-56, jun. 2015.

MARIQUE, A.-F. et al. An online interactive tool to assess energy consumption in residential buildings and for daily mobility. Energy and Buildings, v. 78, p. 50-58, ago. 2014.

MILLER, E.; ROORDA, M. Prototype Model of Household Activity-Travel Scheduling. Transportation Research Record, v. 1831, n. 1, p. 114-121, 1 jan. 2003.

MILLER, J. H. Complex adaptive systems: an introduction to computational models of social life. Princeton, N.J: Princeton University Press, 2007.

MINDALI, O.; RAVEH, A.; SALOMON, I. Urban density and energy consumption: a new look at old statistics. Transportation Research Part A: Policy and Practice, v. 38, n. 2, p. 143-162, fev. 2004.

MOLL, H. C. et al. Pursuing More Sustainable Consumption by Analyzing Household Metabolism in European Countries and Cities. Journal of Industrial Ecology, v. 9, n. 1-2, p. 259-275, 8 fev. 2008. 
MUSCALAGIU, I.; EMIL, P. H.; NEGRU, V. Enhancing DisCSP-Netlogo from Simulation to Real-execution of Agents in Distributed Constraints. Procedia Computer Science, v. 35, p. 261-270, 2014.

OCDE, O. /. World Energy Statistics 2016. [s.I.] OECD Publishing, 2016.

PAGLIARA, F. (ED.). Residential location choice: models and applications. Berlin: Springer, 2010.

PAPASTAMATIOU, l. et al. How "OPTIMUS" is a city in terms of energy optimization? e-SCEAF: A web based decision support tool for local authorities. Information Fusion, v. 29, p. 149-161, maio 2016.

PENNA, A. L. A.; OLIVEIRA, F. A. Leis de escala e a dinâmica do crescimento em estruturas biológicas. Revista Brasileira de Ensino de Física, v. 30, n. 3, p. 3301.1-3301.5, set. 2008.

PETERS, G. P.; HERTWICH, E. G. $\mathrm{CO}_{2}$ Embodied in International Trade with Implications for Global Climate Policy. Environmental Science \& Technology, v. 42, n. 5, p. 1401-1407, mar. 2008.

PMSP, P. DO M. DE S. P. Portal da Prefeitura da Cidade de São Paulo. Institucional. Disponível em: <http://www.prefeitura.sp.gov.br/cidade/secretarias/transportes/acesso_a_informacao/index.php? $p=150849>$. Acesso em: 28 fev. 2017.

POPULATION FUND (ED.). People and possibilities in a world of 7 billion. New York, NY: UNFPA, 2011.

PORTUGALI, J. Complexity, cognition and the city. Heidelberg ; New York: Springer, 2011.

RASKIN, P. D. Methods for estimating the population contribution to environmental change. Ecological Economics, v. 15, n. 3, p. 225-233, dez. 1995.

RATTI, C.; BAKER, N.; STEEMERS, K. Energy consumption and urban texture. Energy and Buildings, v. 37, n. 7, p. 762-776, jul. 2005.

REINDERS, A. H. M. E.; VRINGER, K.; BLOK, K. The direct and indirect energy requirement of households in the European Union. Energy Policy, v. 31, n. 2, p. 139-153, jan. 2003.

REITER, S.; MARIQUE, A.-F. Toward Low Energy Cities: A Case Study of the Urban Area of Liége, Belgium. Journal of Industrial Ecology, v. 16, n. 6, p. 829-838, dez. 2012.

REN, Z. et al. A model for predicting household end-use energy consumption and greenhouse gas emissions in Australia. International Journal of Sustainable Building Technology and Urban Development, v. 4, n. 3, p. 210-228, set. 2013.

REN, Z.; PAEVERE, P.; MCNAMARA, C. A local-community-level, physically-based model of end-use energy consumption by Australian housing stock. Energy Policy, v. 49, p. 586-596, out. 2012.

RICHARDSON, I.; THOMSON, M.; INFIELD, D. A high-resolution domestic building occupancy model for energy demand simulations. Energy and Buildings, v. 40, n. 8, p. 1560-1566, jan. 2008.

RICKWOOD, P. Residential Operational Energy Use. Urban Policy and Research, v. 27, n. 2, p. 137155, jun. 2009.

SANTAMOURIS, M. Cooling the cities - A review of reflective and green roof mitigation technologies to fight heat island and improve comfort in urban environments. Solar Energy, v. 103, p. 682-703, maio 2014. 
SÃO PAULO, E. DE. Anuário de Energéticos por Município no Estado de São Paulo - 2014 ano base 2013: Informações Energéticas. São Paulo, SP: SECRETARIA DE ENERGIA E MINERAÇÃO, 2014.

SÃo PAULO, E. DE. BALANÇO ENERGÉTICO do ESTAdO DE SÃo PAULO. São Paulo: Secretaria de Energia $\quad$ Mineração, 2016a. Disponível em: <http://dadosenergeticos.energia.sp.gov.br/Portalcev2/intranet/BiblioVirtual/menu.asp>.

SÃO PAULO, E. DE. Anuário de Energéticos por Município no Estado de São Paulo - 2016 ano base 2015: Informações Energéticas. São Paulo, SP: SECRETARIA DE ENERGIA E MINERAÇÃO, 2016b.

SONG, L.; WOO, W. T. China's dilemma: economic growth, the environment and climate change. [Canberra]; [Washington, D.C.]; [Beijing, China]: Anu E Press : Asia Pacific Press ; Brookings Institution Press ; Social Sciences Academic Press (China), 2008.

STEPHAN, A.; CRAWFORD, R. H.; DE MYTTENAERE, K. Towards a comprehensive life cycle energy analysis framework for residential buildings. Energy and Buildings, v. 55, p. 592-600, dez. 2012a.

STEPHAN, A.; CRAWFORD, R. H.; DE MYTTENAERE, K. Towards a comprehensive life cycle energy analysis framework for residential buildings. Energy and Buildings, v. 55, p. 592-600, dez. 2012b.

STERN, D. I. The Rise and Fall of the Environmental Kuznets Curve. World Development, v. 32, n. 8, p. 1419-1439, ago. 2004.

SU, W.; GU, C.; YANG, G. Assessing the Impact of Land Use/Land Cover on Urban Heat Island Pattern in Nanjing City, China. Journal of Urban Planning and Development, v. 136, n. 4, p. 365-372, dez. 2010.

SUSCA, T.; GAFFIN, S. R.; DELL'OSSO, G. R. Positive effects of vegetation: Urban heat island and green roofs. Environmental Pollution, v. 159, n. 8-9, p. 2119-2126, ago. 2011.

TAHA, H. Urban climates and heat islands: albedo, evapotranspiration, and anthropogenic heat. Energy and Buildings, v. 25, n. 2, p. 99-103, jan. 1997a.

TAHA, H. Urban climates and heat islands: albedo, evapotranspiration, and anthropogenic heat. Energy and Buildings, v. 25, n. 2, p. 99-103, jan. 1997b.

TENG, M. et al. Multipurpose greenway planning for changing cities: A framework integrating priorities and a least-cost path model. Landscape and Urban Planning, v. 103, n. 1, p. 1-14, out. 2011.

THEEUWES, N. E. et al. Seasonal dependence of the urban heat island on the street canyon aspect ratio: Street Geometry and the Urban Heat Island. Quarterly Journal of the Royal Meteorological Society, v. 140 , n. 684 , p. 2197-2210, out. 2014a.

THEEUWES, N. E. et al. Seasonal dependence of the urban heat island on the street canyon aspect ratio: Street Geometry and the Urban Heat Island. Quarterly Journal of the Royal Meteorological Society, v. 140, n. 684, p. 2197-2210, out. 2014b.

T'SERCLAES, P. DE et al. (EDS.). Promoting energy efficiency investments: case studies in the residential sector. Paris: OECD/IEA and AFD, 2008.

TSO, G. A study of domestic energy usage patterns in Hong Kong. Energy, v. 28, n. 15, p. 1671-1682, dez. 2003. 
UN, D. OF E. A ND S. A., Population Division. World Urbanization Prospects: The 2014 Revision. New York, NY: [s.n.]. Disponível em: <https://esa.un.org/unpd/wup/Publications/Files/WUP2014Report.pdf>.

VILLAÇA, F. Espaço intra-urbano no Brasil. São Paulo, SP: Studio Nobel, 1998.

VRINGER, K.; BLOK, K. The direct and indirect energy requirements of households in the Netherlands. Energy Policy, v. 23, n. 10, p. 893-910, out. 1995.

WANG, Q. Effects of urbanisation on energy consumption in China. Energy Policy, v. 65, p. 332-339, fev. 2014.

WIEDENHOFER, D.; LENZEN, M.; STEINBERGER, J. K. Energy requirements of consumption: Urban form, climatic and socio-economic factors, rebounds and their policy implications. Energy Policy, v. 63, p. 696-707, dez. 2013.

WIER, M. et al. Effects of Household Consumption Patterns on $\mathrm{CO}_{2}$ Requirements. Economic Systems Research, v. 13, n. 3, p. 259-274, set. 2001.

WORLD WIDE FUND FOR NATURE. Living planet report 2012 biodiversity, biocapacity and better choices. Gland, Switzerland: World Wide Fund for Nature, 2012.

$\mathrm{XU}, \mathrm{Q}$. et al. Water Saving and Energy Reduction through Pressure Management in Urban Water Distribution Networks. Water Resources Management, v. 28, n. 11, p. 3715-3726, set. 2014a.

$\mathrm{XU}$, Q. et al. Water Saving and Energy Reduction through Pressure Management in Urban Water Distribution Networks. Water Resources Management, v. 28, n. 11, p. 3715-3726, set. 2014b.

$\mathrm{XU}, \mathrm{X}$. Y.; ANG, B. W. Analysing residential energy consumption using index decomposition analysis. Applied Energy, v. 113, p. 342-351, jan. 2014.

YAO, R.; STEEMERS, K. A method of formulating energy load profile for domestic buildings in the UK. Energy and Buildings, v. 37, n. 6, p. 663-671, jun. 2005.

$Y E, H$. et al. A sustainable urban form: The challenges of compactness from the viewpoint of energy consumption and carbon emission. Energy and Buildings, v. 93, p. 90-98, abr. 2015.

YIN, Y.; MIZOKAMI, S.; MARUYAMA, T. An analysis of the influence of urban form on energy consumption by individual consumption behaviors from a microeconomic viewpoint. Energy Policy, v. 61 , p. 909-919, out. 2013a.

YIN, Y.; MIZOKAMI, S.; MARUYAMA, T. An analysis of the influence of urban form on energy consumption by individual consumption behaviors from a microeconomic viewpoint. Energy Policy, v. 61 , p. 909-919, out. 2013b.

YONGLING, Y. Energy Consumption and Space Density in Urban Area. Energy Procedia, v. 5, p. 895899, 2011.

YORK, R.; ROSA, E. A.; DIETZ, T. STIRPAT, IPAT and ImPACT: analytic tools for unpacking the driving forces of environmental impacts. Ecological Economics, v. 46, n. 3, p. 351-365, out. 2003.

YUN, G. Y.; STEEMERS, K. Behavioural, physical and socio-economic factors in household cooling energy consumption. Applied Energy, v. 88, n. 6, p. 2191-2200, jun. 2011. 
ZHANG, C.; ANADON, L. D. Life Cycle Water Use of Energy Production and Its Environmental Impacts in China. Environmental Science \& Technology, v. 47, n. 24, p. 14459-14467, 17 dez. 2013.

ZHANG, Y.; ZHENG, H.; FATH, B. D. Analysis of the energy metabolism of urban socioeconomic sectors and the associated carbon footprints: Model development and a case study for Beijing. Energy Policy, v. 73, p. 540-551, out. 2014.

ZHAO, X.; LI, N.; MA, C. Residential energy consumption in urban China: A decomposition analysis. Energy Policy, v. 41, p. 644-653, fev. 2012.

ZUCARO, A. et al. Urban resource use and environmental performance indicators. An application of decomposition analysis. Ecological Indicators, v. 47, p. 16-25, dez. 2014. 


\section{APÊNDICE A - SÍNTESE DOS ESTUDOS CONSIDERADOS NA REVISÃO BIBLIOGRÁFICA}

Tabela 19 - Resumo do foco e características das cidades estudadas na revisão bibliográfica

\begin{tabular}{|c|c|c|c|c|c|}
\hline \multirow{2}{*}{ № } & \multirow{2}{*}{ FOCO DA ANÁLISE } & \multicolumn{3}{|c|}{ CARACTERÍSTICAS DAS CIDADES ANALISADAS } & \multirow{2}{*}{ REFERÊNCIA } \\
\hline & & PRINCIPAL & SECUNDÁRIA & SECUNDÁRIA & \\
\hline 1 & $\begin{array}{l}\text { Urbanização e } \\
\text { Consumo de energia }\end{array}$ & $\begin{array}{c}\text { Renda (Curva de } \\
\text { Kuznets) }\end{array}$ & $\begin{array}{c}\text { Padrão de } \\
\text { consumo familiar }\end{array}$ & $\begin{array}{l}\text { Análise do ciclo } \\
\text { de vida dos bens }\end{array}$ & $\begin{array}{c}\text { (ALA-MANTILA; } \\
\text { HEINONEN; } \\
\text { JUNNILA, 2014) }\end{array}$ \\
\hline 2 & $\begin{array}{c}\text { Densidade e } \\
\text { Consumo direto de } \\
\text { combustível } \\
\end{array}$ & $\begin{array}{l}\text { Densidade } \\
\text { Urbana }\end{array}$ & Uso do solo & & $\begin{array}{l}\text { (BROWNSTONE; } \\
\text { GOLOB, 2009) }\end{array}$ \\
\hline 3 & $\begin{array}{l}\text { Comportamento e } \\
\text { Consumo de energia }\end{array}$ & $\begin{array}{l}\text { Comportamento } \\
\text { familiar }\end{array}$ & $\begin{array}{c}\text { Padrão de } \\
\text { consumo familiar }\end{array}$ & $\begin{array}{c}\text { Atividades e } \\
\text { hábitos familiares }\end{array}$ & $\begin{array}{c}\text { (CARLSSON- } \\
\text { KANYAMA; } \\
\text { ENGSTRÖM; KOK, } \\
\text { 2008) -2, p. } 221- \\
\text { 235, } 8 \text { fev. } 2008 . \\
\end{array}$ \\
\hline 4 & $\begin{array}{l}\text { Ilha de calor } \\
\text { (mitigação) }\end{array}$ & $\begin{array}{l}\text { Infraestrutura } \\
\text { urbana verde }\end{array}$ & Áreas verdes & Uso do solo & (CAVAN et al., 2014) \\
\hline 5 & $\begin{array}{l}\text { Transmissão de } \\
\text { energia, } \\
\text { características das } \\
\text { residências e ilha de } \\
\text { calor } \\
\end{array}$ & Forma Urbana & $\begin{array}{l}\text { Transmissão e } \\
\text { perda }\end{array}$ & $\begin{array}{c}\text { Característica } \\
\text { das famílias com } \\
\text { foco no } \\
\text { aquecimento/resf } \\
\text { riamento interno }\end{array}$ & $\begin{array}{c}\text { (EWING; RONG, } \\
2008)\end{array}$ \\
\hline 6 & $\begin{array}{l}\text { ilha de calor } \\
\text { (formação) }\end{array}$ & $\begin{array}{l}\text { Tamanho da } \\
\text { cidade }\end{array}$ & Telhado verde & & $\begin{array}{c}\text { (AMBROSINI et al., } \\
2014)\end{array}$ \\
\hline 7 & $\begin{array}{c}\text { Transporte público e } \\
\text { Emissões }\end{array}$ & $\begin{array}{l}\text { Transporte } \\
\text { público }\end{array}$ & $\begin{array}{l}\text { Consumo de } \\
\text { energia }\end{array}$ & Emissões & $\begin{array}{l}\text { (BUBECK; } \\
\text { TOMASCHEK; } \\
\text { FAHL, 2014) }\end{array}$ \\
\hline 8 & $\begin{array}{c}\text { Forma Urbana e } \\
\text { consumo de energia }\end{array}$ & $\begin{array}{c}\text { Rede de } \\
\text { distribuição de } \\
\text { água } \\
\end{array}$ & & & (FILION, 2008) \\
\hline 9 & $\begin{array}{c}\text { Planejamento } \\
\text { urbano - transporte } \\
\text { público e } \\
\text { gerenciamento de } \\
\text { tráfego } \\
\end{array}$ & $\begin{array}{l}\text { Transporte } \\
\text { público }\end{array}$ & $\begin{array}{l}\text { Transporte } \\
\text { particular }\end{array}$ & Emissões & $\begin{array}{l}\text { (HICKMAN; HALL; } \\
\text { BANISTER, 2013) }\end{array}$ \\
\hline 10 & $\begin{array}{l}\text { Eficiência nos } \\
\text { sistemas de } \\
\text { transporte }\end{array}$ & Forma urbana & $\begin{array}{l}\text { Transporte em } \\
\text { geral }\end{array}$ & Emissões & (HORNER, 2013) \\
\hline 11 & $\begin{array}{l}\text { Sistemas de } \\
\text { transporte }\end{array}$ & $\begin{array}{l}\text { Transporte - } \\
\text { Troca particular } \\
\text { para público }\end{array}$ & $\begin{array}{l}\text { Atrativos para } \\
\text { troca }\end{array}$ & Emissões & \\
\hline 12 & $\begin{array}{c}\text { Forma Urbana e } \\
\text { consumo de energia }\end{array}$ & $\begin{array}{c}\text { Condicionamento } \\
\text { de ar }\end{array}$ & Densidade & Uso do solo & $(\mathrm{KO}, 2013)$ \\
\hline 13 & $\begin{array}{c}\text { Comportamento } \\
\text { familiar e Consumo } \\
\text { de energia }\end{array}$ & renda & $\begin{array}{l}\text { Tamanho da } \\
\text { cidade }\end{array}$ & $\begin{array}{c}\text { Grau de } \\
\text { urbanização }\end{array}$ & (LENZEN, 1998) \\
\hline 14 & Uso do solo & Transporte & $\begin{array}{l}\text { Emissões de } \\
\text { CO2 }\end{array}$ & & (LIU; SHEN, 2011) \\
\hline
\end{tabular}




\begin{tabular}{|c|c|c|c|c|c|}
\hline 15 & Uso do solo & Ilhas de calor & $\begin{array}{l}\text { Temperatura da } \\
\text { superfície do solo }\end{array}$ & & (LI et al., 2014) \\
\hline 16 & Eficiência energética & $\begin{array}{l}\text { Uso da } \\
\text { edificação }\end{array}$ & $\begin{array}{l}\text { Mobilidade } \\
\text { urbana }\end{array}$ & & $\begin{array}{l}\text { (MARIQUE et al., } \\
\text { 2014) }\end{array}$ \\
\hline 17 & $\begin{array}{c}\text { Densidade e } \\
\text { Consumo de energia }\end{array}$ & Uso do solo & $\begin{array}{l}\text { Mobilidade } \\
\text { urbana }\end{array}$ & & $\begin{array}{l}\text { (MINDALI; RAVEH; } \\
\text { SALOMON, 2004) }\end{array}$ \\
\hline 18 & $\begin{array}{l}\text { Comportamento } \\
\text { familiar e Consumo } \\
\text { de energia }\end{array}$ & $\begin{array}{l}\text { Consumo } \\
\text { sustentável }\end{array}$ & Infraestrutura & & (MOLL et al., 2008) \\
\hline 19 & $\begin{array}{l}\text { Emissões de CO2 } \\
\text { em viagens } \\
\text { internacionais }\end{array}$ & Transporte & $\begin{array}{l}\text { Emissões de } \\
\text { CO2 }\end{array}$ & & $\begin{array}{c}\text { (PETERS; } \\
\text { HERTWICH, 2008) }\end{array}$ \\
\hline 20 & $\begin{array}{c}\text { Comportamento } \\
\text { familiar e Consumo } \\
\text { de energia }\end{array}$ & Renda & & & $\begin{array}{c}\text { (REINDERS; } \\
\text { VRINGER; BLOK, } \\
\text { 2003) } \\
\end{array}$ \\
\hline 21 & $\begin{array}{l}\text { Comportamento } \\
\text { familiar e Consumo } \\
\text { de energia }\end{array}$ & $\begin{array}{l}\text { Comportamento } \\
\text { familiar }\end{array}$ & & & $\begin{array}{l}\text { (RICHARDSON; } \\
\text { THOMSON; } \\
\text { INFIELD, 2008) }\end{array}$ \\
\hline 22 & $\begin{array}{c}\text { Comportamento } \\
\text { familiar e Consumo } \\
\text { de energia }\end{array}$ & $\begin{array}{l}\text { Formato do } \\
\text { edifício }\end{array}$ & Renda & $\begin{array}{l}\text { Densidade } \\
\text { familiar }\end{array}$ & (RICKWOOD, 2009) \\
\hline 23 & Análise do edifício & $\begin{array}{l}\text { Energia } \\
\text { incorporada }\end{array}$ & Transporte & uso da edificação & $\begin{array}{c}\text { (STEPHAN; } \\
\text { CRAWFORD; DE } \\
\text { MYTTENAERE, } \\
\text { 2012) }\end{array}$ \\
\hline 24 & Clima urbano & ilhas de calor & Albedo & $\begin{array}{c}\text { Evapotranspiraçã } \\
0\end{array}$ & (TAHA, 1997) \\
\hline 25 & $\begin{array}{l}\text { Geometria Urbana } \\
\text { (formação de } \\
\text { Canyons) }\end{array}$ & $\begin{array}{l}\text { Geometria } \\
\text { Urbana }\end{array}$ & Ilha de calor & & $\begin{array}{c}\text { (THEEUWES et al., } \\
\text { 2014) }\end{array}$ \\
\hline 26 & $\begin{array}{l}\text { Características das } \\
\text { famílias }\end{array}$ & $\begin{array}{l}\text { Comportamento } \\
\text { familiar }\end{array}$ & $\begin{array}{l}\text { Consumo de } \\
\text { energia }\end{array}$ & & (TSO, 2003) \\
\hline 27 & $\begin{array}{c}\text { Urbanização e } \\
\text { consumo de energia }\end{array}$ & Urbanização & $\begin{array}{l}\text { Consumo de } \\
\text { energia }\end{array}$ & & (WANG, 2014) \\
\hline 28 & $\begin{array}{c}\text { Comportamento } \\
\text { familiar e Consumo } \\
\text { de energia }\end{array}$ & Urbano & Suburbano & Rural & $\begin{array}{c}\text { (WIEDENHOFER; } \\
\text { LENZEN; } \\
\text { STEINBERGER, } \\
\text { 2013) } \\
\end{array}$ \\
\hline 29 & $\begin{array}{c}\text { Ambiente e } \\
\text { emissões de CO2 } \\
\text { pelas famílias } \\
\end{array}$ & $\begin{array}{l}\text { Emissões de } \\
\text { CO2 }\end{array}$ & Densidade & Clima & (WIER et al., 2001) \\
\hline 30 & $\begin{array}{l}\text { Distribuição de água } \\
\text { e consumo de } \\
\text { energia }\end{array}$ & $\begin{array}{c}\text { Rede de } \\
\text { distribuição de } \\
\text { água }\end{array}$ & Vazamento & Pressão da rede & (XU et al., 2014) \\
\hline 31 & $\begin{array}{c}\text { Aquecimento } \\
\text { doméstico e } \\
\text { consumo de energia }\end{array}$ & $\begin{array}{l}\text { Aquecimento } \\
\text { ambiental }\end{array}$ & $\begin{array}{l}\text { Aquecimento de } \\
\text { água }\end{array}$ & & $\begin{array}{c}\text { (YAO; STEEMERS, } \\
\text { 2005) }\end{array}$ \\
\hline
\end{tabular}




\begin{tabular}{|c|c|c|c|c|c|}
\hline 32 & $\begin{array}{c}\text { Forma Urbana e } \\
\text { consumo de energia }\end{array}$ & Forma Urbana & $\begin{array}{l}\text { Consumo de } \\
\text { bens e serviços }\end{array}$ & Transportes & $\begin{array}{c}\text { (YIN; MIZOKAMI; } \\
\text { MARUYAMA, 2013a) }\end{array}$ \\
\hline 33 & $\begin{array}{c}\text { Densidade } \\
\text { populacional urbana } \\
\text { e consumo de } \\
\text { energia }\end{array}$ & $\begin{array}{l}\text { Densidade } \\
\text { Urbana }\end{array}$ & $\begin{array}{l}\text { Consumo de } \\
\text { energia }\end{array}$ & Renda & (YONGLING, 2011) \\
\hline 34 & $\begin{array}{c}\text { Resfriamento } \\
\text { ambiental e } \\
\text { consumo de energia }\end{array}$ & $\begin{array}{l}\text { Condicionamento } \\
\text { de ar }\end{array}$ & Renda & $\begin{array}{l}\text { Comportamento } \\
\text { individual }\end{array}$ & $\begin{array}{c}\text { (YUN; STEEMERS, } \\
\text { 2011) }\end{array}$ \\
\hline 35 & $\begin{array}{c}\text { Metabolismo Urbano } \\
\text { e Consumo de } \\
\text { energia }\end{array}$ & $\begin{array}{l}\text { Metabolismo } \\
\text { Urbano }\end{array}$ & $\begin{array}{l}\text { Emissões de } \\
\text { CO2 }\end{array}$ & & $\begin{array}{c}\text { (ZHANG; ZHENG; } \\
\text { FATH, 2014) }\end{array}$ \\
\hline 36 & $\begin{array}{c}\text { Consumo residencial } \\
\text { urbano }\end{array}$ & $\begin{array}{l}\text { Densidade } \\
\text { Urbana }\end{array}$ & Renda & $\begin{array}{l}\text { Comportamento } \\
\text { individual }\end{array}$ & $\begin{array}{c}\text { (ZHAO; LI; MA, } \\
\text { 2012) }\end{array}$ \\
\hline
\end{tabular}




\section{APÊNDICE B - MÉDIAS DOS RESULTADOS PARA OS 64 AJUSTES INICIAIS UTILIZADOS NA CALIBRAÇÃO DO MBA}

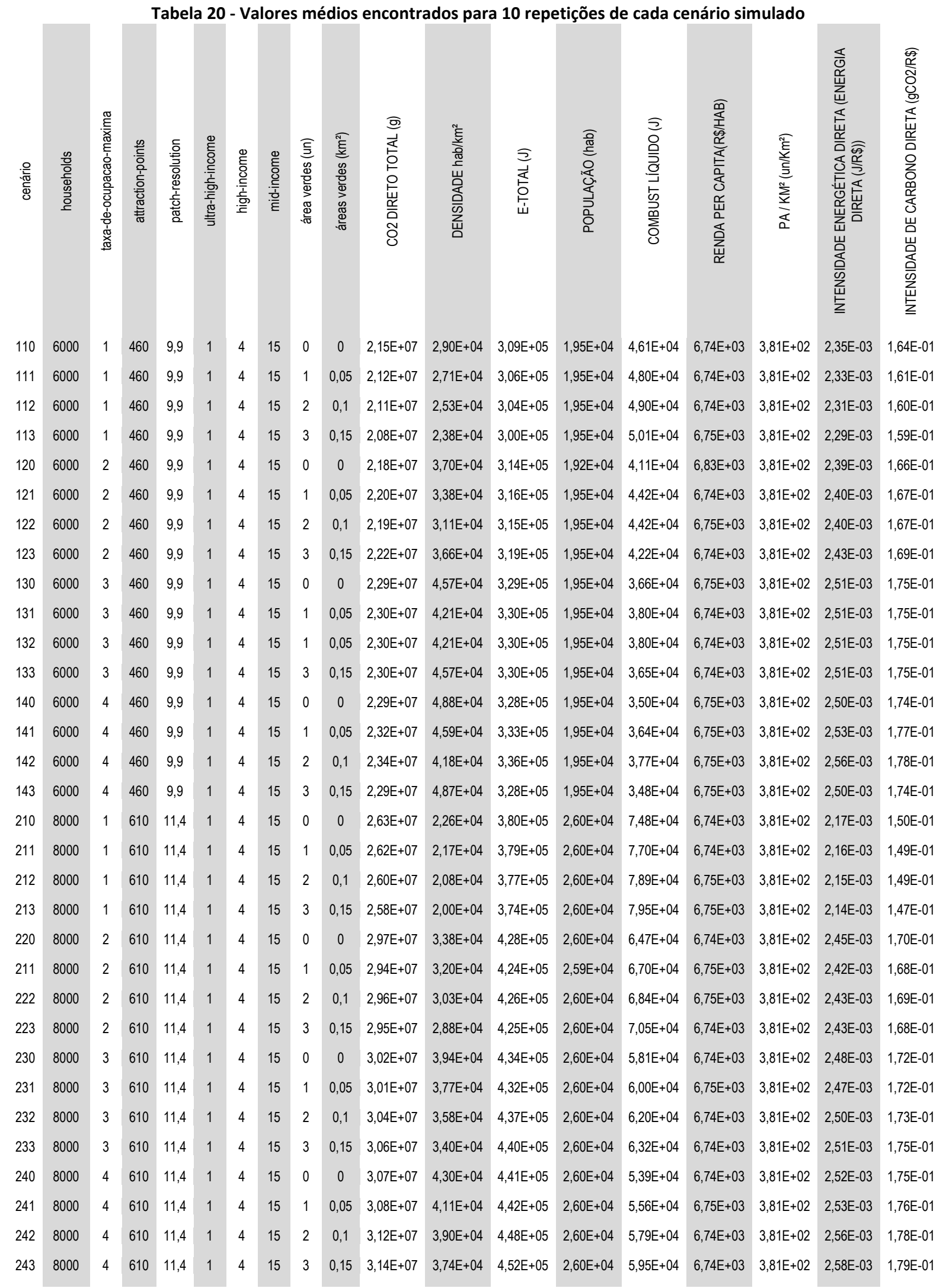




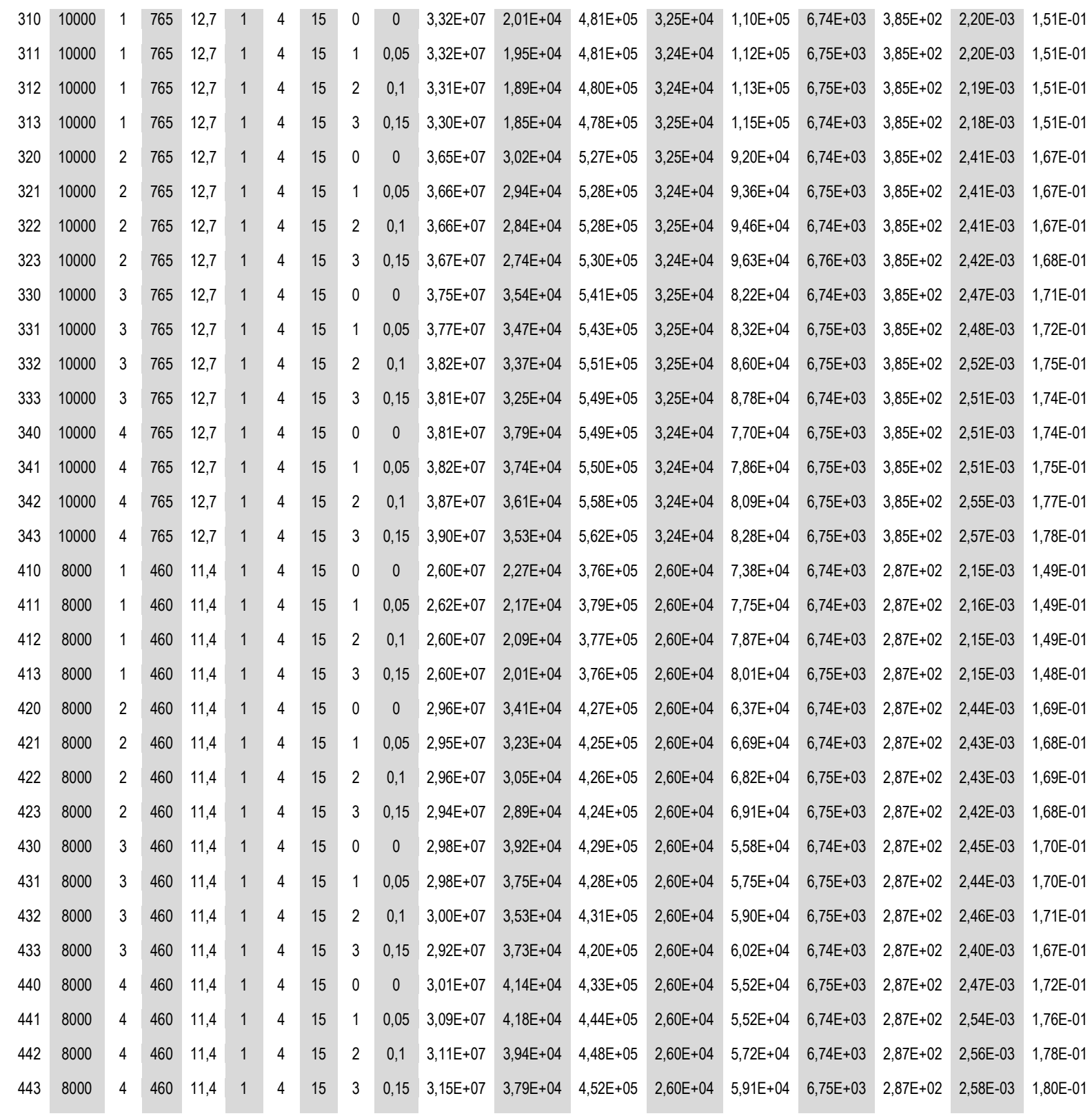

- Para identificar o arranjo da cidade simulada na tabela 20: Para o valor constante na coluna "cenário" o digito da centena, corresponde ao cenário simulado, o dígito da dezena corresponde à taxa de ocupação adotada e o dígito da unidade indica a quantidade de áreas verdes inseridas na cidade. 


\section{APÊNDICE C - CONSUMO PERCENTUAL POR SERVIÇO ENERGÉTICO}

\begin{tabular}{|c|c|c|c|c|c|c|c|c|c|c|c|}
\hline 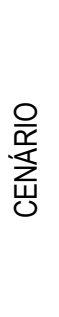 & 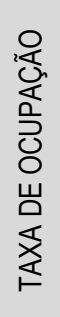 & 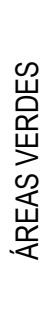 & 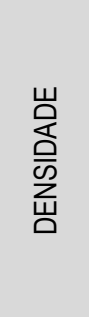 & 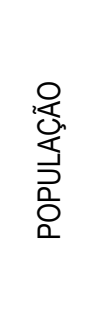 & $\begin{array}{l}\text { 㟯 } \\
\text { 㤩 } \\
\stackrel{0}{\Sigma}\end{array}$ & 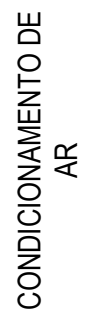 & 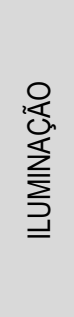 & 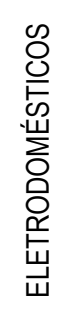 & 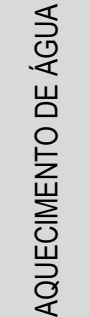 & $\begin{array}{l}\text { 은 } \\
\text { 岕 } \\
\text { O }\end{array}$ & 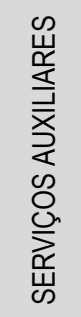 \\
\hline 1 & 1 & 0 & 29039 & 19475 & $63,7 \%$ & $3,9 \%$ & $5,3 \%$ & $7,6 \%$ & $11,5 \%$ & $2,7 \%$ & $5,3 \%$ \\
\hline 1 & 1 & 1 & 27051 & 19494 & $65,1 \%$ & $3,7 \%$ & $5,2 \%$ & $7,3 \%$ & $10,8 \%$ & $2,6 \%$ & $5,3 \%$ \\
\hline 1 & 1 & 2 & 25313 & 19480 & $65,8 \%$ & $3,5 \%$ & $5,2 \%$ & $7,1 \%$ & $10,6 \%$ & $2,6 \%$ & $5,2 \%$ \\
\hline 1 & 1 & 3 & 23769 & 19462 & $66,7 \%$ & $3,3 \%$ & $5,1 \%$ & $7,0 \%$ & $10,2 \%$ & $2,5 \%$ & $5,2 \%$ \\
\hline 1 & 2 & 0 & 37029 & 19246 & $60,1 \%$ & $3,7 \%$ & $5,2 \%$ & $7,7 \%$ & $11,4 \%$ & $2,8 \%$ & $9,2 \%$ \\
\hline 1 & 2 & 1 & 33803 & 19484 & $61,9 \%$ & $3,5 \%$ & $5,1 \%$ & $7,4 \%$ & $10,5 \%$ & $2,7 \%$ & $9,0 \%$ \\
\hline 1 & 2 & 2 & 31137 & 19473 & $62,0 \%$ & $3,4 \%$ & $5,1 \%$ & $7,3 \%$ & $10,4 \%$ & $2,7 \%$ & $9,1 \%$ \\
\hline 1 & 2 & 3 & 36598 & 19491 & $60,4 \%$ & $3,7 \%$ & $5,2 \%$ & $7,6 \%$ & $11,3 \%$ & $2,8 \%$ & $9,0 \%$ \\
\hline 1 & 3 & 0 & 45715 & 19468 & $55,6 \%$ & $3,6 \%$ & $5,3 \%$ & $8,1 \%$ & $11,8 \%$ & $3,1 \%$ & $12,5 \%$ \\
\hline 1 & 3 & 1 & 42089 & 19481 & $56,6 \%$ & $3,5 \%$ & $5,3 \%$ & $7,7 \%$ & $11,2 \%$ & $3,0 \%$ & $12,8 \%$ \\
\hline 1 & 3 & 2 & 45724 & 19494 & $55,6 \%$ & $3,6 \%$ & $5,3 \%$ & $8,0 \%$ & $11,7 \%$ & $3,1 \%$ & $12,5 \%$ \\
\hline 1 & 3 & 3 & 45726 & 19483 & $55,5 \%$ & $3,7 \%$ & $5,3 \%$ & $8,1 \%$ & $11,8 \%$ & $3,1 \%$ & $12,6 \%$ \\
\hline 1 & 4 & 0 & 48807 & 19453 & $54,5 \%$ & $3,4 \%$ & $5,3 \%$ & $8,1 \%$ & $11,4 \%$ & $3,2 \%$ & $14,1 \%$ \\
\hline 1 & 4 & 1 & 45926 & 19466 & $55,1 \%$ & $3,3 \%$ & $5,2 \%$ & $7,7 \%$ & $11,0 \%$ & $3,0 \%$ & $14,5 \%$ \\
\hline 1 & 4 & 2 & 41831 & 19472 & $55,9 \%$ & $3,2 \%$ & $5,1 \%$ & $7,6 \%$ & $10,4 \%$ & $3,0 \%$ & $14,8 \%$ \\
\hline 1 & 4 & 3 & 48665 & 19471 & $54,2 \%$ & $3,5 \%$ & $5,4 \%$ & $8,1 \%$ & $11,5 \%$ & $3,2 \%$ & $14,1 \%$ \\
\hline 2 & 1 & 0 & 22574 & 25981 & $71,0 \%$ & $3,4 \%$ & $4,6 \%$ & $6,8 \%$ & $9,8 \%$ & $2,4 \%$ & $2,0 \%$ \\
\hline 2 & 1 & 1 & 21743 & 25982 & $71,8 \%$ & $3,2 \%$ & $4,6 \%$ & $6,6 \%$ & $9,5 \%$ & $2,4 \%$ & $1,9 \%$ \\
\hline 2 & 1 & 2 & 20804 & 25964 & $72,6 \%$ & $3,0 \%$ & $4,5 \%$ & $6,4 \%$ & $9,2 \%$ & $2,3 \%$ & $1,9 \%$ \\
\hline 2 & 1 & 3 & 20048 & 25960 & $73,0 \%$ & $2,9 \%$ & $4,5 \%$ & $6,3 \%$ & $9,0 \%$ & $2,3 \%$ & $2,0 \%$ \\
\hline 2 & 2 & 0 & 33815 & 25975 & $64,0 \%$ & $3,4 \%$ & $4,7 \%$ & $7,1 \%$ & $10,5 \%$ & $2,6 \%$ & $7,7 \%$ \\
\hline 2 & 2 & 1 & 31978 & 25937 & $65,2 \%$ & $3,3 \%$ & $4,6 \%$ & $6,9 \%$ & $9,8 \%$ & $2,5 \%$ & $7,6 \%$ \\
\hline 2 & 2 & 2 & 30283 & 25963 & $65,7 \%$ & $3,1 \%$ & $4,6 \%$ & $6,8 \%$ & $9,8 \%$ & $2,5 \%$ & $7,6 \%$ \\
\hline 2 & 2 & 3 & 28821 & 25980 & $66,6 \%$ & $3,0 \%$ & $4,5 \%$ & $6,6 \%$ & $9,4 \%$ & $2,4 \%$ & $7,6 \%$ \\
\hline 2 & 3 & 0 & 39384 & 25976 & $60,7 \%$ & $3,4 \%$ & $4,8 \%$ & $7,4 \%$ & $10,8 \%$ & $2,8 \%$ & $10,0 \%$ \\
\hline 2 & 3 & 1 & 37700 & 25965 & $61,7 \%$ & $3,3 \%$ & $4,8 \%$ & $7,2 \%$ & $10,1 \%$ & $2,8 \%$ & $10,2 \%$ \\
\hline 2 & 3 & 2 & 35756 & 25997 & $62,3 \%$ & $3,2 \%$ & $4,7 \%$ & $7,0 \%$ & $10,0 \%$ & $2,7 \%$ & $10,2 \%$ \\
\hline 2 & 3 & 3 & 33997 & 25975 & $62,6 \%$ & $3,1 \%$ & $4,6 \%$ & $6,9 \%$ & $9,9 \%$ & $2,6 \%$ & $10,3 \%$ \\
\hline 2 & 4 & 0 & 42959 & 25986 & $58,2 \%$ & $3,3 \%$ & $4,9 \%$ & $7,5 \%$ & $10,9 \%$ & $3,0 \%$ & $12,1 \%$ \\
\hline 2 & 4 & 1 & 41085 & 25958 & $58,9 \%$ & $3,2 \%$ & $4,8 \%$ & $7,3 \%$ & $10,5 \%$ & $2,9 \%$ & $12,3 \%$ \\
\hline 2 & 4 & 2 & 39040 & 25982 & $59,7 \%$ & $3,1 \%$ & $4,7 \%$ & $7,1 \%$ & $10,2 \%$ & $2,8 \%$ & $12,4 \%$ \\
\hline 2 & 4 & 3 & 37363 & 25969 & $60,3 \%$ & $3,0 \%$ & $4,7 \%$ & $7,0 \%$ & $9,8 \%$ & $2,7 \%$ & $12,6 \%$ \\
\hline 3 & 1 & 0 & 20080 & 32486 & $74,7 \%$ & $2,8 \%$ & $4,1 \%$ & $5,9 \%$ & $8,5 \%$ & $2,1 \%$ & $1,8 \%$ \\
\hline 3 & 1 & 1 & 19543 & 32443 & $75,2 \%$ & $2,7 \%$ & $4,1 \%$ & $5,8 \%$ & $8,4 \%$ & $2,1 \%$ & $1,8 \%$ \\
\hline 3 & 1 & 2 & 18949 & 32423 & $75,6 \%$ & $2,6 \%$ & $4,0 \%$ & $5,8 \%$ & $8,2 \%$ & $2,1 \%$ & $1,8 \%$ \\
\hline
\end{tabular}




\begin{tabular}{|c|c|c|c|c|c|c|c|c|c|c|c|}
\hline 3 & 1 & 3 & \multicolumn{2}{|c|}{$18463 \quad 32464$} & \multicolumn{2}{|c|}{$76,0 \% \quad 2,5 \%$} & $4,0 \%$ & $5,7 \%$ & $8,0 \%$ & $2,1 \%$ & $1,8 \%$ \\
\hline 3 & 2 & 0 & 30188 & 32466 & $67,9 \%$ & $3,1 \%$ & $4,3 \%$ & $6,6 \%$ & $9,4 \%$ & $2,4 \%$ & $6,3 \%$ \\
\hline 3 & 2 & 1 & 29358 & 32446 & $68,3 \%$ & $3,0 \%$ & $4,3 \%$ & $6,5 \%$ & $9,2 \%$ & $2,4 \%$ & $6,3 \%$ \\
\hline 3 & 2 & 2 & 28367 & 32470 & $68,6 \%$ & $2,9 \%$ & $4,2 \%$ & $6,4 \%$ & $9,1 \%$ & $2,4 \%$ & $6,4 \%$ \\
\hline 3 & 2 & 3 & 27409 & 32409 & $69,0 \%$ & $2,9 \%$ & $4,2 \%$ & $6,3 \%$ & $9,0 \%$ & $2,3 \%$ & $6,4 \%$ \\
\hline 3 & 3 & 0 & 35370 & 32481 & $64,2 \%$ & $3,1 \%$ & $4,5 \%$ & $6,9 \%$ & $10,0 \%$ & $2,6 \%$ & $8,7 \%$ \\
\hline 3 & 3 & 1 & 34733 & 32454 & $64,4 \%$ & $3,1 \%$ & $4,5 \%$ & $6,8 \%$ & $9,6 \%$ & $2,6 \%$ & $9,0 \%$ \\
\hline 3 & 3 & 2 & 33722 & 32457 & $64,9 \%$ & $3,0 \%$ & $4,4 \%$ & $6,6 \%$ & $9,6 \%$ & $2,5 \%$ & $9,0 \%$ \\
\hline 3 & 3 & 3 & 32547 & 32467 & $65,5 \%$ & $2,9 \%$ & $4,3 \%$ & $6,5 \%$ & $9,3 \%$ & $2,5 \%$ & $9,0 \%$ \\
\hline 3 & 4 & 0 & 37893 & 32421 & $62,0 \%$ & $3,1 \%$ & $4,6 \%$ & $7,0 \%$ & $10,1 \%$ & $2,7 \%$ & $10,5 \%$ \\
\hline 3 & 4 & 1 & 37378 & 32427 & $62,5 \%$ & $3,1 \%$ & $4,5 \%$ & $6,9 \%$ & $9,6 \%$ & $2,7 \%$ & $10,7 \%$ \\
\hline 3 & 4 & 2 & 36129 & 32446 & $62,9 \%$ & $3,0 \%$ & $4,4 \%$ & $6,7 \%$ & $9,6 \%$ & $2,6 \%$ & $10,8 \%$ \\
\hline 3 & 4 & 3 & 35266 & 32424 & $63,4 \%$ & $2,9 \%$ & $4,4 \%$ & $6,6 \%$ & $9,3 \%$ & $2,5 \%$ & $11,0 \%$ \\
\hline 4 & 1 & 0 & 22682 & 25971 & $70,9 \%$ & $3,4 \%$ & $4,7 \%$ & $6,8 \%$ & $9,8 \%$ & $2,5 \%$ & $2,0 \%$ \\
\hline 4 & 1 & 1 & 21730 & 25978 & $72,0 \%$ & $3,1 \%$ & $4,5 \%$ & $6,6 \%$ & $9,4 \%$ & $2,3 \%$ & $1,9 \%$ \\
\hline 4 & 1 & 2 & 20886 & 25981 & $72,5 \%$ & $3,0 \%$ & $4,5 \%$ & $6,4 \%$ & $9,3 \%$ & $2,3 \%$ & $1,9 \%$ \\
\hline 4 & 1 & 3 & 20103 & 25964 & $73,0 \%$ & $2,9 \%$ & $4,5 \%$ & $6,3 \%$ & $9,1 \%$ & $2,3 \%$ & $1,9 \%$ \\
\hline 4 & 2 & 0 & 34065 & 25976 & $63,7 \%$ & $3,5 \%$ & $4,8 \%$ & $7,1 \%$ & $10,6 \%$ & $2,6 \%$ & $7,7 \%$ \\
\hline 4 & 2 & 1 & 32303 & 25967 & $65,1 \%$ & $3,3 \%$ & $4,6 \%$ & $6,9 \%$ & $9,8 \%$ & $2,5 \%$ & $7,7 \%$ \\
\hline 4 & 2 & 2 & 30529 & 25950 & $65,6 \%$ & $3,2 \%$ & $4,6 \%$ & $6,8 \%$ & $9,8 \%$ & $2,5 \%$ & $7,7 \%$ \\
\hline 4 & 2 & 3 & 28899 & 25966 & $66,0 \%$ & $3,0 \%$ & $4,6 \%$ & $6,7 \%$ & $9,6 \%$ & $2,5 \%$ & $7,6 \%$ \\
\hline 4 & 3 & 0 & 39157 & 25975 & $59,9 \%$ & $3,4 \%$ & $5,0 \%$ & $7,6 \%$ & $11,0 \%$ & $2,9 \%$ & $10,1 \%$ \\
\hline 4 & 3 & 1 & 37548 & 25955 & $60,8 \%$ & $3,3 \%$ & $4,9 \%$ & $7,4 \%$ & $10,4 \%$ & $2,9 \%$ & $10,3 \%$ \\
\hline 4 & 3 & 2 & 35335 & 25958 & $61,4 \%$ & $3,3 \%$ & $4,8 \%$ & $7,2 \%$ & $10,3 \%$ & $2,8 \%$ & $10,3 \%$ \\
\hline 4 & 3 & 3 & 37319 & 25981 & $62,6 \%$ & $3,3 \%$ & $4,8 \%$ & $7,3 \%$ & $10,2 \%$ & $2,8 \%$ & $9,1 \%$ \\
\hline 4 & 4 & 0 & 41432 & 25953 & $59,4 \%$ & $3,2 \%$ & $4,9 \%$ & $7,5 \%$ & $10,7 \%$ & $2,9 \%$ & $11,4 \%$ \\
\hline 4 & 4 & 1 & 41790 & 25968 & $58,8 \%$ & $3,2 \%$ & $4,9 \%$ & $7,3 \%$ & $10,5 \%$ & $2,9 \%$ & $12,4 \%$ \\
\hline 4 & 4 & 2 & 39388 & 25970 & $59,4 \%$ & $3,1 \%$ & $4,8 \%$ & $7,2 \%$ & $10,2 \%$ & $2,8 \%$ & $12,5 \%$ \\
\hline 4 & 4 & 3 & 37905 & 25954 & $60,1 \%$ & $3,1 \%$ & $4,7 \%$ & $7,0 \%$ & $9,8 \%$ & $2,7 \%$ & $12,7 \%$ \\
\hline
\end{tabular}




\section{APÊNDICE D - EMISSÕES PERCENTUAIS POR SERVIÇO ENERGÉTICO}

Tabela 22 - Participação percentual de cada serviço energético nas emissões de $\mathrm{CO}_{2}$ para os 64 ajustes.

\begin{tabular}{|c|c|c|c|c|c|c|c|c|c|c|c|}
\hline 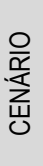 & 崖焉 & 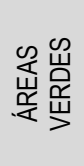 & $\begin{array}{l}\text { 岩 } \\
\text { 空 } \\
\text { 㟧 }\end{array}$ & 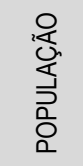 & 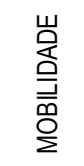 & 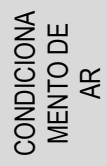 & 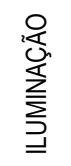 & 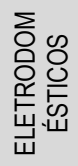 & 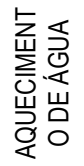 & 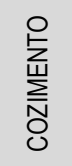 & 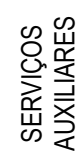 \\
\hline 1 & 1 & 0 & 29039 & 19475 & $61,6 \%$ & $4,2 \%$ & $5,7 \%$ & $8,1 \%$ & $12,3 \%$ & $2,5 \%$ & $5,7 \%$ \\
\hline 1 & 1 & 1 & 27051 & 19494 & $63,0 \%$ & $3,9 \%$ & $5,6 \%$ & $7,8 \%$ & $11,6 \%$ & $2,5 \%$ & $5,6 \%$ \\
\hline 1 & 1 & 2 & 25313 & 19480 & $63,8 \%$ & $3,7 \%$ & $5,5 \%$ & $7,6 \%$ & $11,3 \%$ & $2,4 \%$ & $5,6 \%$ \\
\hline 1 & 1 & 3 & 23769 & 19462 & $64,7 \%$ & $3,5 \%$ & $5,5 \%$ & $7,5 \%$ & $10,9 \%$ & $2,4 \%$ & $5,6 \%$ \\
\hline 1 & 2 & 0 & 37029 & 19246 & $57,9 \%$ & $3,9 \%$ & $5,5 \%$ & $8,1 \%$ & $12,1 \%$ & $2,7 \%$ & $9,7 \%$ \\
\hline 1 & 2 & 1 & 33803 & 19484 & $59,8 \%$ & $3,7 \%$ & $5,4 \%$ & $7,8 \%$ & $11,1 \%$ & $2,6 \%$ & $9,6 \%$ \\
\hline 1 & 2 & 2 & 31137 & 19473 & $59,9 \%$ & $3,6 \%$ & $5,4 \%$ & $7,8 \%$ & $11,1 \%$ & $2,6 \%$ & $9,6 \%$ \\
\hline 1 & 2 & 3 & 36598 & 19491 & $58,3 \%$ & $3,9 \%$ & $5,5 \%$ & $8,1 \%$ & $12,0 \%$ & $2,7 \%$ & $9,6 \%$ \\
\hline 1 & 3 & 0 & 45715 & 19468 & $53,3 \%$ & $3,9 \%$ & $5,6 \%$ & $8,5 \%$ & $12,5 \%$ & $2,9 \%$ & $13,2 \%$ \\
\hline 1 & 3 & 1 & 42089 & 19481 & $54,3 \%$ & $3,7 \%$ & $5,6 \%$ & $8,2 \%$ & $11,9 \%$ & $2,8 \%$ & $13,5 \%$ \\
\hline 1 & 3 & 2 & 45724 & 19494 & $53,4 \%$ & $3,8 \%$ & $5,6 \%$ & $8,5 \%$ & $12,4 \%$ & $2,9 \%$ & $13,3 \%$ \\
\hline 1 & 3 & 3 & 45726 & 19483 & $53,2 \%$ & $3,9 \%$ & $5,7 \%$ & $8,5 \%$ & $12,5 \%$ & $2,9 \%$ & $13,3 \%$ \\
\hline 1 & 4 & 0 & 48807 & 19453 & $52,2 \%$ & $3,6 \%$ & $5,7 \%$ & $8,5 \%$ & $12,1 \%$ & $3,0 \%$ & $14,9 \%$ \\
\hline 1 & 4 & 1 & 45926 & 19466 & $52,8 \%$ & $3,5 \%$ & $5,5 \%$ & $8,2 \%$ & $11,7 \%$ & $2,9 \%$ & $15,4 \%$ \\
\hline 1 & 4 & 2 & 41831 & 19472 & $53,6 \%$ & $3,4 \%$ & $5,5 \%$ & $8,0 \%$ & $11,1 \%$ & $2,8 \%$ & $15,7 \%$ \\
\hline 1 & 4 & 3 & 48665 & 19471 & $52,0 \%$ & $3,7 \%$ & $5,7 \%$ & $8,6 \%$ & $12,1 \%$ & $3,0 \%$ & $14,9 \%$ \\
\hline 2 & 1 & 0 & 22574 & 25981 & $69,2 \%$ & $3,6 \%$ & $5,0 \%$ & $7,3 \%$ & $10,5 \%$ & $2,3 \%$ & $2,1 \%$ \\
\hline 2 & 1 & 1 & 21743 & 25982 & $70,1 \%$ & $3,4 \%$ & $4,9 \%$ & $7,1 \%$ & $10,2 \%$ & $2,2 \%$ & $2,1 \%$ \\
\hline 2 & 1 & 2 & 20804 & 25964 & $70,8 \%$ & $3,2 \%$ & $4,8 \%$ & $6,9 \%$ & $9,9 \%$ & $2,2 \%$ & $2,1 \%$ \\
\hline 2 & 1 & 3 & 20048 & 25960 & $71,2 \%$ & $3,1 \%$ & $4,8 \%$ & $6,8 \%$ & $9,7 \%$ & $2,2 \%$ & $2,1 \%$ \\
\hline 2 & 2 & 0 & 33815 & 25975 & $62,0 \%$ & $3,6 \%$ & $5,0 \%$ & $7,6 \%$ & $11,2 \%$ & $2,5 \%$ & $8,2 \%$ \\
\hline 2 & 2 & 1 & 31978 & 25937 & $63,1 \%$ & $3,5 \%$ & $4,9 \%$ & $7,4 \%$ & $10,5 \%$ & $2,4 \%$ & $8,1 \%$ \\
\hline 2 & 2 & 2 & 30283 & 25963 & $63,6 \%$ & $3,4 \%$ & $4,9 \%$ & $7,2 \%$ & $10,4 \%$ & $2,4 \%$ & $8,1 \%$ \\
\hline 2 & 2 & 3 & 28821 & 25980 & $64,5 \%$ & $3,2 \%$ & $4,8 \%$ & $7,0 \%$ & $10,0 \%$ & $2,3 \%$ & $8,1 \%$ \\
\hline 2 & 3 & 0 & 39384 & 25976 & $58,5 \%$ & $3,6 \%$ & $5,1 \%$ & $7,9 \%$ & $11,5 \%$ & $2,7 \%$ & $10,6 \%$ \\
\hline 2 & 3 & 1 & 37700 & 25965 & $59,5 \%$ & $3,5 \%$ & $5,1 \%$ & $7,7 \%$ & $10,8 \%$ & $2,6 \%$ & $10,9 \%$ \\
\hline 2 & 3 & 2 & 35756 & 25997 & $60,2 \%$ & $3,4 \%$ & $5,0 \%$ & $7,5 \%$ & $10,7 \%$ & $2,5 \%$ & $10,8 \%$ \\
\hline 2 & 3 & 3 & 33997 & 25975 & $60,5 \%$ & $3,3 \%$ & $4,9 \%$ & $7,3 \%$ & $10,5 \%$ & $2,5 \%$ & $10,9 \%$ \\
\hline 2 & 4 & 0 & 42959 & 25986 & $56,0 \%$ & $3,5 \%$ & $5,2 \%$ & $8,0 \%$ & $11,6 \%$ & $2,8 \%$ & $12,9 \%$ \\
\hline 2 & 4 & 1 & 41085 & 25958 & $56,7 \%$ & $3,4 \%$ & $5,2 \%$ & $7,8 \%$ & $11,1 \%$ & $2,7 \%$ & $13,1 \%$ \\
\hline 2 & 4 & 2 & 39040 & 25982 & $57,5 \%$ & $3,3 \%$ & $5,0 \%$ & $7,6 \%$ & $10,8 \%$ & $2,6 \%$ & $13,2 \%$ \\
\hline 2 & 4 & 3 & 37363 & 25969 & $58,0 \%$ & $3,2 \%$ & $5,0 \%$ & $7,4 \%$ & $10,4 \%$ & $2,5 \%$ & $13,4 \%$ \\
\hline 3 & 1 & 0 & 20080 & 32486 & $73,1 \%$ & $3,0 \%$ & $4,4 \%$ & $6,4 \%$ & $9,1 \%$ & $2,1 \%$ & $1,9 \%$ \\
\hline 3 & 1 & 1 & 19543 & 32443 & $73,6 \%$ & $2,9 \%$ & $4,4 \%$ & $6,3 \%$ & $9,0 \%$ & $2,0 \%$ & $1,9 \%$ \\
\hline 3 & 1 & 2 & 18949 & 32423 & $74,0 \%$ & $2,8 \%$ & $4,3 \%$ & $6,2 \%$ & $8,8 \%$ & $2,0 \%$ & $1,9 \%$ \\
\hline 3 & 1 & 3 & 18463 & 32464 & $74,4 \%$ & $2,7 \%$ & $4,3 \%$ & $6,1 \%$ & $8,6 \%$ & $2,0 \%$ & $1,9 \%$ \\
\hline
\end{tabular}




\begin{tabular}{|c|c|c|c|c|c|c|c|c|c|c|c|}
\hline 3 & 2 & 0 & 30188 & 32466 & $65,9 \%$ & $3,3 \%$ & $4,6 \%$ & $7,0 \%$ & $10,1 \%$ & $2,3 \%$ & $6,7 \%$ \\
\hline 3 & 2 & 1 & 29358 & 32446 & $66,4 \%$ & $3,2 \%$ & $4,6 \%$ & $6,9 \%$ & $9,9 \%$ & $2,3 \%$ & $6,7 \%$ \\
\hline 3 & 2 & 2 & 28367 & 32470 & $66,6 \%$ & $3,1 \%$ & $4,5 \%$ & $6,8 \%$ & $9,8 \%$ & $2,3 \%$ & $6,8 \%$ \\
\hline 3 & 2 & 3 & 27409 & 32409 & $67,0 \%$ & $3,1 \%$ & $4,5 \%$ & $6,7 \%$ & $9,6 \%$ & $2,2 \%$ & $6,9 \%$ \\
\hline 3 & 3 & 0 & 35370 & 32481 & $62,1 \%$ & $3,3 \%$ & $4,8 \%$ & $7,4 \%$ & $10,6 \%$ & $2,5 \%$ & $9,3 \%$ \\
\hline 3 & 3 & 1 & 34733 & 32454 & $62,3 \%$ & $3,3 \%$ & $4,8 \%$ & $7,3 \%$ & $10,3 \%$ & $2,5 \%$ & $9,6 \%$ \\
\hline 3 & 3 & 2 & 33722 & 32457 & $62,8 \%$ & $3,2 \%$ & $4,7 \%$ & $7,1 \%$ & $10,2 \%$ & $2,4 \%$ & $9,6 \%$ \\
\hline 3 & 3 & 3 & 32547 & 32467 & $63,4 \%$ & $3,1 \%$ & $4,6 \%$ & $6,9 \%$ & $10,0 \%$ & $2,3 \%$ & $9,6 \%$ \\
\hline 3 & 4 & 0 & 37893 & 32421 & $59,9 \%$ & $3,3 \%$ & $4,9 \%$ & $7,5 \%$ & $10,8 \%$ & $2,6 \%$ & $11,1 \%$ \\
\hline 3 & 4 & 1 & 37378 & 32427 & $60,3 \%$ & $3,3 \%$ & $4,8 \%$ & $7,4 \%$ & $10,2 \%$ & $2,6 \%$ & $11,5 \%$ \\
\hline 3 & 4 & 2 & 36129 & 32446 & $60,8 \%$ & $3,1 \%$ & $4,7 \%$ & $7,2 \%$ & $10,2 \%$ & $2,5 \%$ & $11,5 \%$ \\
\hline 3 & 4 & 3 & 35266 & 32424 & $61,2 \%$ & $3,1 \%$ & $4,7 \%$ & $7,0 \%$ & $10,0 \%$ & $2,4 \%$ & $11,7 \%$ \\
\hline 4 & 1 & 0 & 22682 & 25971 & $69,1 \%$ & $3,6 \%$ & $5,0 \%$ & $7,3 \%$ & $10,4 \%$ & $2,4 \%$ & $2,1 \%$ \\
\hline 4 & 1 & 1 & 21730 & 25978 & $70,3 \%$ & $3,4 \%$ & $4,9 \%$ & $7,0 \%$ & $10,1 \%$ & $2,2 \%$ & $2,1 \%$ \\
\hline 4 & 1 & 2 & 20886 & 25981 & $70,8 \%$ & $3,2 \%$ & $4,9 \%$ & $6,9 \%$ & $9,9 \%$ & $2,2 \%$ & $2,1 \%$ \\
\hline 4 & 1 & 3 & 20103 & 25964 & $71,3 \%$ & $3,1 \%$ & $4,8 \%$ & $6,8 \%$ & $9,7 \%$ & $2,2 \%$ & $2,1 \%$ \\
\hline 4 & 2 & 0 & 34065 & 25976 & $61,6 \%$ & $3,7 \%$ & $5,1 \%$ & $7,6 \%$ & $11,3 \%$ & $2,5 \%$ & $8,2 \%$ \\
\hline 4 & 2 & 1 & 32303 & 25967 & $63,0 \%$ & $3,5 \%$ & $5,0 \%$ & $7,4 \%$ & $10,5 \%$ & $2,4 \%$ & $8,2 \%$ \\
\hline 4 & 2 & 2 & 30529 & 25950 & $63,5 \%$ & $3,4 \%$ & $4,9 \%$ & $7,2 \%$ & $10,4 \%$ & $2,4 \%$ & $8,2 \%$ \\
\hline 4 & 2 & 3 & 28899 & 25966 & $64,0 \%$ & $3,3 \%$ & $4,9 \%$ & $7,1 \%$ & $10,3 \%$ & $2,4 \%$ & $8,2 \%$ \\
\hline 4 & 3 & 0 & 39157 & 25975 & $57,7 \%$ & $3,7 \%$ & $5,3 \%$ & $8,1 \%$ & $11,7 \%$ & $2,8 \%$ & $10,7 \%$ \\
\hline 4 & 3 & 1 & 37548 & 25955 & $58,6 \%$ & $3,6 \%$ & $5,2 \%$ & $7,9 \%$ & $11,0 \%$ & $2,7 \%$ & $11,0 \%$ \\
\hline 4 & 3 & 2 & 35335 & 25958 & $59,2 \%$ & $3,5 \%$ & $5,1 \%$ & $7,7 \%$ & $11,0 \%$ & $2,7 \%$ & $10,9 \%$ \\
\hline 4 & 3 & 3 & 37319 & 25981 & $60,5 \%$ & $3,5 \%$ & $5,1 \%$ & $7,7 \%$ & $10,9 \%$ & $2,6 \%$ & $9,7 \%$ \\
\hline 4 & 4 & 0 & 41432 & 25953 & $57,2 \%$ & $3,4 \%$ & $5,2 \%$ & $7,9 \%$ & $11,4 \%$ & $2,8 \%$ & $12,1 \%$ \\
\hline 4 & 4 & 1 & 41790 & 25968 & $56,5 \%$ & $3,4 \%$ & $5,2 \%$ & $7,8 \%$ & $11,2 \%$ & $2,7 \%$ & $13,2 \%$ \\
\hline 4 & 4 & 2 & 39388 & 25970 & $57,2 \%$ & $3,3 \%$ & $5,1 \%$ & $7,6 \%$ & $10,9 \%$ & $2,6 \%$ & $13,3 \%$ \\
\hline 4 & 4 & 3 & 37905 & 25954 & $57,8 \%$ & $3,3 \%$ & $5,0 \%$ & $7,4 \%$ & $10,5 \%$ & $2,6 \%$ & $13,5 \%$ \\
\hline
\end{tabular}




\section{APÊNDICE E - DEFINIÇÕES DE TERMOS UTILIZADOS NESTE TRABALHO \\ EFICIÊNCIA ENERGÉTICA}

O conceito de eficiência energética aplicado às cidades sustentáveis está relacionado à redução do total de energia suficiente para manter o mesmo padrão de utilização dos serviços e produção existentes, seja este objetivo alcançado através da aplicação de novas tecnologias ou novos processos.

Em termos técnicos a eficiência energética é medida pela relação entre a quantidade de energia empregada em uma atividade e aquela disponibilizada para sua realização, ou seja, quanto menor a quantidade de energia disponibilizada para realização da mesma atividade, diz-se maior a eficiência energética.

ENERGIA PRIMÁRIA

São Fontes Primárias de Energia todas aquelas que são provenientes diretamente da natureza. Recursos naturais de energia (combustíveis fósseis (petróleo; gás natural), o vento, a água, o sol) são exemplos de fontes primárias de energia.

\section{ENERGIA SECUNDÁRIA}

São Fontes Secundárias de Energia aquelas que resultam da transformação de Fontes Primárias. Energia obtida a partir de fontes primárias (óleo diesel, gasolina, eletricidade) são exemplos de fontes secundárias.

\section{INTENSIDADE ENERGÉTICA}

Intensidade energética é a medida da demanda energética associada à economia de um determinado país. É calculada pelo valor global da energia consumida nesse país dividida pelo seu produto interno bruto em um determinado período e pode ser apresentada, por exemplo, em Megajoules/dólar.

\section{CONSERVAÇÃO DE ENERGIA}

Referindo-se ao uso consciente, a queda do consumo ou aumento da eficiência de forma que a quantidade de energia total consumida seja menor do que habitualmente é, reduzindo as perdas de energia, mas atendendo o mesmo nível de usos finais energéticos. 
USO RACIONAL DE ENERGIA

Consiste em utilizar energia somente em situações realmente necessárias, reduzindo as perdas e eliminando o consumo supérfluo sem alterar os padrões de necessidade e conforto de que a atividade necessita. 


\section{APÊNDICE F - CÓDIGO DA PROGRAMAÇÃO DO NetLogo}

extensions [matrix bitmap]

breed [industrias industria]

breed [comercios comercio]

breed [cidades cidade]

breed [estacoes estacao]

breed [habitantes habitante]

breed [arvores arvore]

habitantes-own

[

status

tamanho-familia

vinculos

dist-vinculos

dist-com-transporte

modal

b-cooker

residencia

area-residencia

uso-GN

USO-SOLAR

e-transporte

e-iluminacao

eletrodomesticos

e-eletrodomesticos

e-aguaq

e-ar

e-coz

e-serv

emission-mobility

emission-ar

emission-lighting

emission-appliances

emission-coz

emission-aguaq

emission-service

globals

escolhido

casa-nova

casa-antiga

dist-atual

dist-nova

lista-de-cidades

lista-populacao

tamanho-medio-residencias

tamanho-medio-familias

raio-ICH

ocupacao-patch-max

vizinhanca-max

vincular-attratcion-points

raio-GN

conectividade-mundo

consumo-e-transporte

consumo-e-ar

consumo-e-iluminacao

consumo-e-aguaq

consumo-e-eletrodomesticos

consumo-e-cozinha

consumo-e-servicos

contador

contador-move-indcom

contador-vizinhanca

densidade-mundo

e-total

total-emission-mobility

total-emission-ar

total-emission-lighting

total-emission-appliances

total-emission-coz

total-emission-aguaq 


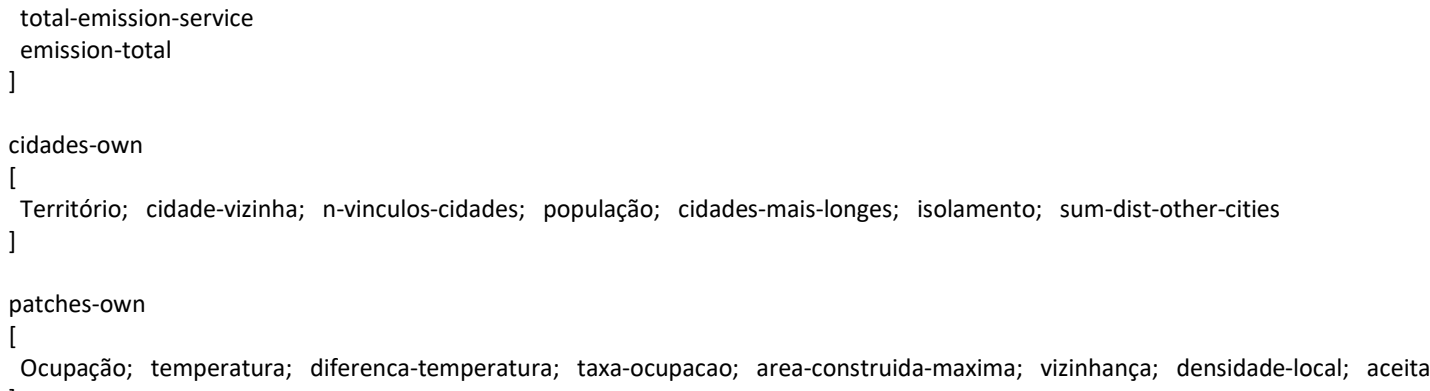




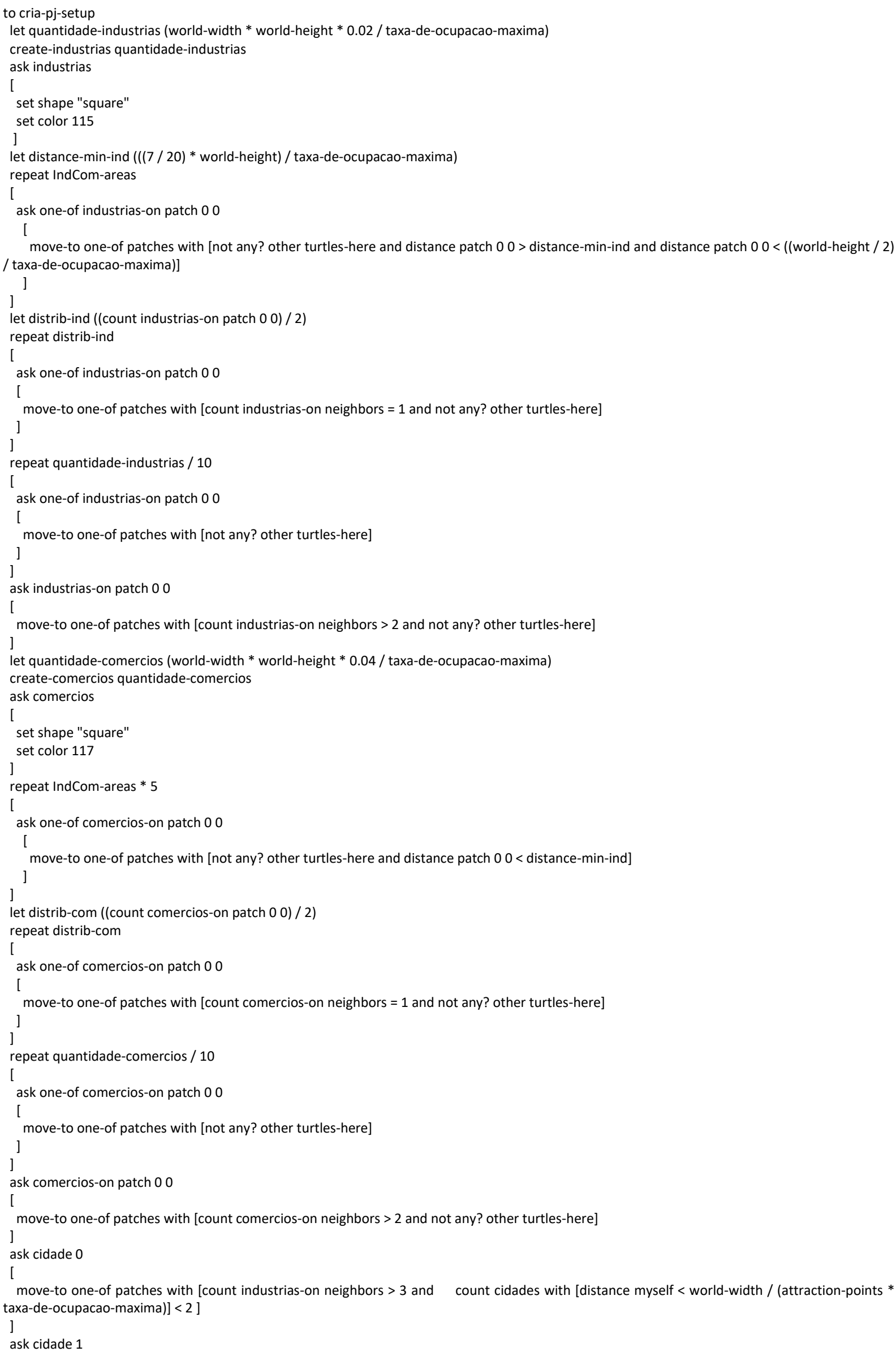



maxima)]

]

set vincular-attratcion-points 2

move-attraction-point

end

to cria-habitantes-setup

create-habitantes households

ask habitantes

[

set status 0

set shape "square"

set heading 0

set color blue

]

repeat ((households - 1)* mid-income / 100) [classifica-habitantes-medios]

repeat ((households - 1$) *$ high-income / 100) [classifica-habitantes-ricos]

repeat ((households - 1) * ultra-high-income / 100) [classifica-instituicoes]

distribui-habitantes

cria-vinculos

cria-lista-de-cidades

cria-lista-de-populacao

ask habitantes

ask cidade residencia

set populacao (populacao +1 )

]

ask habitantes

[

set tamanho-familia 4 - status + random 3

]

ask habitantes

set area-residencia $(40+30 *$ status + random 40$)$

ask habitantes

set residencia [who] of one-of cidades with-min [distance myself]

ask habitantes

set b-cooker $(1+(1+$ random 100) / 100

set uso-GN random 100

set uso-SOLAR random 100

atribui-modal

end

to atribui-modal

repeat int (count habitantes with [status $=0$ ] * .05)

[

ask one-of habitantes with [status $=0$ and modal $=0$ ]

set modal 2

ask habitantes with [status $=0$ and modal $=0$ ]

set modal 1

repeat int (count habitantes with [status $=1$ ] *.25)

ask one-of habitantes with [status $=1$ and modal $=0$ ]

[

set modal 2

]

ask habitantes with [status $=1$ and modal $=0$ ]

[

set modal 1

repeat int (count habitantes with [status $=2]^{*} .60$ ) 


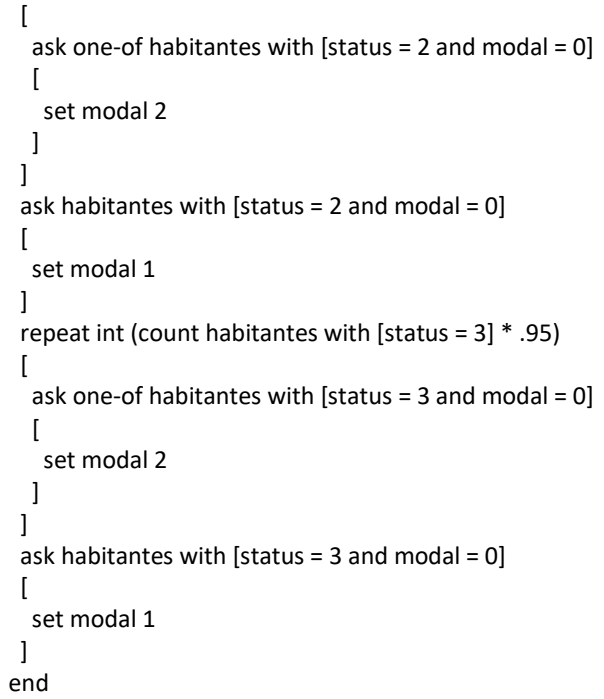

to atribui-area-construida-maxima 


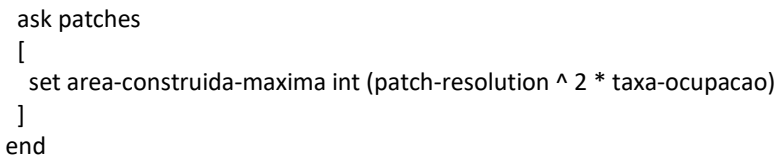




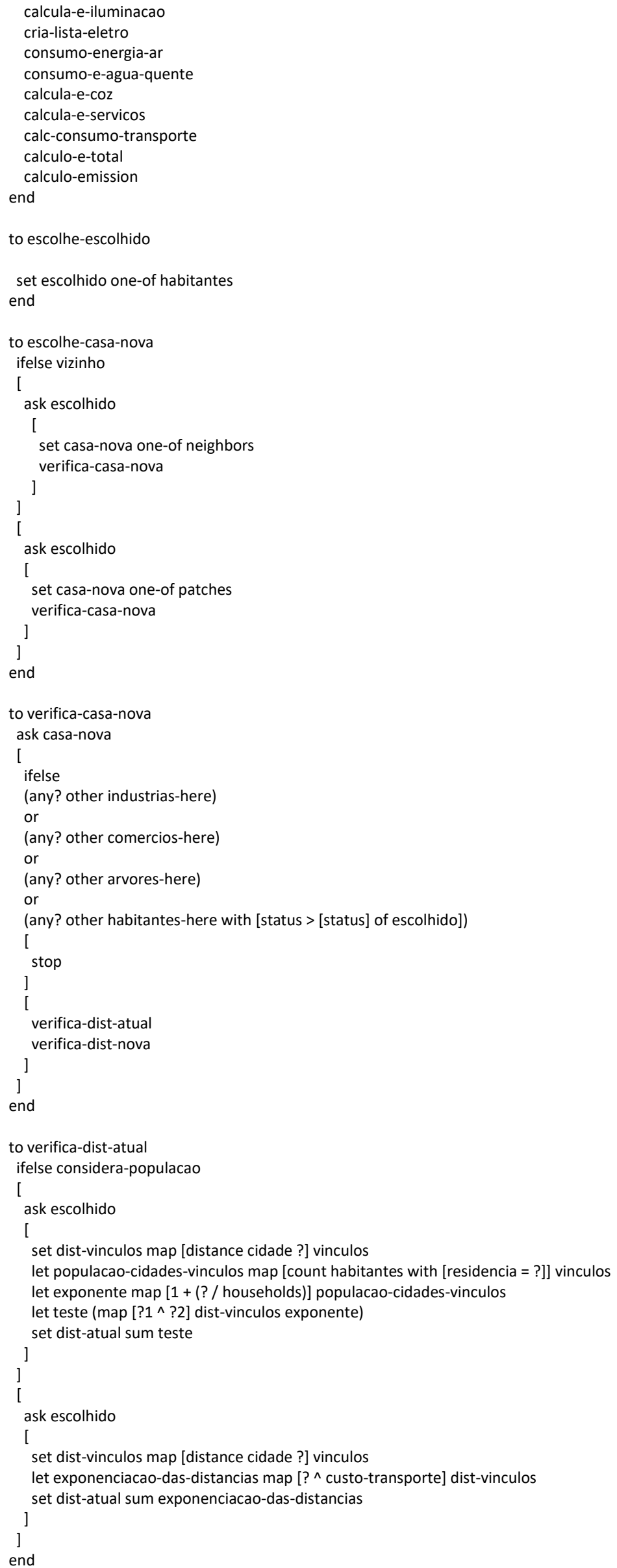




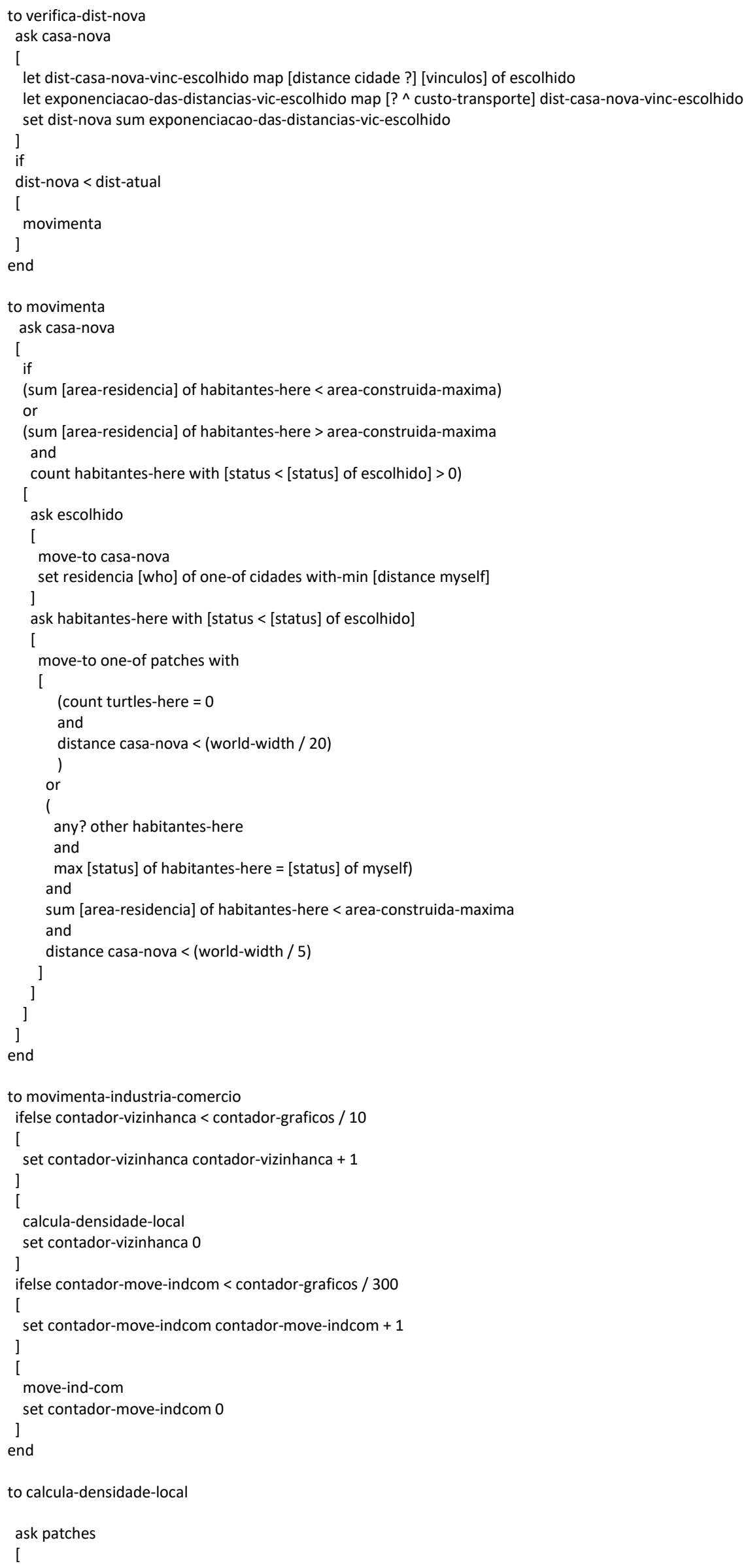


set densidade-local int ((sum [tamanho-familia] of habitantes with [distance myself < raio-ICH]) + (count comercios with [distance myself $<$ raio$\mathrm{ICH} / 2$ ] * ocupacao-patch-max))

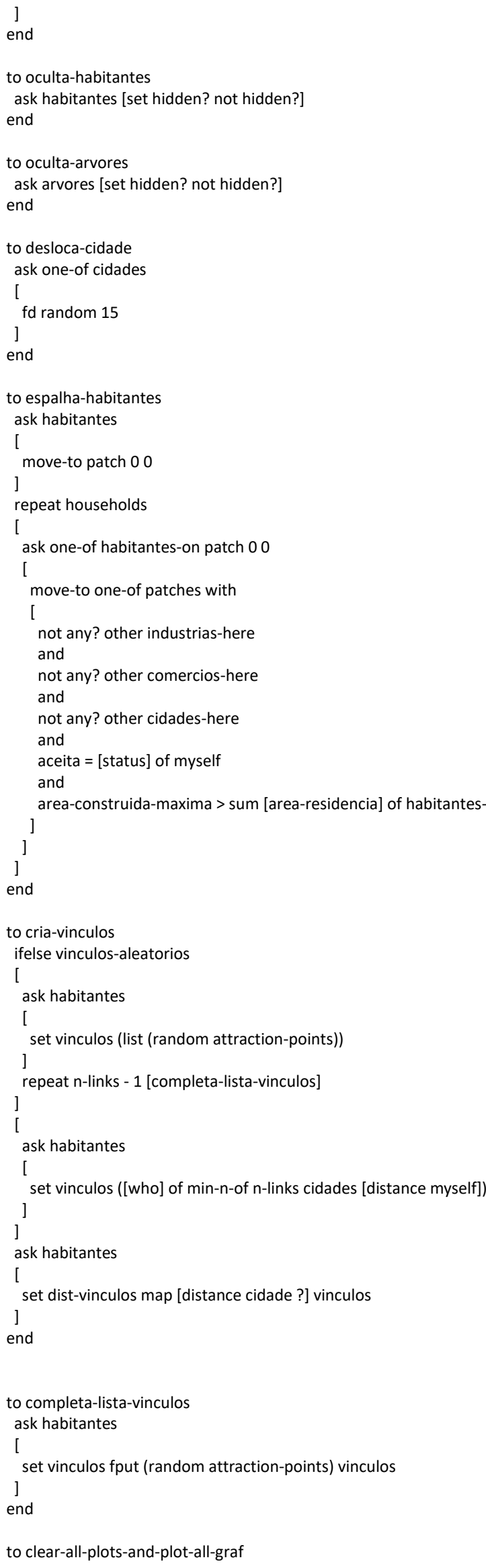




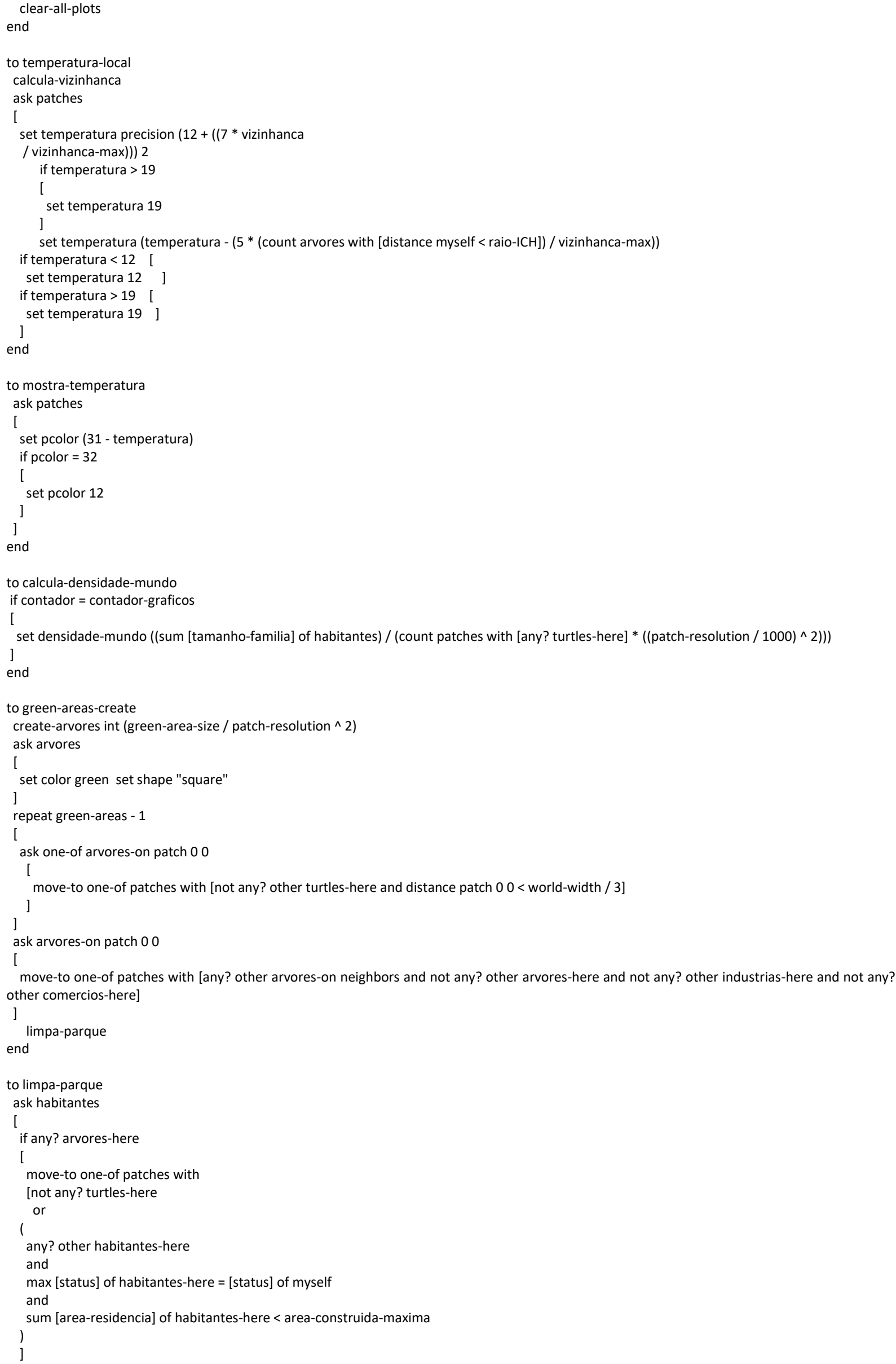




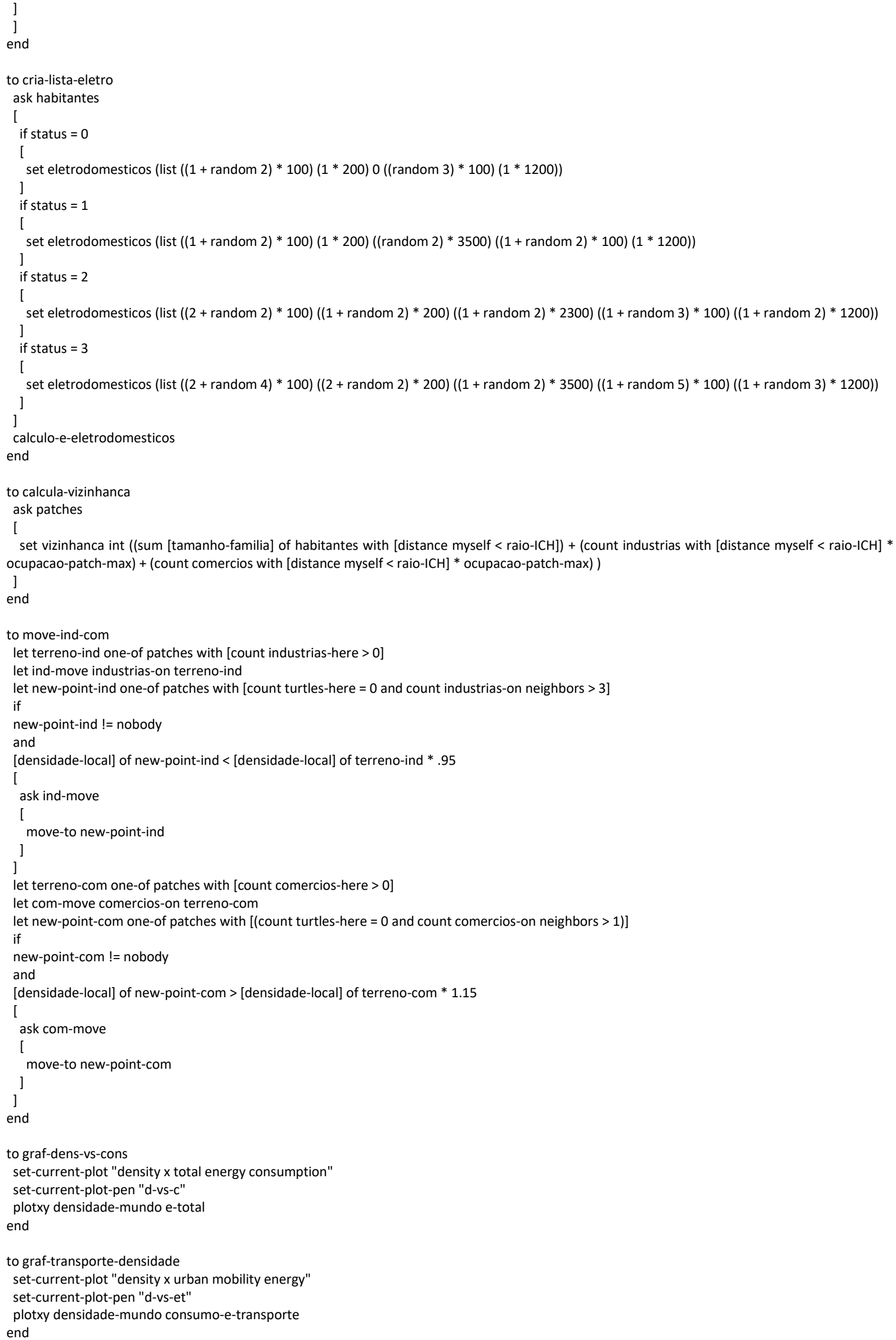




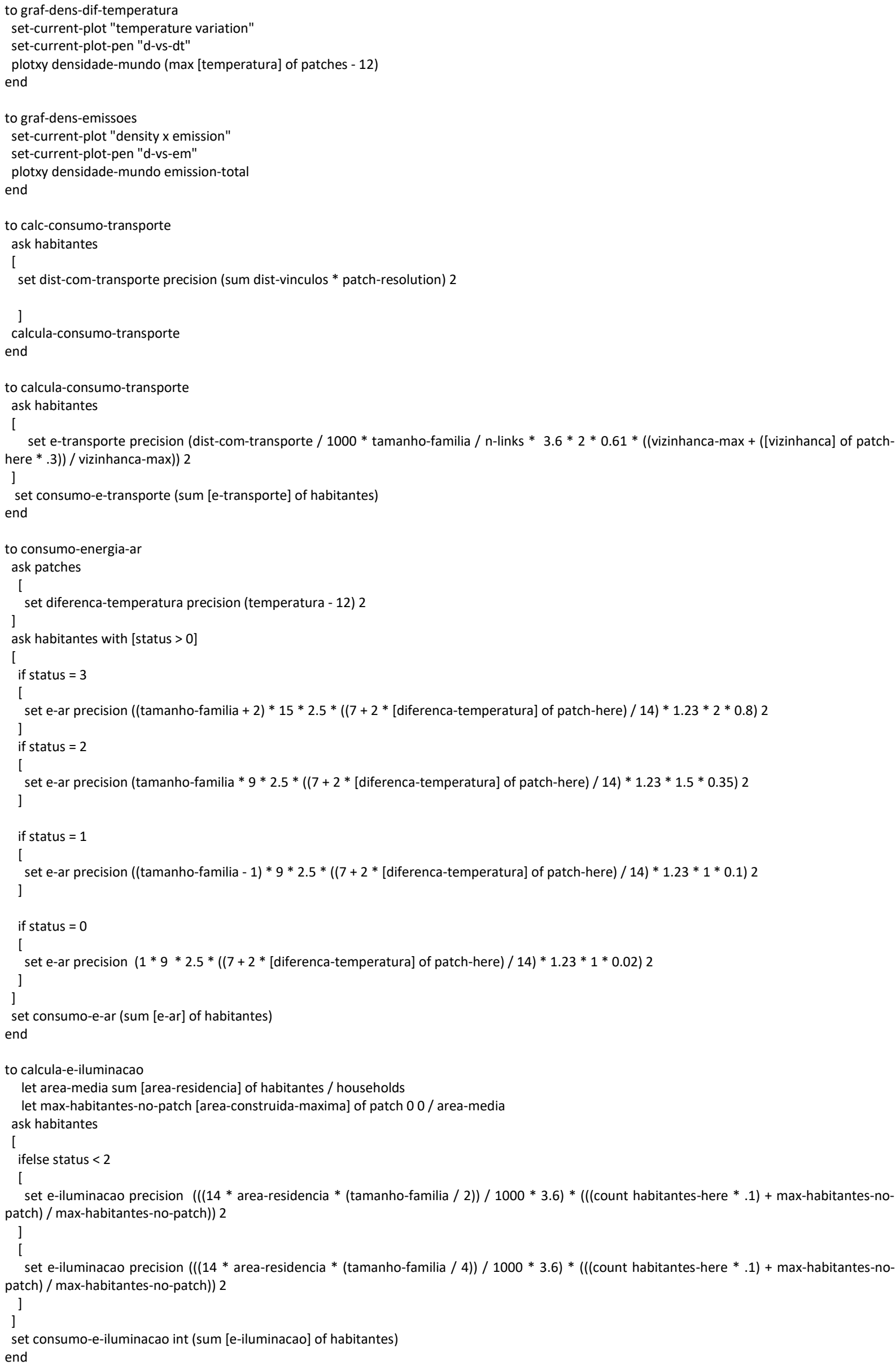




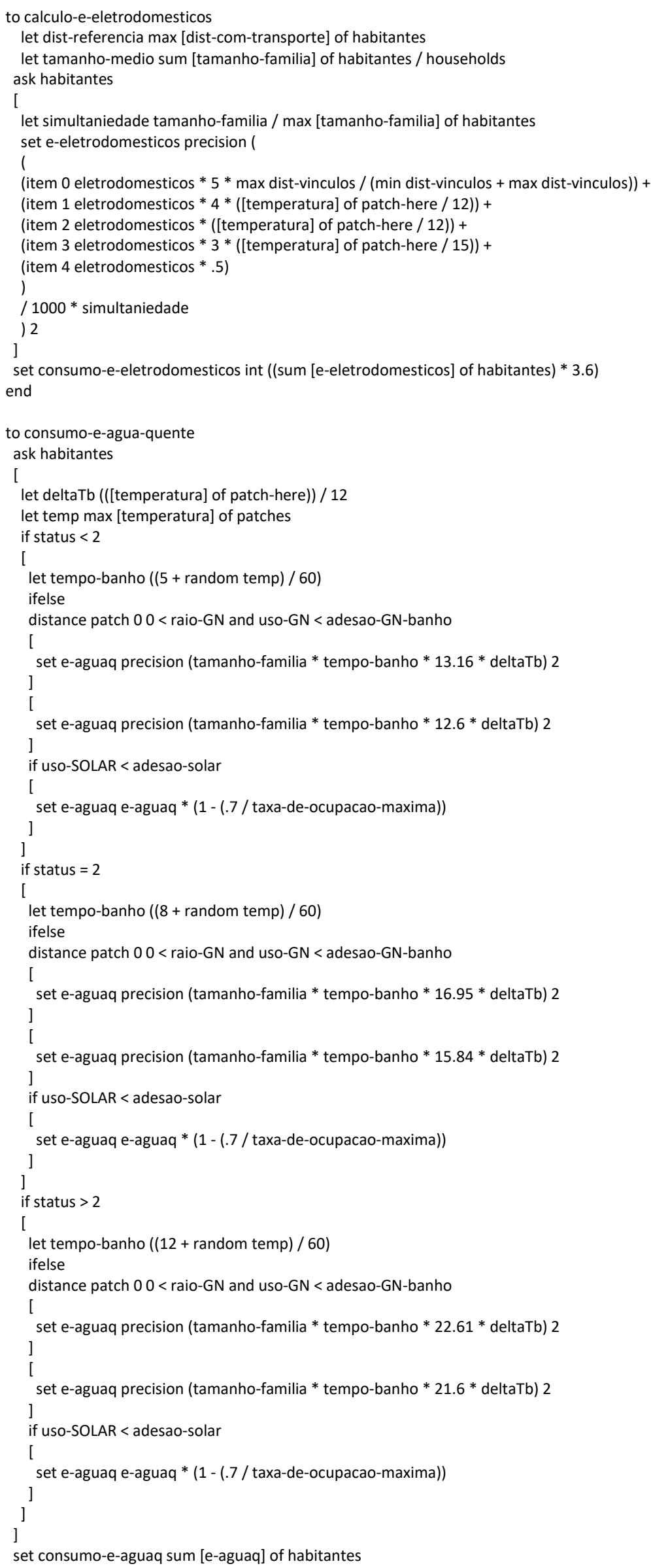




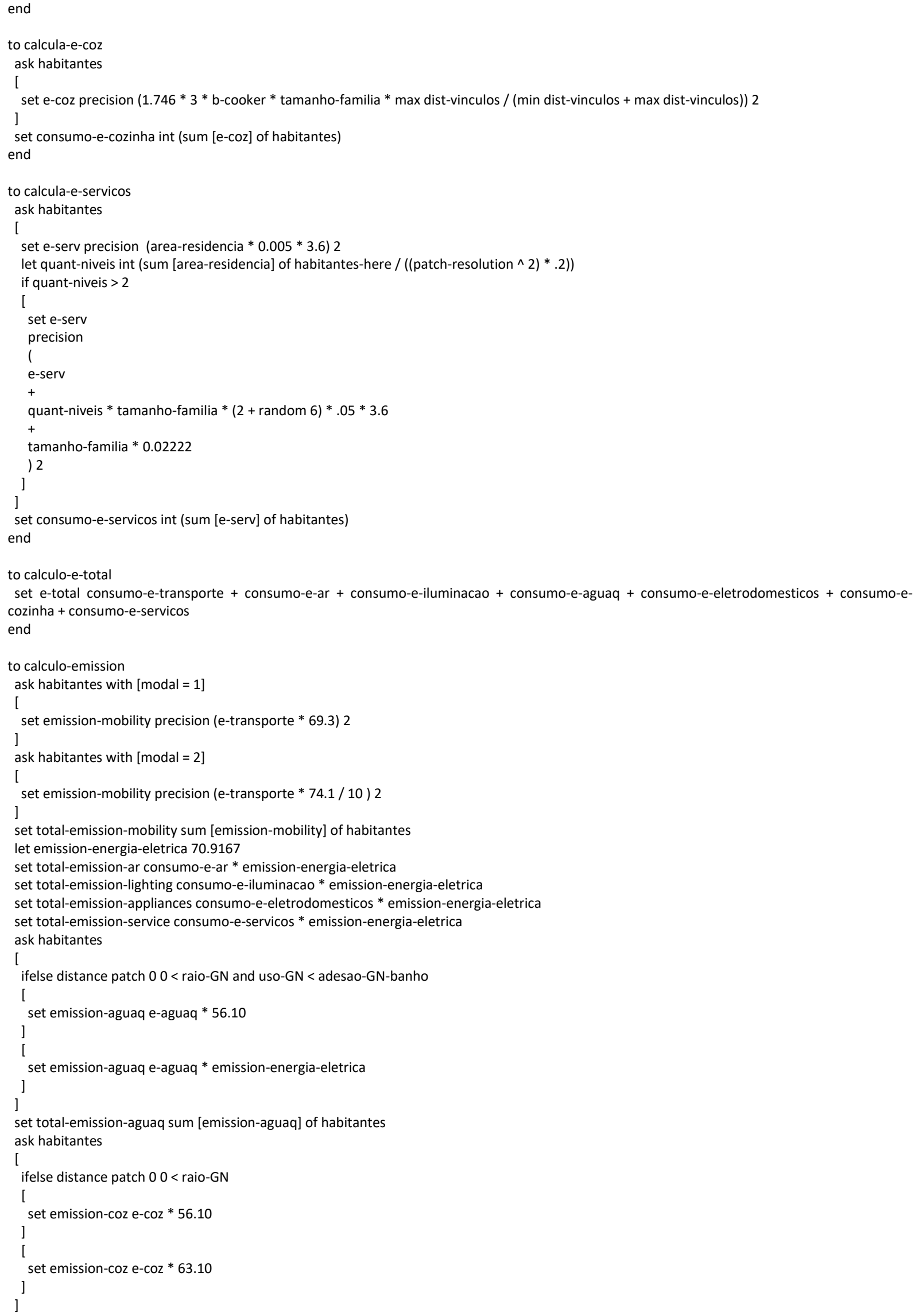

